\title{
AUTONOMY OF PUBLIC SERVICE DELIVERY UNITS IN VIETNAM: AN INSTITUTIONAL PERSPECTIVE
}

\author{
BY \\ VO THI HAI MINH
}

\begin{abstract}
A thesis
submitted to the Victoria University of Wellington in fulfilment of the requirements for the degree of Doctor of Philosophy
\end{abstract}

Victoria University of Wellington 2018 



\begin{abstract}
Intrigued by the burgeoning commercialisation of public services in Vietnam, this research seeks to understand the nature of autonomy that public service delivery units have been given as part of the greater effort of the Government of Vietnam to separate business and service provision from state management. In addressing this objective, the research bases its analysis on historical institutionalism and sociological institutionalism that illuminate insights into institutional factors shaping the autonomy policies and the implementation of the policies in practice. The main data sources the research draws on are legal documents, government reports and in-depth interviews with managers and staff of public service delivery units.

The research findings illustrate that autonomy is very limited in many aspects of management because the autonomy reforms are largely influenced by the socialistoriented market path dependence. Amidst the exhaustion of resources and legitimacy due to the regime's flawed economic structure and inherent problems of cronyism and corruption, autonomy is utilized primarily as a strategic instrument to mobilize resources indispensable for the socialist survival. This policy direction creates incentives for the various forms of rent-seeking and corrupt behaviour among public service delivery units, occasioning the rapid and aggressive commercialization of public services. While the root of these problems lies in the intent of the policies, these problems are further nurtured by historical and cultural factors, and seriously compounded by the absence of an effective regulatory and accountability system and the lack of political commitment to fight corruption from the top leaders.

The research addresses the gap in the academic literature by offering an illuminating insight into the nature of autonomy of a country context and demonstrating the merit of converging historical institutionalism and sociological institutionalism for the study of public policies. The research's significant contribution to policy-making is that it highlights the need to build institutions to fit in well with the reform ideas, especially when such ideas are borrowed or transferred from advanced countries with welldeveloped institutional foundations.
\end{abstract}





\section{ACKNOWLEDGEMENT}

I would like to express my sincere gratitude to my primary supervisor, Associate Professor Karl Lofgren, for the continuous support of my $\mathrm{PhD}$ thesis. His guidance, especially his theoretical and methodological consciousness, helped me a great deal in all the time of my research and writing of this thesis. I also would like to render my warmest thanks to my second supervisor, Dr. Wonhyuk Cho, for the valuable advice on my thesis as well as on the academic career I have been aiming for.

I am wholeheartedly grateful to Rob Laking for the generous, kind, and unconditional assistance that I could not ask for more from a lecturer of my Master's study. His thoughtful advice and feedback on every bit of my thesis helped improve it greatly. My sincere thanks also go to my former second supervisor, Associate Professor Bill Ryan, for his consistent support and encouragement during the significant time of my research journey. I wish to acknowledge my appreciation to Professor Bob Gregory for his helpful comments on my research proposal that guides me throughout my research journey.

I would like to extend my sincere thanks to all the academic and administrative staff of the School of Government for the kind support that I have received for the past years. I am deeply indebted to the New Zealand - ASEAN Scholarship for enabling me to achieve my academic dream. I am thankful for the support and sharing from my research fellows during the whole journey.

I should like to express my grateful thanks to my Vietnamese colleagues who have enabled me to conduct the field trip for this research. I am truly grateful to my research's participants who have provided me with meaningful perspectives.

I wish to thank my husband for his love, caring, and wholehearted support. I love to thank my children for coming to me and filling my life with joy and happiness. You are my endless source of inspiration.

Finally, this thesis is for you, my Vietnamese fellows. 



\section{TABLE OF CONTENTS}

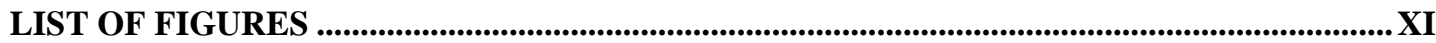

LIST OF TABLES ..............................................................................................................................XIII

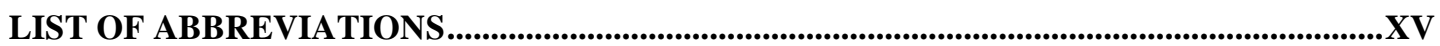

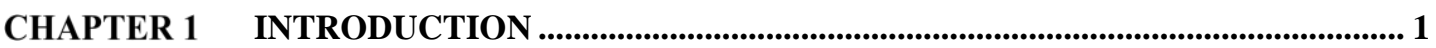

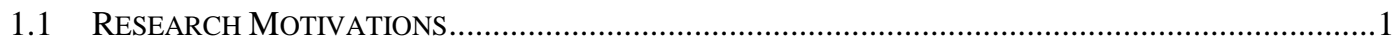

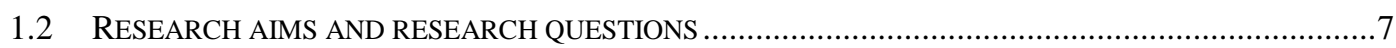

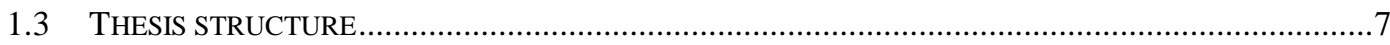

CHAPTER 2 AUTONOMY CONCEPTS AND PRACTICES: A LITERATURE REVIEW 11

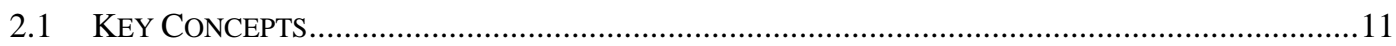

2.1.1 Delegation as part of the New Public Management reforms............................ 11

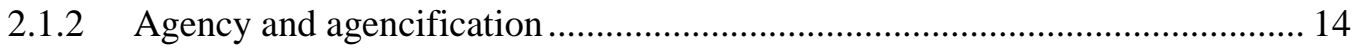

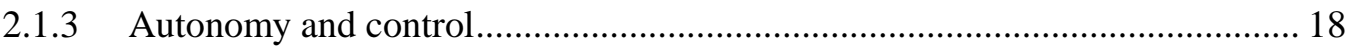

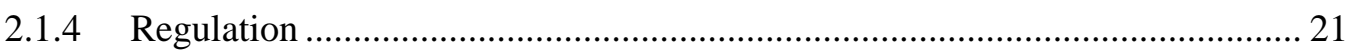

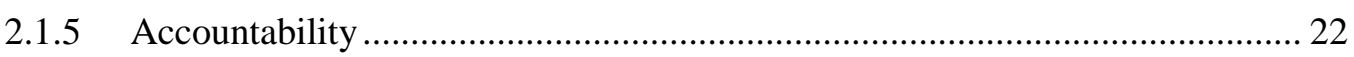

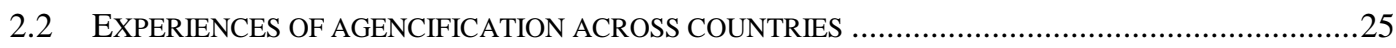

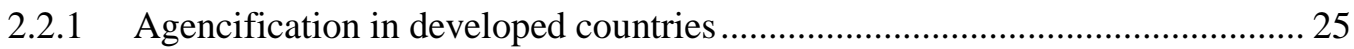

2.2.2 Agencification in developing and transitional countries ................................ 28

2.3 AUTONOMISATION OF PUBLIC SERVICE DELIVERY UNITS IN VIETNAM ........................................32

2.3.1 How has Vietnam's decentralisation been characterised? ............................... 32

2.3.2 How is the autonomy of PSDUs in Vietnam featured by existing studies? ..... 35

CHAPTER 3 PUBLIC SERVICE DELIVERY UNITS IN VIETNAM..................................... 45

3.1 PUBLIC SERVICES AND PUBLIC SERVICE DELIVERY UNITS ................................................45

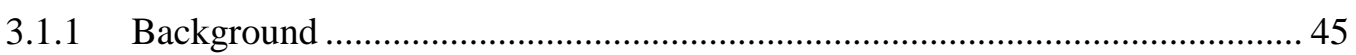

3.1.2 Autonomisation of public service delivery units...................................... 48

3.1.3 Accountability in public services ....................................................... 52

3.2 OVERVIEW OF HEALTH CARE AND HIGHER EDUCATION IN VIETNAM ..................................65

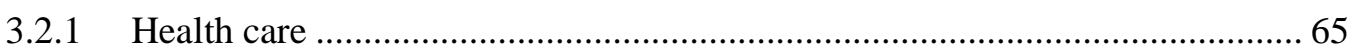

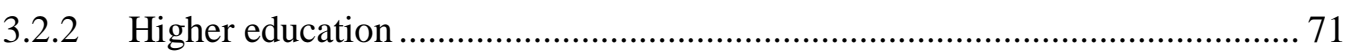

CHAPTER 4 NEO-INSTITUTIONALISM: A FRAMEWORK FOR THE STUDY OF AUTONOMY ……................................................................................................................................ 77

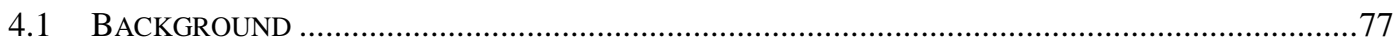

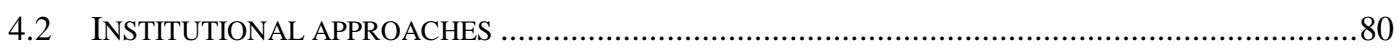

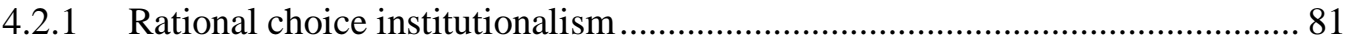

4.2.2 Historical institutionalism ............................................................. 82

4.2.3 Sociological institutionalism ....................................................... 83

4.3 CHOICE OF INSTITUTIONAL APPROACHES FOR THE STUDY OF AUTONOMY ............................8

CHAPTER 5 RESEARCH METHODOLOGY ...........................................................93

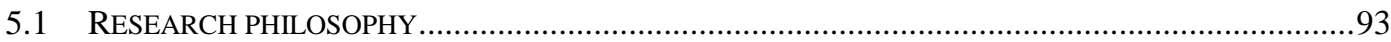


5.2 A QUALITATIVE RESEARCH METHODOLOGY ................................................................... 93

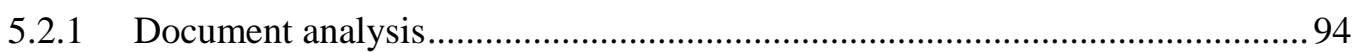

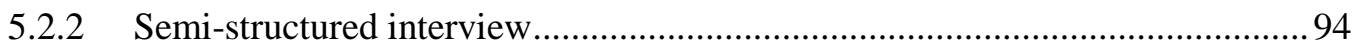

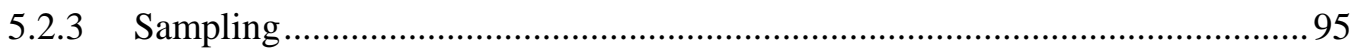

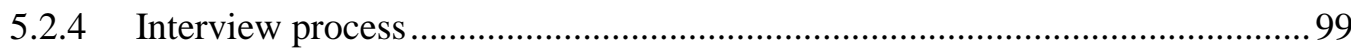

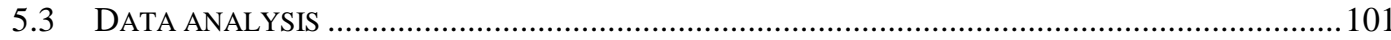

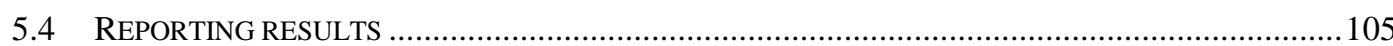

CHAPTER 6 AN INSTITUTIONAL ANALYSIS OF THE SUBSTANCE AND EVOLUTION OF THE AUTONOMY POLICIES IN VIETNAM................................................107

6.1 THE YEAR 1986 - A CRITICAL JUNCTURE: FROM CENTRALISM TOWARDS MARKET

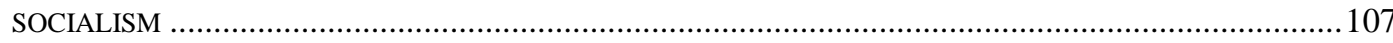

6.2 1986 - 2006: PATH DEPENDENCE AND INCREMENTAL POLICY CHANGES ............................. 112

6.2.1 Implications of Vietnam's institutional environment for policy reforms ....... 112

6.2.2 The rhetoric of the autonomisation of public services .............................. 117

6.2.3 The myth of the "socialisation" of public services .................................... 125

6.32007 - PRESENT: A RADICAL POLICY CHANGE .......................................................... 129

6.3.1 Vietnam's political economy from 2007 to present................................... 129

6.3.2 Implications of Vietnam's political economy for the autonomy policies....... 133

\section{CHAPTER 7 AN INSTITUTIONAL ANALYSIS OF THE AUTONOMY PRACTICES OF} VIETNAM'S PUBLIC SERVICE DELIVERY UNITS ................................................................143

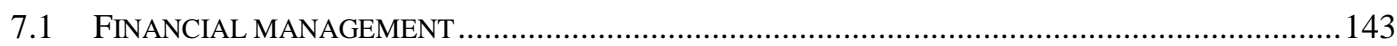

7.1.1 Fees and charges and state subsidy................................................ 144

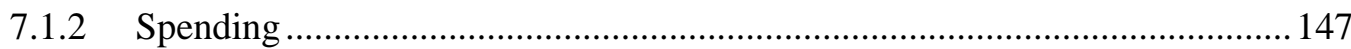

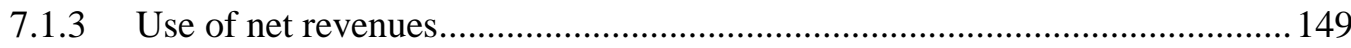

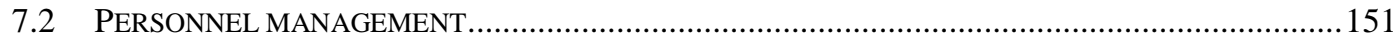

7.2.1 Recruitment, appointment and dismissal of state employees ....................... 151

7.2.2 Performance appraisal, wages and additional income ................................ 157

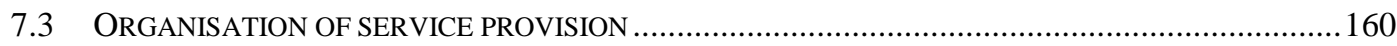

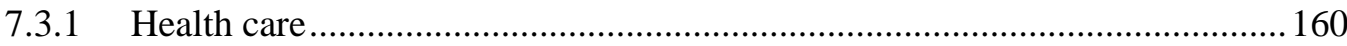

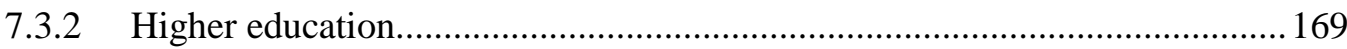

CHAPTER 8 THE NATURE OF AUTONOMY OF PUBLIC SERVICE DELIVERY UNITS IN VIETNAM

8.1 AUTONOMY IS THE POLITICAL RHETORIC AIMED AT CONSOLIDATING THE VCP'S LEGITIMACY......

8.1.1 Autonomy is bound by a system of formal and informal rules and norms and cultural values 186

8.1.2 Autonomy is accompanied by the control of inputs and processes .............. 187

8.1.3 Autonomy is not associated with depoliticisation ..................................... 188

8.1.4 Consideration of the research finding in relation to prior research ............... 190 
8.2 AUTONOMY IS ABOUT GENERATING ALTERNATIVE NON-BUDGETARY SOURCES OF REVENUE UNDER THE LABEL OF "SOCIALISATION"

8.2.1 Consideration of the research finding in relation to prior research 196

8.3 AUTONOMY, WHICH IS CONDUCTED AGAINST POOR REGULATION AND WEAK ACCOUNTABILITY, IS ALIGNED WITH RENT-SEEKING AND CORRUPT BEHAVIOUR

8.3.1 Consideration of the research finding in relation to prior research 201

CHAPTER 9 CONCLUSION ....................................................................................................... 207

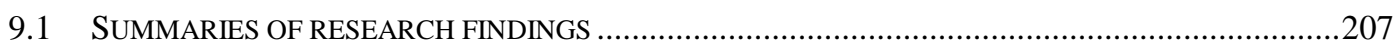

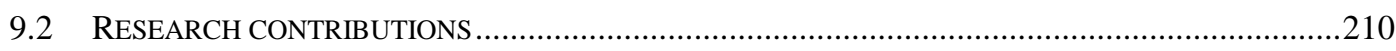

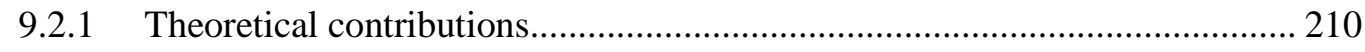

9.2.2 Research implications for policy-making ....................................... 211

9.3 LIMITATIONS AND FUTURE RESEARCH …...............................................................2 212

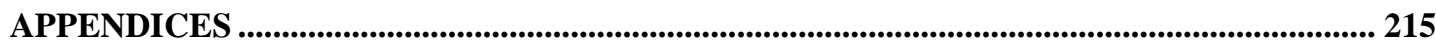

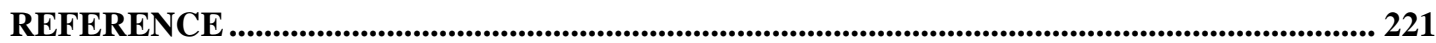





\section{LIST OF FIGURES}

Figure 3-1: Organisational structure of state management agencies responsible for public service sector 48

Figure 3-2: Accountability relations within the party-state of Vietnam..... 54

Figure 3-3: Number of Corruption Related Stories Covering Court and Non-Court

Cases, All Newspaper (October 2006 - September 2011) 63

Figure 3-4: The structure of the health care system in Vietnam. 66

Figure 3-5: Channels of financing sources for the Vietnam health care system. 68

Figure 3-6: Structure of national education system .72

Figure 3-7: The structure of higher education financing in Vietnam 74 



\section{LIST OF TABLES}

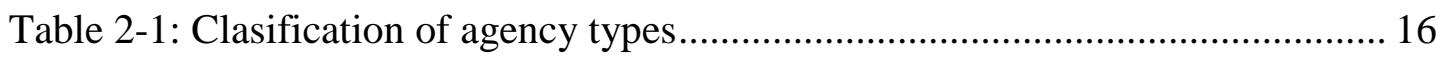

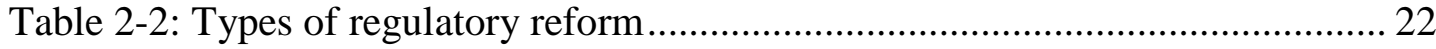

Table 2-3: Features of the Traditional, NPM-like and Network-like Control and Accountability System

Table 3-1: Revenue-generating public units under the management of the Vietnamese Government. .46

Table 4-1: Historical and sociological institutionalism's contributions to the study of autonomy 92

Table 5-1: Studied cases - characteristics and interviewees................................... 98

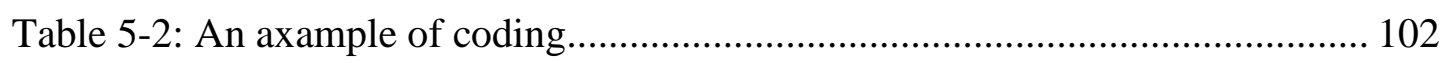

Table 5-3: An example of a taxonomic scheme of codes ...................................... 103

Table 6-1: Law on State-Owned Enterprises 1995: Autonomy and Constraints (the part in italics indicate the constraints on autonomy) .......................................... 118

Table 6-2: Government Decree 10/ND-CP 2002: PSDUs Autonomy and Constraints (The parts in italics indicate the constraints on autonomy) 120

Table 6-3: Government Decree 43/ND-CP 2006: PSDUs Autonomy and Constraints (The parts in italics indicate the constraints on autonomy) 121

Table 6-4: Government Decree 16/ND-CP 2015: PSDUs Autonomy and Constraints (The parts in italics indicate the constraints on autonomy)................................... 136

Table 7-1: Formal and Informal Features of Autonomy ..................................... 181 



\section{LIST OF ABBREVIATIONS}

\begin{tabular}{|c|c|}
\hline ADB & Asian Development Bank \\
\hline APEC & Asia Pacific Economic Cooperation \\
\hline ASEAN & Association of Southeast Asian Nations \\
\hline $\mathrm{CPV}$ & Communist Party of Vietnam \\
\hline EU & European Union \\
\hline GDP & Gross Domestic Product \\
\hline IMF & International Monetary Fund \\
\hline MOET & Ministry of Education and Training \\
\hline MOF & Ministry of Finance \\
\hline $\mathrm{MOH}$ & Ministry of Health \\
\hline MPI & Ministry of Planning and Investment \\
\hline NPM & New Public Management \\
\hline NGOs & Non-Governmental Organisations \\
\hline ODA & Official Development Assistance \\
\hline OECD & Organisations for Economic Cooperation and Development \\
\hline $\mathrm{PhD}$ & Doctor of Philosophy \\
\hline PPC & Provincial People's Committee \\
\hline PSDUs & Public Service Delivery Units \\
\hline SMEs & Small and Medium Enterprises \\
\hline SOEs & State-Owned Enterprises \\
\hline UK & United Kingdom \\
\hline UN & United Nations \\
\hline UNDP & United Nations Development Programme \\
\hline UNESCO & United Nations Educational, Scientific and Cultural Organization \\
\hline US & United States \\
\hline USA & United States of America \\
\hline USD & United States Dollar \\
\hline VND & Vietnamese Dong \\
\hline WTO & World Trade Organisation \\
\hline
\end{tabular}





\section{CHAPTER 1}

\section{INTRODUCTION}

\subsection{Research Motivations}

In 2002, through the issuance of Government Decree 10, Vietnam officially formalized the autonomisation of public service delivery units (PSDUs), granting their management varying degrees of authority over their finance, personnel, organisation and management practices, and particularly over fees and charges for their services. Since then, a number of legal normative documents have been formulated to govern the autonomisation of generic PSDUs and sectoral PSDUs. To date, the results of the autonomy reforms in public service delivery have been controversial. Communist Party of Vietnam's Executive Committee (2011), in its notification of the Politburo's Concluding Remark dated 26/05/2011 on the Ministry of Finance's Project "Renovating the operational mechanism of public service delivery units, intensifying the "socialization" of some particular public services" asserts that the renewal of PSDUs' operational mechanism has garnered a number of positive outcomes. The most notable, according to the Concluding Remark, is the increased investment of the multiple economic sectors in public services which contributes to intensifying the size and quantity of services, diversifying forms of services and enhancing service quality. The Concluding Remark also notes that the management mechanism has been improved with the increased autonomy and self-responsibility on the part of PSDUs, the more clearcut role and responsibility of the heads of PSDUs, the increased selfgenerated budget to expand and improve facilities, and the increased incomes of PSDUs' employees. The Concluding Remark subsequently asserts that improved public services have responded better to diversifying the demands of service users, thus ensuring the social wellbeing and enhancing the living conditions of the citizenry. The Concluding Remark confirms the correct guidelines of the Communist Party of Vietnam (CPV) in reforming the operational mechanism of PSDUs and in intensifying the "socialization" of PSDUs, despite acknowledging some shortcomings in state management such as the late implementation of autonomy in a number of sectors, the lack of proactiveness and effectiveness in harnessing state and social capital, the unplanned investment in facilities, the limited size and quality of services, the mix of non-profit and for-profit services at some PSDUs and in some forms of service, and the infrequent supervision and inspection and the lack of proper detection and punishment of misconducts in the "socialization" process. 
The Report of Ministry of Finance and Ministry of Home Affairs (2012) on the implementation of Government Decree 43 regarding the autonomy and selfresponsibility of PSDUs continues to elaborate in more detail these positive impacts. Accordingly, the autonomisation of PSDUs is reported to help increase capital mobilization from credit organisations and PSDUs' employees or through joint ventures for further investment in facilities and service-related activities; to expand and diversify forms of services, thus substantially increasing self-generated revenues; to enhance the savings of PSDUs; and to improve the incomes of employees. Most notably, the self-generated revenues of central PSDUs reached approximately 12,516.6 billion VND in 2010, accounting for 68.84 per cent of their operating expenses; those of local PSDUs were 27,539 billion VND, making up 43.44 per cent of their operating expenses. The self-generated revenues of PSDUs increased from 37,509 billion VND in 2008 to 39,808.8 billion VND in 2009, and to 40,055.9 billion VND in 2010. The self-generated revenues and the savings of the state-subsidised operating expenses have increased the additional incomes of PSDUs' employees to 150-250 per cent of the state-stipulated basic wage. The Report reaffirms the correct autonomy policies of the government and their significant contribution to the quality improvement and diversification of public services even though the Report recognizes some common implementation shortcomings including the late and inconsistent implementation of the autonomy policies, the late issuance or adjustment of norms, standards, and user-fees, the lack of monitoring criteria, the inefficient allocation of state budget, the pursuit of service quantity at the expense of service quality and the abuse of technology for raising revenues among some PSDUs, and income disparity between state employees.

In contrast to the above remarks by CPV and the Vietnamese Government, Vietnam's autonomy reforms in public service delivery have so far received much criticism from the country's reform observers. Overall, there has been increasing concern over the financial burden of household out-of-pocket expenditure on public services, most notably health care and education, as the consequence of the autonomisation of PSDUs. World Bank and Ministry of Health (2011) discover the increase in the people's health care expenditure burden resulting from the unexpected and unintended effects of hospital autonomisation such as the overuse of revenue-generating services, increase in treatment costs, and high costs of medicines. Wagstaff and Bales (2012) also find that hospital autonomisation has led to large increases in out-of-pocket 
spending on hospital care and higher spending per treatment episode. Similarly, London (2013) explores the connection between hospital autonomisation and more costly and intensive treatment methods. The author especially points to the rapid expansion of commercial activities within the shell of public hospitals where "patientrequested" services are distinct from normal services.

In higher education, Nguyen and Fraser (2007) assert that public universities use their increasing leeway to marketize their educational services for more sources of income through a range of commercial activities such as opening branches in other provinces, offering high-demand courses or cooperation with foreign educational institutions. Equally, McCornac (2012) affirms that an effect of decentralized financing in higher education is the commercialisation of higher education manifested through crowded public university classrooms and various revenue-generating part-time training programmes. Likewise, Pham (2012) points out that autonomy incentivizes public universities to expand student enrolment for in-service and on-site training and in the high-demand fields of studies to increase revenues while investment in higher education increases slowly or even remains unchanged.

Besides a propensity for the uncontrolled commercialisation of public services, corruption is widely perceived to be rife and institutionalised among various totally and partially financially autonomous PSDUs. Among others, extorting informal or "envelope" payments from service users is reported to be common among state employees in both health care and education sectors (World Bank, 2009). For example, a Medical University of Hanoi study finds that about 70 per cent of medical practitioners interviewed admitted that they sometimes or often ask for or accept informal payments, although some regard these payments as gifts (Acuna-Alfaro, 2009). Another study by Towards Transparency in 2011 reports that 29 per cent of urban residents who have had contact with health services in the last 12 months had to pay bribes, almost double the number who reported paying bribes in 2007 (Vian, Brinkerhoff, Feeley, Salomon, \& Vien, 2012). Informal payment to obtain good academic scores and the purchase of degrees and titles are believed to be widespread in higher education (McCargo, 2004; Vallely \& Wilkinson, 2008).

So far, the cost burden resulting from increasing formal and informal payments to access public services including health care and education has been serious and even unbearable among poor and middle-income households. A study by Hoang, Nguyen, Saksena, James, and $\mathrm{Xu}$ (2013) using data from the Vietnamese Living Standards 
Surveys 2002, 2004, 2006, 2008 and 2010 finds that out-of-pocket health payments of households increased over the study period, making up 4.6-6.0 per cent of total household expenditure. The study also finds that household out-of-pocket health expenditure as a share of the total health expenditure has been always high, ranging from 50-70 per cent, which indicates equity problems such as catastrophic health expenditure and impoverishment. Indeed, a study by Xu et al. (2003) shows that 10.5 per cent of Vietnamese households were affected by catastrophic health expenditures, the highest of 59 countries included in the analysis. van Doorslaer et al. (2007) confirm that Vietnam has the highest incidence of catastrophic health expenditure in Asia.

Catastrophic health expenditure is pointed out as an important cause of impoverishment. For poor and middle-income households, spending on inpatient treatment can amount to high medical expenditures, which in many cases could lead to debts and poverty. A survey on health expenditure in 30 hospitals indicates that the expenditure on an inpatient treatment episode of acute pneumonia for a child under 5 years of age is sometimes higher than average monthly non-food expenditure, in the case of appendicitis 11 times higher, and in the case of stroke 22 times higher, nearly equal to the non-food expenditure of an average person for two years (Ministry of Health \& Health Partnership Group, 2008). The number of individuals pushed into poverty by out-of-pocket catastrophic payments is the highest in countries such as Vietnam, China, India and Bangladesh (van Doorslaer et al., 2007). For Vietnam only, high medical costs and a lack of social security are reported to be pushing an estimated three million people per year below the poverty line (Vian, 2010 cited in Forsberg, 2013).

Similar to health care, annual household expenditure on education has been rising over time. Also, the share of household expenditure on education is as high as over 50 per cent of the total expenditure on education (London, 2006). Increased household expenditure on mass education can be attributed to a range of cost components such as school fees which increase over time and as students advance through grades, annual construction contributions which are compulsory and payments for "extra study" (học thêm), an informal education economy which is pervasive but typically underreported. To date, the cost of education remains a major obstacle to schooling, especially for the poor and vulnerable. According to an analysis of the Vietnamese Living Standard Survey 2002, 2004 and 2006, the poorest quintile households have the highest dropout ratios; the dropout ratio of pupils in the 6-10 age group (primary level) was 5.7 times 
higher than that of rich households, and of pupils in the 15-17 age group (uppersecondary level) was 3.2 times higher (Bui, 2011).

Higher education is in the same situation where public universities are increasingly relying on tuition fees. Based on a university survey by the Ministry of Education and Training (MOET) in 2005, regional and other public universities relied particularly on tuition fees, compared to colleges and national and local universities; universities offering degrees in economics and law had almost half their revenues coming from tuition fees and charges (World Bank, 2008). The increasing role of tuition fees in the financing system continues to limit disadvantaged groups' access to higher education. An analysis of the 2004 Vietnamese Household Living Standards Survey shows that ethnic minorities which constitute over 13 per cent of the population account for 4 per cent of those enrolled in higher education and just 1 per cent of all ethnic minorities have a higher education degree (Ibid.). The analysis also shows that the richest quintile has the highest levels of participation in tertiary enrolment, over 15 per cent more than that of the near richest quintile and nearly four times that of the poorest quintile (Ibid.). A survey in 2012 explores that none of the poorest and only 1.3 percent of the secondpoorest groups have obtained tertiary education (Government of Vietnam \& World Bank, 2017).

In sum, the above description has offered startling different views of the impacts of autonomisation between the mainstream documents and the international critiques. Central to the mainstream documents are positive outcomes of autonomisation from the increased capital mobilization to invest in service expansion and diversification, which in turn contributes to increased alternative revenue sources and improving state employees' incomes. Meanwhile, the international critiques have expressed serious concern over the implications of autonomisation for the cost burden of public services and the accessibility of public services for the poor and vulnerable. From another perspective, the consequences of the rapid increase in the non-budgetary revenues on the part of public service providers might be the heavy cost burden placed on the shoulders of service users. Simultaneously, public services are inaccessible to those who cannot afford the increased costs that may be induced by public service providers' strong incentives to generate revenues.

The divergent perspectives on the autonomisation results puzzle the researcher greatly. As a Vietnamese citizen, the researcher has been told her whole life that the guidelines and policies of CPV are always right. Further, in her school days, the researcher was 
often taught that socialism is much more equitable than feudalism and colonialism where heavy fees and taxes had been the unbearable burden of the people. With the belief in what she was told and taught, the researcher is entirely confused about the above contrasting portrayal of autonomisation. The researcher does not know whether the statements about the correctness of the autonomy policies of the CPV's Concluding Remark and the Vietnamese Government's Report are completely true or at least whether these official statements tell the whole story. The researcher is uncertain when these mainstream documents reiterate that the practices in pursuit of profits are just the by-products of autonomisation and only take place at a few times and places.

These official statements obviously are in marked contrast to the critiques of international observers who are deeply concerned about the heavy cost burden associated with the autonomisation of public services. Being born and raised in Vietnam, the researcher can vouch for the widespread public concern about the serious pressure that the various taxes and fees have been imposing on the Vietnamese people. The researcher herself has experienced at some time and other in her life the pressure of mounting taxes and fees in accessing public services. Hence, the researcher shares the idea that the cost burden of public services is pushing millions of Vietnamese people into poverty and stripping the poor and vulnerable of their basic rights to access public services.

While the researcher trusts the credibility of the existing studies, their lack of detailed elaboration makes the researcher unsure about why and how autonomisation occasions commercial activities that lead to the heavy cost burden among a majority of poor and middle-income households in Vietnam. The researcher is intrigued by the question as to whether the connection between autonomisation and commercialisation is intrinsic or whether commercialisation is driven by some other forces when public service providers are autonomised. In other words, the researcher aspires to know the CPV's underlying intent when it designs the autonomy policies and authorizes the autonomisation of public service providers in the whole country. The researcher also needs to understand how the autonomisation of public service providers is governed within the Vietnamese government system and whether this autonomisation process conforms to or deviates from the primary intention of the autonomy reforms.

In general, the researcher is puzzled by the inquiry into the meaning of autonomy in the Vietnamese context. To date, a few researchers have examined autonomisation and its impacts on service provision, but little is known about the substance of the 
autonomy policies and their implementation in practice. While autonomy is multidimensional, current research only investigates some particular dimensions, leaving the subject far from being fully understood. Further, prior research just touches on the autonomy of PSDUs in one particular sector while Vietnamese autonomisation is targeted at numerous public services. This research is designed to fill this gap by exploring the substance of the autonomy policies and the implementation of these policies among PSDUs. Simultaneously, this research seeks to understand the autonomy of PSDUs across sectors, paying particular attention to health care and higher education, the sectors that are likely to be the most exposed to the autonomy reforms.

The existing studies do not thoroughly capture PSDUs' perceptions and practices of autonomy in relation to the organization of service provision, personnel, and financial issues. Nor do they encapsulate the shape of autonomy when it is influenced by the various institutional factors embedded in the historical, politico-administrative, socioeconomic and cultural settings within which PSDUs operate. Therefore, this research attempts to fill this gap, with an anticipation that the findings can offer an in-depth insight into autonomy in Vietnam.

\subsection{Research aims and research questions}

The aim of the thesis is to study the meaning of autonomy of public organisations in contemporary Vietnam through examining the substance of the autonomy policies and the practices of autonomy of hospitals and universities. This aim leads to the following research question:

\section{What is the meaning of the autonomy of PSDUs in Vietnam?}

To answer the research question, the following research sub-questions will be used to guide the researcher throughout the thesis:

a) What is the substance of the autonomy policies of PSDUs in Vietnam?

b) How is autonomy practised in finance, personnel, and organization of service provision among public hospitals and public universities in Vietnam?

c) What are the specific institutional factors that affect the autonomy of public hospitals and public universities in Vietnam and how do they affect it?

\subsection{Thesis structure}

The rest of the thesis is organized as follows. Chapter 2, following, discusses the objectives of the dual process of autonomisation and agencification as part of the 
broader reforms guided by the New Public Management Paradigm. The chapter then reviews the existing literature on the core concept of autonomy: how it is defined and why and how it relates to the other concepts of control and accountability. The literature review particularly considers the autonomy reforms in both developed and developing countries, paying special attention to transitional countries that share a similar background to Vietnam. The chapter further reviews the existing studies on Vietnam's decentralisation and autonomisation to understand how they are defined and characterised. The discussion of literature helps identify the gaps which the thesis attempts to fill, including the issue of rapid commercialisation of public services when PSDUs are autonomised.

Chapter 3 provides a background of Vietnam's public services and PSDUs with a focus on the health care and higher education sectors. The chapter includes a review of the country's accountability system, particularly its key accountability institutions.

Chapter 4 draws on the institutional approach to politics to elaborate the theoretical framework for the research analysis. In doing so, some institutional theory is discussed to discern the institutional implications for policy outcomes. In considering the choice of the institutional approaches for the study of autonomy, the chapter ascertains the key attributes of the three major institutional versions - rational choice institutionalism, historical institutionalism, and sociological institutionalism. Finally, the chapter justifies the use of some theoretical insights from historical institutionalism and sociological institutionalism for the study of autonomy of PSDUs in Vietnam.

Chapter 5 gives an outline of the research methods used in the thesis. The chapter explains why the research has used the qualitative research methodology and identifies the methods used for the research. It includes information about case selection and research participants. It outlines some of the difficulties in the field including approaching cases and participants. Finally, it describes how research data is analysed and research results presented.

Chapter 6 analyses the substance and evolution of the autonomy policies in Vietnam's public service delivery over time. It is divided into three sections. The first section describes and analyses the transformation from centralism to market socialism in 1986 - a critical juncture that sets a new economic development trajectory for the country. The second section justifies the implications of the path dependence of the socialistoriented market economy for policy outcomes for the 1987 - 2006 period. The characteristics of the policy-making process and their potential influence on policy 
outcomes are also examined in the section. The section then describes and analyses the substance of the autonomy policies and of the "socialization" of public services and points out the connection between "socialization" and autonomisation. The third section discusses Vietnam's political economy from 2007 to date and its implications for the "socialization" and autonomisation of public services.

Chapter 7 presents the analysis of the practices of autonomy across hospitals and universities in relation to financial management, personnel management, and organization of service provision. The analysis demonstrates that the autonomy of PSDUs is bound by a system of formal and informal rules and norms and cultural values. The analysis reveals the rent-seeking and corrupt behaviour among PSDUs that is induced by the strong autonomy incentives.

In chapter 8 , the main research findings are discussed with reference to the existing literature. The research argues that autonomy in contemporary Vietnam is the political rhetoric aimed at consolidating the VCP's political legitimacy since autonomy is bound by a system of formal and informal rules and norms and cultural values; it is accompanied by the control of inputs and processes; and it is not associated with depoliticisation. The research further maintains that autonomy is about generating alternative non-budgetary sources of revenue under the myth of "socialisation". The research affirms that autonomy, which is conducted against poor regulatory and weak accountability frameworks, is aligned with rent-seeking and corrupt behaviour.

Chapter 9 presents the conclusion to be drawn from the study and the academic and practical contributions of the research. The research limitations and the implications for further research are also presented in the chapter. 



\section{CHAPTER 2}

\section{AUTONOMY CONCEPTS AND PRACTICES: A LITERATURE REVIEW}

This literature review chapter aims to understand some key concepts surrounding autonomy and to identify the gaps in the literature on autonomy in general and in Vietnam in particular. The chapter is divided into three sections. The first section introduces the concept of delegation as part of the global reforms inspired by the New Public Management (NPM) paradigm. It then examines relevant literature to understand how an agency is defined and why agencification (defined below) occurs. Afterwards, the concept of autonomy and the autonomy-related concepts of regulation and accountability are investigated. The second section explores experiences of agencification in both developed and developing countries. The third reviews the existing literature on the autonomisation of PSDUs and particularly of public hospitals and public universities in Vietnam to discern how autonomy is defined and characterised and what effects the autonomy implementation has produced so far. In doing so, the gaps in the literature on autonomisation in Vietnam is identified.

\subsection{Key Concepts}

\subsubsection{Delegation as part of the New Public Management reforms}

The delegation of public services has been central to the reform agendas of many public sectors throughout the world. Delegation is defined as the transfer of power from executive departments or ministries at the national level or from the state administration at the regional or local level to another public or private organization (Overman, 2016). Hood (2010) distinguishes four ideal-typical forms of delegation, which include decentralisation, agencification, contracting out, and privatization. First, decentralisation refers to the delegation of tasks from higher to lower levels of government (Overman, 2016). Second, agencification concerns the transfer of tasks to structurally disaggregated public bodies (Verhoest, Van Thiel, Bouckaert, \& Laegreid, 2012). For both decentralisation and agencification, the tasks and functions remain publicly owned. The third form of delegation is the contracting out of public tasks to public or private organizations. Finally, the last form of delegation is privatization, whereby the government divests a certain task or organization (Overman, 2016).

The principal theoretical underpinning of delegation is NPM, which is "a shorthand name for the set of broadly similar administrative doctrines which dominated the bureaucratic reform agenda in many of the OECD countries from the late seventies" (Hood, 1991, pp. 3-4). It is "a new paradigm which attempts to combine modern 
management practices with the logic of economics, while still retaining core public service values" (OECD, 1998, p. 5). This NPM paradigm contains such key reform ideas as a focus on the achievement of results and the personal responsibility of managers; managerial flexibility to explore cost-effective alternatives; a shift towards performance measurement using performance indicators and standards; a decentralized management environment matched with personal responsibilities of managers; a wider use of market-type instruments in the delivery of public services; a shift to greater competition in the public sector; and greater accountability and transparency through reporting on results and their full costs (Keating, 2001).

The NPM-driven public sector reforms carried out by many Western governments were triggered by the global economic upheavals of the 1970s of the twentieth century. In the face of financial difficulties, there was an apparent decline in citizen trust in the capability of governmental institutions to run large welfare states (Pollitt, Bathgate, Caulfield, Smullen, \& Talbot, 2001). These circumstances created tremendous pressures on governments to restrain their public expenditure while still maintaining the quality of public services (Hughes, 2003). Governments, therefore, sought ways to reform the public sector to economize, to restore trust, and to improve the quality of services. From the NPM perspective, the delegation of tasks is expected to generate both political and economic benefits, notably increased efficiency and effectiveness, greater flexibility, improved accountability, increased political stability, enhanced user satisfaction, increased citizen trust, and democratization (Hood, 1991; Osborne \& Gaebler, 1992; Pollitt, 1993).

NPM is rooted in the theoretical bases of economics, notably public choice, and private management (Anderson \& Klaassen, 2012; Hood, 1991; Hughes, 2003). The key assumption of the public choice theory is the view of rationality (Hughes, 2003). As Stigler (1975, p. 171) puts it:

"A rational man must be guided by the incentive system within which he operates. No matter what his own personal desires, he must be discouraged from certain activities if they carry penalties and attracted towards others if they carry large rewards. The carrot and the stick guide scientists and politicians as well as donkeys".

An assumption of such carrot and stick behaviour is applicable to any area. Individual bureaucrats are assumed to be driven by their own self-interest, rather than the public interest. Similarly, politicians are regarded as trying to maximize votes and/or money. 
With this economic assumption about behaviour, the public choice theory argues that the maximum utilization of market forces inside and outside government will produce the best outcomes (Hughes, 2003). The theory thus advocates more freedom, choice and competition in the public sector as well as a greater use of practices and tools of the private sector (i.e. entrepreneurship, contracting-out services, fee-for-service charges, downsizing, management by results, strategic planning and management, incentives systems, performance measurement and evaluation) in performing public activities (Hood, 1991; Hughes, 2003).

Public choice theory rose to prominence in the last two decades of the twentieth century amidst the rising influence of neoliberal doctrine, notably with the advocacy of the economist Milton Friedman (Harvey, 2007). Central to neoliberalism is the strong commitment to the ideals of individual freedom and adherence to free market principles of neo-classical economics (Harvey, 2007; Hood, 1991; Hughes, 2003). The premise is that human well-being can best be advanced by liberating the freedom and skills of the individual within a system characterised by property rights and free markets. With such strong belief in the power of market, neoliberals were strongly opposed to Marxism, socialism, state centralized planning, and even Keynesian state interventionism (Harvey, 2007). Neoliberalism advocates the adoption of policies expressly aimed at reducing the size of government since government bureaucracy significantly limits individual freedom and efficiency (Hughes, 2003). Neoliberalism does not require the withdrawal of the state, but a transformation of the role of the state from intervening to creating the right institutions for markets to produce their benefits (Foucault, 2008). As Stigler (2001, pp. 346-347) argues:

“There is a 'special responsibility' for government to create the institutional infrastructure that markets require in order to work effectively. At a minimum, this institutional infrastructure includes effective laws and the legal institutions to implement them. If markets are to work effectively, there must be wellestablished and clearly defined property rights; there must be effective competition, which requires antitrust enforcement; and there must be confidence in the markets, which means that contracts must be enforced and that antifraud laws must be effective, reflecting widely accepted codes of behaviour".

Besides seeing government bureaucracy as large and pervasive and thus restricting choices by individuals, the neoliberals argued that the traditional bureaucratic model 
was less effective than market because it did not provide incentives and rewards equivalent to those of the market (Hughes, 2003). The NPM paradigm emerged as "a direct response to the inadequacies of the traditional public administration particularly to the inadequacies of public bureaucracies" (Behn, 2002, p. 30). Primarily based on Max Weber's theory of bureaucracy, the traditional model of public administration can be characterised as "an administration under the formal control of the political leadership, based on a strictly hierarchical model of bureaucracy, staffed by permanent, neutral and anonymous officials, motivated only by the public interest, serving any governing party equally, and not contributing to policy but merely administering those policies decided by the politicians" (Hughes, 2003, p. 17). Once a profound success and widely emulated by countries around the world, the traditional public administration model was criticized for being rigid and bureaucratic, rulebound, and narrowly focused and preoccupied with structure and process (Hughes, 2003). Subsequently, despite having such important values entrenched in many public sectors as impersonality and merit-based appointment, the model has been discredited theoretically and practically and increasingly superseded by the NPM paradigm that is more relevant to the changing world (Ibid.).

\subsubsection{Agency and agencification}

As a form of delegation, agencification refers to the creation of semi-autonomous organizations that operate outside the hierarchy of a ministerial department (Peters \& Pierre, 2001; Verhoest et al., 2012; Yesilkagit, 2004). In transitional countries, agencification means not only the creation of new public bodies for new functions but an increase in the autonomy of existing legally separate bodies (Beblavy, 2001). Since the 1980s, agencification has been taking place in many public sectors in western countries, in transitional economies and in the developing world (Laking, 2005). In particular, most western countries, which have a longstanding tradition of using agencies to conduct much of the government work, has witnessed a significant increase in the number of agencies (Laking, 2005; van Thiel, 2004; Wettenhall, 2005). The proliferation of agencies is so great that it is considered an "international trend", a “fever", or a "policy fashion" (Pollitt et al., 2001; van Thiel, 2004).

Although agencification is regarded as the "hallmark" of NPM (Schick, 2002), there remains no common agreement on the usage of agencies and what they actually are. Besides agencies, other terms such as "autonomous bodies", "quangos", "nonmajoritarian institutions", "non-departmental public bodies", "extra-governmental 
organisations", and "subsidiary organisations" are also used in discussions about agencification (Gill, 2002). Pollitt et al. (2001) define agencies as the bodies that have the following characteristics: they are at arm's length from the main hierarchy of government; they carry out public tasks; their core staff are public servants (albeit not necessarily civil servants); they are financed, in principle, by the state budget and in cases in which agencies can recover much of their financial needs from charges, the state must retain the residual financial liability; and they are subject to a public law.

In a later study, Pollitt, Talbot, Caulfield, and Smullen (2004, p. 10) maintain that a public organization can be classified as an agency if it has "some degree of structural disaggregation" and "some degree of autonomy". Specifically, the criteria that generally define an agency are that an agency is not a commercial corporation; it has public law status; it is functionally disaggregated from the core of its ministry or department of state; and it enjoys some degree of autonomy not amounting to full statutory independence from its ministry/department of state, in which the ministry/department of state could alter its budgets and main operational goals (Pollitt et al., 2004, p. 10).

OECD (2002) suggests three main types of organisations that can be classified as agencies: departmental agencies, public law administrations, and private law bodies (excluding government companies). The detailed account of these categories of organisations is provided in table $2-1$, which is reproduced in a later study by Laking (2005) based on OECD (2002). 
Table 2-1: Clasification of agency types

\begin{tabular}{|c|c|c|c|}
\hline Attribute & Departemental agencies & Public law administrations & Private law bodies \\
\hline $\begin{array}{l}\text { Institutional } \\
\text { and legal } \\
\text { foundations }\end{array}$ & $\begin{array}{l}\text { Part of ministries. } \\
\text { No separate legal identity } \\
\text { from the State. } \\
\text { Function under public law }\end{array}$ & $\begin{array}{l}\text { Function mostly under public } \\
\text { law, but can be partially } \\
\text { separate or fully separate legal } \\
\text { bodies }\end{array}$ & $\begin{array}{l}\text { Quasi-corporations } \\
\text { and non- } \\
\text { commercial private } \\
\text { law bodies }\end{array}$ \\
\hline $\begin{array}{l}\text { Governance } \\
\text { structure and } \\
\text { control }\end{array}$ & $\begin{array}{l}\text { No governing board } \\
\text { (although might have } \\
\text { advisory board). } \\
\text { Director-general }^{1} \text { is } \\
\text { directory appointed by the } \\
\text { minister. } \\
\text { Minister has formal (but } \\
\text { less direct) control while } \\
\text { the director-general is } \\
\text { responsible for } \\
\text { management of the } \\
\text { organisation }\end{array}$ & $\begin{array}{l}\text { May either have a governing } \\
\text { board or single person } \\
\text { authority, possibly with } \\
\text { advisory board. } \\
\text { Top governance has } \\
\text { management responsibility, } \\
\text { minister has indirect control. }\end{array}$ & $\begin{array}{l}\text { Usually have a } \\
\text { governing board, } \\
\text { and minister has } \\
\text { indirect control. }\end{array}$ \\
\hline $\begin{array}{l}\text { Financial } \\
\text { management } \\
\text { and } \\
\text { personnel } \\
\text { rules }\end{array}$ & $\begin{array}{l}\text { Staff employed under } \\
\text { general civil service rules } \\
\text { for appointment, } \\
\text { promotion and removal. } \\
\text { Input control on the price } \\
\text { and quantity of labour are } \\
\text { generally relaxed. } \\
\text { Most funded through } \\
\text { allocations from the State } \\
\text { budget and budget is } \\
\text { annually reviewed } \\
\text { through the annual State } \\
\text { budget process. } \\
\text { Some are partially } \\
\text { financed by user fees }\end{array}$ & $\begin{array}{l}\text { Staff rules vary between full } \\
\text { civil service controls, } \\
\text { differentiated controls, and } \\
\text { outside civil service but subject } \\
\text { to a general framework for } \\
\text { State servants. } \\
\text { Most PLAs are financed by tax } \\
\text { revenue, and their budget is } \\
\text { part of general budget law, } \\
\text { although they often can carry } \\
\text { forward surpluses. }\end{array}$ & $\begin{array}{l}\text { Staff usually } \\
\text { employed under } \\
\text { general labour } \\
\text { laws, with no (or } \\
\text { limited) external } \\
\text { controls on inputs. } \\
\text { Usually mostly } \\
\text { financed by sales } \\
\text { revenue and can } \\
\text { carry forward } \\
\text { surpluses, borrow } \\
\text { and lend. } \\
\text { Budgets are } \\
\text { separate from those } \\
\text { of ministries. }\end{array}$ \\
\hline Function & $\begin{array}{l}\text { Usually delivery of non- } \\
\text { commercial services to } \\
\text { citizens and support } \\
\text { services to other State } \\
\text { sector bodies. }\end{array}$ & $\begin{array}{l}\text { Created for a differentiated } \\
\text { governance structure } \\
\text { (governing board), allowing } \\
\text { more management autonomy or } \\
\text { policy independence in some } \\
\text { cases, for a differentiated } \\
\text { control environment, or for } \\
\text { managerial autonomy. } \\
\text { Specific functions vary } \\
\text { tremendously, from service } \\
\text { delivery to regulatory and } \\
\text { quasi-judicial functions. }\end{array}$ & $\begin{array}{l}\text { Might have a full } \\
\text { profit objective or } \\
\text { mainly a service } \\
\text { objective function. }\end{array}$ \\
\hline
\end{tabular}

Source: Laking (2005)

\footnotetext{
${ }^{1}$ Equivalent to the term "chief executive"
} 
Greve, Flinders, and Van Thiel (1999) use quangos as a generic term comprising four types of organisations. Compared to agencies defined by Pollitt and his associates and OECD, the definition of quangos is much broader, covering not only contract agencies subsidiary to ministries and public bodies at arms' length from the hierarchy, but also state-owned companies and voluntary or charity organisations performing public functions. Similarly, Christensen and Lægreid (2004) deal with both central agencies as "internal autonomisation" and government enterprises as "external autonomisation" in their study of Norwegian autonomisation. In this connection, Wettenhall (2005, p. 624) notes that some non-departmental public bodies have commercial functions while others have executive functions and they both are "acknowledged by agencification theory when it goes soft".

There are variances in the functions and tasks that agencies are generally charged with. Harden and Marquand (1997) identify three types of tasks delegated to quangos: policy implementation, scrutiny (i.e. supervision, regulation, and auditing) and providing information or advice to government. Bouckaert and Peters (2004) come up with a greater number of function categories which autonomous and semi-autonomous organisations usually perform. These include implementation of public policy (i.e. direct service delivery, transfer of funds), regulation, advice and policy development, information, research, tribunals and public enquiries, and representation.

As a form of delegation, the creation of semi-autonomous agencies can thus be justified by political and economic expectations as mentioned above. It is, however, worth discussing the reasons why many public sectors see the merit in agencification. Laking (2005) suggests two most common reasons given by government of the OECD countries in setting up agencies are to improve the performance of the public sector and to legitimate public decision-making. The argument for the first reason is that organisations that are given specific objectives and the freedom to make management decisions will perform better than those with unclear objectives and limited autonomy. For the second reason, the assumption is that public decision-making can be made more credible by separating it from direct political intervention. In this respect, Flinders and Buller (2006) claim that the rationale for depoliticization can be made on public policy and political grounds. From the public policy perspective, a reduction in the control of politicians through delegation is believed to improve governance since politicians are assumed to be self-interested vote maximizers having little specialist knowledge and being tied to short-term electoral cycles. From a political perspective, 
the delegation of tasks to semi-autonomous agencies can restore the credibility of the decision-making process and revitalize trust in politicians and political institutions. Delegation is also perceived to bring benefits for politicians who wish to avoid direct responsibility for certain decisions.

Pollitt et al. (2004, pp. 19-20) identify both positive reasons and less noble motives that encapsulates the various justifications governments across countries may use for the creation of agencies. The positive reasons include the following: to lessen political interference to allow the managers to manage, and thereby achieve higher efficiency and to allow regulatory or quasi-judicial decisions to be taken in an impartial way; to strengthen political oversight by creating separate organizations that can be given clear targets; to put public services closer to their users so as to increase userresponsiveness; to enhance expertise by allowing specialization, which is assumed to increase effectiveness and efficiency; to enhance flexibility through freeing from central civil service rules, which is assumed to lead to higher quality services and efficiencies; to facilitate partnership with other public sector bodies and/or with voluntary groups, and/or with commercial companies; to create "islands of excellence" in failing or "backward" public administrations - mainly in developing countries.

Apart from these desired expectations, the creations of agencies may be driven by less noble motives such as paying off political allies; creating patronage for some party or faction; enabling politicians to avoid responsibility; insulating senior civil servants from routine operational work by leaving them with more high status policy and strategy work; massaging civil service numbers to make it look as though downsizing and economies are realized; gaining legitimacy by imitating an organisational fashion; creating islands of income generation for various purposes (Pollitt et al., 2004, p. 20).

\subsubsection{Autonomy and control}

The issue of autonomy is at the heart of agencification. The concept of autonomy has been discussed extensively in the literature, but there is still no complete consensus on its definition. According to Olsen (2009, p. 441), the term "auto nomos" refers to the Ancient Greek city-state, implying "self-governing and the right to organize one's internal affairs and give the law to oneself without external influence. Along this line, Maggetti (2007), relates autonomy to the ability to turn preferences into authoritative actions without external constraints. This definition is widely applicable (Maggetti and Verhoest (2014), but it fails to reflect the relational nature of autonomy. van Thiel (2004) defines autonomy as the ownership of the rights of production. Hence, 
autonomy is mostly evolving who decides goals, tasks, budget, labour, capital, outputs, outcomes, prices of goods and services and the production process. Christensen's (2001) notion of autonomy is in relation to the formal exemption of an agency head from full political control of the parent ministry. Verhoest, Peters, Bouckaert, and Verschuere (2004b, p. 104) perhaps offer a more comprehensive autonomy concept that captures these different ideas of autonomy. By looking at autonomy from two perspectives: "the level of decision-making competencies of the agency" and "the exemption of constraints on the actual use of decision-making competencies of the agency", Verhoest and associates come up with the various dimensions of autonomy, including managerial, policy, structural, financial, legal, and interventional indicators (Ibid.). Managerial autonomy means the discretion in the choice and use of financial, human and other resources whereas policy autonomy implies the freedom regarding objectives, target groups, policy instruments, quality and quantity of outputs, processes and procedures, and issuing of general regulations or decisions in individual cases (Lægreid \& Verhoest, 2010, p. 4). The four other dimensions of autonomy stress that the extent to which government can constrain the agency's actual decision-making competencies is determined by the level of budget financing, hierarchy, agency's legal status and government's intervention (Verhoest et al., 2004b). It is worth emphasizing that the different dimensions of autonomy are not necessarily positively correlated (Christensen, 2001; Verhoest et al., 2004b). It is, therefore, problematic to draw conclusions about autonomy based on only a single relationship (parent ministry and agency), subject matter (finance, personnel, organization, policy), or instrument (legal rules, economic incentives) (Olsen, 2009).

The notion of autonomy incorporates the implications of the relationship between elected politicians (principal) and bureaucrats (agent) in the delegation of public authority from core government to semi-autonomous agencies. Central to the relationship is the efforts of the principal to minimize any possibility of the agent's shirking which may arise from asymmetric information (where strategic advantages rest with the agent in charge of implementation), moral hazard (when agent do not act in the interest of their principal), and adverse selection (when the quality of the agent's services are not as expected prior to autonomisation) (Lane, 2000; Maggetti \& Verhoest, 2014).

These agency problems require politicians to employ control methods to influence the decisions and behaviour of the agency so as to achieve government objectives. Control 
is obviously the inverse of autonomy and linked to the different dimensions of autonomy (Verhoest et al., 2004b). Ex ante (input and process) control and ex post (result) control represent the two control approaches which differ entirely in the way they structure the work of agencies. The ex ante control approach has its footing in the plan model where "a true projection about how matters identified as cases will be handled by public employees" (Lane, 2000, p. 151). It emphasizes "the 'before the act' formulation of detailed rules, regulations, and standards and approved requirements that give directions to agencies so that the objectives desired by politicians will be achieved (Lægreid \& Verhoest, 2010, pp. 4-5). With the imposition of ex ante control, agencies' set of choice alternatives is restricted and corresponds to the preferences of their principal (Yesilkagit, 2004). The purpose is to make agencies adhere to the centrally imposed directives, rules, and regulations (Lane, 2000). In the meantime, ex post control approach is mainly concerned with "whether the intended organizational goals have been achieved by the agency and whether there is a need for corrective future action" (Lægreid \& Verhoest, 2010, p. 5). Ex post control is thus conducted mostly through objective setting, monitoring, evaluation, audit, and sanctions (Ibid.). As the primary concern of ex post control is about efficiency and goal accomplishment, rather than rule orientation or plan adherence, it allows for flexibility, adaptation, and unconventionality (Lane, 2000). It follows that the conferment of increased autonomy on agencies should be accompanied by a shift in the traditional ex ante control towards a new way of control, which is more ex post and result-oriented (Verhoest, Peters, Bouckaert, \& Verschuere, 2004a).

The autonomy concept not only reflects the principal-agent relation but it is also the result of the public organisations' embeddedness in complex multi-actor and multilevel institutional structures which shape their independence and control (Maggetti \& Verhoest, 2014; Olsen, 2009). In other words, the formal (de jure) autonomy of agencies is just one of the chief dimensions that political principals can control when delegating tasks and powers to their agents. The formal autonomy that a constitutional or legal framework provides for agencies does not necessarily mean effectual autonomy in practice (Greve et al., 1999). Maggetti (2007) introduces the term "de facto independence" to connote the informal, actual autonomy agencies perceive to have in their day-to-day management activities. According to the author, de facto independence can be seen as the combination of the (relative) self-determination of agencies' preferences and the (relative) lack of restrictions in their operation. 


\subsubsection{Regulation}

Regulation is regarded as a specific form of control employed by core government in delegating tasks and powers to agencies (Roness, Verhoest, Rubecksen, \& MacCarthaigh, 2008). Regulation is defined broadly as "all forms of social control or influence" including state-derived and market-derived mechanisms (Baldwin \& Cave, 1999). In a more narrow definition, regulation refers to: a) goal formulation, rulemaking, and standard-setting; b) monitoring, information-gathering, scrutiny, inspection, audit, and evaluation; and c) enforcement, behaviour-modification, and the application of rewards and sanctions (Hood, Rothstein, \& Baldwin, 2001) Regulation is thus linked to control of agencies on the basis of pre-determined goals, rules, and standards through which agencies' behaviour is monitored, evaluated, and eventually rewarded or sanctioned.

Like control, regulation comes in two forms: ex ante regulation of inputs and processes and ex post regulation of results (Roness et al., 2008). In the case of ex ante regulation of inputs and processes, the major concern is legality, namely compliance with rules and standards, fairness, integrity, and procedural correctness (Verhoest, 2005). In contrast, by regulation of results, the main emphasis is on the achievement of results, including quality, efficiency and effectiveness, and cost-effectiveness (Ibid.). Agencification has produced a great number of semi-autonomous agencies and this, in turn, increases the need for regulation (Christensen \& Lægreid, 2006). In other words, agencification and regulation go in tandem. While agencies may have more autonomy, they are also subject to an increase in oversight from ex ante authorization to ex post audit, management by objectives, and performance measurement.

Hansen and Pedersen (2006) point to the distinction between reactive and proactive regulation to distinguish between attempts to influence something already in place and attempts to ensure the quality of future regulation. The distinction helps identify four different types of regulatory reforms (see table 2-2). Firstly, deregulation means the reduction and simplification of rules in place. The purpose is to limit rule-based regulation that has already been adopted by governments. Secondly, better regulation aims to simplify and improve the quality of future regulation by enhancing the quality of legislation. Thirdly, reregulation deals with the changes made to the regulatory system by altering the organisation of regulation or by introducing new technologies. Lastly, alternative regulation supplements or replaces the traditional rule-based instruments by applying a range of new, modern and rational tools and instruments. 
Table 2-2: Types of regulatory reform

\begin{tabular}{|l|l|l|}
\hline & $\begin{array}{l}\text { Reactive - reform of } \\
\text { areas already } \\
\text { regulated }\end{array}$ & $\begin{array}{l}\text { Proactive - attempts to } \\
\text { improve new or } \\
\text { supplementary regulation }\end{array}$ \\
\hline $\begin{array}{l}\text { Traditional rule-based } \\
\text { regulation - attempts to } \\
\text { improve regulation through } \\
\text { rules and traditional means } \\
\text { of control }\end{array}$ & $\begin{array}{l}\text { Deregulation } \\
\text { Simplification of } \\
\text { rules } \\
\text { Sunset regulation }\end{array}$ & $\begin{array}{l}\text { Better regulation } \\
\text { Regulatory Impact } \\
\text { Assessment (RIA) } \\
\text { Law-programme }\end{array}$ \\
\hline $\begin{array}{l}\text { New means of regulation }- \\
\text { attempts to introduce new } \\
\text { policy instruments and } \\
\text { different means of control in } \\
\text { regulation }\end{array}$ & $\begin{array}{l}\text { Reregulation } \\
\text { E-government } \\
\text { Independent } \\
\text { regulatory authorities }\end{array}$ & $\begin{array}{l}\text { Alternative regulation } \\
\text { Green taxes } \\
\text { Advanced regulation } \\
\text { Self-regulation } \\
\text { Differentiated regulation }\end{array}$ \\
\hline
\end{tabular}

Source: Hansen and Pedersen (2006)

\subsubsection{Accountability}

Accountability is a concept that is closely related with steering and control (Mulgan, 2003). Accountability refers to the "obligation of individuals or agencies to provide information about, and/or justification for, their actions to other actors, along with the imposition of sanctions for failure to comply and/or to engage in appropriate action" (Brinkerhoff, 2004, p. 372). The essence of accountability is answerability, indicating the obligation of the accountable actors to answer questions regarding their decisions and/or actions (Ibid.).

Verhoest (2005) indicates that the control system in cybernetics comprises three subsystems (planning and target setting, measurement and monitoring, and evaluation, audit, and feedback) and each of these subsystems is involved in accountability. For example, public agencies are accountable for achieving objectives, fulfilling tasks and respecting rules and norms set and controlled by their parent ministry. Table 2-3 summarises features of the control and accountability system in a traditional Weberian bureaucracy and a NPM-like public sector. 
Given that accountability can be exercised by different bodies with the authority to monitor agencies, there is more than one type of accountability relationship beyond the principal-agent accountability dimension. Busuioc, Curtin, and Groenleer (2011), for example, look at managerial accountability (vis-à-vis the management board), political accountability (vis-à-vis political institutional actors), (quasi-) judicial

Table 2-3: Features of the Traditional, NPM-like and Network-like Control and Accountability System

\begin{tabular}{|c|c|c|c|}
\hline Features of system & $\begin{array}{l}\text { The traditional } \\
\text { Weberian control } \\
\text { and accountability } \\
\text { system }\end{array}$ & $\begin{array}{l}\text { The NPM-like } \\
\text { control and } \\
\text { accountability } \\
\text { system }\end{array}$ & $\begin{array}{l}\text { The network- } \\
\text { like control and } \\
\text { accountability } \\
\text { system }\end{array}$ \\
\hline $\begin{array}{l}\text { Dominant } \\
\text { mechanisms }\end{array}$ & $\begin{array}{l}\text { Bureaucratic } \\
\text { mechanism } \\
\text { (detailed } \\
\text { bureaucratic } \\
\text { control cycle) }\end{array}$ & $\begin{array}{l}\text { Market } \\
\text { mechanism }\end{array}$ & $\begin{array}{l}\text { Social } \\
\text { mechanism and } \\
\text { weak } \\
\text { bureaucratic } \\
\text { control cycle }\end{array}$ \\
\hline Dominant focus & $\begin{array}{l}\text { Inputs and } \\
\text { procedures }\end{array}$ & $\begin{array}{l}\text { (Details) results } \\
\text { (and transactions) }\end{array}$ & $\begin{array}{l}\text { (General) results } \\
\text { (and network } \\
\text { relations) }\end{array}$ \\
\hline Dominant moments & Ex ante & Ex post & Ex post \\
\hline Dominant criteria & $\begin{array}{l}\text { Legality, fairness, } \\
\text { integrity, } \\
\text { procedural, } \\
\text { correctness, } \\
\text { economy }\end{array}$ & $\begin{array}{l}\text { Efficiency, } \\
\text { effectiveness, } \\
\text { cost- } \\
\text { effectiveness, } \\
\text { quality }\end{array}$ & $\begin{array}{l}\text { Overall } \\
\text { effectiveness, } \\
\text { quality and } \\
\text { responsiveness }\end{array}$ \\
\hline $\begin{array}{l}\text { Dominant actors } \\
\text { within central } \\
\text { government }\end{array}$ & $\begin{array}{l}\text { Horizontal } \\
\text { ministers with their } \\
\text { respective control } \\
\text { agents }\end{array}$ & $\begin{array}{l}\text { Spending } \\
\text { ministers with } \\
\text { their respective } \\
\text { control agents }\end{array}$ & $\begin{array}{l}\text { No real dominant } \\
\text { actors }\end{array}$ \\
\hline $\begin{array}{l}\text { Dominant institution } \\
\text { for governance }\end{array}$ & Hierarchy & Market & Networks \\
\hline
\end{tabular}

Source: (Verhoest, 2005)

accountability (vis-à-vis financial forums). Romzek (1998, pp. 197-198) examines hierarchical accountability (an emphasis on obedience to directives, including rules and standard operating procedures), legal (a focus on compliance with externally derived expectations or performance standards and scrutiny and oversight), political accountability (responsiveness to the expectations of elected officials and clientele) 
and professional accountability (responsibility and deference to expertise). She especially argues that public sector reforms strive to reduce "an overemphasis on inputs and processes"; they "emphasize deregulation, increased discretion and flexibility, and greater emphasis on outputs and outcomes" and the types of accountability these reforms advocate and promote "are professional and political types that rely on deference to expertise, increased discretion, and responsiveness" (Romzek, 1998, p. 205). In a similar vein, Behn (2002, pp. 210-211) argues:

"We need to accept that accountability is not just about finances and fairness, but about finances, fairness, and performance. Traditional hierarchical accountability might make sense for finances and fairness. It might even make some sense when results are something that one person or one unit produces. It does not make sense, however, in a nonhierarchical world of collaboratives. Thus we need a new mental model of accountability; we need to shift from the implicit conception of linear, hierarchical, uni-directional, holder-holdee accountability to an explicit recognition that we need mutual and collective accountability. And we need to do both of these things simultaneously - to shift our accountability emphasis from finances and fairness to finances, fairness, and performance while rethinking what accountability (for all three) might mean.

Accountability is not only multidimensional, but it is also a dynamic concept (Thomas, 2003). There are various traditional means or mechanisms of accountability such as official rules, codes of conducts, professional ethics, minister control, legislative committees, parliamentary questions, financial audits, judicial reviews, advisory committees, ombudsmen, anti-corruption agencies, public hearings, opinion polls, and media scrutiny (Haque, 2007). These traditional means of accountability have been well-established in democratic societies, especially in Western countries where there has always been serious concern to make government accountable (Ibid.). With the creation of semi-autonomous agencies as a centrepiece of NPM reforms, the means of accountability has shifted from ex ante procedural control to ex post result-based control (Verhoest, 2005). As a result, there emerge new means or mechanisms of accountability such as the presence of users, interest groups and other stakeholders in boards, performance management, customer satisfaction surveys, public reporting, use of websites, freedom of information laws, externally oriented quality instruments like quality charters, certification, benchmarking, quality systems like ISO, and balanced 
scorecard (Verschuere, Verhoest, Meyers, \& Peters, 2006). The introduction of these mechanisms of accountability is aimed at strengthening not only the upward accountability to politicians but also the direct accountability of agencies towards citizens, clients, customers, and other groups.

Among the new accountability mechanisms, performance management is at the heart of the NPM reforms because the mechanism is believed to help counterbalance agencies' autonomy and increase their performance, transparency and accountability (Drewry, Greve, \& Tanquerel, 2005; Verhoest, 2010). Performance management means that government specifies performance targets and formulates performance indicators to help identify whether the planned targets have been achieved (Drewry et al., 2005). In this respect, targets are defined as "objectives with definite timescales associated with cost or efficiency levels" and an indicator as "a proxy measure used when output or performance is not directly measurable" (Wilkinson, 2005, p. 11). Performance management is often materialized in the form of performance contracting - a tool that helps specify the expectations of a government department towards its agencies (Drewry et al., 2005; Pollitt \& Talbot, 2004; Pollitt et al., 2004; Verhoest, 2010; Verhoest et al., 2012). In performance contracts, formulated into a specific agreement, contract, plan or statement of some sort, both principal or purchaser (ministry) and agent or provider (agency) agree on performance targets, performance indicators to measure expected results specified in the form of outputs and outcomes. Based on performance contracts, agencies can measure and report on their performance and make their decisions on performance-related pay/reward and discipline. Likewise, ministries can monitor agencies' performance, make resource allocation decisions accordingly and hold agencies accountable for their performance.

\subsection{Experiences of agencification across countries}

\subsubsection{Agencification in developed countries}

During the past decades, governments of most OECD countries have experimented with new forms of agency-type organisations that are structurally disaggregated from core ministries and have some level of autonomy. In the Netherland and the UK, the proliferation of agencies has involved the shifting of a large number of civil servants from core ministries into agencies (Laking, 2005; Pollitt et al., 2001). Similarly, the new public management reforms in New Zealand have expanded significantly the number of "Crown Entities" at central government level (Laking, 2005). Meanwhile, in some countries such as Finland, Sweden, and the U.S.A, central government 
agencies have existed as an important category of public body for a long time, yet still undergone significant changes to be more performance oriented, economical and customer focused (Pollitt et al., 2001).

Although most OECD countries embarked on the agencification trend along the NPM line, their agencies vary considerably in organizational forms and degrees of managerial autonomy. While agencies in some countries (e.g. the UK), are within their parent ministries and their staff remain civil servants, agencies in some others (e.g. ZBOs in the Netherland) are positioned outside their parent ministries and the employment status of staff takes different forms from that of mainstream civil servants (van Thiel, 2000). In the UK, agencies have formally received a great deal of autonomy on personnel and financial matters but, in some cases, this authority is constrained by some informal forms of central control and guidance (Pollitt et al., 2001). Compared with agencies in the UK, agencies in Sweden have enjoyed much greater autonomy, since, under the constitutional framework, government and parliament are prevented from giving agencies any detailed instruction on their decisions and actions pertaining to managerial issues (Pierre, 2004).

In most OECD countries, the agency initiative entails the adoption of some versions of performance-contracting frameworks which set out policies, budget, performance targets and results to be achieved. In Sweden, for instance, in the early 1990s, the government launched "management by result" or "management by objective" whereby government control of agencies is maintained through the specification of performance targets and performance requirements and agencies are guaranteed by the constitution to have the right to determine on strategies to achieve the planned targets (Pierre, 2004). In Australia, performance reporting is emphasized as a counterbalance to the devolution of responsibility for resource management from the Commonwealth to the state and service delivery agencies (McGuire, 2004). Public service delivery agencies are required to specify outputs, outcomes and performance indicators in terms of effectiveness, efficiency, access and equity, quality and appropriateness (Ibid.).

The creation and restructuring of agencies at arm's length from parent ministries in OECD countries have been largely a positive experience so far. Laking (2005, p. 8) states that "in most OECD countries, agencies generally work well and meet important needs of good governance". According to the OECD in a study of public agencies across its member countries, governments of most countries studied report that different goals of agencification have been achieved, including increased efficiency 
and innovation; bringing management of services closer to citizens; allowing more effective partnerships between different levels of government; involving citizens, private sector or civil society organisations in the management of agencies; and allowing central ministries to concentrate on policy-making (OECD, 2002). A review of the literature on the effects of agency reform in Europe finds improvements in management processes and organisational culture and an orientation towards results and service users. (Dan, 2014). For example, the Austrian experience with agencification has led to improved efficiency, attributed to the improvements in management processes as a result of an increase in autonomy and a decrease in inputs mainly pertinent to staff reductions (Ibid.). The UK's Next Steps Programme has resulted in a decline in administrative costs and an improvement in the overall management among executive agencies (Talbot, 2004). The Flemish and Dutch agencification has seen an improvement in managerial innovation and result-oriented steering (Verhoest, Verschuere, \& Bouckaert, 2007). The adoption of management by results in Swedish agencies has enhanced orientation towards results (Sundström, 2006). The review also finds improvements in transparency and accountability across various countries such as France and the UK (Dan, 2014). In the UK, for instance, there has been an increase in the accountability of agency chief executives for the achievement of targets within budgets (Talbot, 2004).

In spite of many positive results, there have been concerns over the issues of policy fragmentation and a loss of coordination faced by governments in most OECD countries during the processes of agencification (Bouckaert, Peters, \& Verhoest, 2010). Dan (2014) finds that 46 per cent of the studies included in the review of the literature on the effects of agencification across Europe identified concerns about fragmentation, coordination and organisational stability. These unintended consequences have been found in a number of countries including Austria, Belgium, Hungary, the Netherlands, Norway, and the UK (Ibid). Governments across OECD countries are, therefore, undertaking "whole of government" reforms to restore central control and coordination (Lægreid \& Verhoest, 2010). The reforms introduce a combination of a vertical integration through stronger central control measures and horizontal collaboration and coordination in the form of networks, teams, projects, etc (Halligan, 2006). That said, agencification is unlikely to be reversed: it has been suggested that only a few semi-autonomous agencies have reverted to the core traditionally vertical integrated hierarchy (Laking, 2005). Hence, the "whole of 
government" reforms signify the trend towards adjusting rather than replacing the NPM reforms (Christensen \& Lægreid, 2006). In other words, agencification is so far irreversible but is occurring in tandem with reassertion of the centre and reregulation.

\subsubsection{Agencification in developing and transitional countries}

The NPM ideas embodying agencification have been infused to the public sector reform programmes in a number of developing and transitional countries over the past decades. These programmes have been generally supported by neoliberal-oriented donors such as the EU, World Bank and IMF. McCourt (2008) notes that during a period of ten years between 1986 - 1996, World Bank sponsored the public sector reform programs in over 68 developing countries, the driving ideology being to create a smaller and more effective public sector.

While agencification has been on the reform agenda of developing and transitional countries, there are great gaps in understanding why and how agencification is initiated and implemented in practice. As ODCD once put it succinctly "Overall, it is poorly defined territory... there is no general overview of agency creation in developing countries or transitional economies comparable to the ODCD [country] work" (OECD, 2002, p. 4). Thin literature on the agencification of developing and transitional countries creates difficulties in studying their experiences in this respect.

That said, existing studies do offer some insights into the agency experiences of developing and transitional countries. Overall, the ideas of agencification vary greatly between countries in terms of the understanding of the policy, the motivation for adoption and the outcomes of the policy implementation. Moynihan (2006) notes that it is the interpretation process that allows policy-makers in different contexts to adopt superficially similar policy concepts and adopt policies unsuitable to the national context. The hybrid characteristics displayed by countries in terms of autonomy and control emphasize the significance of context in shaping policy choices (Bowornwathana, 2006; Moynihan, 2006). That the agency experiences are not in line with the underlying assumptions of agencification challenges the view held by NPMminded reforms such as World Bank that the agencification ideas can be emulated in different parts of the developing world (Sulle, 2010).

A literature review on agencification across developing and transitional countries shows that agencification often is pursued to protect important functions from poor governance in core government (Laking, 2005). For example, the Tanzania Revenue 
Authority was established in 1996 to enhance performance in revenue collection in Tanzania and to isolate it from the rampant corruption in the Tanzanian public sector (Fjeldstad, 2002). Autonomous agencies are created in Pakistan to be independent from the bureaucratic command and control system (Painter, 2012). The strongest motive behind the creation of Thai autonomous public organisations is the desire to escape from the rigidity of the cumbersome single-hierarchy model of bureaucracy (Bowornwathana, 2004). In most countries in Central and Eastern Europe, agencification is regarded as an instrument to get rid of the legacy of a highly centralised communist administration (Randma-Liiv, Nakrosi, \& Hajnal, 2012).

For some countries, for example, China and countries in Central and Eastern Europe, agencification is not only associated with generating democratic market mechanisms in a response to centralised management but also linked to transferring the responsibility for public services to agencies without providing corresponding financial support (Beblavy, 2001; Moynihan, 2006; Painter, 2008, 2014). Notably, in China, in the context that the state has sought to diminish subsidy and other kinds of official support, the autonomisation of local service delivery units is expected to help generate resources to supplement official salaries and recover service costs (Painter, 2014).

Very often, agencificiation is introduced in developing and transitional countries as a condition for joining international institutions and receiving external aid (Laking, 2005; Moynihan, 2006; Painter, 2012).

As with motivations for adoption, agencies across countries display distinct features of autonomy and control and in many cases these features fail to embrace the NPMagency ideas. In Tanzania, for example, while agencification has increased some level of flexibility in the management of public policies, agencies still have elements of traditional model in that they are tightly controlled ex ante in several aspects and their operational autonomy in financial and human resources is especially restricted (Sulle, 2010). In particular, agencies do not have enough freedom in making strategic decisions in employing staff, determining the work-force size and setting salary (Ibid.). Caulfield (2004) argues that Tanzania's centralised management system is the biggest problem in its implementation of the agency program. As for performance-based accountability, agencies in Tanzania generally are not controlled based on their results because the development of performance goals are left to agencies themselves and ministries have weak performance monitoring and evaluation systems (Sulle, 2010). 
The creation of autonomous public organisations in Thailand is a NPM reform diffusion process which tends to be highly political with intended reform consequences unresolved and unintended consequences emerging (Bowornwathana, 2004). Accordingly, agencification is employed by the powerful civil-service elite as a form of patronage, since semi-autonomous agencies create opportunities for senior civil servants to be promoted and for retired political officials to be appointed as members of executive boards (Bowornwathana, 2006). This explain why old problems of Thai bureaucracy such as the spoils system and nepotism is still rampant among the new autonomous public organisations. Meanwhile, Thai autonomous public organisations are still under substantial control of central officials and of board members appointed by the cabinet (Bowornwathana, 2004). The creation of new autonomous public organisations by upgrading a sub-unit in an organisation or by merging two or more small units from different organisations is leading to a bigger government instead of a smaller one as expected (Ibid.).

In China, the ruling political party (Chinese Communist Party) exercises strong influence over governance (Martin, 2013). Within the Chinese universities in particular, party-state control remains a salient element in almost all university affairs including academic freedom, setting university goals, appointing university-level leaders, setting up specialties or programs, degree and certificate granting, setting enrolment quotas, and determining tuition and fee levels (Billinton \& Xin, 2000).

In Central and Eastern Europe, agencification takes place in the absence of a systemic conceptual and legal framework (Beblavy, 2001). The consequence of such approach is that there is very little substantial institutional innovation. In the event that there is institutional innovation, it is often transplanted from other countries, often with foreign aid and advice. The problem is that such institutional innovation is usually undertaken in the lack of a supporting legal, accountability, and financial framework. In Slovakia, for example, agencification, while allowing increases in or formalisation of bureaucratic autonomy, neglects the issues of improved performance or accountability (Moynihan, 2006). At the same time, agencification is meant to assure external stakeholders including the EU that Slovakia is reforming its public sector following the set of administrative standards prescribed by the EU as part of the accession process (Ibid.). Another example is Latvia where agencification apparently gives more freedom but this freedom is not matched by new arrangements for the ministry to hold its agencies to account and for civil society organisations to hold ministries and 
agencies up for parliamentary and public scrutiny (Pollitt, 2004). Financial accountability is not strong and non-financial performance such as quality standards, customer service, accuracy and speed is not measured and monitored by ministries (Ibid.). There has been evidence of corruption, both petty and at higher political levels in both Slovakia and Latvia (Moynihan, 2006; Pollitt, 2004).

A notable feature of agencification in developing and transitional countries, which departs from the NPM reforms in most developed countries is the use of agencification as a means of raising revenues and tax burden. In countries in Central and Eastern Europe, this is done through stealth taxation (e.g. compulsory insurance payments) and increasing user charges to cost-recovery level and reducing tax funding of public services (Beblavy, 2001). In China, public hospital governance reforms create incentives to charge patients for excessive treatments since public hospitals which are not provided sufficient government funding are allowed to distribute profits to staff (Allen, Cao, \& Wang, 2014). While dramatically cutting back on public financing for the health sector and allowing substantial degree of distribution of profits to staff, the Chinese government fails to establish effective and strong regulatory institutions (Tam, 2010). The consequence of hospital autonomisation and privatisation is that a majority of Chinese hospitals, while state-owned, are increasingly operated as commercial enterprises (Ibid.). Perverse consequences so far include a striking decline in the accessibility to health care of vulnerable populations and dramatic deterioration in service quality (Ibid.).

Laking (2005) suggests several factors that may contribute to the problems that developing and transitional countries often encounter. More often than not, transitional and developing countries embark on agenfication without a clear or legitimate public policy justification. In particular, agencies are created in circumstances when the right rules and systems for external direction and control of agencies have yet to be put in place. For instance, in Latvia, as there is no legal basis for such institutions as agencies, many agencies are given the legal form of private sector joint stock companies wholly owned by the state while having non-profit status (Pollitt, 2004). In many countries including Pakistan, Latvia, Slovakia, Tanzania and China, control is focused on regulatory compliance and procedural correctness rather than service quality and performance (Moynihan, 2006; Painter, 2012; Pollitt, 2004; Yang, Vidovich, \& Currie, 2007). In the Slovakian case, the creation of agencies is neither accompanied by central controls for either inputs or outputs nor an effective performance framework 
(Moynihan, 2006). Agencification is thus primarily associated with agency autonomy and political power, a weak centre and the absence of effective accountability mechanisms (Ibid.). In China, the objective of revenue generation overrides government efforts to establish a sound regulatory system governing the autonomised and privatised health sector (Tam, 2010).

Weakness in internal governance, especially in planning, task definition, managing staff, reporting, internal control, and audit is another contributing factor (Laking, 2005). In Tanzania, for instance, performance measurement tends to focus on internal (e.g. staff) performance rather than output measurement (Caulfield, 2004). Agencies in Latvia do not often have clear policy objectives and proper internal reporting and auditing functions (Pollitt, 2004). In Thailand, agency-type autonomous public organisations are criticized for being inefficient in budget spending, particularly due to using surpluses to reward staff with bonuses and traveling expenses (Bowornwathana, 2012).

\subsection{Autonomisation of public service delivery units in Vietnam}

\subsubsection{How has Vietnam's decentralisation been characterised?}

The sharing of power and functions between the Vietnamese central government and its subordinates has so far captured due attention from scholars. Most consideration focuses, however, on the general transfer of responsibilities and power from central government to lower administrative levels. In other words, the intergovernmental relations between state management agencies in Vietnam has been researched the most until now. The delegation of responsibilities and power from state management agencies responsible for the service sectors to PSDUs also has started drawing some fresh interest among researchers in recent times.

To date, there have been several remarkable studies about the transfer of responsibilities and power from central government to its subordinates that provide some in-depth insights into this structural change in different areas and from different aspects. Current research has recently examined the major focuses of Vietnam's decentralisation, which are in the areas of budget, investment, administration and personnel management, land and natural resources, planning management, stateowned enterprises, and public services. Existing studies also have so far considered the country's fiscal, administrative, and political aspects of decentralisation. 
These assessments have helped illuminate the nature of decentralisation and several of its impacts. Most notably, research concludes that decentralisation is a bottom-up reform process rather than a policy-induced reform. This is manifested not only in much "fence breaking" experimentation by provinces to harness market forces to increase food production prior to Đổi Mới (reform), but also in many provinces gaining more economic and financial strength thanks to the economic reform and as a result being able to push for increased autonomy (Jandl, 2014; Riedel \& Turley, 1999). The change from a centralised model of governing towards a more decentralised government system does not result from a sudden change of mind and heart of political elites but arises from the critical needs of capital and resources of the state sector in particular and the country in general (Jandl, 2014).

While there may be pressure from the grassroots level for decentralisation, the process of developing a decentralisation plan is heavily top-down, with little participation from local authorities (Adam, 2003; Vu, Le, \& Vo, 2007). This top-down decentralisation approach is employed in the sense that functions that upper levels of government should not perform are assigned to lower levels (Vu et al., 2007). This is a reversal of the popular bottom-up decentralization approach in which the upper level will be responsible for tasks that the lower level is unable to perform. In a top-down approach, the decentralization framework in Vietnam is primarily shaped by central government. Ultimately, the approach has served to reinforce the power and influence of central government, demonstrated in its control of crucial budgetary processes and administrative decisions (Beeson \& Pham, 2012). The inherent consequence of this approach is that central government often finds itself under substantial pressures due to workload while the lower levels of government are unnecessarily constrained $(\mathrm{Vu}$ et al., 2007). Also, the lower levels of government tend to seek opportunities to relinquish their accountability, leaving central government the primary accountable actor (Vu, Zouikri, \& Deffains, 2014).

Although there has been increased decentralisation for sub-national governments, this decentralisation process is narrowly limited to administrative decentralisation (Fritzen, 2002; Vu et al., 2007). The emphasis is the deconcentration of administrative responsibilities and tasks to local government rather than the devolution of political power where elected representative bodies are decision-makers (Fritzen, 2005b; Vasavakul, 2002). Administrative decentralisation generates only a limited level of autonomy since the lower levels of government must still follow the guidance of the 
upper levels. As a result, decentralisation of decision-making responsibilities quite often does not correspond with decentralisation of responsibilities for fiscal and personnel matters. Fiscally, sub-national governments in Vietnam can be called spending units of central government because they do not have the power to decide their expenditure at their various levels (Vo, 2009).

There exists a difference between formal decentralisation and informal decentralisation (Vu et al., 2014). Fforde and De Vylder (1996) claimed that many of provincial government's policy experiments and initiatives that had been considered fence-breaking and illegal by central government were subsequently legalized (see also Jandl, 2014; Malesky, 2004; Painter, 2008). Litvack and Rondinelli (1999) found that some local governments had more latitude than others in implementing central laws and regulations and in experimenting with local strategies. Vietnam's highly hierarchical and fragmented government organisational structure creates various discretionary opportunities for local government to implement and enforce central laws and regulations (Painter, 2005; Vu et al., 2014). In particular, the four-tier government system from the central to three sub-national levels creates space for the outcomes of central policies to be subject to local discretion. Moreover, the tradition of self-sufficiency requires local governments to resort to a variety of fees and charges and to seek local economic activities (Painter, 2005). As a result, local government has become more autonomous and influential over central government, especially when their financial contributions to the state budget are significant.

Additionally, the "village culture", which prioritizes local rules over national laws and regulations, plays an influential role in the relationship between central and local government and in many cases downplays the effects of national laws that conflict with local rules (Fritzen, 2002; Vu et al., 2014; Vu et al., 2007). This is especially the case when national laws are inconsistent, complex and ambiguous, leaving local government substantial freedom to expedite laws and regulations issued by central government. Nguyen, Pham, Bui, and Dapice (2004) contend that a majority of legal documents in Vietnam are either outdated or ambiguous and complex, thus leading local government to interpret central laws and regulations in their own way. Tenev, Carlier, Chaudry, and Nguyen (2003) find that the legislation system is inconsistent in the sense that most laws only provide a general framework and leave implementers with substantial discretion to work out the details. 
Up until now, the effects of decentralisation have been mixed. While decentralisation has complemented market transition and unleashed the private sector, there has been little evidence showing that decentralisation has improved public service delivery and reduced poverty $(\mathrm{Vu}, 2016 \mathrm{~b})$. In fact, decentralisation, in the health sector, for example, has created gaps between provinces in per capita health spending, partly owing to the budget allocation based on population norms with little consideration of revenue and cost disadvantages and variations in need (Lieberman, Capuno, \& Hoang, 2005). This allocation mechanism preserves the inequalities favouring richer provinces in government health spending. Provinces have substantial discretion over resource allocation to districts and communes, but great fiscal decentralisation is not necessarily pro-poor since there are considerable inequities between poor and rich parts of a province (Lieberman \& Wagstaff, 2009). Similarly, in the education sector, there exist disparities in the provision and financing of primary and lower secondary education across different segments of the population (Cobbe, 2011).

In short, the extensive research on Vietnam's decentralisation gives a fairly comprehensive picture of the reform process. While the broad decentralisation reform is beyond the focus of this research, a discussion of the literature review on decentralisation offers some insights into how central government shares power and responsibilities with its subordinates and what factors have exerted influence on the actual autonomy of local government. That will help shape the subsequent analysis on the nature of autonomisation and how it is affected by surrounding environmental factors.

\subsubsection{How is the autonomy of PSDUs in Vietnam featured by existing studies?}

As mentioned above, the autonomisation of PSDUs has recently attracted some attention from scholars. Current research mostly focuses its study on autonomy implementation in health care and higher education. Of extant research on the subject, there have been a few studies, including empirical research, that use survey-based, quantitative and/or qualitative methods to explore how autonomisation unfolds and what implications it creates for service provision. Some scholars have particularly demonstrated their interest in studying hospital autonomisation and its impacts on hospital outcomes. Wagstaff and Bales (2012), for example, investigate the effects of hospital autonomisation through drawing on survey data covering all Vietnam's public hospitals and Household Living Standards Survey data. The study finds that autonomisation leads to more hospital admissions and outpatient visits although the 
effects are not large. Autonomisation does not, however, affect bed stocks or bedoccupancy rates; neither does it increase hospital efficiency. The study further finds that autonomisation leads to a more intensive style of care characterised by more lab tests and imaging per case. While the study does not find evidence of autonomisation leading to higher total costs, the study does find that autonomisation sometimes results in large increases in out-of-pocket spending on hospital care and higher spending per treatment episode.

Despite uncovering some important effects of hospital autonomisation, the study results are not clear-cut and strong as one might have anticipated. The authors point to two reasons for the study's limited results. The first is that the autonomisation process had already begun in 1989 when hospitals were first allowed to collect partial userfees and deliver some services on a cost-recovery basis. It thus can be interpreted that these reforms had already had some effects on hospital outcomes by the time the study started measuring them. The second is that the autonomisation process is incomplete and the various elements of hospital autonomy such as decision rights, residual claims, market exposure, and accountability have yet to be mutually coherent.

A survey of 18 hospitals by World Bank and Ministry of Health (2011) shows that autonomisation has generated a range of benefits including a significant growth in total hospital revenues, with the most growth coming from social health insurance payments; increased capital investment in medical equipment; expansion of the range of services; an increase in hospital utilization; and a substantial growth of incomes of medical staff. However, these benefits mostly concentrate in central hospitals and hospitals in large cities because they could tap a large population of patients with financial means to pay for high-priced health services and could harness "social" capital investment. The survey, at the same time, points to several unintended effects of hospital autonomisation. Of most importance is the decline of efficiency which is indicated by the increase in the average length of stay in most hospitals and the increase in the treatment cost invoiced to Vietnam Social Security. Autonomisation is found to have widened the gap between hospitals at different levels, especially between provincial and district hospitals. There is evidence showing that personnel has moved from lower to higher level hospitals, from rural to urban areas, and from unprofitable to profitable specialities (e.g. from paediatrics and mental health to services that use high tech equipment). Similar to the findings of Wagstaff and Bales (2012), the survey finds a correlation between autonomisation and increases in the use of high tech 
laboratory tests and diagnostic imaging in some hospitals. The survey also finds an association between autonomisation and high cost of medicines. Unlike the study of Wagstaff and Bales (2012) which finds no evidence of autonomisation affecting bedoccupancy rates, the survey points out the issue of overcrowding, indicated by the bedoccupancy rates of over 100 per cent in many hospitals. While the survey finds no robust evidence to make a rigorous assessment of clinical quality, rational service use, and patient satisfaction, the survey does find that medical staff inputs per bed are substantially below standards of the Ministry of Health (MOH).

London (2013) uses mixed methods to analyse the effects of autonomisation in fourteen hospitals distributed across the municipal, provincial, and district levels in three cities, four provinces, and six districts across northern, central, and southern Viet Nam. London discovers autonomisation is associated with the rapid expansion of "patient-requested" services, the installation of technically-sophisticated diagnostic equipment, and the increased mobilization of capital for investment in infrastructure and equipment. Like other studies, London's research finds an association between autonomisation and costly and intensive treatment methods, but as ever, his study finds no clear indication about whether these treatment methods are linked to improved quality and a response to needs or the abuse of available equipment driven by financial incentives. Another key finding is that staff pay increases substantially in fully autonomous hospitals but appears less striking in the remaining provincial and district hospitals. The management of human resources is also found to be affected by autonomisation. While surveyed hospitals report little real discretion over the hiring and firing of full-time staff, they tend to have some leeway to hire flexible labour. Autonomisation also appears to boost a sense of shared enterprise among staff, who themselves benefit from increased investment in or subsidizing training as a result of higher autonomy. A last important finding is a significant positive correlation between autonomy and increased revenues. In particular, provincial and municipal hospitals which have high autonomy tend to have their revenues increased the most dramatically whereas revenue increases in district hospitals seem to be insignificant. An interesting finding is that revenue growth from user-fees accelerates at the municipal and provincial hospitals.

Different from the above predominantly quantitative studies, Tran et al. (2015) employ a qualitative method to collect data from six hospitals to identify how the autonomy reforms affect public hospital governance and performance. The study specifically 
finds that autonomisation increases hospitals' proactiveness in reallocating their budgets to invest in their priority activities, in raising funds from outside sources, and in coordinating joint-ventures with the private sector to invest in hospital services. While having more latitude in finance and investment, public hospitals' autonomy over human resource management is still limited, particularly in recruitment and firing of permanent staff. Accountability is reported to be weak among the studied hospitals, especially in relation to clinical quality and patient safety.

As with hospital autonomisation, the autonomisation of universities in Vietnam has lately drawn some great interest from researchers. That universities remain subject to a highly centralized system of control is a major concern. Hayden and Lam (2007), in their qualitative study, examine the institutional autonomy of Vietnam's universities in reference to Berdahl (1990) identifying institutional autonomy with the power of the university to determine its goals and programs and the means to pursue such goals and programs. The authors also base their study on Tight's (1992) account of institutional autonomy associated with the freedom to be self-governing, to exercise corporate financial control, to make their own staffing decisions, to select their own students, to decide on their own curriculum, and to assess and certify the academic performance of their own students. The authors argue that universities in Vietnam do not have much institutional autonomy given the lack of some of the specific freedoms considered by Tight.

Dao (2014), by means of a single case-study approach, seems congruent with Hayden and Lam (2007) in maintaining that a lack of institutional autonomy is reported during the course of the interview. The studied university, though designated "regional" and "key", appears not to have more freedom to make decisions than most other universities. He further argues the university's autonomy granted by MOET seems conditional considering that the university is allowed to award degrees, but only on blank certificates purchased from MOET, and to deliver study programmes, but only when they are approved by MOET. He also emphasizes the restricted ability of the university's staff members to have much influence over senior management appointments.

George (2011) focuses her analysis on Vietnam's higher education curriculum frameworks to study university autonomy. In keeping with the findings of existing studies about university autonomy, she contends that there is a high degree of state intervention in the university curriculum, manifested not only in the highly prescriptive 
frameworks for compulsory Marxist-Leninist studies but also in the detailed MOETprescribed frameworks for non-compulsory specialist studies. Based on the comparison of the available curriculum frameworks (economics, social sciences, and humanities), she finds that only a limited proportion of a degree programme is left to be determined by a university faculty teaching the subject. Even the teaching materials introduced by university teachers must be approved by a university academic board. A monopoly on curriculum textbooks for use throughout the higher education system is still maintained, with almost no academic or other oversight to ensure they are of high quality.

Besides an emphasis on the limited autonomy of Vietnam's universities, a few researchers have turned their attention to the connection between autonomisation and the revenue-generating practices among universities. Pham (2012), for instance, explores the highly common practice of expanding student enrolment among universities to increase revenues. Of particular concern is that the expansion of student enrolment is not accompanied by increased investment in higher education or due consideration of academic capacity. Equally, Nguyen, Hamid, and Moni (2016) claim that the implementation of the English as a medium of instruction programme, whilst producing some positive outcomes for a university in the move towards selfgovernance, does not satisfy many of the necessary conditions to ensure quality. The authors contend that it is the income generated from the programme that leads the university to compromise quality through setting low English requirements when recruiting students for the programme.

Apart from descriptions, some scholars have made attempts to provide analysis to the features of autonomisation as well as to the correlation between autonomisation and the revenue-generating motivation. In health care, Fritzen (2007, p. 81), in studying the challenges associated with the state role following the rollout of the autonomy policy, refers to the negative aspects of commercialisation of health services and the rising inequalities of health outcomes as the adverse impacts of autonomisation. $\mathrm{He}$ attributes the problems to the weak steering and coordination system that makes it difficult for the central health authorities to hold the health workforce accountable. In elaborating this point, he emphasizes the weak capacity of ministry authorities in using remuneration as a tool to steer workforce behaviour and incentives. He also points to the infrequent and poor supervision whereby the weakest link lies in the management information system to ensure effective monitoring of service standards. 
London (2008, p. 126), in a study of the role of the state in a time of change, claims that the autonomisation of public hospitals threatens to undermine principles of equity since it is "an odd type of privatization whereby the state (and the Party and individuals associated with both) seek to generate and exploit the benefits of commoditized health services". Later in his empirical study of hospital autonomisation, London (2013) insists that in the absence of significant regulations, the financial incentives provided by autonomisation have occasioned the rapid expansion of commercial activities within public hospitals.

Forsberg (2011, p. 18) seems to support London's claim in maintaining that the autonomisation of public hospitals is "a form of privatization with public hospitals turning into profit centers" because the autonomy policies offer strong economic incentives for staff to cover operating costs from service users. She believes an effective accountability system can constrain the power and incentives that the autonomy policies give hospitals' managers but, given the absence of a norm-based quality assurance system and strong coordination between $\mathrm{MOH}$ and public hospitals, that remains a huge challenge.

In higher education, Hayden and Lam (2007) seek to explain the lack of university autonomy by looking at the natural reluctance of policy-makers to give up direct bureaucratic control over a sector that generates new knowledge and market expertise important to the national economy as well as the culture of centralised planning and bureaucratic decision-making that results in the uncertainty of practitioners about what autonomy implies and requires in terms of new accountability relationships and how it should be managed in conditions of scarce resources and limited expertise.

London (2010) refers to the MOET's “outmoded, over-centralized, and conservative management approach" as the main problem of higher education. He sees this management approach driven by "entrenched interests and fear of change that scorns initiative and prevents educators from responding to local needs". At the same time, he points to the trend of promoting new business ventures that are not linked to higher education mission with an aim to raising revenues among universities. He associates these revenue-generating practices with the stratification of the higher education system, considering this as the hazard of autonomisation.

Painter (2008) notes that with the introduction of fees and charges, decentralisation in the provision of services such as health and education is at the same time a process of public service commercialisation. Painter also suggests the incentives and freedoms 
conferred on PSDUs are to promote greater revenue autonomy so that PSDUs become self-reliant in the funding of their operation and payment for their workers. In this connection, he affirms that "socialization" that requires the people's resources to be mobilized and an end to subsidy becomes part of the decentralisation process. He then concludes that the decentralisation process in Vietnam is actually a dual process of vertical and horizontal transfer of power and resources. In another study several years later, Painter (2014) continues to affirm that autonomisation is a measure to cover the cost of retaining state employees in conditions of fiscal constraints because government budgets are increasingly reliant on limited taxation system. Painter believes the consequence of this policy measure is that PSDUs are pushed into the market where they are expected to recover their costs and extract revenues from customers. The marketization of the service sector ahead of the building of a good governance system, in his view, has created opportunities for profit- and for rentseeking among PSDUs. He then points out that the government of Vietnam has been conducting some remedial measures such as accountability at the grass-roots level, regulatory reforms and financial restructuring to address the adverse consequences of autonomisation.

Overall, existing studies have made great strides in helping us understand some of the important features of autonomisation and its impacts on public services. Most importantly, current literature reinforces the argument that autonomy, whilst restrained, provides PSDUs with incentives to generate revenues. The consequence of autonomisation is the rapid commercialisation of public services accompanied by service delivery abuses and corruption. The literature review partly helps to answer the research question.

There are, however, serious limitations in prior studies that explains why current understanding about PSDUs' autonomy is incomplete. The biggest limitation of prior studies is data constraints to enable deep analysis of the features of autonomy and the connection between autonomisation and the commercialisation effect. In specifics, empirical studies on hospitals, which are mostly quantitative, are limited to description with research results largely indicative. These studies lack a detailed elaboration on how autonomy is characterised and why it is associated with the commercialisation of health services. Studies that adopt qualitative methods do offer some details about hospital autonomy but their lack of critiques significantly constrain the research outcomes. 
In relation to higher education, several details about universities' autonomy have been reflected in empirical studies and, taken together, these details do provide an understanding of some autonomy dimensions. Nevertheless, description is still predominant in these studies with little analysis offered to understand the autonomy features in an in-depth manner. In particular, empirical studies that focus on the commercialisation effect of autonomy in higher education appear to be thin which obviously requires further research.

Meanwhile, studies by some prominent Vietnam observers such as Fritzen, London, Painter have sought to characterise the autonomy features, especially with respect to the commercialisation effects. While a better understanding of the autonomy impacts is obtained, these analyses are, in most cases, not validated by empirical data to strengthen arguments. These analyses also do not elaborate in a persuasive manner how and why autonomy is designed in ways that result in unexpected outcomes.

The significant gap in prior literature motivates the researcher to conduct an empirical study that employs qualitative methods to offer a deeper insight into the features of PSDUs' autonomy and its implications for service provision.

The existing literature provides a foundation for the scholarship of the study of autonomisation and its implications for service outcomes. However, there are still gaps in our understanding. As the above review of the literature shows, prior studies mostly focus their enquiries into one or some of the many dimensions of autonomy while autonomy is a multi-dimensional matter. The autonomy policies target PSDUs of all the service sectors but prior research investigates mainly the autonomy of PSDUs in one particular sector (e.g. either health care or higher education). As a result, the current literature only provides an incomplete picture of autonomisation. This study will, therefore, employ a multi-dimensional and cross-sectional approach to gain a complete picture of autonomisation and explain why autonomisation is associated with the burgeoning commercialisation of public services and the risks of rent-seeking and corruption. In doing so, the study will examine the different dimensions of PSDUs' autonomy in relation to the organization of service provision, personnel, and financial issues. The research will consider the autonomy of PSDUs across sectors, paying particular attention to health care and higher education, the sectors that are the most susceptible to the autonomy reforms.

The current literature suggests that there is a gap between de jure (formal) autonomy and de facto (informal) autonomy of central government's subordinate units. Yet, there 
have so far been very few attempts to characterise the formal and informal features of autonomy in existing research on the autonomisation of PSDUs. Little is therefore known about whether the actual practice of PSDUs conforms to or departs from the formal control imposed on them and what factors have led to such conformity or departure. Further examination is thus required into how autonomy is formally and informally characterised and what factors contribute to shaping such characterisation. To date, studies on PSDUs' autonomy lack a sound theoretical framework that helps guide the identification of formal and informal factors influencing autonomy and understand the way such factors combine to enable/constrain the actual practice. This explains why there is a serious lack of understanding about formal and informal features of autonomy as elaborated above. Based on historical and sociological institutionalism, this study will consider the institutional environment surrounding the formulation of the autonomy policies to explore how they evolve and form and to obtain a deep understanding of the underpinnings of the autonomy incentives. This study also will investigate the actual autonomy practices of PSDUs and how they are shaped by formal and informal rules, conventions, norms, routines, and cultural belief.

Last but not least, extant studies on autonomisation in Vietnam have not covered public employees' experiences and perceptions of how they practise autonomy on the ground. Neither have they covered the thoughts of ministry officials about how the autonomy policies that they are involved in developing have been implemented and monitored. Hence, this research is carried out to fill this gap. To do so, the research will gather evidence about the decision spaces that PSDUs in health care and higher education have in dealing with the organization of service provision, personnel, and financial issues, what opportunities and challenges that autonomisation creates, and what, and in which ways, institutional factors exert influence on the decision spaces of PSDUs. Evidence that will be collected will help provide answer to the research question: what is the meaning of the autonomy of PSDUs in Vietnam? 



\section{CHAPTER 3}

\section{PUBLIC SERVICE DELIVERY UNITS IN VIETNAM}

So far, Vietnam's autonomy reforms have primarily targeted public services. This chapter provides an overview of Vietnam's public services and PSDUs in an attempt to clarify the notion that the autonomy reforms have been limited to public services. Some background of the autonomisation of PSDUs and the accountability arrangements as a counterbalance to autonomisation are also examined. The chapter then provides an outline of the country's health care and higher education sectors to better understand Vietnam's public hospitals and public universities - the two types of PSDUs that probably have been the strongest exponents of the autonomy reforms.

\subsection{Public services and public service delivery units}

\subsubsection{Background}

Public services (dịch vụ công) in Vietnam are categorized into three groups: (i) public administrative services (dịch vụ hành chính công) include pure public services and merit goods such as licensing, registration, certification, and authentication; (ii) public services (dịch vụ công cộng/dịch vụ sự nghiệp công) consist of impure services such as education, health care, science and technology, culture and sports, and social security and (iii) utility services (dịch vụ công ích) comprise impure services such as water and electricity supply, waste disposal, sanitation, post and telecommunication, and transportation (Dang, 2017). Public services of group two are mostly social services and mainly provided by PSDUs. Meanwhile, a majority of utility services are provided by state-owned enterprises (SOEs). The autonomy reforms target both PSDUs and SOEs, but there is a separate management mechanism for SOEs since they are engaged not only in utility services but in business-for-profits activities as well. Hence, it is public services of group two that is the target of this study.

PSDUs constitute revenue-generating public units (đơn vị sự nghiệp có thu/đơn vị sự nghiệp công lập) which are defined in Law 58/2010/QH12 on State Employees as organizations "established under law by a competent state agency, a political organization or a socio-political organization, having statutory status and providing public services and serving state management work" (National Assembly of Vietnam, 2010, p. 3). Accordingly, revenue-generating public units are engaged in two major functions - service provision and state management (i.e. regulation). However, according to Vo and Lofgren (2016), who review Government Decree 
Table 3-1: Revenue-generating public units under the management of the Vietnamese Government

\begin{tabular}{|c|c|}
\hline Sectors & Revenue-generating public units \\
\hline Education \& Training & $\begin{array}{l}\text { universities, colleges, vocational centres, technology } \\
\text { centres, primary, secondary and upper secondary } \\
\text { schools, kindergartens }\end{array}$ \\
\hline Health & $\begin{array}{l}\text { hospitals, health centres, preventive health centres, } \\
\text { research institutes }\end{array}$ \\
\hline Culture \& Communication & $\begin{array}{l}\text { libraries, museums, cultural and artistic centres, radio } \\
\text { stations, television stations, news agencies }\end{array}$ \\
\hline $\begin{array}{l}\text { Labour, Veterans, Social } \\
\text { Affairs \& Social Insurance }\end{array}$ & $\begin{array}{l}\text { job centres, social security centres, veterans nursing } \\
\text { centres, rehabilitation centres... }\end{array}$ \\
\hline Science \& Technology & research and development organizations \\
\hline $\begin{array}{l}\text { National Resources \& } \\
\text { Environment }\end{array}$ & $\begin{array}{l}\text { meteorology centres, geology and mineral centres, } \\
\text { environmental consultation centres }\end{array}$ \\
\hline $\begin{array}{l}\text { Agriculture \& Rural } \\
\text { Development }\end{array}$ & $\begin{array}{l}\text { agricultural extension centres, forestry extension } \\
\text { centres, fishery extension centres, forest management } \\
\text { units, clean water supply and hygiene centres }\end{array}$ \\
\hline Transport & $\begin{array}{l}\text { vehicle inspection centres, register, port management } \\
\text { units }\end{array}$ \\
\hline Sports & sport centres \\
\hline Finance & finance management units regarding land, property \\
\hline Investment & SMEs support centres \\
\hline Telecommunication & information centres \\
\hline $\begin{array}{l}\text { Population, Family \& } \\
\text { Children }\end{array}$ & propaganda centres \\
\hline
\end{tabular}

Source: Vo and Lofgren (2016)

$181 / 2005 / \mathrm{Q}$-TTG on the classification and ranking of revenue-generating public units, revenue-generating public units are largely revenue-generating public service delivery units (see table 3-1). 
Under the Law on State Employees, PSDUs are statutory entities governed by public law. They have their own seals and accounts and accounting apparatus organized in accordance with the Accounting Law. Unlike SOEs, PSDUs are not allowed to be only involved in commercial and for-profit services. Staff of PSDUs are state employees, unlike heads of PSDUs, who have the same civil servant status as staff of ministries' departments. The core distinction is that civil servants are obliged to be loyal to the party-state while state employees give regard to the guidelines of the Party and the laws of the state. State employees are entitled to do business and work after official hours. Civil servants do not have the right to do so. However, this does not apply to heads of PSDUs because under the Law on State Employees, they still retain their appointed professional title and thus may engage in service delivery activities outside of their official hours.

PSDUs of each sector are under the state management of a ministry or ministeriallevel agency. There are four layers of state administration in Vietnam, but the central and provincial levels are the two levels where most of the coordination takes place (Ministry of Planning and Investment, 2006). All the central state management agencies report to the Prime Minister. Provincial state management agencies report to the Chairman of Provincial People's Committees (PPC) who report to the Prime Minister. As central agencies and respective provincial agencies have functional relationships, provincial agencies technically report to their respective line minister (Figure 3-1).

The operation of revenue-generating public units, according to the Law on State Employees, is stipulated to be under the mechanism of autonomy (tự chủ) and selfresponsibility (tự chịu trách nhiệm), in line with the effort to separate public service provision and business management from state administration functions that the Vietnamese government sets out in its public administrative reform agenda. 
Figure 3-1: Organisational structure of state management agencies responsible for public service sector

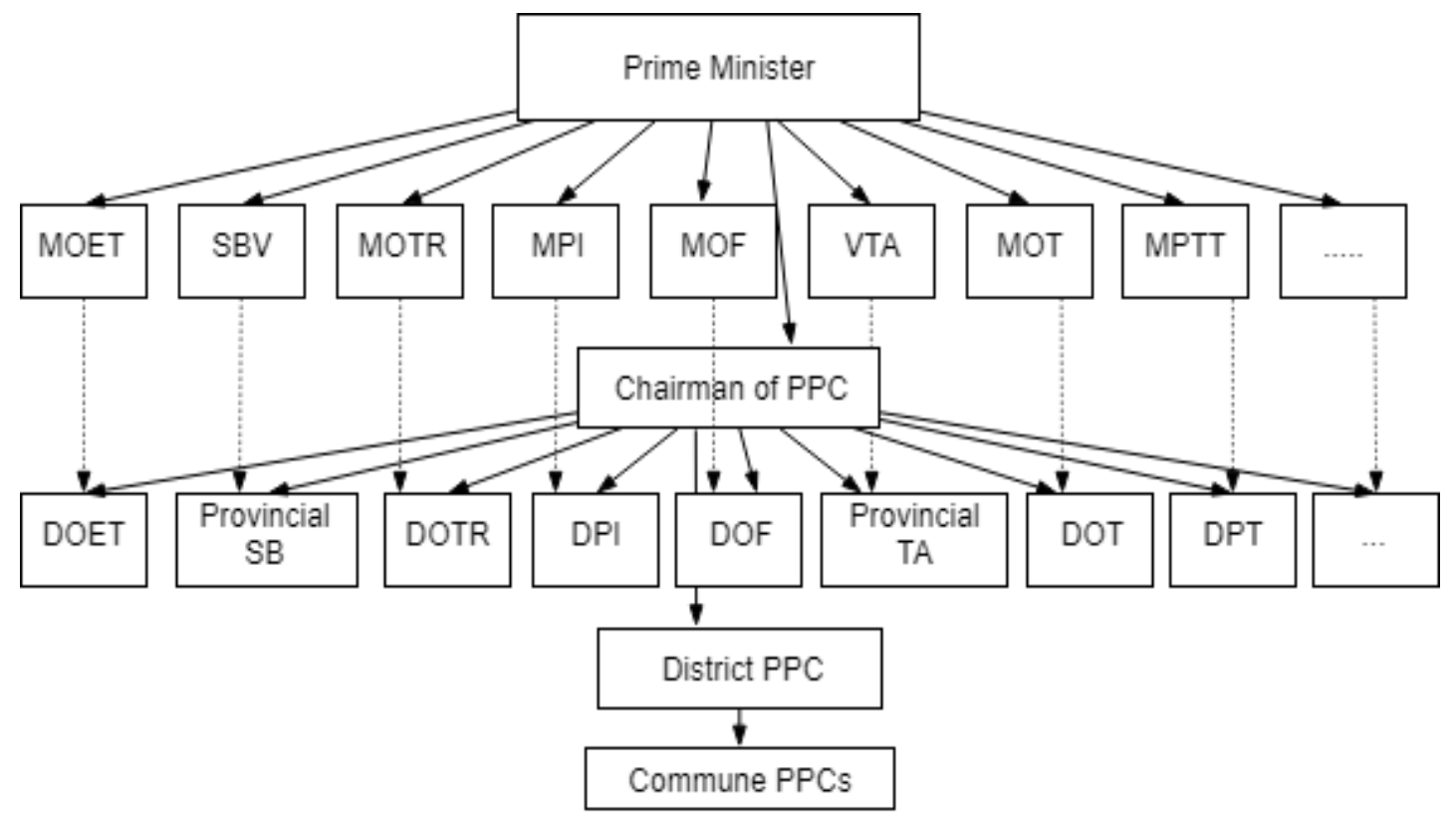

Source: Ministry of Planning and Investment (2006)

PSDUs in Vietnam thus share many common features with semi-autonomous agencies in many other countries. They are statutory entities, structurally disaggregated from their line ministry and given some degree of autonomy but not fully independent from their line ministry. They carry out a public task for a not-for-profit purpose and are, in principle, financed by the state budget and staffed with state employees who give regard to the guidelines of CPV and the laws of the state. Unlike other countries, heads of PSDUs are civil servants, obliged to be loyal to CPV. This may potentially make the autonomisation of PSDUs in Vietnam distinctive from most other Western countries where civil servants/state employees are expected to be neutral and impartial. In this respect, more details will be discussed in chapter 6 .

\subsubsection{Autonomisation of public service delivery units}

Chapter 2 shows that agencification is carried out in many developed and developing countries. The chapter also shows that this process takes place in a number of functional areas of the state including regulation, service delivery, adjudication, research, information, and policy advice. Vietnam's autonomy reforms have been so far targeted mainly at public service delivery and business management in an effort to separate these two functions from state administration (see also Vasavakul, 2002). These reforms have been much more about delegating autonomy to existing legally public bodies, most of which had been established and operated under the centrally- 
planned management mechanism (see also Vo \& Lofgren, 2016). In other words, the country's autonomy reforms are the process of allowing PSDUs and SOEs greater freedom from central/local governance and management rather than the creation of new public organisations operating at arm's length from central/local state management agencies. As a result, Vietnam's reform with respect to this matter is often referred to as autonomisation rather than agencification. The following provides some brief background of the autonomy policies. An analysis of the policy intents and contents will be further provided in chapter 6 .

Like some other countries, the autonomisation of PSDUs is part of the broader decentralization process which involves the transfer of power and responsibility from central government to public bodies including PSDUs, SOEs, and local government. It should be noted here that PSDUs and SOEs exist at central and local government which means that they are under the direct management of either ministries or local authorities. Furthermore, within the Vietnamese unitary state, local government exists as the deconcentrated agent of the central government (Fritzen, 2005b; Vasavakul, 2002). In this administrative system, executive power is centralized (quyền lực tập trung), but there is a delegation of management tasks and jurisdiction (phân cấp thẩm quyền quản lý) to local government authorities (Vasavakul, 2002). The major focuses so far are in the areas of budget, investment, administration and personnel management, land and natural resources, planning management, state-owned enterprises, and public services ( $\mathrm{Vu}, 2016 \mathrm{~b})$.

The policy measure that signifies the effort to separate business management and service provision from state administration functions is represented in the Law on State-Owned Enterprises in 1995. The Law grants SOEs the right to manage and use funds, land, and natural resources, and to transfer, lease, rent and mortgage properties under their management. SOEs are given legal status and have freedom in choosing partners, including "non-state" (i.e. private) and foreign enterprises to do business with. SOEs can also hire and fire employees. While granting SOEs power in several areas, the Law at the same time modifies the government's role in exercising state management of SOEs. For instance, the government promulgates policies and mechanisms of management with respect to different types of SOEs, incentive policies, and policies on subsidies and price subsidies; determines the objectives and development strategies; and sets up the criteria, norms, and salary units in relation to products and services. 
Alongside the delegation of public services to SOEs, the autonomisation of PSDUs takes place with the issue of government decrees that grant PSDUs varying degrees of autonomy in finance, personnel, and the organisation and management of service provision. Decree 10 in 2002 classifies revenue-generating PSDUs as fully or partially self-financing entities according to their relative dependence on the state budget (Government of Vietnam, 2002). Depending on their designation, PSDUs are given degrees of autonomy over spending and the allocation of net revenues. In 2006, Decree 10 was replaced by Decree 43, which divides PSDUs into three categories - fully selffinancing, partially self-financing and fully state-subsidized units, fixed triennially and gives them different levels of autonomy according to their financial performance (Government of Vietnam, 2006). Compared to Decree 10, Decree 43 confers greater managerial and financial autonomy on PSDUs. Fully and partially self-financing PSDUs are entitled to decide on property procurement, spending and investment. All types of PSDUs can borrow capital from credit institutions and mobilize capital from their cadres and public employees for investment in service activities. While Decree 10 puts relatively stringent caps on staff additional incomes, Decree 43 tends to relax the caps with fully self-financing units freed to decide on their staff additional incomes. The latest change in autonomisation measures is the issue of Decree 16 in 2015 in replacement of Decree 43. Unlike Decree 10 and Decree 43, Decree 16 classifies PSDUs into four groups - PSDUs that self-finance capital and operating expenses; PSDUs that self-finance operating expenses; PSDUs that partially self-finance operating expenses; and fully state-subsidized PSDUs - and grants PSDUs degrees of managerial and financial autonomy corresponding to their designation (Government of Vietnam, 2015a). The most notable change in this autonomisation measure is that self-financing units are entitled to determine fees and charges according to market mechanisms while units fully and partially subsidized by the state budget are allowed to determine fees and charges on the basis of economic - technical norms and cost norms issued by competent state agencies, according to which a roadmap for a full count of costs is prescribed from 2016 when the Decree was issued until 2020.

It is worth emphasizing that the autonomisation of PSDUs follows the change in the state's role in public services when it embarks on Đổi Mới in 1986. Under the centralplanning system, public services were free and the state was the sole provider of services. During Đổi Mới, public services were opened to private providers and user fees in health and education were introduced in 1989. These policies are promoted 
through the "socialization" (xã hội hóa) process, aimed at mobilizing social potentials and resources to improve the outcomes of public services. This understanding of "socialization" is unique to Vietnam. Socialization, in its original meaning, concerns "the state assuming costs or ownership over a given social activity" whereas in Viet Nam, it "refers to 'all segments of society contributing' to some sphere of social life" (London, 2010, p. 369). The objective of the autonomisation of PSDUs is associated with this policy, that is, according to Decree 43, to realize the "socialization" of service provision through harnessing "social contributions" (via user fees and charges) to the development of public services, thus reducing the state budget subsidy. The immediate objective of the autonomisation of PSDUs, also according to Decree 43, is to increase revenues step by step to ensure staff incomes.

Besides the above objectives, autonomisation is promoted to address weak state management, which the party-state ${ }^{2}$ points out to be the main contributing factor to the low quality of public services. The Party's recognition of the weaknesses in state management and commitment to improve public service provision through autonomisation is demonstrated in Political Reports of the Party Central Committee. For example, the Political Report of the $9^{\text {th }}$ Central Committee to the 10th Congress in 2006 attributes low quality in education and health care services to several key factors, including weak state management (Party Central Committee, 2006). The Report thus points out the necessity to fundamentally transform the management mechanism of PSDUs through delegating autonomy, promoting self-financing and operating on a not-for-profit basis. The Political Report of the $10^{\text {th }}$ Central Committee to the 11 th Congress in 2011 continued to promote the reform of the organization and operation of PSDUs in line with autonomisation and "socialization" (Party Central Committee, 2011). The Report encouraged PSDUs, especially those in the areas of health care, education and training, and science and technology, to increase their competitiveness to provide better quality public services.

2 The party-state term is often referred to as the national ruling organization in Vietnam (Shanks, Luttrell, Conway, Vu, \& Landinsky, 2004). It signifies the CPV's penetration of the government apparatus. 


\subsubsection{Accountability in public services}

Chapter 2 demonstrates that the development of the various forms of public accountability is crucial to counterbalance autonomy. In Vietnamese, accountability (trách nhiệm giải trình) is correctly defined as the responsibility to explain, present and justify, just like the global definition of accountability. Nevertheless, in Vietnam's autonomy reforms, accountability is mistakenly interpreted as self-responsibility (tự chịu trách nhiệm). In Government Decree 43, the term "self-responsibility" juxtaposes the term "autonomy" in every provision in relation to autonomy. In Government Decree 16, the autonomy mechanism of PSDUs is prescribed, that is the regulations with respect to autonomy and self-responsibility in task performance, organisational apparatus, personnel, and finance. The use of the term "self-responsibility" instead of "accountability" gives rise to the belief that "accountability in practice becomes synonymous to autonomy" (Vo \& Lofgren, 2016, p. 33). The term also may lead to a misunderstanding that PSDUs "should be absolutely free in organizing their activities and that they should be accountable to themselves only and not to any body, organization or agency” (Ngo, 2006, p. 238).

To date, Vietnam's public accountability system is still in its infancy. Accountability is mostly limited to the responsibility to report to the line management agencies (Pham, 2014). The existing reporting practice is, however, mostly against inputs and processes with almost no specific performance benchmarks and indicators to measure performance (Vo \& Lofgren, 2016). As there are very few measures which relate specifically to performance, the accountability of state agencies and officials for outcomes is largely limited (Fritzen, 2005b). So far, this top-down or hierarchical accountability still remains prominent in Vietnam's accountability system. Pham (2015) claims that top-down accountability has existed in Vietnam since early times when the public administration operated according to the top-down authority allocation with clearly specified responsibilities and disciplines, submission encouraged, and disobedience punished. In a hierarchical accountability relationship, state agencies and officials are responsible to their line management agencies for compliance with official instructions (Vasavakul, 2014). Hoang (2017) regards this form of accountability as passive, in that it is restricted to requiring state agencies and officials, when requested by stakeholders, to "provide, explain and clarify information about the execution of their assigned tasks and authorities, and their responsibilities in implementing such tasks and authorities", as stipulated in the Government Decree 
90/ND-CP in 2013 - the first legal document providing for the accountability of state agencies in the implementation of assigned tasks and authorities.

Besides unitary hierarchical accountability, there are several other dimensions of Vietnam's current public accountability relations. Figure 3-2 depicts the accountability relationships between the key institutions of Vietnam's party-state apparatus according to the CPV's 2016 Charter and the 2013 Constitution. By Constitution, CPV is the leading political force; the three top branches of the state - the legislature, the executive, and the judiciary - are united in a unitary political system led by CPV. The government is accountable to the National Assembly which is regarded as the supreme body of state power. The government is required to report to both the National Assembly and the President of the state.

Theoretically, there is little difference in the structure of the state between Vietnam and Western liberal states, other than the existence of a single party state (Gillespie, 2006). The distinction, however, lies in how the real power is practised in making decisions, especially in relation to redistribution and spending on public goods. As Nguyen, Teicher, and Smith (2010) observe, as CPV remains the most influential political actor in the system, the National Assembly, whilst having an increasing influence on the government, is not truly independent and has yet to realise its full potential. In the meantime, the role of the President of the state is largely ceremonial even though it may exert some minor influence on the government. The following discusses in detail the key accountability institutions - CPV, the central government, the National Assembly, civil society, and the media to better understand how public accountability is exercised in Vietnam. 
Figure 3-2: Accountability relations within the party-state of Vietnam

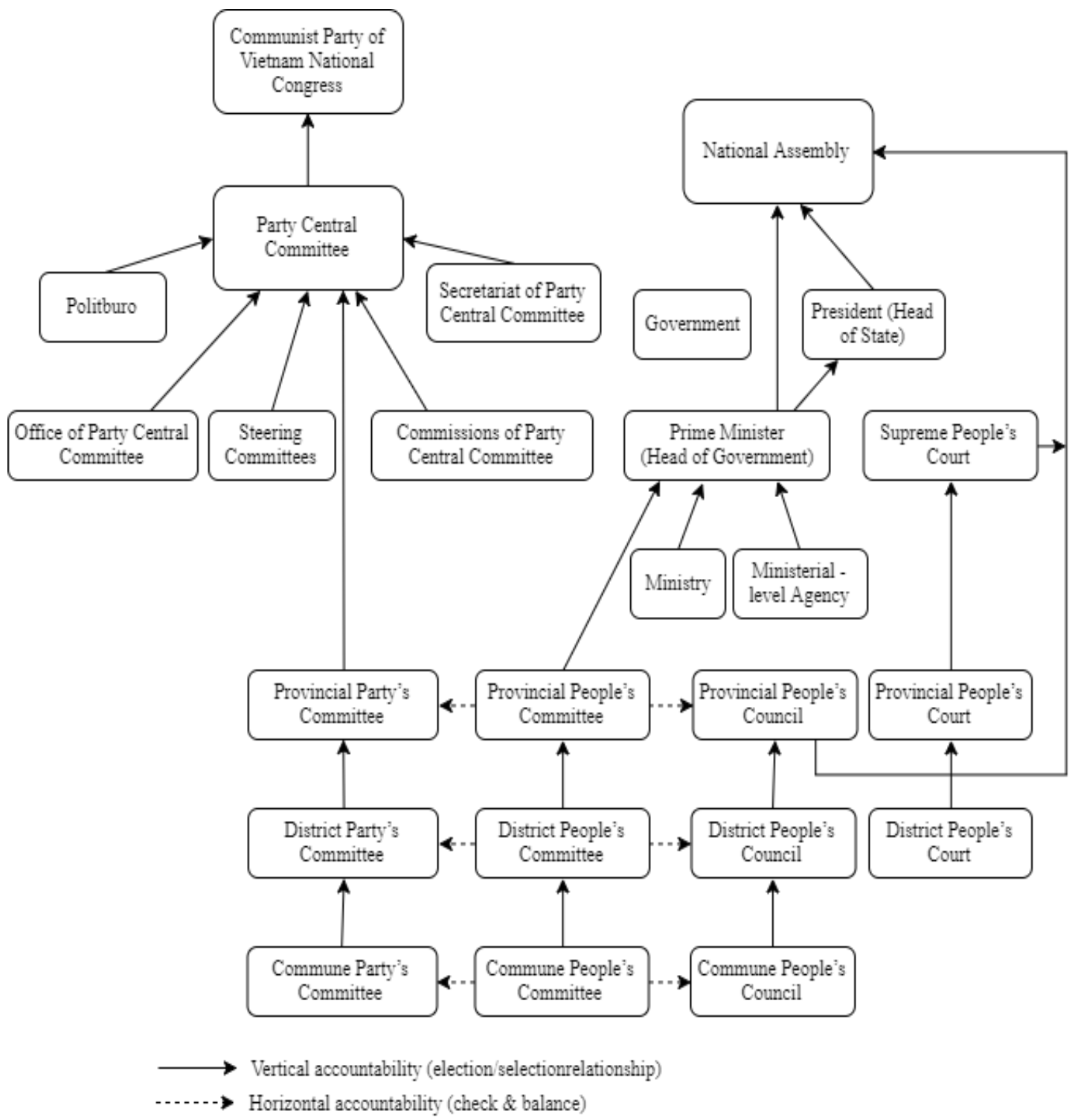

Devised by the researcher based on Communist Party of Vietnam (2016) \& National Assembly of Vietnam (2013a)

\subsubsection{The Communist Party of Vietnam}

Article 4 of the 2013 Constitution states "The Communist Party of Vietnam - the vanguard of the Vietnamese working class, simultaneously the vanguard of labourers and of the Vietnamese nation, the faithful representative of the interests of the working class, labourers and the whole nation, acting upon the Marxist-Leninist doctrine and Ho Chi Minh's thought, is the leading force of the state and society" (National Assembly of Vietnam, 2013a). With this statement, the sole leadership role of CPV is institutionalized in the Constitution. Accordingly, the Vietnamese people have no right to elect their country leaders. 
At the same time, Article 4 of the 2013 Constitution also states "The Communist Party of Vietnam maintains close ties with the People, serves the People, submits to People's supervision and is accountable to the People in its decisions" (National Assembly of Vietnam, 2013a). However, as demonstrated below, the personal responsibility and the accountability of Party members and organisations at the highest level are limited.

According to the Charter of the Communist Party of Vietnam (2016), the highest institution of CPV is the Party's National Congress, held every five years. The National Congress elects the Party Central Committee, which is the Party's supreme organ between Party Congresses. The Party Central Committee then elects the Politburo and the Secretariat of the Central Committee. In principle, appointments to the key Party positions are subject to a vote by Party members but "the vote is in reality just a formality, with the real decision being made elsewhere" (Gainsborough, 2003, p. 41). In fact, the body that nominates candidates is the powerful Commission for Organisation and Personnel of the Party Central Committee, led by a Politburo member (Nguyen et al., 2010). Candidates nominated by this Commission in any elections must be approved by the Politburo. Moreover, as most members of the Party Central Committee come from government ministries/ministry-level agencies or from provinces/cities, they have few incentives to challenge the decision of the Politburo (Ibid.).

So there are no democratic elections in Vietnam, even within the Party. The most influential political figures are chosen from among the Politburo. Under the Constitution, the President of the state, the Prime Minister, and the Chief Procurator of the Supreme People's Court are elected by the National Assembly. Interestingly enough, that is simply a rubber-stamp procedure, since there is normally only one candidate for each position, introduced by the Congress and approved by the Politburo (Holmes, 2016).

In addition to the lack of democratic elections, the communist core tenets of "criticism and self-criticism" (phê và tự phê) and "collective leadership, individual responsibility" (tập thể lãnh đạo, cá nhân phụ trách) or “democratic centralism” (dân 
chủ tập trung) ${ }^{3}$ also hamper outsiders from holding Party members accountable. The "criticism and self-criticism" practice emphasizes the need for Party members to be critical of themselves while citizens' participation in the supervision of its operation is not expected. Equally, the "collective leadership, individual responsibility" or the "democratic centralism" principle diminishes the personal responsibility of top leaders, who are bound by resolutions, plans, and decisions of Party organisations.

As its supremacy is guaranteed in the Constitution, CPV is interpenetrated with all parts of the state apparatus and present in all segments of the society (London, 2009). Article 4 of the 2013 Constitution stipulates that "all organisations and members of VCP operate within the framework of the Constitution and the law" (National Assembly of Vietnam, 2013a). To date, the Party's operation has not been legislated whatsoever. Neither has its leadership over the government system and society been regulated. The operations of the Party Central Committee, the Politburo and other Party organizations are still "in a closed loop, with insufficient participation and no efficient supervision from the public or the National Assembly" (Huynh \& Pham, 2015, p. 18). The Party operates under its own charter and resolutions, with no transparent linkages to the official legal system (Ibid.). Opinions provided by Party organizations are not official and are not binding from the legal point of view (Ibid.). This unclear relationship has created a grey area in public governance and in the distribution of authority and accountability among Party and government organizations.

\subsubsection{Government}

The 2013 Constitution defines the government as the executive agency of the National Assembly and the highest administrative body of Vietnam. The government carries out its work by issuing legal documents based on the laws passed by the National Assembly and its Standing Committee. Article 94 and 95 of the Constitution states that the government and the Prime Minister are responsible to the National Assembly and

\footnotetext{
${ }^{3}$ When alive, Ho Chi Minh once put it, "Collective leadership is democratic. Individual responsibility represents centralism. Collective leadership, individual responsibility means democratic centralism. Not delivering tasks in this manner is against democratic centralism". Ho Chi Minh justified the combination of the two terms in that "The leadership that is not collective leads to excusing, arbitrary and subjective behaviour. The outcomes can be compromised. The responsibility that is not taken by an individual results in indiscriminate, disordered and anarchic activities. The outcomes also can be compromised. Hence, collective leadership and individual responsibility always should go hand in hand".
} 
report to the National Assembly as well as the President (National Assembly of Vietnam, 2013a).

While the government is required to be responsible and accountable to the National Assembly for its portfolios, the power of the Prime Minister in forming the cabinet is largely restrained by laws and Party intervention. Under the 2013 Constitution, the Prime Minister is the head of the government but the Prime Minister is merely granted the power to appoint or dismiss vice ministers and officials of equal ranks of ministries and ministerial-level agencies (Ibid.). The appointment or dismissal of Deputy Prime Ministers, Ministers, and heads of ministerial-level agencies, whilst formally recommended by the Prime Minister to the National Assembly for approval, are actually determined by the Party Commission for Organisation and Personnel and the Politburo (Nguyen et al., 2010).

As in the case of the Prime Minister, ministers have insufficient power to appoint their deputy ministers while they are accountable to the Prime Minister for their portfolios. On some occasions, ministers are "afraid" of their deputies because the deputies are nominated by more powerful individuals or Party organisations such as the Party Commission for Organisation and Personnel (Ibid.). The effects of the law and the intervention of the Party result in a significant mismatch between the powers and responsibilities of cabinet members. This mismatch may give rise to circumstances in which it is impossible to hold cabinet members accountable for problems arising from their portfolio management.

Besides the composition of the cabinet, policy decision-making and implementation within the government are not autonomous. The Constitution claims that the Party "leads" and the state "manages" with an aim to distance the routines of the state administration from the politics of the Party leadership. However, in practice, the Party still intervenes in the state management through a set of mechanisms, thus violating the principle of "law-governed state" prescribed by the Constitution (Painter, 2003). For example, the Party issues directives to guide policy-making of the government and sets up Party Affairs Committees (generally known as Ban Cán Sự) within each government agency. The Party works with state agencies through Ban Cán Sự which report to the Politburo and Secretariat on government decisions and implementation of policies. At local government, the Party Committees play a decisive decision-making role. Party Committee heads or deputies generally are the chairpersons of the People's Councils and Party cadres assume the headship of specialized branches in local 
government (Vasavakul, 2002). The Party extends to the grassroots level with its basic units called Party Cells (Chi Bộ). Party members usually play an important role at all levels of government. All the top executive positions, particularly at the ministerial level, are assumed by Party members (Ibid.).

While the personal responsibility of Cabinet members is restrained due to the lack of power supported by law and the Party's intervention, the scope for holding them accountable is further limited because of the overbearing nature of the executive relative to the legislative and judicial branches (Fritzen, 2006). The machinery of government in Vietnam has always been extensive because the system was established on the basis of the Soviet model of socialism whereby the Communist Party implements its absolute leadership over society through the state and the government discharges all functions of management, from the macro to the micro-level, and from the public to the business sector (Dao, 1997). So far, the power of the government has further expanded with Đổi Mới that emphasizes the development of market institutions for economic growth (Vasavakul, 2001).

At sub-national level of government, the accountability of administrators is blurred by a "double subordination" structure whereby state management agencies at the local level, whilst functionally administered by their central line ministries, are administratively placed under local authorities (Fritzen, 2005a; Wescott, 2003). The result is that local state management agencies responsible for health care, education and other services have a dual reporting responsibility to the local people's committee and council, and to the central line ministries.

\subsubsection{National Assembly}

As provided by the 2013 Constitution, the National Assembly is the supreme body of state power and the highest lawmaking body (National Assembly of Vietnam, 2013a). Since Đổi Mới, the National Assembly has become more independent from the executive and more assertive in their role (Abuza, 2001). The National Assembly now has more full-time deputies than in the past and its sessions are of better quality with increasingly substantive deliberation (Vasavakul, 2014). As a result, its main function, the promulgation of legislation, has been better performed in both qualitative and quantitative terms. Deputies have been more defiant and frequently require prime minister and ministers to explain their performance in sessions which are live broadcasted (Ibid.). On some occasions, the National Assembly turns down proposals of the government. The National Assembly also approves the allocation of the state 
budget among sectors, programmes, and provinces and oversees the government's expenditure of state budget. The oversight role of the National Assembly has been increasingly improved, especially since it has the right to cast votes of confidence $(\mathrm{Vu}$ et al., 2015).

Hitherto, the National Assembly is far from being able to check or to balance the power of the government. It is yet to fulfill its functions and tasks prescribed in the Constitution. For example, it is authorized to make laws but in practice, it is unable to draft all the laws. In fact, it assigns much of its lawmaking power to the government (Vasavakul, 2002). The National Assembly holds plenary meetings only twice a year to debate laws and policies, leaving the consideration of most laws and policies to the National Assembly Standing Committees. Just like the lawmaking process in which the National Assembly only comments and passes laws proposed by the government, the National Assembly's decision on the government's budget proposal is often a formality even though it has the power to allocate the state budget (Vu et al., 2015). In relation to the monitoring of the state budget and assets, the state Audit Office, which is created by the National Assembly according to the Constitution, has often been late to detect serious violations (Ibid.).

The limitations of the National Assembly stem from many causes. Besides the lack of resources and capacity, the fundamental cause lies in the fact that the National Assembly does not have true autonomy (Nguyen et al., 2010; Vasavakul, 2014; Vu et al., 2015). In theory, the power of the National Assembly rests with its political mandates which are authorized by constituents. Nevertheless, deputies of the National Assembly do not actually represent their designated constituencies. Most of them are members of the Party and state agencies, representing the interests of the Party and the state. Currently, about 92 per cent of seats in the National Assembly belong to Party members and two-thirds of deputies are central or local government officials or SOE executives ( $\mathrm{Vu}$ et al., 2015). This implies that representation from the business sector and civil society is minimal. Further, the National Assembly's deputies are organized into 63 delegations, corresponding to 63 provinces of the nation. This delegate structure discourages deputies from acting contrary to the interests of local and central governments, and ultimately of the Party, significantly affecting the National Assembly's ability to operate effectively and independently (Ibid.).

The ability of the National Assembly to maintain its functional independence is also affected by the deputy selection methods which make it hard for qualified candidates 
to be elected. The elections of the National Assembly's deputy candidates are not competitive; they are selected through vetting rounds managed by the Fatherland Front - an organization led by the Party. This vetting mechanism has hampered the election of qualified candidates, as evidenced by the fact that independent candidates for the National Assembly make up only a tiny number in the National Assembly (London, 2014; Vu et al., 2015).

Additionally, the lack of professionalism is another factor that inhibits the National Assembly's independence from the government. Unlike the executive system with strong bureaucratic rules and traditions inherited over generations, the Vietnamese legislature is inherently weak (Fritzen, 2006; Vu et al., 2015). In historical perspective, the power of elected bodies in Vietnam is new with little experience in political campaigns, articulating voters' concerns, persuading and leading public opinion, and maintaining their constituency ( $\mathrm{Vu}$ et al., 2015). While a prerequisite for powerful parliamentarians is that they are truly voted in by their constituents, in Vietnam, this is non-existent given that the National Assembly deputy election is characterised by the "Party elect, people vote" (đảng cử dân bầu) practice. The work of National Assembly deputies is also not professionalized. At present, three-quarter of the National Assembly's deputies are elected for the first time; they work part-time or serve as deputies and government officials (Ibid.). The National Assembly's deputies have few meeting sessions with their constituents, usually one before and one after the National Assembly's annual sessions (Ibid.)

\subsubsection{Civil society}

Civil society (xã hội dân sự) was considered taboo and rarely mentioned in the press in Vietnam for a long time. From the view of the communist elites, civil society is construed as a group of dissidents resisting or even conspiring against the socialist regime (Huynh \& Pham, 2015). Despite political persecution, civil society, as a social force, emerged during the wartime. During 1955-1956 period, for instance, a group of prominent intellectuals, artists and writers published Nhân Văn, a newspaper and Giai Phẩm, a periodical, with articles demanding freedom of speech and independence from the Party’s intervention. Although the Nhân Văn - Giai Phẩm movement was crushed with some arrested and others sent to the re-education camp, this social force has been emerging, albeit with constraints and suppressions on movements viewed by the Party to challenge its monopolistic leadership. 
Besides the state or businesses, Vietnam also has civil society organisations. According to Nørlund and Nam (2007), Vietnam's traditional categorisation of civil society organisations into mass organisations, professional associations, Vietnamese NGOs and community-based organisations is controversial, since some types of organisations such as mass organisations and professional organisations are not independent of the party-state. Mass organisations, for example, are considered as the right hand of the Party and established to support the implementation of the state's policies and programmes. They are primarily funded by the state although they also receive financial support from donors to carry out their programmes and campaigns. As a consequence, their activities generally are not useful or effective. The Trade Union or the Vietnam General Confederation of Labour, for example, has not done a good job in representing the rights of workers, as expected of it as a workers' organisation.

While Vietnamese NGOs are more innovative than other organisations regarding their programmes and methodologies, they usually are small organisations with limited funding and do not have a membership base as mass organisations. Vietnamese NGOs are involved in activities such as social service delivery, research, and social work. Community-based organisations are often self-generated, operating at the grassroots level, and so often do not have an independent legal framework for their operation. They are formed for purposes related to people's livelihoods (rural areas) or environment, culture and recreation (cities).

After Đổi Mới was launched in 1986, and especially with the expansion of the internet in 1997, the growth of political civil society has been phenomenal (Bui, 2013). There have been several political groups rising up to claim for the promotion of democracy, human rights and religious freedom in Vietnam. Some of the prominent groups that can be listed are: People's Democratic Party of Vietnam, Vietnam Populist Party, Democratic Party of Vietnam, Committee for Human Rights in Vietnam, Free Journalists Association of Vietnam, Bloc 8406, Vietnam Progression Party, Vietnam Alliance for Democracy and Human Rights, Independent Labour Union of Vietnam, United Workers-Farmers Association and Independent Journalist Association of Vietnam (Thayer, 2009). These groups are considered illegal by the party-state and therefore have no standing in the socialist regime. Since they are not recognised by the state, the number of members joining in these groups is limited. Nonetheless, membership of these groups is diverse, ranging from intellectuals, writers, lawyers, 
journalists, bloggers to priest, activist, businessmen, veterans, high-profile members of the communist party and overseas Vietnamese. So far, many members of these groups have been brutally persecuted by the Vietnamese authorities for their opposition to CPV.

In recent time, self-motivated individuals and activists publicly express their critiques of political, environmental, and socio-economic issues on Facebook pages and in blogs. Many demonstrators and activists have been harassed, arrested and given harsh sentences in prison. According to Human Rights Watch, there are about 110 political prisoners in Vietnam, although the country denies holding any (Murray, 2017).

\subsubsection{Media}

The media play a critical role in holding politicians and administrators to account. In most Western democratic countries, the media is even considered to have the "Fourth Estate" watchdog role. The media's role in this respect is so far restricted in Vietnam primarily because the country has no privatized media agencies. To date, all 600 newspapers and 100 radio and TV stations are owned and controlled by the Party and the state (BTI, 2012). The mainstream media are closely censored by the powerful Central Party Commission for Propaganda and Education. Being tightly controlled and censored over content, the media is "the mouthpiece of the Party", focusing on top down dissemination of policies instead of reflecting many truly urgent issues in society or any feedback from the grassroots level (Hoang, 2002)

Coverage on sensitive topics such as corruption on the mainstream media has never been easy due to this restrictive environment, including warnings, dismissals, and arrests of journalists and editors. A study on media's coverage of corruption in Vietnam from 2006-2011 reported that fifty-one per cent of all stories which covered corruption cases had been officially released (Transparency International et al., 2011). A large majority of these stories were short, with little or no follow-up, and noninvestigative in nature because they are usually based on information provided directly by the police. The media failed to pursue nearly half of the cases reported after they went to trial, while twenty-one per cent of stories covered cases not subject to 
Figure 3-3: Number of Corruption Related Stories Covering Court and NonCourt Cases, All Newspaper (October 2006 - September 2011)

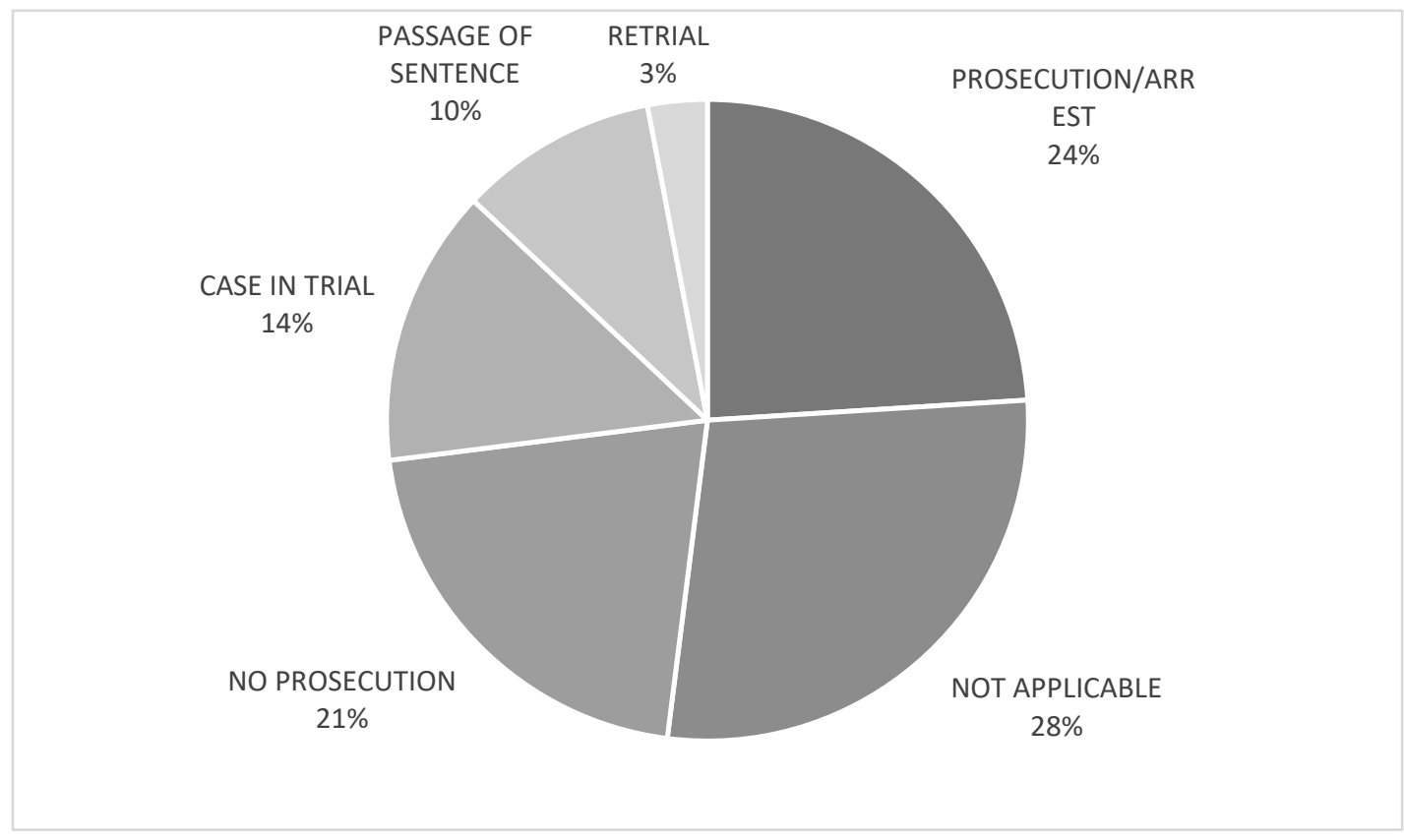

Source: Transparency International, Towards Transparency, UKaid, British Embassy, and UNDP (2011)

prosecution (see figure 3-3).The Media Law in 2016, in replacement of the revised Media Law in 1999, whilst stating that no organisation or individual can prevent “journalists and reporters from carrying out their lawful professional activities", dilutes the Constitution-prescribed freedom of speech through prohibiting the media's disclosure of state secrets or dissemination of information against the Socialist Republic of Vietnam including information that relates to "distorting, defaming or negating the people's administration" or is "untruthful, distorted or slanderous and harmful to the reputation of organisations or ... the dignity of individuals" (National Assembly of Vietnam, 2013b). The Law requires the media to "provide truthful information ... to protect the viewpoints, guidelines, and policies of the Party and policies and laws of the state" (Ibid.).

So far, legislation has been manipulated by the Vietnamese authorities to curtail media freedom (McKinley, 2008). It has been common for police to use violence, intimidation, and raids of homes and offices to silence journalists and bloggers who report on sensitive topics (Freedomhouse, 2016). Authorities also have employed both legal mechanisms and harassment to intimidate and punish critical journalists, bloggers, and their family members. Over the years, a number of journalists and editors have been dismissed, prosecuted and imprisoned for "distorting facts and slandering 
individuals" in coverage of corruption cases, "abusing the rights to freedom and democracy to defame the communist regime" or "abuse of authority" in "anti-state" writings. The Vietnamese authorities, whilst promoting Vietnam as an image of open and globalized economy, have recently intensified repression of old and new media (Crispin, 2012).

In sum, a good system of checks and balance is essential in a single-party state, especially to curb the abuses of power and the widespread rent-seeking and corrupt practices within the executive. Unfortunately, under the Constitution in Vietnam, the three forms of state power - the executive, legislature, and judiciary - are inseparable although there is a separation of functions and tasks among the three branches. As further argued above, Prime Minister and ministers are increasingly influenced by the National Assembly, but they do not have authority commensurate with their accountability. Meanwhile, the National Assembly is no more than the puppet of CPV since it acts in the interest of the Party and is under tight control of the Party. While CPV has the most influence in the political system, the accountability of Party members and organisations at the highest level is limited due to the lack of democratic elections and the nature of the communist core tenets of "criticism and self-criticism" and democratic centralism. Meanwhile, the role of the media and civil society in constraining the Party's power is limited because of their lack of independence from the party-state. Although political civil society and critical journalism and blogging are growing, these movements have so far been under harsh oppression with a great number of activists, bloggers and journalists harassed, intimidated and imprisoned. With political power unchallenged, CPV has so far maintained its sole, absolute, and comprehensive leadership over the state and society. As Sir John Dalberg-Acton once put it "power tends to corrupt, and absolute power corrupts absolutely". Chapter 7 will unravel how power is abused and corruption practised in a context where almost all the available accountability institutions and mechanisms are dysfunctional, which undoubtedly results from the Party's absolute power. 


\subsection{Overview of health care and higher education in Vietnam}

\subsubsection{Health care}

\subsubsection{Organisational structure}

There are both public and private health systems in Vietnam. The public health system is organised along a four-tiered pyramid (see figure 3-4). At the top is $\mathrm{MOH}$ which formulates and executes health policy and programmes in the country. $\mathrm{MOH}$ undertakes the state regulatory function of health protection, care, and promotion for the general population. Health professional agencies at the provincial level (Provincial Health Bureaus), district level (District Health Centres) and commune level (Commune Health Stations) carry out the policies set out by MOH. However, these state management agencies are under the management in terms of organisation, staffing and financing of the People's Committee at their respective levels, having the assigned function of assisting the respective People's Committee to undertake the regulatory function of health protection and care for the population in their respective area.

$\mathrm{MOH}$ has direct control of central general and specialty hospitals, research institutes, medical and pharmaceutical universities/colleges and pharmaceutical SOEs. The Provincial Health Bureau manages general and specialty hospitals and provincial preventive health centres. Under the District Health Centre, there is a district hospital, a district preventive centre and several inter-communal polyclinics. The Commune Health Station is mainly involved in primary care, including preventive care, hygiene and sanitation, normal delivery, ambulatory services, drug supply, family planning and health promotion activities in the community. 
Figure 3-4: The structure of the health care system in Vietnam

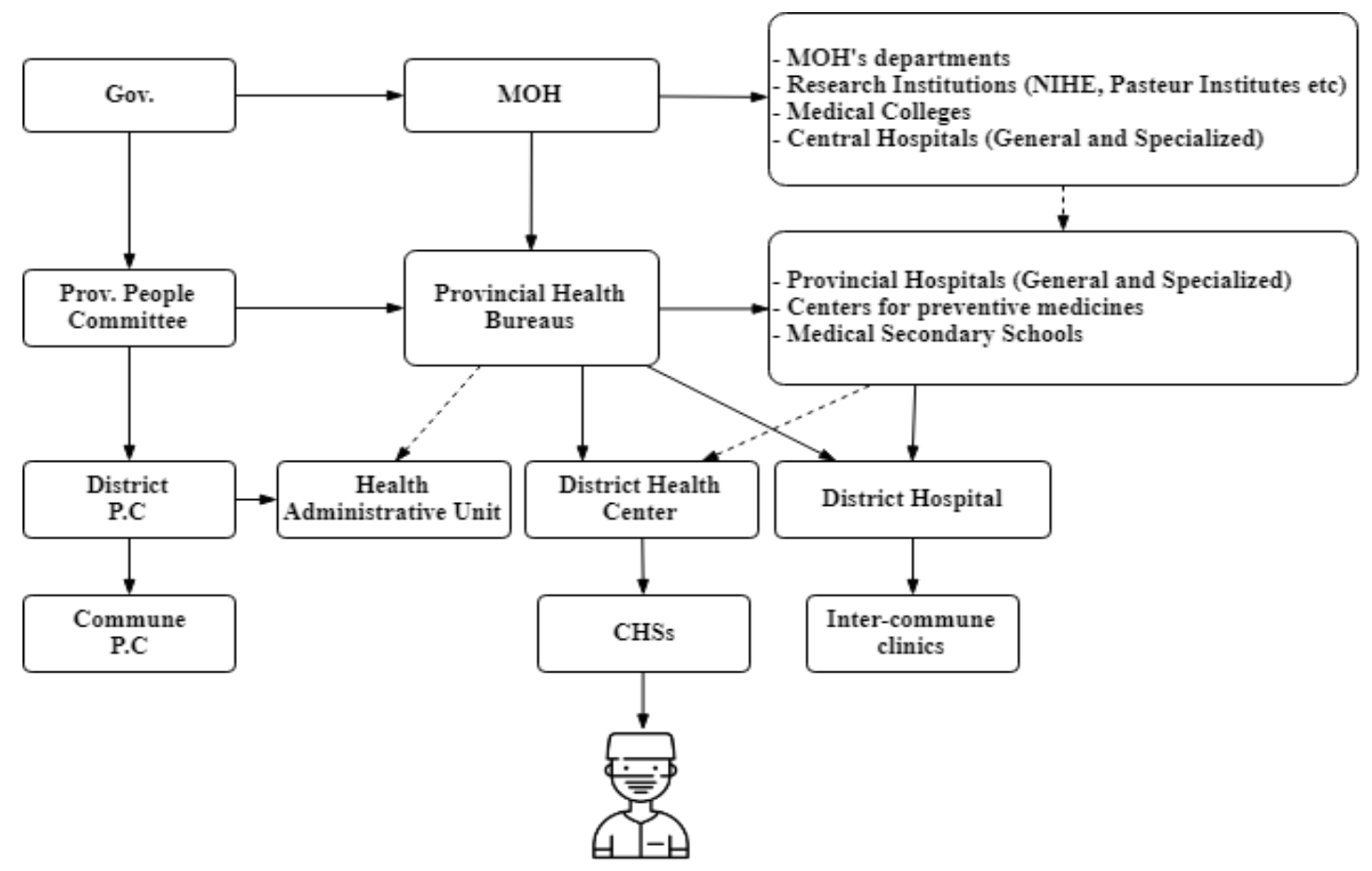

Source: World Health Organisation (2011)

According to Ministry of Health \& Health Partnership Groups (2012), as of 2010, Vietnam had a total of 1087 hospitals with 17 general hospitals and 23 specialised hospitals at the central level. There are 153 general hospitals and 125 specialised hospitals at the provincial level; and 615 general hospitals at the district level (Ibid.). Other sectors such as agriculture, public security, defence, and transportation also have their own hospitals with the number staying at around 23 hospitals, most of which are general (Ibid.).

The private hospital sector is relatively underdeveloped; as of 2010, Vietnam had 102 private hospitals with private hospital beds accounting for only 3 per cent of the total beds. In recent years, some private hospitals are well invested and become high-quality health care providers for the wealthy people (Ibid.). Some joint-venture and foreign invested health establishments have also operated in Vietnam, mostly in big cities.

Vietnam's health care services operate according to the referral system, where patients enter the system at the level of primary care and doctors or other health workers at that level decide whether they should be transferred to other levels of the system. Commune Health Stations, which provide primary care and preventative care, form the first tier of the health care delivery network. Curative care is mostly carried out at higher health care tiers (hospitals at district, provincial and central levels). Hospitals 
at the district line, which are often smaller in size than provincial and central hospitals, are often assigned basic curative health care services. Hospitals at the provincial line carry out more complex health care techniques (secondary care) and receive patients transferred from hospitals at the district line. Central hospitals are the last line, carrying out in-depth specialized techniques (tertiary care) and receiving patients transferred from the lower lines.

According to the referral guidelines set out in the MOH Circular 10 in 2009 guiding the registration of the first point of care for insured patients and referral mechanisms, insured patients can only use services at the Commune Health Stations and district hospitals where they are registered (the national health insurance schemes are discussed below in Section 3.2.1.2). In principle, insured patients must be referred to provincial and central hospitals when necessary. When bypassing lower-level referral facilities, insured patients must pay a higher co-payment rate depending on the level where they access health services. The co-payment rate is 30 per cent at district hospitals, 50 per cent at provincial hospitals, and 70 per cent at central hospitals (World Bank, 2014). In practice, the referral system is ineffective largely due to the low quality of care at the primary level facilities.

\subsubsection{Financing}

Vietnam's health care expenditure is financed from three main sources: state budget, insurance contributions and direct out-of-pocket payments by households (see figure 3-5). State budget allocation comes from general tax revenues. The amount of the allocation, therefore, depends on the total revenues collected and the priority given to health in comparison with other sectors. The state budget allocation for health in Vietnam, at about 1.2 per cent of GDP, is very low by international standards (Lieberman \& Wagstaff, 2009). While the total health expenditure, around 5-6 per cent of GDP, is in line with international expectation, the government share is modest, accounting for only one-quarter of the total health expenditure (Ibid.). Of the total health expenditure in 2010,70 per cent of the funds go to curative care at the central and provincial levels (Forsberg, 2011). While 60 per cent of the total health expenditure is used to cover staff salaries, 37 per cent is allocated to health sector development, of which 46 per cent and 51 per cent are distributed to national and provincial levels respectively (Ibid.). The remainder of only 3 per cent is allocated to 
Figure 3-5: Channels of financing sources for the Vietnam health care system

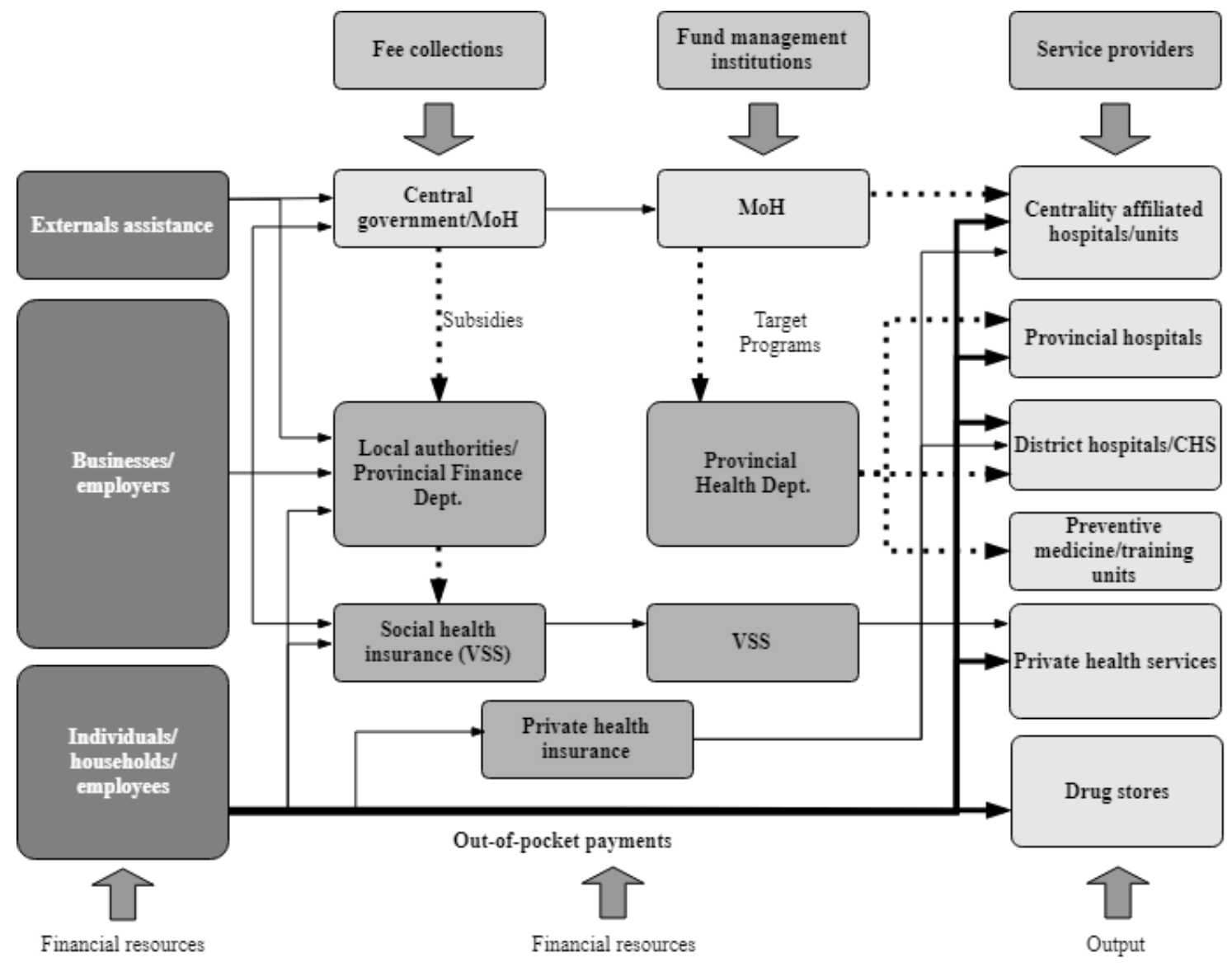

Source: Ministry of Health and Health Partnership Group (2008)

district and commune levels (Ibid.). These figures demonstrate the inequitable distribution of public spending with a large proportion allocated to curative care at higher level facilities.

Vietnam's total health expenditure draws largely on household direct out-of-pocket payments. The share of these payments in total health expenditure is high by international standards, ranging from 50 per cent -70 per cent (Ministry of Health \& Health Partnership Group, 2008). Direct out-of-pocket payments by households include those for the purchase of drugs, formal and informal payment of hospital fees, diagnostic service fees and other expenses related to using medical care at state and private facilities self-medication. Reports from 731 public hospitals nationwide show that the main source of hospital revenues in 2007 was from out-of-pocket payments, accounting for 59.4 per cent of all revenues and representing an increase of 26.5 per cent from 2006 (Ministry of Health \& Health Partnership Group, 2008) Surprisingly, while out-of-pocket payment is the sole means for financing health care for those not covered by social health insurance, it also is the dominant source for those covered by 
the scheme (Ramesh, 2013). It is estimated that informal (and usually illegal) payment makes up as much as 20 per cent of health care spending for patients receiving "better" quality inpatient care and 7 per cent for those receiving "normal" care (Akram-Lodhi, Chernomas, \& Sepehri, 2005).

The national health insurance system was introduced in 1992 with an aim to mobilising more resources and mitigating the negative impacts of user fees. Vietnam has two national health insurance schemes - a compulsory scheme and a voluntary scheme. The compulsory scheme consists of a social health insurance scheme for the formally employed and the health care funds for the poor. Voluntary health insurance, also administered by the state (Vietnam Social Security), targets population groups not covered by the compulsory insurance. Currently, national health insurance covers around 80 per cent of health expenses of an insured patient, who is responsible for the remaining 20 per cent (Hoang et al., 2013).

According to World Health Organisation (2011), in 2010, the national health insurance covered 50.8 million people, accounting for around 60 per cent of the population. Although children under 6 years of age, the elderly, the poor and the near poor are compulsorily enrolled in social health insurance under the Health Insurance Law in 2009, enrolment rates are still low among the near poor and other groups whose premiums are substantially subsidised by the state. In 2011, about 31.9 million Vietnamese people were not enrolled in social health insurance, of which 7.4 million were the near-poor and students whose enrolment is partially subsidized by the state and 1.9 million were children whose enrolment is fully subsidized by the state (World Bank, 2014). Of the 14.3 million classified as poor or belonging to ethnic minorities whose enrolment is fully subsidized by the state, nearly 0.3 million were not enrolled (Ibid).

Enrolment in social health insurance does not necessarily mean effective coverage of the insurance scheme. While social health insurance covered over half of the population in 2008 , it accounted for only 17.6 per cent of total health expenditure (Ministry of Health \& Health Partnership Group, 2011). A 2011 study of internal migrants shows that about 15 per cent did not possess a health insurance card and when ill 78 per cent of migrants had to pay out of pocket for health care (World Bank, 2014). For the beneficiaries of social health insurance among migrants, the scheme covered only 10 per cent of health care costs while 60 per cent of migrants did not seek care at all (Ibid.). Some major financial and nonfinancial factors undermine effective 
coverage. First and foremost is the fact that the voluntary health insurance scheme of Vietnam Social Security reimburses only a part of the provider's cost, leaving the remainder covered by household direct out-of-pocket payments. Second is the lack of confidence in the quality of primary health services given the fact that the lowest levels of care such as Commune Health Stations and district hospitals are underfinanced and disadvantaged in terms of the distribution of human resources for health as a result. For example, only two-thirds of Commune Health Stations in most regions of Vietnam have medical doctors (Ibid.). Most staff at Commune Health Stations lack the competencies to perform designated services and deal with emerging health problems (Ibid.). Finally, beneficiaries' poor understanding of their insurance entitlements results in patients not enrolling in the scheme, not using the health insurance card, or paying more in copayments.

\subsubsection{Quality assurance and accreditation}

Vietnam has little experience with implementing quality assurance for its health care system. Accreditation was virtually not applied in health care before the issue of the Law on Health Examination and Treatment in 2009. Only a few hospitals such as the French-Vietnam hospital in Ho Chi Minh city and the Cao Thang Ophthalmology hospital were accredited while some hospitals have received certification of quality management system according to ISO 9001: 2000 and 9001: 2008 (Ministry of Health \& Health Partnership Groups, 2012). Reasons for the limited accreditation of service quality among hospitals include the lack of service quality standards, the absence of approved accreditation agencies and the lack of incentives for hospitals to apply for accreditation.

The establishment of the Medical Service Quality Management Division under the MOH's Medical Services Administration in 2011 is a new step in the enhancement of the hospital quality management system. Among other functions and responsibilities, the Division is responsible for providing direction, guidance, monitoring, and evaluation of the implementation of clinical regulations and national technical standards in health care facilities. Following the forming of the Medical Service Quality Management Office, 55.4 per cent of all hospitals nationwide have established an office or unit for quality management by May 2015 (Ministry of Health \& Health Partnership Group, 2015)

In 2013, MOH took a bold step by issuing a set of indicators for public hospitals to conduct the self-assessment of their service quality. This step was taken after the 
approval of the 2009 Law on Examination and Treatment which sets new regulations for quality assurance for the first time in Vietnam. The standards include 83 criteria categorized into 5 groups: patients, hospital staff, professional activities, quality improvement activities, and specialized criteria applied only to maternal care. Each criterion is divided into 5 levels of performance. In total, there are 1487 subcategories of quality requirements hospitals are expected to satisfy. The set of standards is construed as "an instrument for measuring hospital quality, with concrete indicators to help hospitals improve their quality, and at the same time an instrument for monitoring by state management agencies and the people" (Ministry of Health \& Health Partnership Group, 2014, p. 115). It is estimated that 90 per cent of hospitals nationwide have implemented self-assessments and over 60 per cent of provincial health bureaus have verified their assessments by 2014 (Ibid.). The accuracy of these self-assessments is, however, open to question considering that the accreditation agencies to validate the self-assessment reports of hospitals are currently under the direct control of $\mathrm{MOH}$ (Vo \& Lofgren, 2016). No external and independent accreditation agency has yet been designated to validate these self-assessments (Ibid.).

\subsubsection{Higher education}

\subsubsection{Organisational structure}

Vietnam's education system is structured into five levels: kindergarten, nursery, primary (5 years from age 6), lower secondary (4 years), and upper secondary (3 years). Technical and vocational training is available after lower secondary school. Higher education options exist after graduation from upper secondary education. The higher education system in Vietnam includes four levels: college, undergraduate, masters and doctoral (figure 3-6). By June 2013, Vietnam had 204 universities and 215 colleges (Dao, 2014). Colleges provide only associate degrees whereas universities can provide bachelors, masters and doctoral degrees. Vietnam also had 71 research institutes authorised to provide $\mathrm{PhD}$ training programmes. Sixteen universities across three regions of the country were designated as key universities, accounting for almost two-thirds of all universities enrolments (Ibid.). Included in this group were national 
Figure 3-6: Structure of national education system

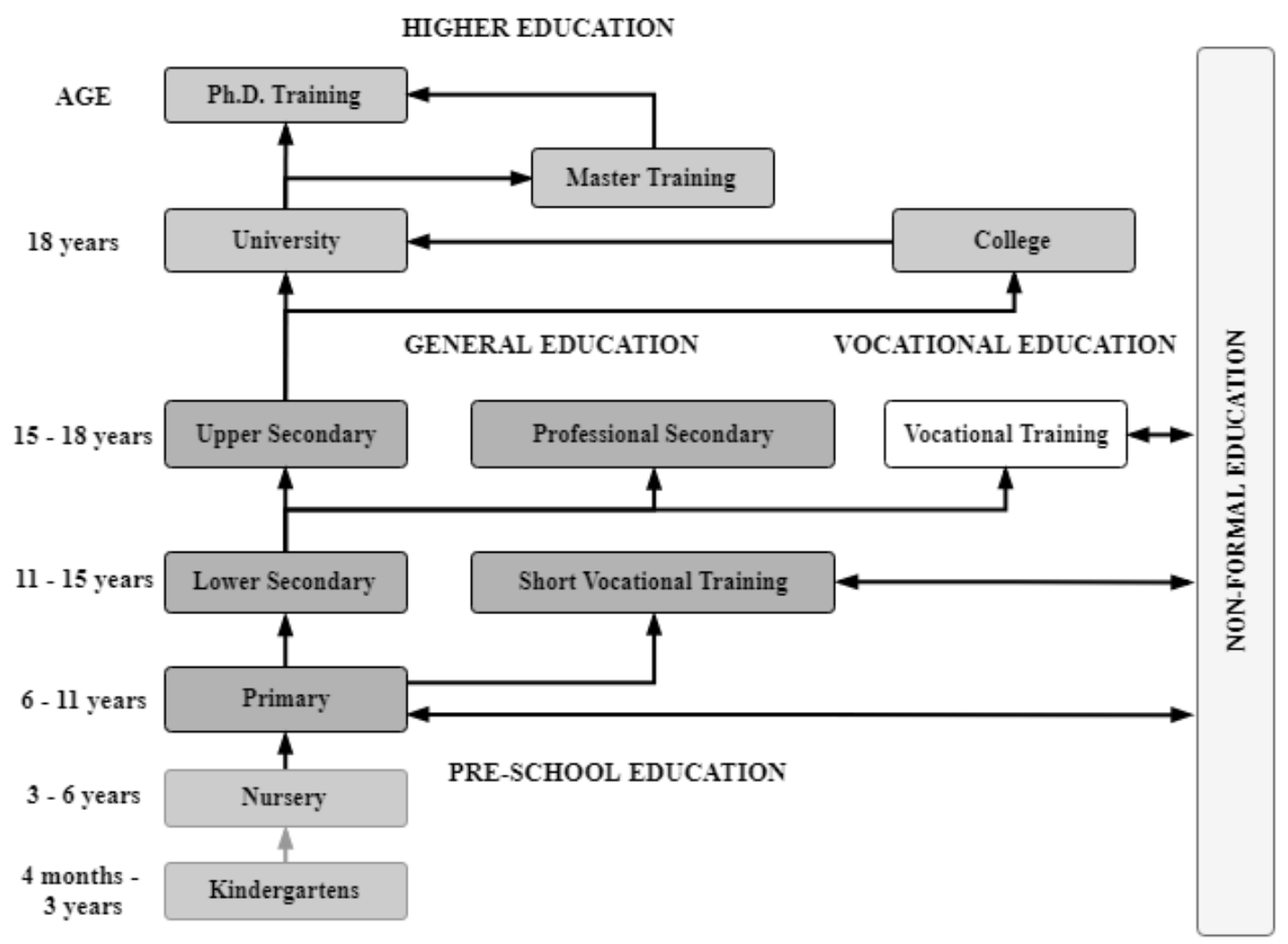

Source: Government Decree 90/ND-CP on 24/11/1993

and regional universities designated to form the base of the reformed higher education system (two national universities in Hanoi and Ho Chi Minh city and regional universities located in Thai Nguyen, Hue, Da Nang, Can Tho) and other large universities. Most remaining universities and colleges had enrolments of less than 3000 students (Ibid.).

The higher education system includes both public and non-public institutions. In 20042005, there were 29 non-public institutions (e.g. people-founded and private institutions), accounting for about 13 per cent of total enrolments (World Bank, 2008). People-founded institutions are owned and managed by non-governmental organisations such as associations, cooperatives, and trade unions. Private universities and colleges are owned and managed by individuals and companies. While peoplefounded institutions rely almost fully on cost recovery, private institutions draw all their incomes from private funding.

The system of public higher education institutions in Vietnam was based on the Soviet model of small and specialised institutions founded and managed by line ministries, provincial governments, and social-political organisations to meet their own labour 
needs. As a result, most higher education institutions are small, specialised and teaching-only with many belonging to ministries, provincial government and socialpolitical organisations other than MOET. So far, a number of public higher education institutions, especially key ones, have now expanded to include a wide range of disciplines and strengthened their research capacity.

MOET has attempted to bring higher education institutions under its control. The effort has been partly successful: MOET is currently responsible for 54 public universities and colleges including all of the key universities while at least 13 other ministries, provincial governments, and social-political organisations are responsible for the remaining 250 public universities and colleges (Dao, 2014). Regardless of their ownership, all higher education institutions must follow MOET's guidelines including admission, curriculum, and tuition rates. MOET is responsible for the management of all universities and colleges except for two national universities which are directly managed by the Cabinet. The ministry has a major responsibility for planning and directing Vietnam's higher education system and a shared responsibility for policy decisions, target settings and sector financing with the Prime Minister's Office, the Ministry of Finance (MOF), and the Ministry of Planning and Investment (MPI). MOET shares responsibility for the oversight of higher education institutions with other ministries, social-political organisations, and Provincial People's Committees.

\subsubsection{Financing}

Vietnam's higher education system relies on a combination of government funding, tuition fees and other sources including private grants or gifts. Like the health care sector, its total public funds allocated to higher education is modest. In 2002, Vietnam spent 4.22 per cent of its GDP on all levels of education, of which almost seventy per cent goes to primary and secondary education, another twenty per cent allocated for pre-primary and vocational schools, leaving higher education nearly ten per cent or less than half a per cent of GDP (World Bank, 2008). This figure is very low compared to the average of 1.22 per cent between 1999 and 2004 among seventy-five countries across the world. Also, Vietnam's private funding sources have so far remained limited whereas countries around the world are drawing nearly three-quarters of their higher education funds from private resources (Ibid.). 
Figure 3-7: The structure of higher education financing in Vietnam

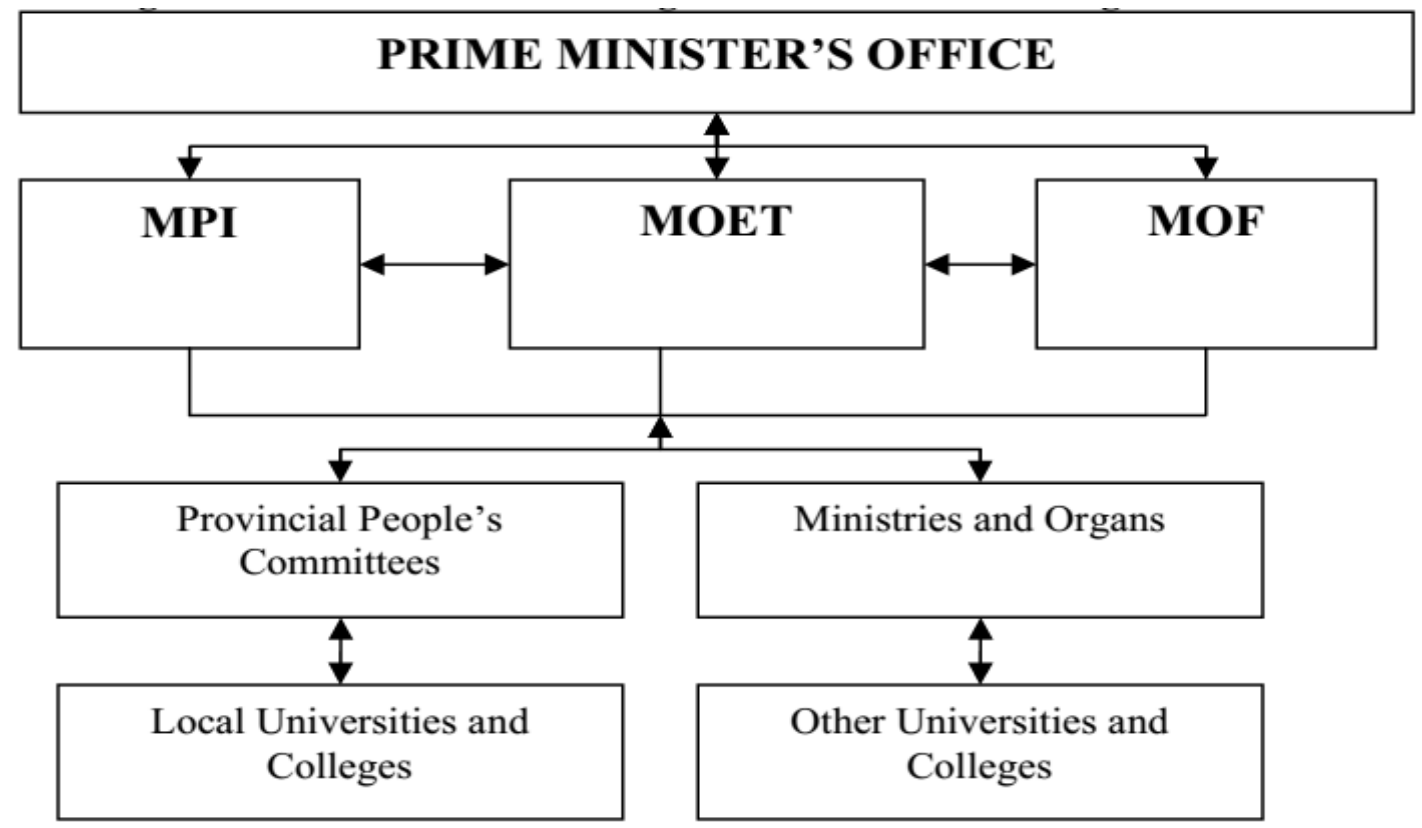

Source: UNDP (2003)

Unlike the health care sector, where government responsibility is increasingly decentralised, giving provincial government greater responsibility in planning and spending decisions, Vietnam's financing of higher education is highly centralised with MOET, MOF and MPI jointly deciding the budget for each higher education institution (see figure 3-7).

Although public universities receive the majority of their budgets from government funding, tuition fees are becoming an increasingly important source of revenues received by public universities to cover their operating costs. It is estimated that as much as 40 per cent of all revenues of higher education institutions come from tuition fees, sales of research-related services and private grants or gifts (World Bank, 2008). Among these items, tuition fees constitute a major source of revenues. For public universities and colleges, which account for over 87 per cent of all higher education enrolments, tuition fees make up about 40 per cent of their revenues whereas gifts and grants are almost negligible (Hayden \& Lam, 2010). The large majority (75-80 per cent) of public higher education students pay tuition fees while certain categories of students, for instance, war invalids' children, orphans, and the academically gifted, have their tuition fees partially subsidized by the state (Ibid.). Students undertaking such programmes as teacher education programmes are fully exempted from paying tuition fees. 
Student loans are a supplementary source of financial assistance for students although they are only available to those already making progress in their studies. The student loan programme was officially approved by the government of Vietnam in 1997 following a pilot programme among four universities (Ngo, 2006). A credit fund was then established with a low interest rate of 50 per cent of ordinary interest rate and a loan period up to 15 years (Ibid.). To date, the success of the student loan programme is far from being fully achieved. Major problems confronting the scheme include the limited availability of loan funds, the failure in the administration of the scheme, and difficulties in recovering debts (Hayden \& Lam, 2010).

Government scholarships for students attending public higher education institutions cover about one-third of the costs of being a full-time student (Ibid.). Funds for these scholarships are, however, limited and distributed to selected students either meritbased or equity-based.

\subsubsection{Quality assurance and accreditation}

An improved quality assurance and accreditation system is expected to contribute to increased service quality and accountability. External accreditation, in particular, is a primary means through which universities and colleges can assure their quality of services to students and society. Until recently, the government of Vietnam has pursued the development of a quality assurance and accreditation system to control performance of higher education institutions. In 2005, the Higher Education Reform Agenda for 2006-2010 identified key reform objectives for the period, including the establishment of a national system of quality assurance and accreditation for education. The Law on Higher Education in 2005 and the amendment in 2012 require that higher education institutions have internal and external accreditation and the results of quality accreditation be publicly announced. Under the Law, higher education institutions can select an education quality accreditation agency recognised by MOET.

Quality Assurance Centres were established, initially at the two Vietnam national universities and later at five regional universities for the implementation of quality insurance at the university level (Westerheijden, Cremonini, \& Empel, 2010). In 2003, MOET took a major step in improving the quality assurance of higher education institutions by establishing the General Department of Educational Testing and Accreditation to take the responsibility for building an accreditation system and coordinating the tests for entrance examinations into universities. In 2007, MOET issued ten quality standards for higher education institutions to implement 
accreditation based on self-assessment. Standards comprise missions and goals of higher education institutions; organization and management; curriculum; training activities; managing cadres, faculty and staff; students; research and development of technology; international cooperation activities; libraries, learning equipment and other facilities; and financial management. Up to 2008, 47 universities and 62 colleges have started the self-assessment process based on these quality standards (World Bank, 2008).

Self-assessment using a national quality assurance system is a positive step towards improving performance and accountability, given that higher education institutions have yet to formulate their own standards for quality assurance associated with their missions and goals. To date, the self-assessment reports of higher education institutions have been internally validated by MOET for the ranking purpose. This accreditation system, however, "tends to be a control instrument rather than a quality improvement instrument" (Westerheijden et al., 2010, p. 193). An independent accreditation agency responsible for the accreditation of higher education institutions has not yet been determined although external accreditation of higher education institutions is stated as an explicit requirement in the Law on Higher Education (Vo \& Lofgren, 2016). 


\section{CHAPTER 4}

\section{NEO-INSTITUTIONALISM: A FRAMEWORK FOR THE STUDY OF AUTONOMY}

This chapter situates the study of autonomy within the neo-institutional approach to politics. The neo-institutional analysis shows that the rules, structures, and cultures of a country's politico-administrative system have important implications for the making and enactment of public policies within it. The meaning of autonomy of Vietnam's PSDUs thus needs to be discerned in the light of the structural features of the country's politico-administrative system as well as the cultural features embedded in the setting. By drawing on the neo-institutional approach, this chapter elaborates a theoretical framework to provide an analysis of the research.

\subsection{Background}

The study of public policies - choices made by government agencies and other organisations including corporations, interest groups, and social and professional organisations - has become well-established in Western political science. As a result, numerous models, concepts and theoretical approaches have been generated to give meaning to different aspects of the policy domain. These approaches incorporate insights from various disciplines including economics, sociology, and organisational theory.

The literature on public policy research suggests there are various approaches to explain the specifics of making and implementing policy. Some emphasize order and regularity while others highlight the random characteristics of policy-making. A commonly used model is the policy cycle, which refers to a series of stages involved in a policy process, typically agenda-setting, formulating policy, making decisions, implementation and evaluation (Shaw \& Eichbaum, 2008). This model "portrays a policy process that is linear, sequential, and goal-directed" (Shaw \& Eichbaum, 2008, p. 21). This model is an ideal type indeed, because, very often, not all stages in this linear order are found in the real life of politics. Nevertheless, the model is still common mainly because of its simplification of the policy process, thereby easing its analysis (Duric, 2011).

In relation to typical policy processes, the concept of policy style gives some useful insights. Policy style is the notable way of making and implementing policy that features the dominant presence of a common set of policy ideas or paradigms, a persistent governance arrangement, and a fixed set of policy actors, resulting in 
consistent policy outcomes and typical policy processes (Howlett \& Tosun, 2017). The concept of policy style suggests that policy-making processes and policy outcomes vary between countries or jurisdictions due to the distinct nature of political system found in each setting. Policy style thus cannot be understood in isolation from regime characteristics including the kinds of existing institutions and their possible implications for the behaviour of policy agents (Ibid.)

The current theoretical approaches to the study of public policy are diverse. John (2013), in his influential book on the analysis of public policy, sums up some of the following "traditional" approaches: the macro socio-economic approach which emphasizes the determining role of the socio-economic context in policies outcomes; the rational choice approach which views policy outputs and outcomes as the result of the rational decisions of participants; the interest group and social network approach which considers network and relationship between members as key factors influencing the policy process; the institutional approaches which sees institutions as formal structures and norms informing policy decisions; and the idea-based approach, which places ideas as a source of policy. Each of these traditional approaches, in the author's view, deals with only a specific aspect of public policy. They are, therefore, individually unable to bring an encompassing analysis to the policy process.

The new institutionalism or neo-institutionalism is the modification of the earlier institutional approach to politics that dominated political science in the first half of the twentieth century. Interest in institutional analysis was renewed in the 1980s. It has become central to the study of politics during the 1990s, a time of many world events such as the collapse of communism that sparked experiments with neo-liberalism of many post-communist countries; the Asian financial crisis that required the adoption of more institutionally sensitive policies; and the recognition of the lack of institutional foundations required for the implementation of neo-liberal policies among postcommunist and developing countries; but recognition too of the many problems arising from the neo-liberal experiments in the advanced capitalist countries (Campbell \& Pedersen, 2001).

Neo-institutionalism, while reflecting many features of the old version of the approach to understanding politics, also enriched the theoretical approach that had informed behaviouralism and rational choice analysis and advanced the study of politics in a number of theoretical and empirical ways. The old institutionalism strictly associates institutions with "material structures" comprising mainly the formal aspects of the 
political system such as the laws, procedures, and structure of the governing system (Marsh \& Stoker, 2010). Meanwhile, contemporary institutional analysis is more concerned with how a political system is embedded in its historical development as well as in its socio-economic and cultural environment (Peters, 1999). Further, the new institutionalism "looks at actual behaviour rather than only at the formal, structural aspects of institutions" (Peters, 1996, p. 206). Instead of the individual behaviour with which both behavioural and rational choice approaches are concerned, collective behaviour has become the dominant approach taken by the new institutionalism to understanding political life (March \& Olsen, 1989). While the old institutionalism is descriptive, the new institutionalism is "characterised by an explicit concern with theory development... [It] seeks to explain [institutions] as a "dependent variable" and, more importantly, to explain other phenomena with institutions as the "independent variables" shaping policy and administrative behaviour" (Peters, 1996, p. 206).

The principal value of the neo-institutional frameworks lies in their institutional implication for policy processes and policy outcomes. March and Olsen (1996) assign great importance to institutions because, in their view, institutions "constitute and legitimize individual and collective political actors and provide them with behaviour rules, conceptions of reality, standard of assessments, affective ties, and endowments, and thereby with a capacity for purposeful action". Clemens and Cook (1999) see institutions as an autonomous political force that structures political action by shaping actors' preferences and identities, by influencing the interpretation of problems and solutions, by constraining and enabling the choice of solutions, and by affecting the way they can be implemented. Referring to the notion of institutional autonomy, Kingdon $(2003$, p. 229) points out that "the notion is that government is not simply pushed and pulled around by societal or economic forces, but has its own autonomy. (...) [I]nstitutions, Constitution, procedures, government structures, and government officials themselves affect the political, social, and economic systems as much as the other way around".

Neo-institutional analysis of politics postulates two distinct forms of institutions' influence over policy and political action: institutions can be both constraining and constitutive (Amenta \& Ramsey, 2010). Institutions, either in formal or informal way, constrain political behaviour through establishing the conditions under which interdependent political actors can function. While institutions limit some forms of action, they may at the same time facilitate others. On the other hand, institutions 
constitute political actors' identities and incentives because institutions establish the viable models and evoke the cultural frameworks for political actions.

The capability of institutions to exert influence on political action is significant primarily because the conception of institutions is encompassing within neoinstitutional frameworks. Institutions are redefined to include not only formal organisations such as bureaucratic hierarchies and market-like exchange networks but also as legal and cultural codes and rules that affect the strategies and courses of action of political actors (March \& Olsen, 1984). This definition emphasizes the informal aspects of institutions such as rules, norms, values, and beliefs, but it does not imply that the formal institutions cease to have its relevance. On the contrary, the relationship between the two is interdependent as Fukuyama (2006, p. 6) succinctly puts it as follows:

"Formal institutions matter, they change incentives, mould preferences, and solve (or fail to resolve) collective action problems. On the other hand, the informal matrix of norms, beliefs, values, traditions, and habits that constitute the society are critical for the proper functioning of formal institutions and a political science that pays attention only to the design of formal institutions and fails to understand normative and cultural factors will fail"

A fundamental property of institutions is that they create stability. Indeed, institutional theory is not usually seen as a theory of organisational change, but instead an analysis of the stability of organisational arrangements (Greenwood \& Hinings, 1996). Much the same can be said about the influential capacity of institutions over policy. The stability of policy within an institutional context arises from several sources, one of which is the theoretical perspective underlying those institutions (Peters, 2016). For instance, historical institutionalism emphasizes path dependence implying adherence to a particular policy direction once it is established while the sociological institutionalism stresses the idea of embeddedness of the political system within the institutional environment.

\subsection{Institutional approaches}

Neo-institutionalism comprises various approaches that seek to understand the role of institutions in explaining policy choices. Three major versions of institutional approaches in political science are rational choice institutionalism, historical institutionalism, and sociological institutionalism (Hall \& Taylor, 1996). The 
following will discuss briefly the major attributes of these three institutional approaches and how they shape policy outcomes.

\subsubsection{Rational choice institutionalism}

Rational choice institutionalism is a theoretical approach that can be defined as "the analysis of choices made by rational actors under conditions of interdependence" (Immergut, 1998). By focusing on institutions within the framework of rational choice theory, the approach holds a behavioural assumption that political actors are selfinterested, acting entirely instrumentally and strategically to maximize the attainment of their preferences. Their behaviour is often driven by a strategic calculus which is profoundly affected by their expectations about the behaviour of others.

The rationality of political actors is however bounded due to information asymmetries. Hence, institutions which emerge as a result of the interdependent and strategic interaction between political actors provide rules and incentives that play a vital role in lowering transaction costs and creating order and stability (North, 1990). The distinct feature of the rule-based institutions is their enforceability which can set constraints on political actions (North, 1990). The rule-based institutions are critical in regulating the behaviour of political actors especially when their rational pursuit of personal gains might produce collectively undesirable outcomes (Ostrom, 1990).

On the other hand, the rule-based institutions shape incentives of political actions through providing information and enforcement mechanisms that produce some predictability about the behaviour of political actors' competitors and allow individual gains from interaction between actors (Hall \& Taylor, 1996). Also, the rule-based institutions provide incentives by constraining the behaviour of these competitors and producing a relatively level playing field for all political actors (Peters, 1999).

By constraining political choices, institutions, therefore, help govern behavioural relations between political actors. The existence of institutions is, therefore, expected to produce some pattern of policy outcomes desired by the institutional designers. In other words, institutions become the major stabilizing or equilibrium force, structuring repeated interactions between utility-maximizing actors (Rakner, 1996). Rational choice institutionalism seeks to explain policy outcomes on the premise of individual preferences and institutional features as a matter of fact. 


\subsubsection{Historical institutionalism}

The basic assumption of historical institutionalists is that once an institution embarks on a path, it becomes likely the institution will persist on the chosen path (Hall \& Taylor, 1996; Peters, 2016). In policy domain, choices that are made of any policy, or any governmental system, will have a continuing influence over subsequent decisions (Peters, 1999). The idea of path dependence is often used by historical institutionalists to posit the persistence of political processes and outcomes (Amenta \& Ramsey, 2010). Pierson (2000) elaborates the increasing returns concept in economics to capture this path dependence notion. When political actors design a policy in a particular direction, the probability of further movement in that direction increases because the relative benefits of such activity compared to the possible alternatives increase over time. In other words, the cost of exit, or taking other possible options, rises. As increasing returns processes are "self-reinforcing", public policies may be "locked in" (Pierson, 1996).

The emphasis of historical institutionalism on institutional persistence indicates institutional inflexibility and resistance to change. That said, it may come as a surprise to some that institutions, while being rigid and resilient, display a typical character of adaptability, especially when that entails their survivability (Thelen, 1999). The forms of change that institutions usually take are incremental rather than the abrupt ones that occur at critical junctures - moments of substantial change that creates a point from which historical developments moves onto a new path (Thelen, 2004).

Grounded in the assumption of path dependence, historical institutionalism claims that public policies and political institutions generate both opportunities and constraints that affect the behaviour of actors involved in the policy-making process (Béland, 2009). Such approach assigns importance to the polity. The formal and informal procedures, routines, norms and conventions embedded in the organizational structure of the polity or the political economy are seen as the key factors that shape collective behaviour and political outcomes (Hall \& Taylor, 1996). On the other hand, historical institutionalism pays particular attention to the allocation of resources that are profoundly influenced by asymmetrical power relations while recognizing the local contexts as the mediating force for those processes (Ibid.). The latter point is based on the shared belief of historical institutionalists according to which institutions are a reflection of particular socio-political contexts. As Thelen (1999) asserts, institutions 
cannot be understood separately from the socio-political setting in which they are embedded.

\subsubsection{Sociological institutionalism}

Sociological institutionalism is a school of thought that evolves mainly within the subfield of organization theory (Hall \& Taylor, 1996). The theoretical approach is "a rejection of rational-actor models, an interest in institutions as independent variables, a turn towards cognitive and cultural explanation, and an interest in properties of supraindividual units of analysis that cannot be reduced to aggregations or direct consequences of individuals' attributes or motives" (Powell \& DiMaggio, 2012, p. 8). With a shift of attention towards cultural and cognitive impacts, sociological institutionalists maintain that institutions shape political behaviour by "providing the cognitive scripts, categories, and models that are indispensable for actions" (Hall \& Taylor, 1996, p. 948). The important point is that such cultural categories are important parts of an actor's underlying cognitive framework virtually invisible to actors and generally taken for granted and as a result actors rarely subscribe to them in a selfconscious or deliberate manner (Campbell, 1998).

Though not denying the assumption by rational choice theorists that actors are purposive, seeking to maximize their utility, sociological institutionalists portray a world of actors seeking to identify their preferences and identities in socially appropriate ways. For example, Hall and Taylor (1996, p. 948) assert that institutions are believed to affect the interests and goals of actors and their identities:

"It follows that institutions do not simply affect the strategic calculations of individuals, as rational choice institutionalists contend, but also their most basic preferences and very identity. The self-images and identities of social actors are said to be constituted from the institutional forms, images and signs provided by social life".

That is to say, actors may be acting rationally, but their perceptions of rationality is framed through, and shaped by, institutions (Nichols, 1998). From this perspective, political decisions cannot be seen as the aggregation of individual preferences but derive from the cognitive process (Immergut, 1998).

The new institutionalism in sociology takes a distinctive approach to explain how institutions originate. Unlike rational choice institutionalists who attribute the formulation of an institution to means-ends efficiency, sociological institutionalists 
contend that a new institution is adopted because it improves the social legitimacy and resources that the organisation and various actors within it need to survive (Hall \& Taylor, 1996). In other words, organisations embrace particular institutional forms and practices because they are considered socially appropriate and valued within the wider cultural environment. Meyer and Rowan (1977), in their foundational article, argue that many formal structures of organisations strongly reflect the myths of their institutional environments. The myths generating formal organisational structures are rationalized prescriptions that specify various social purposes and appropriate means for the organization to follow. They are highly institutionalized to the extent that they are beyond the discretion of any actor or organization and as such, they are taken for granted as legitimate. Organisations ceremonially adopt such rationalized institutional structures because they are legitimated externally and as such, they may proceed to decouple such structural changes from their actual practices to take into account local circumstances and practical realities. DiMaggio and Powell (1983), drawing on this earlier work, claim that rationalization and any other forms of organisational change result from the structuration of organisational fields - a process largely affected by the state and the professions in ways that lead to organisational homogeneity in structure, culture, and output. Accordingly, isomorphism is the result from three sources of pressure: coercive isomorphism that stems from political influence and the problem of legitimacy; mimetic isomorphism deriving from standard responses to uncertainty; and normative isomorphism aligned with professionalization.

As the new institutionalism in sociology employs such cognitive and cultural explanations, the approach sees the logic of appropriateness as the fundamental logic of political and policy outcomes. A political action is seen appropriate when it is acted according to "the institutionalized practices of a collectivity and mutual understanding of what is true, reasonable, natural, right and good" (Olsen, 2007, p. 3). The purpose underlying such action is aligned with roles and identities more than with interests, and with the selection of rules more than with individual rational calculations (March \& Olsen, 1998).

\subsection{Choice of institutional approaches for the study of autonomy}

The literature shows that a number of empirical, mostly quantitative, studies do not adhere to one specific institutional approach in analysing policy outcomes and the conduct of government. Instead, they tend to combine theoretical insights from two or more approaches in their analysis. Quite a few empirical studies utilize the insights 
from all three institutional approaches to reflect the implications of the instrumental and cultural aspects of organisations for the study of public policy. While the instrumental perspective emphasizes rational action, the logic of consequence, the formal structure of organisations, and the technical environment, the cultural perspective stresses the logic of appropriateness, path dependence, organisational culture such as informal norms and values, and political-administrative culture (Christensen, Lægreid, Roness, \& Røvik, 2007). For instance, Lægreid, Opedal, and Stigen (2005) use three different theoretical perspectives - an instrumental, a cultural and an environmental perspective - to analyse the autonomy and control experience across Norwegian hospitals. The instrumental perspective highlights the formal and hierarchical aspects of hospital reform while the institutional perspective emphasizes the cultural features of the reform and of the health sector, and the environmental perspective stresses the characteristics of political processes and policy types.

Another telling example is a quantitative study by Verhoest (2010) which employs the ideas from the three institutional approaches to explain the similar and different features of a number of public agencies across three states of Norway, Ireland, and Flanders. In so doing, the author builds a layered explanatory model based on the four perspectives aligned with the three institutional streams. The four perspectives represent the different logics of action - the logic of consequences or the logic of appropriateness - and emphasize the different ideas or theoretical lenses - formal organisational structure and rational choice, organisational culture and path dependence, organisational tasks, and institutional environments including the politico-administrative environment.

A further notable example is a quantitative study by Christensen, Danielsen, Laegreid, and Rykkja (2016) which applies both structural-instrumental and cultural perspective to analyse the utilization of the two different coordination mechanisms - hierarchical and network arrangements - for crisis management in six European countries. The structural-instrumental perspective is employed to explain the possible connection between the use of crisis management coordination mechanisms - whether they are hierarchical or network-oriented - and administrators' perceptions of coordination quality. Meanwhile, the cultural perspective is used to examine what values embedded in the government system administrators emphasize and how these values are connected with the choice of coordination mechanisms. 
The examples of empirical studies demonstrate the possibility, and potential value, of the convergence of various institutional approaches to the study of public policy. This resonates with some of the calls for the integration of institutional approaches by new institutionalists. Hall and Taylor (1996), for instance, maintain that an interchange of the three institutional approaches is all but essential because each approach captures different dimensions of human behaviour and the effects institutions have on behaviour. Christensen and Lægreid (2006) also argue that the study of agencies and regulatory reforms features theoretical pluralism and it is, therefore, vitally important to take a broader, more mixed approach which blends different organisational and institutional perspectives. Specifically, the range of organisational features and environmental institutions that might exert influence on political choice and the scope for managerial strategies of agencies must include the structural form of the organization, the primary tasks, the political-administrative traditions and culture as well as the external economic and ideological pressures. Scott (2013) attempts to construct an encompassing theoretical framework that encapsulates most contemporary views of institutions. The framework incorporates the culturalcognitive, normative, and regulative aspects of institutions labelled as three pillars of institutions. Whilst recognising the substantial differences in the types and bases of institutional order, the motives for compliance, the logics of action, mechanisms, indicators employed, and the rationale for legitimacy, the author considers the incorporation necessary since the three pillars, together with associated activities and resources, are supplementary and complementary in providing stability and meaning to social life. In this connection, the logic of appropriateness must be considered and mixed with the logic of consequence (March \& Olsen, 1989, 1998). Instead of one single dominant logic, one needs to take into account different logics of action in search of a complementary explanation for different purposes and in different contexts (Olsen \& March, 2004).

Despite strong advocates of synthesis, some institutional theorists object to such developments by arguing that institutional approaches are different and incompatible in their ontological positions. Hay and Wincott (1998), in reaction to the advocate of Hall and Taylor to incorporate insights from institutional perspectives, argue that such a dialogue between them is far more restricted because of their different "social ontologies" - the calculus and cultural approach posited by rational choice and sociological institutionalism respectively. In their critique of the pillars framework, 
Phillips and Malhotra (2008) also argue that the different institutional elements cannot be integrated into a theoretical framework due to their ontological incompatibility:

"The fact that coercive and normative mechanisms are externally managed by other actors makes them very different from the taken-for-grantedness of cognitive mechanisms. Where coercive and normative mechanisms result in strategic action and often resistance, cognitive mechanisms function by conditioning thinking" (Phillips \& Malhotra, 2008, p. 717).

This research incorporates the theoretical insights from historical institutionalism and sociological institutionalism for the analysis of autonomy of public service providers in Vietnam. The potential application of these two institutional approaches, as opposed to rational institutionalism, responds to the ongoing efforts to integrate various institutional approaches of several theoretical and empirical studies, and at the same time addresses the persistent concern with the incompatibility of institutional approaches expressed by some of the new institutionalists. The theoretical choices are justified below:

In the first place, this research maintains that rational choice institutionalism cannot account for the typical complexity of context and actor preferences surrounding the formulation and implementation of Vietnam's autonomy policies that the research aims to examine. The main reason is that rational choice institutionalism adopts a deductive methodology which means that explanations are deduced from the approach's principal assumptions about the preferences of actors (Bell, 2002), that is that actors are rational. The assumption of the existence of a behavioural element is regarded a strength of the rational choice approach (Peters, 1999), but this strength is limited in that it specifies individual interests and goals exogenously to the institutional environment, whilst in the context of the Vietnamese autonomy reform, the preferences of participating actors can be multifaceted, ambiguous, and difficult to identify as a priori. The ahistorical nature of rational choice institutionalism is another reason. In particular, the approach cannot shed light on the ramifications of Vietnam's historical transformation from centralism to marketization and deregulation as well as the developments in the perception of Vietnamese decision-makers towards the autonomy policies. A further reason is that rational choice institutionalism mainly focuses on the rational aspects of political behaviour and downplays the importance of cultural factors such as values, beliefs, symbols, models and the like (Suchman \& Edelman, 1996). The limitation of employing such a narrow rational framework is that 
it construes political action as an adaptation to means-ends efficiency (Scott, 2013) and that it treats institutions simply as devices and functions of political optimization (Zafirovski, 2004).

In the second place, this research contends that sociological institutionalism and historical institutionalism are the preferable theoretical approaches and methodologies to be employed in the study of the substance of autonomy of Vietnam's PSDUs, particularly the way the policy evolves over time and is carried out in practice. The reason for this potential application is that these institutional approaches are likely to address the limitations of rational choice institutionalism and that they promise to provide the fullest accounts of politics and institutions of any of the social sciences. First, both historical and sociological institutional approaches use inductive methodology by holding that preferences are endogenous (Bell, 2002). Despite not denying the assumption about rationality, the two approaches posit that rationality itself is structurally and culturally generated. As Katznelson (1998) argues, "rationality can only be inferred over time; that [a] particular version makes sense only in specific normative and institutional settings which are culturally and structurally thick, not just strategically lean". The general idea underpinning historical and sociological institutionalism is that political actors can be calculating, but also interpretive and reflexive. Rather than depicting preferences in relatively static terms, both approaches introduce a dynamic and temporal dimension to the analysis which portrays the probability that actors adapt their preferences and behaviour to new and evolving contexts. Obviously, this perspective allows the research to capture the dynamic processes of the formation of endogenous preferences of interpretive actors involved in the Vietnamese autonomy scenario. This perspective also recognizes the possible nuance and complexity in relation to the preferences of actors, as opposed to rational choice theory's overly simplistic deductive specification of goals and interests.

Second, unlike rational choice neo-institutionalism, historical and sociological institutionalism adopts theoretical pluralism as a preferable epistemological position (Zafirovski, 2004). The underlying ontological rationale is that numerous existing institutional forms cannot be exhaustively explained in economic terms as material and purposive structures. Alternatively, various non-economic factors can be used to explain the persistence of such institutions. It is apparent that a pluralist epistemology better captures a multidimensional structural ontology such as the interactive and 
constitutive relationship between the institutional environment and political actions that this research discerns.

Third, the historical and sociological study of institutions differs from the rational choice institutional theory in that it treats institutions as predating and conditioning individual actions rather than following and deriving from them as the latter postulates (Zafirovski, 2004). Institutions within these schools of thought, therefore, constitute explanatory factors of behaviour, not the dependent ones as in the rational choice study of institutions. This explanatory power of institutions promises to shed light on the Vietnamese autonomy reform by assigning the meaning to the institutional factors underpinning the autonomy reform.

Fourth, compared to the logics of consequences introduced by rational choice institutionalism, the logics of appropriateness on which historical institutionalism and sociological institutionalism are based promise to give a fuller account of the reasoning of actions and the sources of their reasoning (Goldmann, 2005). The logic of appropriateness offers a more complex and comprehensive view of political motives and goals because it does not exclude the self-interested calculation and anticipation of consequences. Instead, the perspective sees such calculation and anticipation as framed by identities and their underlying institutional rules, norms, and values. This means the perspective construes preferences as changing, endogenous and formed within the broader institutional environment. Considering these attributes, the logic of appropriateness is the preferred logic of action that the research will use to explain the outcomes of autonomy policy reform in Vietnam.

Fifth, historical institutionalism distinguishes itself by locating institutions in a causal change that accommodates a role for other forces, notably socioeconomic development and the diffusion of ideas or beliefs (Hall \& Taylor, 1996). In this respect, the historical approach depicts a world that is broader and more complex than the world of preferences and institutions. In other words, institutions are not the only causal force in politics; rather, their relations to other factors such as the political economy and ideas or beliefs are a matter of concern. It can be said that this perspective brings the richness to the analysis by enabling an inquiry into the possible causal relationship between autonomy policy choices and the national political economy - an important explanatory force.

Sixth, a notable feature of historical institutionalism is its notions of history and dynamics of change. Hence, the approach allows for the search for path dependence 
effects or more specifically for the impacts of the institutionalized settings and institutionalized public policies made in the past (Pierson, 2000). This insight offers clues for an understanding of the continuity in the autonomy policies that Vietnamese politicians adopt and maintain over time. Further, the historical approach also recognizes the slow and incremental changes in the interests of actors, in the policy ideas and in the institutional environment in which action occurs. This perspective may offer the likelihood that the complexities of history and the dynamism in preferences and contexts the research is dealing with can be ascertained.

Seventh, the sociological approach to institutions provides essential accounts of the causal power of culture and cognition, emphasizing those rule-bound and ceremonial aspects of human behaviour that rational choice institutionalists fail to consider (Suchman \& Edelman, 1996). According to Fligstein and Freeland (1995), theories that treat political, institutional and cultural factors as causal elements offer better insights into empirical data than do economic theories such as the rational choice theory. As such, the employment of sociological institutionalism will potentially help give a better understanding of the Vietnamese way of perceiving and practising autonomy by explaining them in cultural terms.

Eighth, the neo-institutionalism in sociology is distinct in its view of legitimacy as the primary source of origin for why organizations take on particular forms, procedures, models, and symbols and how such practices are diffused through organisational fields or across societies (Hall \& Taylor, 1996). This view helps explain why organisations still adopt many institutional forms and practices even though, whilst being legitimated externally, they might be dysfunctional in terms of achieving the organisation's formal goals. The view also helps explain the reason why organisations embrace some particular institutional forms and practices that may reflect a society's cultural practices, such as myths and ceremonies, transmitted into organizations. It follows that the perspective may provide a better understanding of the decoupling of actual practices from structural changes. Furthermore, the approach might help answer possible inquiries into the isomorphic structures, culture, and outputs that organisations in the same field may experience in practice. These theoretical insights will add further richness to the analysis of the Vietnamese autonomy reform in terms of how and why the policy is formed and practised the way it has been.

Ninth, historical and especially sociological institutionalism define institutions broadly. Altogether, institutions are conceptualized as formal and informal rules and 
norms, culture, and values embedded in the organisational structure of the polity. This encompassing specification of institutions allows the research to explore the substance and process of autonomy policy development and implementation by associating them with the rules, structures, and culture of the Vietnamese administrative and political system. Hence, using both approaches can offer the most plausible and comprehensive exploration of the influence of the structural and cultural features of the Vietnamese politico-administrative system on the substance, evolution, and conduct of the autonomy policy.

In general, both historical and sociological institutional approaches demonstrate their strengths in studying the implications of institutions for political behaviour and policy outcomes. Theoretical insights from these institutional perspectives that are expected to contribute to the study of autonomy of Vietnamese service providers are summarized in table 4-1. 
Table 4-1: Historical and sociological institutionalism's contributions to the study of autonomy

\begin{tabular}{|c|c|c|c|}
\hline $\begin{array}{l}\text { Institutional } \\
\text { Approaches }\end{array}$ & $\begin{array}{l}\text { Distinct } \\
\text { attributes of } \\
\text { historical } \\
\text { institutionalism }\end{array}$ & $\begin{array}{l}\text { Distinct attributes of } \\
\text { sociological } \\
\text { institutionalism }\end{array}$ & $\begin{array}{l}\text { Shared attributes of } \\
\text { historical and } \\
\text { sociological } \\
\text { institutionalism }\end{array}$ \\
\hline \multirow[t]{3}{*}{$\begin{array}{l}\text { Potentially } \\
\text { Contributing } \\
\text { Theoretical } \\
\text { Insights }\end{array}$} & $\begin{array}{l}\text { An important } \\
\text { concern is the } \\
\text { relationship } \\
\text { between the } \\
\text { socio-political } \\
\text { environment } \\
\text { and institutional } \\
\text { design and } \\
\text { policy choices. }\end{array}$ & $\begin{array}{l}\text { An emphasis on the } \\
\text { taken-for-granted } \\
\text { cultural and cognitive } \\
\text { aspects of behaviour; } \\
\text { cultural categories } \\
\text { embedded in institutions } \\
\text { are believed to influence } \\
\text { political actions and } \\
\text { policy choices }\end{array}$ & $\begin{array}{l}\text { Assumption of } \\
\text { endogenous preference } \\
\text { formation; rationality } \\
\text { is structurally and } \\
\text { culturally constituted; } \\
\text { preferences are } \\
\text { complex, multifaceted } \\
\text { and difficult to identify } \\
\text { as a priori. }\end{array}$ \\
\hline & $\begin{array}{l}\text { The continuity } \\
\text { of policy } \\
\text { choices due to } \\
\text { path } \\
\text { dependence } \\
\text { effects }\end{array}$ & $\begin{array}{l}\text { Legitimacy regarded as } \\
\text { the primary source of } \\
\text { origin for the adoption } \\
\text { of organisational forms } \\
\text { and practices; }\end{array}$ & $\begin{array}{l}\text { The logics of } \\
\text { appropriateness } \\
\text { regarded as the logics } \\
\text { of actions; the self- } \\
\text { interested calculation } \\
\text { of consequences is not } \\
\text { excluded; preferences } \\
\text { construed as changing } \\
\text { and formed within the } \\
\text { institutional } \\
\text { environment. }\end{array}$ \\
\hline & $\begin{array}{l}\text { Incremental } \\
\text { changes in actor } \\
\text { preferences, } \\
\text { policy ideas, } \\
\text { and institutional } \\
\text { environment are } \\
\text { likely to lead to } \\
\text { changes in } \\
\text { policy choices. }\end{array}$ & $\begin{array}{l}\text { Organisational forms } \\
\text { and practices reflect } \\
\text { myths and ceremonies } \\
\text { in the cultural } \\
\text { environment; } \\
\text { Decoupling between } \\
\text { structural changes and } \\
\text { actual practices; } \\
\text { Organisational } \\
\text { isomorphism in } \\
\text { structures, practices and } \\
\text { policy outputs under } \\
\text { coercive, normative and } \\
\text { mimetic pressures }\end{array}$ & $\begin{array}{l}\text { Institutions defined } \\
\text { broadly to include } \\
\text { formal and informal } \\
\text { rules and norms, } \\
\text { cultures, and values } \\
\text { embedded in the } \\
\text { organisational } \\
\text { structure of the polity. }\end{array}$ \\
\hline
\end{tabular}




\section{CHAPTER 5}

\section{RESEARCH METHODOLOGY}

\subsection{Research philosophy}

The intent of this research is to elicit an in-depth understanding about how the concept of autonomy is perceived and practised within a country context. Therefore, it takes a constructivist ontology and interpretive epistemology because this research paradigm allows the researcher to investigate meanings which are constructed from the perceptions and actions of the participants within their own, particular social contexts (Bryman, 2008). In the light of the ontological and epistemological foundations, this research chooses to take qualitative methodology in its research strategy.

\subsection{A qualitative research methodology}

Qualitative research methodology is "a particular tradition in social science that fundamentally depends on watching people in their own territory and interacting with them in their own language on their own terms" (Kirk \& Miller, 1986, p. 9). The research methodology provides insights into how "official figures" are produced and reproduced through social interactions (Barbour, 2008). Moreover, it is about meaning-making in that the approach draws out the meaning that individuals and groups give to behaviour, experiences and social phenomena (Walter, 2010). This research applies qualitative methodology since the approach enables the researcher to study what participants perceive the world and how they make sense of and interpret phenomena. Through the eyes of participants, the researcher can generate a clearer picture of their perceptions about the autonomy concept and how it is practised in their particular settings.

Qualitative research approach involves three kinds of data collection: 1) in-depth, open-ended interviews; 2) direct observations; and 3) written documents (Patton, 2002). This research employs interviews and document analysis as the two methods for collecting data. Interviews help gain direct quotations from people about their perceptions, experiences, perspectives, feelings, and knowledge (Ibid.). Document analysis entails studying the content of the existing data source, which usually includes written material or documents (van Thiel, 2014). More details of these two research methods will be discussed next. 


\subsubsection{Document analysis}

Documents refer to written material produced either before or after the research is conducted. They usually consist of organisational records, findings from previous audits, policies, memos, archived records, emails, websites, minutes of meetings, fieldwork notes, and letters (Emmerson \& Goodrick, 2013). Document analysis can inform studies in several ways. The analysis can inform an in-depth interview phase or can provide researchers with information about the background context of the study (Ibid.). Document analysis also helps highlight questions researchers can investigate later in the research (Ibid.). This research analyses Vietnam's autonomy legal frameworks in public services in general and in health care and higher education in particular. These analyses are conducted in the light of the country's path dependence, policy-making environment, and political economy. These analyses help inform and understand the substance and evolution of the autonomy policies, particularly the de jure autonomy of PSDUs. From this, an assessment can be made whether the de facto autonomy of PSDUs, which is discerned based on the empirical data obtained from interview, is consistent with de jure autonomy of PSDUs or whether de facto autonomy is different from de jure autonomy due to the influence of internal and external factors. This research also draws on various types of documents such as the reports of CPV and the Vietnamese Government regarding the implementation of autonomy among public service providers. This type of documents not only informs the research question but also offers additional insights that supplement and support the other data sources.

\subsubsection{Semi-structured interview}

Interviews are a flexible way of collecting data in which the researcher can ask further questions to obtain a better and fuller understanding of the given answers (van Thiel, 2014). In this research, open-ended, in-depth interviews were carried out with internal managers and staff from public hospitals and public universities and with external stakeholders to gain a more holistic view about the de facto autonomy of service providers. The perspectives from these internal and external participants were then compared and contrasted for cross-validation purposes.

Unlike structured interviews where interviewees are asked the same set of questions, semi-structured interviews do not follow a pre-structured sequence of questions, so the interview process is "fluid" and further questions may arise in the conversation between researcher and participant (Emmerson \& Goodrick, 2013). Furthermore, the 
semi-structured approach gives interviewees leeway in how to reply while ensuring key topics set by the researcher are covered (Bryman, 2008). The approach also enables interviewees not only to answer the interview questions but also to give more insights or information which may lead the researcher into further inquiries (Ibid.). Consequently, semi-structured interviews were designed in this research to enable greater flexibility in the sequence of questions asked and further discovery and elaboration of information from interviewees. Interviewees were given an interview guide that included a set of questions to focus on. During the interviews, the researcher let the conversation take its natural course, allowing interviewees to express themselves freely.

\subsubsection{Sampling}

\subsubsection{Choice of cases}

Sampling is a selection of possible units of studies from the total population of interest (i.e. people, situations, cases, or sources) (van Thiel, 2014). This research makes a non-random and purposive selection of cases for interviews. According to Patton (2002), purposive sampling is often used in qualitative research to select cases to study in-depth. A purposive selection of cases offers researchers opportunities to gain rich information about the subject of interest (Thomas, 2010). Further, Yin (2014) suggests that a multiple-case study approach should employ a non-random and purposive choice of cases with different characteristics to reflect the various outcomes proposed by theory. A purposive selection of multiple cases enables researchers to explore the research topics from various perspectives where different backgrounds, experiences, and perceptions make the data rich and meaningful (Stake, 2006). Also, researchers are advised to choose cases that exemplify a broader category of which they are members so as to increase generalizability (Bryman, 2008).

It follows from above that one's case selection should be guided by two objectives: a representative sampling and variations on the dimensions of theoretical backgrounds (Seawright \& Gerring, 2008). Among various techniques of case selection, a diverse case method is suggested as a strategy to increase the representativeness of the sample of cases and the variations in terms of theoretical explanations (Ibid.). This study chose cases based on their organisational and financial differences in a bid to maximize case diversity. Organisational hierarchy and financial capability are the two important factors the researcher considered likely to encompass the useful variations of the cases chosen in terms of the degree of autonomy and the institutional environment within 
which the cases are situated. As mentioned in chapter three, the Vietnamese hospital system consists of three levels of care operating according to the referral system: tertiary care at central hospitals, secondary care at provincial hospitals, and primary and secondary care at district hospitals. Central hospitals are under the direct management of $\mathrm{MOH}$ while provincial and district hospitals are technically managed by Provincial Health Bureaus and District Health Centres respectively and financially and personally managed by People's Committees at respective level. Also identified in chapter three, the higher education system in Vietnam comprises over three hundred public universities and colleges, one-fifth of which, including all key universities, is under the direct management of MOET. At least thirteen other ministries, provincial governments, and social-political organisations are responsible for the remaining organisations. Chapter three further clarifies that the autonomy policies give PSDUs different degrees of autonomy based on their financial capability, generally classified into fully self-financing, partly self-financing, and fully state-subsidized units.

While aiming for each category to have a case as a representative, the researcher could not fully realise this desire due to the practical issue pertinent to gaining access to cases. She initially approached four PSDUs including two hospitals and two universities, all considered leading units in their respective areas. To obtain a permission from each PSDU, the researcher asked a staff member, to whom she was introduced through some personal contacts, to convey her request to the head or the person in charge of the unit. Three of her four requests received a negative response. One hospital turned down the researcher's request to interview its staff because it considered autonomy implementation a state secret and so it could not allow the researcher to approach its staff without the permission from the Provincial Health Bureau, its state management agency. The researcher's request to the other hospital was even not presented to its head or person-in-charge because her contact refused to assist the researcher for reasons of research sensitivity. In one university, only one out of quite a few staff invited agreed to participate in the interview. The researcher's contact informed her that the person in charge of the unit would not enable his staff to join the interview.

Subsequently, the researcher had to turn to contacts from MOH and MOET made when working for a UNDP-funded project assisting these ministries in carrying out their public administration reforms. In doing so, the researcher was aware that she was not free to choose her cases because that process also was determined by the two 
ministries. This turned out to be true for the university cases whereby MOET, not the researcher, picked two universities for her to approach in her study. Although these two universities are well-represented financially with one being fully self-financing and the other partly self-financing, they are not one of the fourteen universities approved under the pilot programme of the 2014 Government Resolution No.77/NQ$\mathrm{CP}$ that offers the highest level of autonomy to public universities that are independent of state budget in their operating and capital expenditure. It was fortunate that the university which the researcher was allowed to approach at the outset is one of the key universities, considered to have some comparative advantages (including autonomy) that the other two do not have.

When turning to MOET and $\mathrm{MOH}$ for their support in approaching cases, the researcher also anticipated that her interviewees might be influenced, even intimidated, by their line ministries if they participated in her research. To mitigate this possibility, during the interview process the researcher attempted to assure them that her research was independent and that she strictly followed the research ethics of the Victoria University of Wellington, especially in relation to maintaining the confidentiality of interviewees and their organisations.

Eventually, three cases of public hospitals and three cases of public universities were chosen for the research. These cases do differ from each other across a number of dimensions the researcher considered important, notably financial capability and organisational hierarchy. Their differing financial and organisational characteristics lead to variations in the degree of autonomy each PSDU is perceived to have and thus have different implications for their performance. Further, the differences in financial capability and organisational hierarchy indicate potential diversity in their institutional environment that shape their perception and implementation of autonomy. Such variations between the selected cases enable a thorough assessment to be made regarding the impacts of institutional factors on the implementation of autonomy of each PSDUs. General patterns relating to the implementation of autonomy of PSDUs, as a result, can be discovered, enabling the research question to be answered.

The six cases studied in this research are referred to as hospital A, hospital B, hospital $\mathrm{C}$, university D, university E, and university F. In each case, managers in charge of finance, personnel, and quality assurance, deputy directors, doctors (in the hospital cases), and managers in charge of academic affairs and research (in the university cases) were chosen to participate in the interview. It was expected that these 
participants, with their knowledge and experiences in their respective areas of management, could provide their in-depth perceptions about the freedom they and their organisation actually have in making managerial decisions. Different dimensions of de facto autonomy assigned to PSDUs could thus be found, helping answer the inquiry into the autonomy concept of the Vietnamese context. The characteristics and interviewees of each case are presented more specifically below:

Table 5-1: Studied cases - characteristics and interviewees

\begin{tabular}{|c|c|c|}
\hline Study Cases & Characteristics & $\begin{array}{c}\text { Interviewees } \\
\text { (29 interviewees from } \\
6 \text { cases) }\end{array}$ \\
\hline Hospital A & $\begin{array}{l}\text { A central specialised hospital under the } \\
\text { direct management of the MOH. It is } \\
\text { the last line to carry out in-depth } \\
\text { specialized techniques and receive } \\
\text { patients transferred from the lower } \\
\text { lines. It is among very few public } \\
\text { hospitals in Vietnam that are fully self- } \\
\text { financing (finance their operating and } \\
\text { capital expenditure). }\end{array}$ & $\begin{array}{l}\text { Four interviewees: } \\
\text { finance manager, } \\
\text { personnel manager, a } \\
\text { doctor, and a deputy } \\
\text { director. }\end{array}$ \\
\hline Hospital B & $\begin{array}{l}\text { A general hospital at the provincial } \\
\text { line, carrying out less complex health } \\
\text { care techniques than hospitals at the } \\
\text { central line and receiving patients } \\
\text { transferred from hospitals at the district } \\
\text { line. The hospital is under the direct } \\
\text { management of the Provincial Health } \\
\text { Bureau. The hospital partly self- } \\
\text { finances its operating expenditure. }\end{array}$ & $\begin{array}{l}\text { Five interviewees: } \\
\text { finance manager, } \\
\text { personnel manager, } \\
\text { quality assurance } \\
\text { manager, a doctor, and a } \\
\text { deputy director. }\end{array}$ \\
\hline Hospital C & $\begin{array}{l}\text { A general hospital at the district line } \\
\text { which is often assigned basic curative } \\
\text { health care services. The hospital is } \\
\text { under the direct management of the } \\
\text { District Health Centre. The hospital is a } \\
\text { partly self-financing unit. }\end{array}$ & $\begin{array}{l}\text { Three interviewees: } \\
\text { personnel manager, a } \\
\text { doctor, and a deputy } \\
\text { director in charge of } \\
\text { financial issues of the } \\
\text { hospital. }\end{array}$ \\
\hline University D & $\begin{array}{l}\text { A public university under the direct } \\
\text { control of MOET. The university } \\
\text { provides a wide range of disciplines } \\
\text { and applies various forms of education } \\
\text { and training including regular (face-to- } \\
\text { face), distance and in-service at } \\
\text { different levels from colleges, } \\
\text { undergraduate and postgraduate and }\end{array}$ & $\begin{array}{l}\text { Six interviewees: } \\
\text { finance manager, } \\
\text { personnel manager, } \\
\text { academic affairs } \\
\text { manager, research } \\
\text { manager, quality } \\
\text { assurance manager, and } \\
\text { a deputy director. }\end{array}$ \\
\hline
\end{tabular}




\begin{tabular}{|l|l|l|}
\hline & $\begin{array}{l}\text { transfer programmes (junior college - } \\
\text { college - undergraduate). The } \\
\text { university fully self-finances operating } \\
\text { and capital expenditure. }\end{array}$ & \\
\hline University E & $\begin{array}{l}\text { As a regional-level public university } \\
\text { under the direct management of MOET, } \\
\text { university E is considered as one of } \\
\text { Vietnam's sixteen key universities. The } \\
\text { university provides a wide range of } \\
\text { disciplines and applies various } \\
\text { educational forms including full-time } \\
\text { undergraduate, post graduate, distance } \\
\text { and in-service. The university is a } \\
\text { partly self-financing unit. }\end{array}$ & $\begin{array}{l}\text { Six interviewees: } \\
\text { finance manager, } \\
\text { personnel manager, } \\
\text { academic affairs } \\
\text { manager, planning } \\
\text { manager, and two } \\
\text { deputy directors }\end{array}$ \\
\hline University F & $\begin{array}{l}\text { A public university under the direct } \\
\text { control of MOET. The university } \\
\text { provides a range of disciplines and } \\
\text { applies various forms of education and } \\
\text { training including full-time } \\
\text { undergraduate, post graduate, and in- } \\
\text { service. The university is a partly self- } \\
\text { financing unit. }\end{array}$ & $\begin{array}{l}\text { Five interviewees: } \\
\text { finance manager, } \\
\text { personnel manager, } \\
\text { academic affairs } \\
\text { manager, research } \\
\text { manager, and a deputy } \\
\text { director. }\end{array}$ \\
\hline
\end{tabular}

\subsubsection{Choice of stakeholders}

To supplement and complement the data collected from cases, this research examines the perceptions and perspectives of external stakeholders in relation to health care and higher education service providers. These contributions provide additional insights into the implementation of autonomy among the service providers and help verify the data the service providers provided. The external stakeholders targeted in this research are primarily senior officials from $\mathrm{MOH}$ and MOET, those whose control of the service providers can influence their implementation of autonomy in practice. Besides these key stakeholders, this research also targeted specialists who have knowledge and expertise in the Vietnamese public administrative reforms, particularly the autonomy reforms in the provision of health care and higher education services. Accordingly, a total of six stakeholders including two senior officials from MOET and two from $\mathrm{MOH}$ participated in the research.

\subsubsection{Interview process}

With the agreement of the heads of the six PSDUs under study, the researcher conducted twenty-nine interviews with deputy directors, managers, and staff. These interviewees are directly involved in the management of their organisation in terms of 
finance, personnel and service organisation and provision and so they have knowledge about the implications of the autonomy policies for their daily management. Also, the researcher conducted six separate interviews with external stakeholders who, as senior managers or former senior managers from ministries (MOH, MOET, and Ministry of Home Affairs), have played an important role in designing the autonomy policies and in controlling the implementation of autonomy among PSDUs.

The interviews took place from November 2015 to January 2016. This was not long after the issuance of Decree 16 on reforming the autonomy mechanism. As a result, interviewees mostly talked about their experiences and perceptions regarding the impacts of the previous autonomy policies (notably Decree 43) on their performance. Before the interviews, the researcher gave interviewees the interview guide including the set of questions so that interviewees could have some ideas about the areas to focus on and prepare answers for the interview. Interviewees were also given the consent form outlining the participants' rights including the right to withdraw from the research within two days after attending the interview without having to give reasons. The researcher affirmed that interviewees' identity would be kept confidential and that the research results would not use their name and no opinions be attributed to them in any way that would identify them. These assurances continued to be emphasized in each interview, thus making respondents feel more comfortable and relaxed about participating in the research.

The researcher conducted the interviews on a one-to-one basis, using a semi-structured interview approach with open-ended questions. Although the questions were prepared in advance, the researcher enabled interviewees to move beyond the questions to express their own views about a particular issue or a past event relating to the topic. To ensure the validity and reliability of the data, the researcher, while conducting the interviews, aimed not to impose the answers or ask questions in ways that might influence interviewee's opinions.

Most of the interviews went smoothly, apart from one interview with a deputy general director of MOET, where the researcher was required to leave his office for asking sensitive questions. As the interviews touched on some sensitive issues, some interviewees were not willing to have their interviews recorded. Others refused to answer questions concerning corruption or answered these questions only in a general way. Not many admitted that their organisations were engaged in corruption although most asserted that corrupt practices do occur in other organisations within the sector. 
Apart from the few interviewees who answered questions cautiously, participants were mostly cooperative and showed their trust in the researcher which resulted in a wealth of information collected.

Ultimately, 35 interviews were completed. All the interviews were conducted in Vietnamese and then translated into English by the researcher. The interviews lasted from one to two hours with an exception of one interview which took about three hours to complete. Most of the interviews were recorded and stored on a laptop. The interviews were then transcribed and labelled for identification. To maintain the confidentiality of interviewees, the researcher removed their names and their organisations from this study.

\subsection{Data analysis}

The volume of data gathered in the qualitative research may seem overwhelming (Emmerson \& Goodrick, 2013). This is evident in the 35 interviews in the research, which generated a relatively large amount of data. In addition, qualitative data are nonnumerical units of information (e.g. statements, text, interview fragments, and images) that are unstructured and cannot be arranged in a hierarchical way (van Thiel, 2014). Researchers are thus advised to structure the data by means of coding, that is the assignment of codes or labels to the different pieces of information so that the data are categorised and subdivided for comparing at a later stage (Ibid.). In this research, NVIVO software was used to manage and code all the data collected including audio recordings, interview transcripts, and documents. With the help of such programme, the research data were stored digitally in a database structure which sorts the interview transcripts and documents (Ibid.). The research data were also classified into different hospitals and universities to facilitate examination of individual cases as well as crosscase analysis.

According to Miles and Huberman (1994), there are two methods of creating codes: the first one is often used by inductive researchers who do not pre-code any datum until after data collection; the other one is to create a list of codes before fieldwork. In this research, data were coded manually using the first method. Although before the coding the researcher was considering some themes that come from prior literature and theoretical framework, she tried not to let these themes guide her data analysis. Also, she used a manual coding approach to make sure that no important information was overlooked. 
The researcher began the coding process of each case by grouping sections of data that have a recurring pattern under a node and assigning each node a label. For example, she pulled all the perspectives about the revenue-generating incentives induced by the autonomy policies of hospital A and examined them together in a node coded "incentives to generate revenues". She also gathered all the opinions of the irrationality of the autonomy policies for the management of hospital A and put them together in a node labelled "autonomy policy irrationality". As the irrationality of the autonomy policies is reflected in different dimensions of management, she decided to add further nodes to these data fragments for their categorisation (taxonomic scheme of coding (van Thiel, 2014)). This coding process was then repeated for the other five cases. During the coding, additional nodes for emerging patterns continued to be formulated, thus generating potential themes for the research (Stake, 2006). Table 5-2 and 5-3 provide examples of coding of interview data of hospital $\mathrm{B}$ and university $\mathrm{F}$ respectively:

Table 5-2: An axample of coding

\begin{tabular}{|c|c|}
\hline Nodes & Data fragments \\
\hline \multirow[t]{4}{*}{$\begin{array}{l}\text { O Hospital B } \\
\text { O Incentives to } \\
\quad \text { generate } \\
\quad \text { revenues }\end{array}$} & $\begin{array}{l}\text { The hospital encourages the medical examination and } \\
\text { treatment faculty to take advantage of fee-paying patients to } \\
\text { increase the hospital's revenue. The revenue-generating } \\
\text { pressure on faculties is substantial and in this regard each } \\
\text { faculty often has a target to accomplish. }\end{array}$ \\
\hline & $\begin{array}{l}\text { Doctors do not care much about the state-stipulated salary } \\
\text { because they now have additional income from the hospital's } \\
\text { net revenues. Thanks to the issue of Decree } 43 \text {, the hospital } \\
\text { has extra sources of revenues through setting up patient- } \\
\text { requested services, in addition to the state-stipulated sources } \\
\text { of revenues. The hospital can establish the fees and charges } \\
\text { for patient-requested services provided that they are } \\
\text { acceptable to patients and that the hospital report the fee and } \\
\text { charge levels to the Department of Health. }\end{array}$ \\
\hline & $\begin{array}{l}\text { If the hospital provides many good services it will attract lots } \\
\text { of patients and so it can obtain high revenue. Many hospitals } \\
\text { are now maximizing services and focusing on high-tech and } \\
\text { high-priced services in order to generate more revenue. This } \\
\text { is common in Vietnam's health sector and leads to great } \\
\text { financial burden on patients. }\end{array}$ \\
\hline & $\begin{array}{l}\text { The hospital has to earn as much revenue as possible because } \\
\text { the state budget allocation to the hospital is limited. In fact, }\end{array}$ \\
\hline
\end{tabular}




\begin{tabular}{|l|l|}
\hline & $\begin{array}{l}\text { the hospital does not report the actual medical records as } \\
\text { patient costs are not to be disclosed. For example, patients } \\
\text { can be discharged after 3-5 days but they are often kept to } \\
\text { stay at the hospital longer. }\end{array}$ \\
\hline
\end{tabular}

Table 5-3: An example of a taxonomic scheme of codes

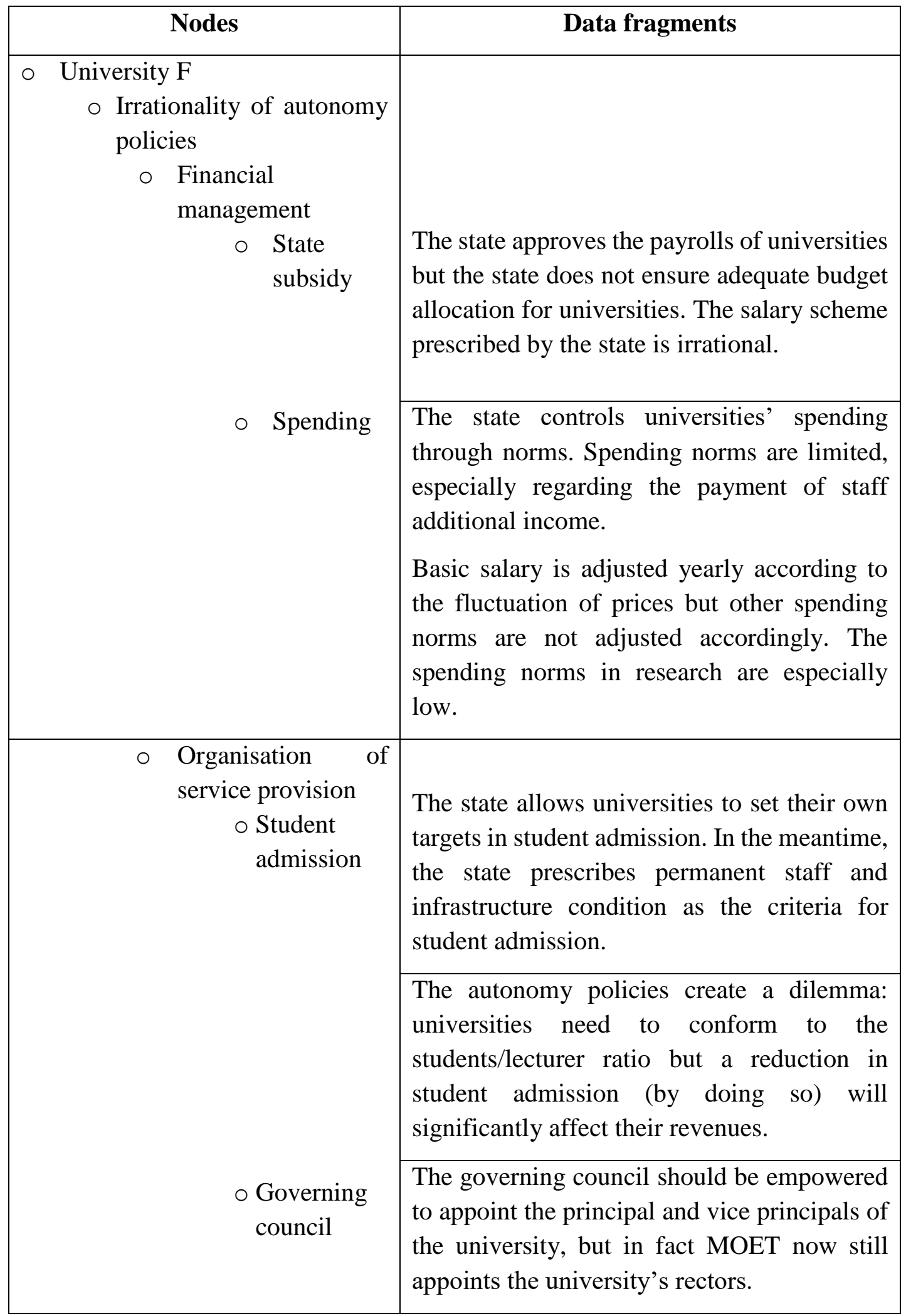


Once an exhaustive set of codes was generated, the codes were analysed using qualitative techniques (van Thiel, 2014). The qualitative analysis interprets texts that are coded in NVIVO nodes to identify the meaning underlying the perspectives and perceptions given by individuals. This research analysed its qualitative data in three phases. First, coded data of each case were integrated to search for patterns, cause and effect relations and other forms of interconnection (van Thiel, 2014). In this stage, the researcher grouped together codes that seem interrelated, facilitating the gradual development for a theoretical explanation (Silverman, 2006). Second, the results of data analysis of each case were compared and contrasted to those of other cases so that a cross-case analysis could be conducted (Yin, 2014). In the phase of cross-case analysis, the themes that emerged through the within-case analysis were collated, enabling a broader level of themes to be identified. Third, the patterns found in crosscase analysis were integrated into the coded content emerging from document analysis, through which further themes of the research were generated.

Throughout the process of data analysis, the researcher always looked at the coded content in the light of the set of formal rules (legislation, regulation, and the organisational structures of Vietnam's political and administrative system) and informal rules, norms, and values embedded in the system. Many of formal and informal rules, norms, and values have been discussed in prior literature. Many were referred to by interviewees whilst some others were reflected based on the researcher's personal experience. For example, a set of Vietnam's laws and under-law documents (decrees, directives, circulars, decisions, and resolutions) were examined, shedding light on the codes that were generated for analysis. Similarly, the four-tier government system with increasing fiscal and administrative power delegated to local government, the self-sufficiency tradition, the "asking and giving" culture, and the "village" culture characterised Vietnam's decentralisation process were considered throughout the data analysis. The formal rules (e.g. spending norms and downsizing) and the informal norms and culture (e.g. the gift-giving culture, the "envelope" culture, and favouritism) referred to by interviewees also were used to offer an explanation for the coded content. Finally, the researcher, whenever possible, reflected on the political features and cultural values peculiar to Vietnam (e.g. the principle of democratic centralism, the value of sentiments over reasons, and the cultural belief that "a bad compromise is better than a good lawsuit") to explain and interpret the coded content. The relation of 
the codes to the theoretical framework helped better understand the underlying meaning that the data gave to the subject being studied.

\subsection{Reporting results}

After generating the main themes of the research, the researcher began to write down the research results. The researcher understands that writing is a process of "finding out", not only to record what we know but to discern what we know (Richardson, 2000). Therefore, the researcher, whilst focusing on the themes that are most relevant to the research question, attempted to present a holistic and truthful story of the underlying meanings of the data and to make arguments relating to the research question. The purpose was to write a final report in a logical, consistent and precise manner so that the main arguments of the research are clearly presented and supported by solid evidence.

Accordingly, the research results are presented according to the following steps. The first step describes and analyses the evolution and substance of autonomy policies in the light of the historical and sociological analysis of Vietnam's institutions. This step mainly drew on Vietnam's autonomy legal framework and scholarly articles reflecting the country's institutional environment to understand how the path dependence, the political economy, the pressures from international community and the pressure for political legitimacy play their role in shaping the country's autonomy reforms. The second describes and analyses the implementation of autonomy among public hospitals and public universities in relation to the historical and sociological institutions that exert influences on the autonomy practices. This step gathered and analysed all the coded interview data with reference to formal and informal rules, norms and cultural values that affect the management practices among PSDUs. The third discusses the main findings of the research based on the themes discovered through the analysis of the autonomy policies, government documents, and cross-case examination. In this step, the research findings are presented with reference to the scholarly articles that crystallise the benchmarks, often the agencification experiences of advanced countries, and the experiences of developing and transitional countries and in relation to prior research on PSDUs' autonomy. It follows from this step that the new data are situated into pre-existing data, creating the foundations for the scholarship of the subject under study. The next chapters will present these steps in sequence. 



\section{CHAPTER 6}

\section{AN INSTITUTIONAL ANALYSIS OF THE SUBSTANCE AND EVOLUTION OF THE AUTONOMY POLICIES IN VIETNAM}

This chapter provides a thorough analysis of the substance and evolution of the autonomy policies in Vietnam. Drawing on the insights from historical and sociological institutionalism, the research examines the evolution and substance of the autonomy policies in two major stages: 1986-2006 and 2007-present. To explain the autonomy policies, the research looks at Vietnam's socialist-oriented market path dependence that has a continuing influence over the policy choice. The path dependence effect also helps the research understand why changes in the autonomy policies are incremental. Besides the path dependence, the research considers other important features of Vietnam's policy context that may affect the decision-making process. The research particularly looks at the influence from international community to establish the coercive, normative, and mimetic pressures imposed on Vietnam policy makers in designing the autonomy policies. A thorough analysis of the autonomy policies in the light of this institutional context helps the research find that autonomy is part of the broader economic reform that Vietnam's communist leaders rationally adopt to improve the social legitimacy and resources to maintain the socialist regime. A further analysis of the autonomy policies in relation to Vietnam's political economy context discovers that Vietnam's communist leaders are becoming more determined to continue boldly up this policy direction.

\subsection{The year 1986 - a critical juncture: From centralism towards market socialism}

The year 1986 marked a critical juncture when Vietnam transformed itself from centralism towards market socialism. Prior to this period, the country suffered from a serious and widespread socio-economic crisis as a direct consequence of the CPV's concerted effort to establish uniform socialist institutions throughout the country. Inherent in the socialist economic system is central planning whereby the state collectivizes all the means of production (through agricultural collectives and stateowned enterprises), appropriates economic resources from state economic producers, redistributes these resources (e.g. investment, subsidies, goods distribution and food coupons) and finances state functions (London, 2003). Applied in Vietnam, this socialist economic development model resulted in a stagnant economy with serious food deficits and a dearth of capital and resources. 
In the agricultural sector, collectivization proved increasingly ineffective and inefficient. The traditional peasant economy was eliminated and peasants were transformed to rural labourers with little control over the means and process of production. Production incentives were weakened by an egalitarian-induced point system, which failed to differentiate between the qualities, quantities, and types of work of cooperatives members. As a consequence, soon after the Vietnam war, the northern part of the country saw a steady decline in agricultural outputs (Tran, 2004) while the south, which strongly resisted collectivization, experienced a situation that "wavered between shortage and bare self-sufficiency in food production" (Vo, 1995, p.19 cited in Henin, 1999, p. 68). Stagnation in agricultural production meant that the state was no longer able to meet the food demands of its people.

The industry also suffered from inefficiency and over-dependence on aid from the Soviet bloc. The operation of SOEs was under the direct control and management of line ministries of central government or their branches at local government. They had to carry out plans and meet targets set up by their umbrella agencies with their profits transferred to government budget and losses made up from government budget expenditure (Ngu, 2003). Being fully subsidized by the state, the enterprises and their workers did not have to be concerned about competence and productivity (Nguyen, 2005). This was further compounded by supply shortages and bottlenecks in the production chain (Ibid.). Consequently, despite huge investment in the sector, the second five-year plan failed to meet any of its targets (Ngu, 2003). Underdevelopment within SOEs meant the total revenues transferred to the state diminished.

The economic crisis seriously affected the Vietnamese people's living standard and the social service system. In 1982, the national per capita income was estimated by the IMF to be at $\$ 160$ which was much lower than other regional countries at that time (Le, 2012). Wage earners were the most affected with their real monthly per capita income in the North declining from an index of 81.8 in 1976 to 57.8 in 1988 while the cost of living base was 100 in 1960 (Ibid.).

The quality of public services including health care and education was significantly compromised since service provision was reliant on the resources generated by the state's socialist economic institutions. By the mid-1980s, national and local investment in health care and education fell sharply, resulting in declining working conditions, shortage of supplies and inadequate funding for workers' wages (London, 2003). The result was a sharp decline in the quality and utilization of education and health services. 
In education, there was a remarkable drop (by over 40 percent in many places) in enrolments in lower and upper secondary education between 1989 and 1991 (Ibid.). For higher education, according to a comprehensive survey report on education and manpower developed by MOET in collaboration with UNDP and UNESCO, universities and colleges lacked equipment, including laboratories and teaching facilities, and books and reference materials for student and staff use; staff salaries were very low and failed to meet the minimum standards of living (Nguyen Xuan Thu, 1997).

Likewise, the health care sector faced a critical shortage of supplies and drugs (Ladinsky \& Levine, 1985) and health workers were not paid (Fritzen, 2007), which invariably affected the quality, scale, and scope of health services. Access to care was, in principle, the right of citizens, but in practice, the availability and quality of services were limited and state elites and urban populace had greater access and better quality services than the majority (London, 2008). Between 1986 and 1990, medical consultations halved and inpatient admissions declined by one-third; self-treatment was found to be a common form of treatment for acute illness (Chen \& Hiebert, 1994).

Domestic problems were aggravated by the Vietnamese military intervention in Cambodia in 1978 followed by a decade-long occupation and a series of attacks across the country's northern border by China. At the same time, development aid on which Vietnam was heavily dependent dropped dramatically from $\$ 370$ million in 1978 to \$106 million in 1983 against the backdrop of the worsening economic condition of the Soviet bloc prior to its actual collapse in 1991 (Fahey, 1997).

Economic difficulties and people's deteriorating economic conditions significantly undermined the people's confidence in the Party's leadership and the managerial capability of state agencies. This is evidenced by an outflow of "boat people" or refugees into Southeast Asia which totalled 835,000 people by the end of 1992, with the peak period being from 1979-1981, and countless others perished at sea (Le, 2012). The CPV's leadership was also challenged by some of its senior members who strongly disagreed with the Party's Stalinist policies, especially the "rehabilitation" policy towards four hundred thousand former employees and military officers in the Saigon regime and the order to resettle two million other southerners into rural “economic zones" (Grinter, 2006). For example, in 1986, the Club of Resistance Fighters with war veterans and senior party officials as members publicly criticized 
the CPV's political monopoly and post-reunification policies and demanded political and economic reforms (Le, 2012).

The socio-economic crisis was indeed a strong blow to the Communist leaders. In 1982, Le Duan, the then Party General Secretary, admitted the failure of the party "to realize the difficulties and complexities of the advance to socialism from a primarily small production economy" (Duiker, 1989, p. 87 cited in Grinter, 2006, p. 153). The Politburo also acknowledged "its managerial ineptitude and the failure of its southern economic policies" (Grinter, 2006, p. 154). The Resolution of the Eighth Plenum of the Vietnam Communist Party's Central Committee (1985) called for "an end to managing the economy mainly with administrative orders and a switch to a period of correctly perceiving and applying objective laws".

In general, by the 1980s, CPV realised that continued economic stagnation would seriously reduce people's trust in the socialist regime and eventually lead to the erosion of its legitimacy (Un, 2018). Economic performance thus emerged as the primary source of legitimation for CPV to regain its damaged legitimacy and maintain the regime's survival (Le, 2012). In this respect, Abuza notes that "People began to link the regime's legitimacy to economic performance and, importantly, their own standard of living. Political legitimacy was no longer rooted in the national struggle, but in economic growth and poverty eradication" (Shanks et al., 2004, p. 22).

Against this background, CPV, in its historic $6^{\text {th }}$ Party Congress in 1986, decided to move the country onto a new path called market socialism under a reform known as Đổi Mới. The reform directives set out by the 6th Party Congress denounced the central planning mechanism and recognised the multi-sectoral commodity economy, operating according to the market mechanism under the management of the socialist state. Private ownership of small enterprises was allowed to operate alongside staterun enterprises. A greater role for market forces in coordinating economic activities between private and state-owned enterprises was also acknowledged.

It should be noted, however, that there had been a de facto market mechanism during the pre-Đổi Mới, period before a formal market system was officially endorsed in 1986. Prior to this key juncture, many "fence breaking" activities were carried out within state-owned enterprises and agricultural cooperatives, with some protected by local authorities and ministries. For example, many state-owned enterprises went outside the plan set by the central government to source inputs from local suppliers (Riedel \& Turley, 1999). Farmers experimented with household production by 
contracting with agricultural co-operatives and getting inputs directly from producers (Fahey, 1997). A number of urban co-operatives were actually family-run businesses (Ibid.). Despite being forbidden, a market mechanism was operational during the prereform period with farmers selling their goods on the street and prices in the black market increasing over 60 per cent a year as compared with 3.5 per cent a year in the state-controlled business sector over the 1976-1980 period (Riedel \& Turley, 1999).

It is worth highlighting that the Vietnamese communists had made some shifts away from hard-line policies before Đổi Mới actually took place. For instance, in 1979, the Party decided to relax some strict controls over private production and abandon the attempt to collectivise the Mekong Delta (FForde, 2004; Riedel \& Turley, 1999). In 1981, the party authorised output contracts in agriculture and allowed state-owned enterprises to trade goods not covered by quota on markets (Ibid.). Aimed at solving the consequences of the previous post-war changes, these policy adjustments were actually the results of the rampant "fence breaking" activities mentioned above. The occurrence of these activities, though a violation of planning directives, reveal that there had been movements at the grassroots levels that contributed to inducing policy change. In other words, pressures for a formal market-oriented reform came from the informal grassroots forces before top leaders actually perceived a need for them.

The institutional transition from centralism to market socialism demonstrates the changing preferences and perceptions of the Vietnamese communist leaders. This political decision was anything but trivial and implied a prolonged abandonment of the goals these communists had fought for all their lives (Riedel \& Turley, 1999). In fact, the decision to reform at the outset did not come from the hearts and minds of the communist politicians. The transformation itself displays the changing attitudes and beliefs of the leaders in response to the dynamic and changing socio-economic context during the pre-Đổi Mới period. More specifically, the attitudes and preferences of the Vietnamese communists were shaken in conditions of great risks and uncertainty posed by the serious socio-economic crisis, the threat to national security and the withdrawal of support from the principal patron. Equally important, under the great pressures of the spontaneous market-oriented practices by factories and co-operatives to cope with the failures of central planning, the calculating communists were pushed to legalise and institutionalise such informal practices and unwritten rules by allowing the formulation of formal market rules. The long-term goal of the transition was to generate resources the communists expect of the market economy and to regain the 
people's trust in the regime that had been exhausted by Đổi Mới. Underlying these strategies and calculations was the communists' ultimate desire to maintain and consolidate the political legitimacy indispensable for the CPV's continued monopolistic rule in the country.

In this respect, a central puzzle arises as to why Đổi Mới was limited to the economic realm and whether some of the architects of the reform were actually reformists. The answer may be that the magnitude of the socio-economic crisis was not considered deep enough for a more far-reaching reform (Dollar \& Ljunggren, 1995). The pressures from below predominantly revolved around economic mismanagement but were not strong enough to amount to a political crisis. Another possible answer lies in the boundaries of the communist leaders' understanding and perceptions and the political constraints of the time (Riedel \& Turley, 1999). This justifies an argument that Đổi Mới was shaped more by economic conditions and the interaction between economics and politics than by the interaction between ideology and politics which can occur only when there are actual debates between rival ideas (Gainsborough, 2002).

Essentially, market socialism was the path CPV chose to develop the Vietnamese economy. The chosen path reflects a top-down management approach which separates the Vietnamese economy from other more liberal or neoliberal market economies (Gillen, 2011). It indicates that the Party continues to embrace the socialist orientation while adopting the market economy model favoured by Western countries. To put it bluntly, the market was introduced to the socialist system without "the regime forsaking its monopolistic grip on political power" (Wu \& Sun, 1998). The consequence of this ideology choice was that Vietnam's economic reforms have always been structured by a mix of statist and neoliberal policies (Painter, 2005). This will be illuminated throughout the analysis.

\subsection{6 - 2006: Path dependence and incremental policy changes}

\subsubsection{Implications of Vietnam's institutional environment for policy reforms}

Đổi Mới initiates Vietnam's official choice of market socialism as the model for development. At the 9th Party Congress in 2001, market socialism was labelled as a socialist-oriented market economy. According to the Political Report of the Party Central Committee of the 8th Tenure to the 9th Party Congress, this meant a multisectoral commodity economy regulated by the market mechanism but operating under the management of the state driven by a socialist orientation. In this multi-sector 
economy, the state economy is prescribed to play a decisive role and form the backbone of the economy. The dictated goal of this economic system is to improve the productive forces of the economy, developing a firm technical-material base for the foundation of socialism, and to improve citizens' living standards.

In this socialist-oriented market economy mechanism, Vietnam's economic trajectory twenty years subsequent to Đổi Mới is characterised by a combination of liberalisation, marketization, and privatisation on the one hand and the maintenance of central planning and control on the other. A market economy under the socialist orientation is not only a matter of the economic system but the operational mechanism for the whole political and social system of the country. The reform of public services, notably the autonomisation of PSDUs, strictly follows this development path. It is based on a new development model that combines "market-based accumulation strategies with authoritarian social regulation" (London, 2003, p. 147). While the market-oriented elements are authorised to liberalise economic forces for the sake of resource generation, the socialist ones mandate the continued authoritarian rule of the communist party.

The Vietnamese choice of its socialist-oriented market economy continues to be shaped and reshaped over time by both domestic and exogenous forces. With respect to international factors, the early 1990s saw a resurgence in development assistance that Vietnam received from international financial institutions (e.g. ADB, IMF, the UN and the World Bank) and bilateral donors (Japan and the US have been by far the largest donors). Since then the development assistance from the international community has substantially contributed to Vietnam's economic performance - the basis on which the Vietnamese leadership has largely relied for its political legitimacy. According to MPI in 2011, the total volume of ODA committed and disbursed increased steadily from USD 2,400 million and USD 1,650 million, respectively, in 2000 to USD 7,905 million and USD 3,541 million in 2010. ODA is the country's significant source of finance, accounting for one-third of the state's public budget (Klingler-Vidra, 2014). The fast-growing form of aid is loans which reached threequarters of Vietnam's total disbursement in 2001 (Painter, 2005). The international community especially focuses its assistance on Vietnam's transition to a market economy with 63 per cent of the total aid allocated to the economic sector and 14 per cent to governance reform during 2000-09 (OECD, 2012). 
The development assistance in Vietnam pushed the country to take policy prescriptions from international donors as a condition for funding (Klingler-Vidra, 2014). In this sense, the Vietnamese policy-makers were under various pressures from powerful donors to carry out economic reforms in line with international conventions and practices. Vietnamese public policies, despite being locked in the path dependence of the socialist orientation, are thus not completely static. Instead, they are evolving and changing over time, reflecting the dynamics in the preferences and ideas of the partystate in the face of the pressure from donors for the adoption of their desired policies. The result is that the Vietnamese public policies may have a potential propensity to converge towards the neoliberal market policies as much as they are shaped by the socialist ideology.

The 1990s onwards has also witnessed Vietnam's increased participation in the global world. This is evidenced by a large number of its bilateral and multilateral trade agreements, notably ASEAN and the Framework Agreement on Economic Cooperation with the European Union in 1995, APEC in 1998, the US bilateral trade agreement in 2000 and WTO accession in 2007. The greater international integration brings both opportunities and challenges for such transitional countries as Vietnam. On the one hand, the country can learn and emulate elements of policies that have been deployed successfully elsewhere. The country's economic sectors are enabled to adopt professional norms and conventions in their fields as a result of international policy dialogues, foreign consultancies, study trips or memberships of professional organisations. On the other hand, the country is under competitive pressures from the attraction of international capital and foreign trade and coercive pressures from the rules and sanctions imposed on their members by international agreements. These external pressures invariably affect the very identities and interests of the party-state, as the country has the desperate need for international capital and trade to sustain its economic growth. The result is that Vietnamese policy choices, whilst being characterised by socialism in nature, may have a possible tendency to mirror neoliberal models, norms, and practices.

In this light, Vietnam can present to the outside world an image of economic liberalisation. However, behind such liberalisation is in fact a different reality. The instance of SOEs privatisation reveals that the Vietnamese leadership adopts a stateled developmental strategy making selective use of the techniques and instruments of neo-liberalism (Painter, 2005). On some occasions, such as in the field of anti- 
corruption, the Vietnamese leadership applies the "take the money and run" approach by appearing to sign up to agreements without proceeding to implement them (Gainsborough, 2010).

So while it is true that external pressures from international agencies and bilateral donors are hard to resist, the impacts of these pressures on Vietnam's policy process of Đổi Mới should not be exaggerated. Again, this is ascribed to the CVP's political commitment to the socialist market economy model. Rational communists are conscious that the market economy can generate higher personal incomes and thus help bolster the regime's legitimacy. Yet, the communists are worried about the likelihood that the economic liberalisation can threaten the party's control and monopolistic position. Vietnam's reform trajectory thus often faces serious resistance from ideologists who remain committed to the continued heavy presence of the state's intervention in the economy. In this connection, a statement of the then Minister of Planning and Investment Tran Xuan Gia in response to the IMF's demand for “accelerated Đổi Mới” at the international donors' Consultative Group meeting in 1999 is worth mentioning: “... you cannot buy reforms with money... no one is going to bombard Vietnam into acting" (Painter, 2005, p. 274). ${ }^{4}$

A serious consequence of the reform dilemma is that a full-fledged reform strategy, on a well-scheduled basis, is never in the agenda-setting of the Vietnamese policymakers. Instead, the Vietnamese reform is "a fluid, conflicted, and not easily controlled phenomenon" (Grinter, 2006, p. 156). It is confronted with serious conceptual and operational divisions among the party leaders over the promotion of a market economy and the state's intervention in the economy (Thayumanavan, 2001). In this connection, Gainsborough (2010, p. 483) states that the Vietnamese reform is "not uninfluenced by neoliberal ideas and practices but [...] indigenous thinking and modes of operating remain dominant". For this, he comes up with a contention that "despite 20 years of reform, which has involved extensive engagement with a wide range of neoliberal

\footnotetext{
${ }^{4}$ In 1997, impacts of the Asian financial crisis on Vietnam's economic growth resulted in its government seeking additional assistance from the IMF. At the same time, the crisis increased the ongoing concern among conservative groups about the direction of the economic reform. The IMF attributed its sharp decline in economic growth to domestic structural weaknesses compounded by the impact of the regional economic crisis and demanded the government to reinforce structural reforms, particularly in the banking, SOEs, and trade areas. Nevertheless, as the International Financial Institutions demanded the government to accelerate its economic reform as funding conditionality, the conflict among the party elites became intense with some of the doubters calling for a reassessment (Thayer, 2001).
} 
actors, the state in Vietnam remains little changed in terms of its underlying political philosophy and many of its practices" (Gainsborough, 2010, p. 476).

Against this background, the Vietnamese policy-making process can be described as "behaviour-led" rather than "rule-led" (Abonyi, 2005). That is, many policy changes are often the results of what is already happening in practice or were initially experiments or pilots. This policy practice reflects the pragmatic approach to policymaking which often does not allow a radical policy change for fear of unexpected consequences. It also represents a gradualist approach to policy change and policy process in Vietnam.

The slow and step-by-step change in policy reforms also has its origin in the policymaking process which is characterised by consensus-seeking and collective decisionmaking. These typical policy-making characteristics are attributed to the policymaking structure pertinent to the country's dual party-state systems. In the Vietnamese structure, any important policy alternative must be screened and presented for consideration and consultation in both systems before a formal policy is finally formulated. State agencies are concerned with the technical issues of the policy alternative including costs and resources, policy tools and implementation feasibility; but the Party's organisations and committees are more attentive to the Party's principal values such as the Party's absolute leadership over society, the conformity to the mainstream ideology, political stability, and social equality. Furthermore, the democratic centralism principle intrinsic to the communist system requires that any important decisions be made by a collective committee of policy elites so that different or conflicting political preferences can be reconciled. With this operational mechanism, no single politician is in the position to impose a major policy change without a broad-based consensus within the regime. Also, this core principle does not allow any policy elites to deviate significantly from the mainstream ideology and political preferences of the Party. The corresponding outcome of such policy-making structure is a policy process characterised by consensus-seeking and collective decision-making. This process represents a sharing of responsibility and political risk, and because of this, it is opaque in that a clear focal point of leadership and responsibility is difficult to identify (Abonyi, 2005).

The pace and direction of the Vietnamese reform are further dictated by its "decentralized, fragmented and sometimes incoherent set of state institutions" (Painter, 2005). In particular, the policy-making process can be ineffective and policies 
even unimplementable because of the lack of inter-ministerial coordination and involvement from other stakeholders outside of the government, which are in turn due to the absence of a procedure and mechanism for such engagement (Ohno, 2009). The most serious issue underpinning the lack of inter-ministerial coordination and involvement from government outsiders is the lack of clear directives from the top (Ibid.). Although policy documents are put out for consultation horizontally, vertically and geographically within the government, a clear roadmap with concrete strategies and action plans is missing in Vietnam's policy process. Consequently, the Vietnamese policies are largely reactive rather than proactive.

In sum, the unique features of Vietnam's policy context have been identified. Above all, the country's policy reforms are determined by the path dependence of socialistoriented market economy where the liberal thinking must be reconciled with, and conceded to, the socialist philosophy. The result of such chosen path is policies that are reformed incrementally rather than radically. The policy-making process that is "behaviour-led" rather than "rule-led" and characterised by consensus-seeking and collective decision-making further makes policies change in an incremental way and within the principle mainstream. The fragmented policy-making structure also contributes to rendering the policy-making process ineffective and difficult to implement in practice.

\subsubsection{The rhetoric of the autonomisation of public services}

\subsubsection{Autonomy policies targeted at public services in general}

The Vietnamese autonomy reforms have taken place against this institutional backdrop. Structured by the socialist-oriented market economy path dependence, the reforms display elements of statist and neo-liberal thinking. Influenced by numerous domestic and international forces which may be conflicting and irreconcilable, they have evolved at a slow pace. At the same time, the reforms show the convergence towards the commercialisation and marketization of public services.

The autonomy reforms began with policies that spark the inception of price liberalisation. Decision No 217-HDBT in 1987, whilst maintaining the state's control over prices of some key products, allowed SOEs to buy inputs and sell products on the market. In 1989, the part user-fee principle was first introduced in both public health care and education services. Decision 44-HDBT introduced a system of school fees applied to students from grade 4 upwards. Students in grades 1, 2, and 3 and from families certified as poor were exempted from school fees. Decision 45/HDBT 
identified health care fees to include fees for health examination, bed occupation, nursing, drugs, blood, tests, X-ray and other services applied to both inpatient and outpatient care. Exemption from health care fees extended to children under 5, war invalids, handicapped people, certified poor families, civil servants and public employees and their close relatives. The introduction of the part user-fee principle indicates that by the end of the 1980s the party-state had abandoned its commitment to universal service provision - the socialist principle that guarantees people's free access to public services. Although the socialist orientation is maintained through some forms of fee exemption and reduction, the part user-fee imposition means there has been a transfer of responsibility for public services from the party-state to citizens alongside the transition from socialism to the socialist market economy.

In the 1990s, the autonomy reforms continued with the separation of economic management and public service delivery from state administration. The motive was to transfer the responsibility of businesses and services from ministries to sub-units mainly tasked with business and service provision. This new approach to management led to the formulation of the Law on State-Owned Enterprises in 1995. The Law is applied to all SOEs but makes a distinction between business-oriented SOEs and utility service SOEs in terms of rights and obligations. The following table summarises the autonomy granted to utility service SOEs. Note that many of these rights are also shared by business-oriented SOEs.

Table 6-1: Law on State-Owned Enterprises 1995: Autonomy and Constraints (the part in italics indicate the constraints on autonomy)

\begin{tabular}{|l|}
\multicolumn{1}{c|}{ Areas within autonomy } \\
\hline Manage and use funds, land, natural and other resources according to laws \\
\hline $\begin{array}{l}\text { Transfer, lease, rent and mortgage properties under management when allowed by } \\
\text { competent state agencies }\end{array}$ \\
\hline $\begin{array}{l}\text { Determine the price of products and services, with exemption to those of products } \\
\text { and services regulated by the state }\end{array}$ \\
\hline $\begin{array}{l}\text { Develop development strategies and annual plans; Development strategies and } \\
\text { annual plans of SOEs need to be approved by competent state agencies }\end{array}$ \\
\hline $\begin{array}{l}\text { Organisational apparatus; organization of service delivery in line with the assigned } \\
\text { tasks }\end{array}$ \\
\hline $\begin{array}{l}\text { Determine payroll and salary units within the state's employee quotas and salary } \\
\text { units frameworks }\end{array}$ \\
\hline
\end{tabular}


Hire and fire employees according to Labour Law; set wages based on salary units and the performance of SOEs

Use the assigned resources to carry out supplementary businesses according to government regulations; conduct investments, joint-ventures, and capital contributions when allowed by competent state agencies; import and export according to state regulations

Use SOEs' depreciation fund according to government regulations in terms of depreciation rate and management

Retain and use fees and charges according to government regulations

Net revenues, after contributing to the investment fund and other required funds, are used to supplement staff income based on their performance and equity. The government stipulates in details the distribution of net revenues.

\section{Areas under government control}

The government promulgates policies and mechanisms of management with regard to different types of SOEs, incentive policies, and policies on subsidies, price subsidies, and preferential treatments applicable to products and services for public benefits.

The government decides on SOEs' establishment, merger, splitting, dissolution, and transfer of ownership

The government determines SOEs' objectives, tasks, and development strategies

The government decides on initial investment and supplementary investment

The government specifies the mode of management of SOEs and the appointment, reward, and discipline towards key titles

The government sets up the criteria and salary units in relation to products and services; establish the wages, allowances, and bonus of members of the Governance Board, General Director or Director of SOEs

\section{Summarised by the researcher based on National Assembly of Vietnam (1995)}

The above summary shows that the Law made some initial attempts to separate SOEs from their line ministries by granting more autonomy to SOEs in finance and personnel. The most notable is the right to retain and use net revenues to supplement staff income. It is easily observable in the table (the italic letters) that most of the managerial areas considered within SOEs' autonomy are stipulated to be in accordance with laws, rules, and regulations, conditional upon the approval of competent state agencies, or bound by some kinds of government frameworks. While some specific laws, rules, and regulations such as Labour law or the state's staff norms and salary 
units frameworks are referred to in the Law, some others mentioned in the Law are not clearly specified, indicating that the state may, when necessary, apply rules and regulations to limit SOEs' decision space. These contradictions can be seen as a policy paradox, implying that the party-state on the one hand may have an intention to delegate power to SOEs but on the other hand promulgates various rules, regulations, quotas, exemptions, and conditions to consolidate its control over the institutions.

The autonomy policies applicable to PSDUs came several years after the SOEs Law. Unlike SOEs, the autonomy policies applicable to PSDUs come in the form of government decrees, not laws passed and ratified by the National Assembly. Government decrees thus have lower legal enforceability than the National Assembly's laws. The first decree that marks the legalization of PSDUs' autonomy is the Government Decree 10 issued in 2002. Decree 10 classifies PSDUs into units fully self-financing their operating expenses and units partially self-financing their operating expenses and grants financial and personnel autonomy to these two types of units. In comparison with SOEs, the scope of autonomy of PSDUs stipulated in Decree 10 is far more limited, revolving around the use of net revenues and payroll. As with SOEs, the degree of autonomy of PSDUs is insignificant because it is bound by numerous rules and regulations of the government, which can be seen through the italic letters in the following summary:

Table 6-2: Government Decree 10/ND-CP 2002: PSDUs Autonomy and Constraints (The parts in italics indicate the constraints on autonomy)

\begin{tabular}{|l|}
\multicolumn{1}{c|}{ Financial Autonomy } \\
\hline $\begin{array}{l}\text { Allowed to borrow from banks or development assistance funds to extend and } \\
\text { improve the quality of products and services }\end{array}$ \\
\hline $\begin{array}{l}\text { Allowed to open deposit accounts at banks or state treasuries; revenues from the } \\
\text { state budget must be opened at state treasuries }\end{array}$ \\
\hline $\begin{array}{l}\text { PSDUs that fully finance operating expenses are financially autonomous in terms } \\
\text { of operating expenses. PSDUs that partially finance operating expenses are allowed } \\
\text { to have their financial estimates fixed over a three year period. }\end{array}$ \\
\hline Fees and charges are regulated by the state \\
\hline $\begin{array}{l}\text { Net revenues must be distributed, in priority order, to the income stabilization fund, } \\
\text { the reward fund, the allowance fund, and the capital fund. The head of units } \\
\text { determines the distribution rate after consultation with the trade union; the } \\
\text { distribution to the reward fund and the allowance fund must not exceed the average } \\
\text { three-month basic payroll of the unit. }\end{array}$
\end{tabular}


The remaining revenues from the state budget and other sources are allowed to be carried over to the subsequent year.

\section{Personnel autonomy}

Allowed to use employees on the payroll assigned by the state; use and manage employees according to the Law on Cadres and Civil servants;

Allowed to sign definite employment contracts in conformity with the Labour Law

The head of PSDUs, after consultation with the trade union, determines wages according to the performance of employees and their department. The staff additional income fund of PSDUs that fully finance operating expenses must not exceed 2.5 times the state-regulated basic payroll; that of PSDUs that partially finance operating expenses must not exceed twice the state-regulated basic payroll of the unit.

Summarised by the research based on Government of Vietnam (2002)

In 2006, Decree 10 was replaced by Decree 43 which modifies and extends the autonomy to multi-dimensions of management including task performance, organizational apparatus, personnel and financial management. Unlike Decree 10, Decree 43 divides PSDUs into units that fully self-finance their operating expenses, units that partially self-finance their operating expenses, and fully-subsidized units, and grants them autonomy depending on their financial self-sufficiency. More details of PSDUs' autonomy in Decree 43 are provided in the following table:

Table 6-3: Government Decree 43/ND-CP 2006: PSDUs Autonomy and Constraints (The parts in italics indicate the constraints on autonomy)

\section{Task performance}

Allowed to take initiative in deciding on measures to fulfill the assigned tasks

Elaborate plans and organize service delivery in accordance with PSDUs' professional domains and capabilities as well as the provisions of law

Entering joint-ventures or cooperation with organizations and/or individuals to provide services

PSDUs which fully and partially self-finance their operating expenses are entitled to decide on property procurement, investment, and capital mobilization according to the plans approved by competent state agencies; participate in bidding; use property for joint-ventures or contribute capital to joint-ventures with domestic and foreign organizations and/or individuals for construction investment and procurement of equipment in accordance with the state's regulations. 


\begin{tabular}{|c|}
\hline Organisational apparatus \\
\hline $\begin{array}{l}\text { Establish, merge, and dissolve subsidiary units, except for PSDUs where, as provided } \\
\text { for by law, this power is vested to the Government, the Prime Minister, ministers or } \\
\text { presidents of provincial-level People's Committees }\end{array}$ \\
\hline Personnel an \\
\hline $\begin{array}{l}\text { PSDUs which fully self-finance their operating expenses are entitled to decide on } \\
\text { their payroll; PSDUs which partially self-finance their operating expenses and fully- } \\
\text { subsidized PSDUs elaborate annual payroll plans based on their payroll quotas and } \\
\text { submit the plans to their overseeing agencies for approval. }\end{array}$ \\
\hline $\begin{array}{l}\text { The head of PSUDs decide to sign definite employment contracts or package } \\
\text { contracts for positions which need no regular staff on the payroll; sign contracts or } \\
\text { other forms of cooperation with domestic and foreign experts. }\end{array}$ \\
\hline $\begin{array}{l}\text { Decide on recruitment of cadres and public employees through examination or } \\
\text { consideration; decide on appointment of public employees (for titles equivalent to } \\
\text { senior experts or lower titles); decide on mobilization, detachment, retirement, job } \\
\text { severance, termination of working contracts, reward or discipline of cadres and } \\
\text { public employees in accordance with the provisions of law; decide on the increase } \\
\text { of salary grades on time or ahead of time for cadres and public employees and } \\
\text { receive, transfer holders of titles equivalent to senior experts or lower titles according } \\
\text { to conditions and criteria prescribed by law }\end{array}$ \\
\hline $\begin{array}{l}\text { eration according to the rank and position- } \\
\text { ate. }\end{array}$ \\
\hline $\begin{array}{l}\text { PSDUs are entitled to retain net revenues (after a deduction is made to distribute to } \\
\text { the capital fund) for paying staff additional income: fully self-financing units decide } \\
\text { on staff total additional income; partially self-financing units decide on staff total } \\
\text { additional incomes, which must not exceed three times the state-regulated basic } \\
\text { payroll of the unit; fully-subsidized units decide on staff total additional incomes, } \\
\text { which must not exceed twice the state-regulated basic payroll of the unit. }\end{array}$ \\
\hline \\
\hline $\begin{array}{l}\text { Allowed to borrow capital from credit institutions, mobilize capital from their cadres } \\
\text { and public employees for investment in service activities }\end{array}$ \\
\hline $\begin{array}{l}\text { Entitled to open accounts at state treasuries to record sources of revenues categorized } \\
\text { as state budget in accordance with the provisions of the state Budget Law; entitled } \\
\text { to open deposit accounts at banks or state treasuries to record revenues and } \\
\text { expenditures }\end{array}$ \\
\hline $\begin{array}{l}\text { levels of fees and charges, but those fees and charges must not exceed } \\
\text { es and charges regulated by competent state agencies }\end{array}$ \\
\hline
\end{tabular}


The head of fully and partially self-financing PSDUS decide on certain levels of operating expenses, which are higher or lower than those set by competent state agencies; the head of fully-state subsidized PSDUs decide certain levels of expenditure on management and regular operations, which must not exceed the levels set by competent state agencies.

Decide on the mode of assigning package expenditures to subsidiary divisions/units; the decision on construction investment, new procurement and overhaul of assets must comply with the provisions of law.

PSDUs are entitled to retain net revenues to set up funds and pay employees additional income. Net revenues must be used in the following priority order: fully and partially self-financing units deduct at least 25 per cent for setting up the capital fund, pay additional income, set up the reward fund, the welfare fund and the reserve fund for income stabilization with the maximum deduction level for the reward fund and the welfare fund not exceeding the average 3-month basic payroll and additional income payment; fully-subsidized units make expenditure on staff additional income, rewards, welfare and allowances, maintenance, and set up income stabilization fund.

The remaining sources of revenues allocated from the state budget for activities other than regular operations can be carried over to the subsequent year.

Summarised by the researcher based on Government of Vietnam (2006)

Decree 43 clearly expands the scope and degree of autonomy granted to PSDUs compared with Decree 10 . While Decree 10 is limited to granting fully and partly selffinancing PSDUs autonomy in using employees on the payroll assigned by the state, Decree 43 entitles PSDUs that fully finance their operating expenses the right to decide their payroll. Decree 43 also puts less stringent caps on PSDUs' expenses on staff additional income and allowances. More flexibilities have been given to PSDUs in terms of task performance, capital mobilization, and joint-ventures. A clearer distinction has also been made in the entitlements between PSDUs that fully and partially finance operating expenses and fully-subsidized PSDUs. All these demonstrate that some changes have been made to the autonomy reforms.

Nevertheless, these changes are insignificant, and conditional due to the presence of numerous legal provisions, conditions, and prescriptions of the government and the state. As shown in the italic letters in the above table, most of the managerial aspects of PSDUs are subject to other state rules and regulations, or according to statestipulated schemes or quotas, or conditional on the state's approval. Again, these contradictions demonstrate a policy paradox, that is the party-state is not willing to relinquish their control over PSDUs despite agreeing to the need for greater autonomy 
for these types of units. Faced with the contradictions, the formal autonomy of PSDUs is thus hugely constraint and even non-existent in some aspects.

The autonomy of PSDUs, whilst limited in various managerial dimensions, is broadened in areas conducive to revenue generation. As stated above, PSDUs are granted more flexibility in terms of service provision, borrowing and mobilizing capital for service provision and procurement of equipment, and establishing jointventures with individuals and private organisations. PSDUs, especially those more financially autonomous, are given greater autonomy in spending and rewarding employees. These entitlements constitute a structure of incentives, constructed to stimulate PSDUs to generate alternative budgetary revenues. This argument will be further analysed in section 6.2.3.

\subsubsection{Autonomy policies targeted at health care and higher education}

Unlike the health sector which follows Decree 10 and Decree 43 in hospital autonomisation, the higher education sector, whilst in line with these two decrees, has issued its own normative legal documents to govern university autonomisation. It can be said that the Law on Education in 1998 and the revision in 2005 are the first attempt to reform higher education institutions towards autonomisation. The country's first Law on Education regards universities as entities that operate in accordance with the law but it is designed mainly to codify the state's discretionary power to intervene in any aspect of university business. The revised Law on Education (National Assembly of Vietnam, 2005) moves further towards separating the education system from the state administrative apparatus when emphasizing that the role of the state is to "increase the autonomy and raise the sense of responsibility of educational institutions" (article 14). What this autonomy means in practice, however, remains unspecified.

Despite aiming to serve as the legislative basis for the governance of higher education, the Education Law in 2005 is explicit in very few of its provisions. The ambiguity of language creates opportunities for the Party and the government to determine how the legislation should be interpreted in specific instances. Article 14 of the Law dictates that the state "exerts unified management of the national educational system with regards to the objectives, programmes, contents, and plan of education", but at the same time it also affirms that the state will "implement decentralization of management to local agencies and enhance the autonomy and accountability of grassroots education establishments". This can be understood that the state retains 
control while encouraging institutional autonomy. Further, article 53 of the Law stipulates that universities should have their own governing council to make decisions about "purposes, strategies, projects and development plan" but in article 41 the authority for "compiling and rectifying the curriculum" belongs to MOET. This means that university self-governance is encouraged but universities do not control their curriculum. So the autonomy policies of the higher education sector reflect the policymaking approach to public services in that they represent the persistent contradiction between the traditional socialism tenets and the pressures of market economy. The result of such policy paradox is that no substantive autonomy is conferred on universities as expected of the revised Law.

To sum up, the unveiling of the formal autonomy of PSDUs, and universities in particular, demonstrates that there exists a policy paradox in the Vietnamese autonomy reforms. That is the paradox between a desire of the party-state to decentralize the decision-making power to PSDUs in line with market mechanism and a desire to retain control of the socialist orientation over these institutions. These desires assert a persistent conflict between the old-fashioned socialist and the neo-liberal thinking within the Vietnamese communist policy-makers in which the triumph often belongs to the socialist principle, not the neoliberal reform imperative. As the legacies of a centralised state are embraced predominantly, the demand for autonomisation becomes less significant. In the face of this policy paradox, the autonomy reforms unfold as a policy rhetoric, promoted far less for addressing backward state management, which has been pointed out as the main contributing factor to the low effectiveness and efficiency of public service delivery, but much more for the attainment of the legitimacy and resources necessary for the survival of the socialist regime. The latter will be discussed further in the following section.

\subsubsection{The myth of the "socialisation" of public services}

The autonomy policy reforms have been initiated in connection with the "socialisation" of public services introduced concurrently by the party-state. Policies on the "socialisation" of public services dated back to the second half of the 1990s. The political report to the $8^{\text {th }}$ National Party Congresses in 1996 states that "the Party vows to effectuate the policy of socialising culture, information, sports, health care, population, family planning, education, and other social activities, aiming to improve the material, spiritual, and physical life of the people" (Party Central Committee, 
2006). This policy was later confirmed in all National Party Congresses' documents and given effect in many legal documents of the government.

Notably, Government Resolution 90 (1997) defines the "socialization" of educational, health care and cultural activities as "the mobilization and organisation of the popular participation in the development of these areas with the aim of improving the outcomes of these services and the physical and spiritual life of the people". The substance of "socialization", according to the Resolution, is to "extend sources of investment, mobilize social potentials in terms of human, material and monetary resources". Besides acknowledging the role of the state in service provision, the Resolution promotes the diversification of forms of service ownership, including the services provided by cooperatives and individuals.

Government Decree 73 (1999) encourages the "socialisation" of educational, health care, cultural and sports activities to mobilize resources of the people and organizations of all economic sectors to enhance the people's level of enjoyment of services in these areas. The Decree especially promotes the development of semipublic, people-founded and private non-state establishments. To this end, the Decree provides for specific preferential policies for land and infrastructure, registration fees, taxes, and credit and insurance.

Government Resolution 05 (2005) continues in this spirit by pointing out that "socialization" is to achieve two ultimate goals: (i) to mobilize intellectual and material potentials from the entire society for the development of health care, education, culture and sports; and (ii) to enable the people, especially the poor and policy beneficiaries, to enjoy increasingly better service outcomes. For "socialization" to be materialized, two main components are put forward in the Resolution. The first concerns renovating the operation of PSDUs by transforming PSDUs from the subsidy mechanism to the mechanism of autonomy and self-financing and renovating the fee-for-service payment mechanism. The second relates to promoting non-state establishments in two forms, people-founded and private, and transforming PSDUs into non-state establishments.

These spirits of "socialization" are also reflected profoundly in Government Decree 43. The Decree asserts that one important objective of granting autonomy to PSDUs is to enable them to develop alternative non-budgetary sources of revenues so they become less reliant on state subsidy. Non-budgetary sources of revenues include selfgenerated incomes such as charges and fees, incomes from service activities, profits 
from joint-venture or cooperation activities, interests on bank deposits; loans; external grants; and gifts. In this direction, the Decree stipulates that the conferment of autonomy on agencies is "to materialize the undertaking of socialization of public services, to mobilize social contributions to the development of public non-business operations, thereby step by step reducing the state budget subsidy" (Government of Vietnam, 2006). This follows that the Decree encourages PSDUs to adopt the entrepreneurial management mode or to switch to the model of enterprises or non-state units in order to bring into full play all of their operational capabilities. A noticeable incentive of financial self-sufficiency is that PSDUs may use sources of revenues to supplement staff income. This incentive is specified in the Decree as follows: "The state encourages PSDUs to increase revenues, save expenses and streamline payroll so as to increase incomes for employees, based on the latter's accomplishment of the assigned tasks". Incentives of the transformation to enterprises or non-state units are also put forward including tax and land preferences as well as property already invested by the state.

Overall, the "socialization" policies refer to the shifting of costs from the state onto society in which autonomisation and privatization of public services are instrumental. While the former is associated with the initiation and expansion of cost recovery schemes through the imposition of various fees and charges, the latter is linked to the transfer from non-profit towards for-profit operational mechanism. Both of these processes signify the retreat of the state from public service provision and the handing over of that responsibility to society.

Hitherto, as described above, these instances of "socialization" are not explicitly represented in the "socialization" policies. Instead, a number of euphemistic words (e.g. mobilization of the popular participation, mobilizing social potentials in terms of human, material and monetary resources, people-founded service providers, non-state organisations...) are used to express the underlying purposes of the policies. On the one hand, the use of euphemistic language indicates that the Vietnamese communist policy-makers wish to emphasize that "socialisation" aims to mobilize human, material and monetary resources from society so that service costs can be shared between the state and society. They do not want to make an impression that "socialisation" is a measure to harness social resources in conditions of state budget shortage. For this, Resolution 90 highlights that "socialization should not be regarded as a temporary and immediate solution to the state shortage of resources; instead, the 
effective use of the people's resources to enable the development of the education, health care, and cultural activities is a long-term policy, the motto of the Party and State's social policies....Socialization is necessary even when the people have high income and the state budget is abundant, since education, health care and culture development is a permanent course" (Government of Vietnam, 1997) On the other hand, the euphemism implies that the Vietnamese communist policy-makers are not comfortable with the ideas of marketization, commercialisation, and privatization of public services even though their "socialisation" policies are meant to converge towards these conceptions. Therefore, such phrases as "the promotion of non-state establishments" and "the transformation of PSDUs into non-state establishments" are used instead of privatization of public services/PSDUs which naturally does not sit well with the collectivist values and socialist ideals.

Moreover, the substance of the "socialization" policies is disguised due to the assurance of the continued role of the state in public service provision. For example, Resolution 90 emphasizes that "the socialization of public services does not mean undermining the role of the state and reducing the allocation of the state budget; in contrast, the state is constantly seeking more revenues to further fund these services" (Ibid.). This promise is later expanded in Resolution 05: "the state will continue to increase resources for investment, concentrating on prioritised objectives and national development programmes of education, health, culture, and sport; at the same time, supporting deep and remote areas and areas populated with many ethnic minority groups as well as subsidizing the poor and preferential targets on the basis of innovating the fee exemption and reduction regime in the direction of direct support to beneficiaries" (Government of Vietnam, 2005)

The noble intentions that the party-state attaches to "socialization" also contribute to render the substance of "socialisation" hidden in the policies. The noble intentions are presented in all of the "socialization" policies, ranging from "improving the outcomes of public services" and "enhancing the people's level of enjoyment of services" to "realizing social equality" and "improving material, spiritual, and physical life of the people". Resolution 05 especially states that "the ultimate objective of the socialization is to create conditions for the whole society, especially the poor and policy targets to benefit increasingly greater outcomes in the areas of education, health care, culture, and sports". 
In general, the "socialisation" policies are myths that the Vietnamese communist politicians create in the transition towards the autonomisation and privatisation of public services. Policy statements suggest mobilization and collaboration to improve and universalize public services, but the specific policies are cost shifting so that the state budget no longer has to bear them. Being fundamental to "socialisation", the autonomisation of public services reveals its overarching goal - that is to develop and expand sources of alternative non-budgetary revenues so that PSDUs become financially self-sufficient. Considering the previous section which argues that the autonomy reform is a fallacy, there is a solid ground to believe that the Vietnamese autonomy policies are primarily aligned with drawing resources from society to cut back on state expenditure on public services. Given the fact that the autonomy reforms so far are mostly limited to public service delivery, leaving other important functions such as regulation and policy advice, which need to be shielded from political intervention, remain with state management agencies, it becomes even more convincing to contend that the primary intention underpinning the autonomy policies is to switch costs to service consumers.

\subsection{7 - present: a radical policy change}

\subsubsection{Vietnam's political economy from 2007 to present}

After two decades of growth, the Vietnamese economy fell into a lengthy period of macroeconomic turmoil and slow growth in the late 2000s (Tran, 2013). This is evidenced by a serious deterioration in most of the important macroeconomic indicators since 2007. The GDP growth rate increased in the 2000-2007 period but started to decline from 8.5 per cent in 2007 down to 5.3 per cent in 2012, the lowest within 13 years (Vuong, 2014). The inflation rate, trade deficits, and fiscal deficits have all increased to record levels since the launch of Đổi Mới. The inflation rate reached its peak of 23 per cent in 2008 and 18 per cent in 2011 seriously affecting the real consumption of the majority middle class and the poor since 50 per cent -80 per cent of an average citizen's income is spent on foods (Ibid.). The trade deficits increased from the low 4.56 per cent in 2006 to the high 15.85 per cent in 2008 and then dropped to 10.28 per cent in 2010 (Tran, 2013). The fiscal deficit for ten years in a row from 2003 to 2012 stayed at an average of 5.3 per cent with that of the year 2009 soaring to 7.2 per cent, creating a large debt burden on the government (Vuong, 2014). In June 2012, the then governor of State Bank of Vietnam Nguyen Van Binh admitted before the National Assembly that bad debts might have reached 10 per cent of the 
total gross loans of the whole banking system (Le, 2013). Especially, the debt to-GDP ratio in Vietnam stands out as one of the steepest increases in the region, reaching 58 per cent in 2014 and 61 per cent in 2015 (Government of Vietnam \& World Bank, 2017).

The severe downturn in Vietnam's economy in the late 2000s, whilst coinciding with the global economic recession in 2008, actually stems from many of its fundamental domestic problems. The most important lies in the country's socialist-oriented economic structure which gives primacy to the state sector at the expense of the recently developing private counterpart. Subsequently, SOEs have always enjoyed the monopoly status or the dominant position in most of the country's strategic industries such as coal, electricity and gas, steels, chemicals, fertilizers, textiles, transportation, post and telecommunication, real estate and finance even although a number of smallsized SOEs have been equitized under the pressure of the international community. SOEs have also been given preferential treatment in terms of critical resources, such as credit, land, and natural resources, and lucrative opportunities, such as public investment and government procurement. Despite all those special favours and advantages, and notwithstanding the many existent reforms to autonomise and modernise the economic sector, SOEs have experienced persistent inefficiency and corruption. According to a survey by MOF and IMF, only about 40 per cent of SOEs were profitable, a further 40 per cent were temporary loss-makers and 16 per cent as permanent loss-makers (General Statistics Office of Vietnam, 2002). Consequently, the contribution of SOEs to the economy is often disproportionate to the favours and resources they enjoy. For example, SOEs made up about 45 per cent of state investment during 2006-2010 period but the sector contributed only 19 per cent of the GDP growth (Pincus, Vu, Pham, Wilkinson, \& Nguyen, 2012).

While the poor performance of the SOE sector is an ongoing issue due to the lack of corporate governance, wastefulness, and corruption, the problem has become even more serious from 2007 to the present time. This is because the Vietnamese government, on the eve of the country's WTO accession in 2006, officially adopted policies to turn existing state general corporations into giant, highly diversified conglomerates (officially called state economic groups) in order to strengthen the SOE sector. This decision was arguably pushed by many Vietnamese conservative politicians obsessed that the WTO accession could weaken SOEs, leading to the loss of the sector's leading role in the domestic market, which in turn threatens the socialist 
orientation of the regime ( $\mathrm{Vu}, 2016 \mathrm{a})$. This decision is also believed to have had the contributing hand of Deputy Prime Minister Nguyen Tan Dung who later replaced the then Prime Minister Phan Van Khai in June 2006 (Ibid.). Unlike his predecessor, who was very cautious with the conglomerate idea, Nguyen Tan Dung sought ways to enable conglomerates to diversify their businesses horizontally. As a politician, he had long been considered to have a cosy relationship with SOEs (Tran, 2013).

The decision to build up state general corporations into state economic groups is, in hindsight, a "reversed SOE reform" ( $\mathrm{Vu}, 2016 \mathrm{a})$. The emergence of state conglomerates further reinforces the already monopolistic, or dominant, position of the state sector, significantly affecting the WTO requirement about a fair competitive business environment. Additionally, under WTO rules, every economic sector is treated equally; however, the Vietnamese state conglomerates are still given many privileges because the state can still deliberately support targeted conglomerates through its industrial policies, which are, in principle, used to target an entire industry. Furthermore, the formation of diversified businesses which extend to insurance, finance, and banking within state conglomerates has created new forms of directed credit and cross-subsidies among SOEs. This new business model has enabled state conglomerates to raise capital from various sources from their own commercial banks, financial companies, and insurance companies. With abundant internal sources of capital, state conglomerates can self-finance many of their business activities without having to rely on government subsidies or directed credit from other commercial banks.

It is the policies regarding the birth of state conglomerates that have exacerbated the existing problems of inefficiency, cronyism, interest groups, rent-seeking and corruption among the SOE sector. The move to diversify businesses, combined with the easy access to natural resources, have resulted in rampant investment by many state conglomerates in both their core and non-core business activities. This is evidenced by the sharp increase in business investment by state conglomerates from around VND 6,000 billion in 2006 to over VND 22,000 billion in 2012, with investment in banks alone accounting for approximately 60 per cent ( Vu, 2016a). Irresponsible investment behaviour, coupled with the lack of good corporate governance, has compounded the inefficiency and wastefulness in the use of resources in the SOE sector. For example, capital accumulation among SOEs increased rapidly, with the average capital per SOE rising from VND 130 billion in 2000 to VND 768 billion in 2008 (World Bank, 2011). 
However, this rapid concentration of capital has not been accompanied by a proportionate increase in outputs and productivity. According to World Bank (2011), the average turnover to capital ratio in SOEs was 1.6 compared with 8.8 for the enterprise sector as a whole in 2000. By 2009, the same ratio for SOEs had dropped to 1.1 while it had increased to 21.0 for the entire sector (Ibid.).

So far, there have been big losses among a series of large state conglomerates such as VINASHIN (Vietnam Shipbuilding Industry Group), VINALINEs (Vietnam National Shipping Lines), VRG (Vietnam Rubber Group), EVN (Vietnam Electricity Group), VNPT (Vietnam Posts and Telecommunication Group), and PVN (Petro Vietnam), which is primarily due to mismanagement and embezzlements. VINASHIN, for example, incurred $\$ 4.4$ billion debt in 2010 due to its reckless investment in not just shipyards and construction companies - its core business - but a great deal of other businesses including insurance, real estate, banking, securities, wholesale and retail trade, and even beer manufacturing (Malesky, Schuler, \& Tran, 2011). VINALINEs' loss of VND366 billion concerns a deal to purchase an old floating dock built in 1965 from a Russian company for as much as US\$9 million through a Singaporean broker, AP Company while the dock's owner offered to sell the facility for less than $\$ 5$ million. The deal was found to bring VINALINEs' corrupt officials \$1.666 million as a kickback (Tuoitrenews, 2013). The most recent significant losses relate to PetroVietnam Construction Joint Stock Corporation, a subsidiary of PVN, which was reported to accumulate a loss of VND 4.212 trillion by June 2013 while its revenue was VND510 billion only (Vietnamnet, 2017). PVN was also found to have other serious losses of VND800 billion because its managers violated the provisions of the Law on Credit Institutions through the contribution of more than allowed capital to Ocean Bank - a weak bank that has been bought by the state Bank at zero VND (Ibid.). The above numbers and examples are only some snapshots of the huge troubles faced by Vietnam's SOE sector. It is understandable that the financial burden that SOEs, especially giant conglomerates, has caused to the country's entire economy is tremendous. What is notable through the recent corrupt cases among the SOEs is the alleged involvement of top officials from the government. Traditionally, the connection between senior bureaucrats and state businessmen is very close because the top executives of SOEs are appointed by a prime minister or a minister in charge. As such, interest groups and cronyism are not new to Vietnam, but they have presented themselves as a more serious problem to the regime under the reign of Prime Minister 
Nguyen Tan Dung (2006 - 2016). In fact, most, if not all, key state businessmen charged with wrongdoings and embezzlements in the recent high-profile corruption cases (e.g. Pham Thanh Binh, Duong Chi Dung, Dinh La Thang, Trinh Xuan Thanh, Tram Be) are widely perceived to have strong ties with Prime Minister Nguyen Tan Dung and his stalwarts. These government-SOE alliances have formed "rent-seekers" factions - groups of interests that use their positions to enrich themselves without benefiting society. Sheltered under political cover, these state businessmen have eroded their enterprises. The cost of their destruction to the country's entire economy is devastating.

\subsubsection{Implications of Vietnam's political economy for the autonomy policies}

\subsubsection{Autonomy policies targeted at public services in general}

Vietnam's political economy from 2007 to the present indicates the serious limitations in state resources. In this context, the party-state highly prioritizes infrastructure development, ahead of social security and environment (Forsberg, 2011). For instance, in the period 2011-2015, total state budget spending on infrastructure accounted for 29.2 per cent of GDP, increasing from 28.4 percent in the period 2006-2010 (Government of Vietnam \& World Bank, 2017). Also, the administrative wage bill, as a result of an increase in public sector employment, has expanded considerably, accounting for 20 per cent of total public spending (Ibid.). Against this backdrop, the financial responsibility for social services, which are seen as social burdens and economic costs (Forsberg, 2011), is significantly transferred to households. Consequently, "socialization" has become a critical political imperative in order to capitalize and privatize public services.

Government Decree 69 (2008), for example, specifically targets non-state organisations in an attempt to speed up "socialisation" of educational, vocational, health care, cultural, sports, and environmental activities. In return for their investment in these types of services, non-state organisations will receive an array of incentives which comprise land, buildings, income tax, value-added tax, registration fees, import and export conditions, credit, capital raising, social and health insurance, and even commendation.

Government Resolution 40 (2012b) promulgates an Action Plan for the realization of the Conclusion Notification of the Politburo on the Government Scheme regarding the "Renewal of the operational mechanism of PSDUs, pushing up socialization of some public service types". The key tasks set out in the Action Plan are related to improving 
institutions for the renewal of the operational mechanism of PSDUs and the reinforcement of the "socialization" of certain types of public services. Specifically, the premise on which the state subsidizes public services will switch from PSDUs' budget estimates to the order and purchase of goods and services on the basis of technical-economical norms and quality standards for each type of goods and services. The financial mechanism of PSDUs that provide highly "socialisable" services and thus can fully self-finance operating expenses (applied to universities, hospitals and several vocational establishments from 2015 onwards) will be transformed in the following direction: assigning autonomy and self-responsibility synchronously in task performance, payroll and personnel, finance and properties; authorising the setting of service prices on the basis of the price framework that adequately incorporates reasonable cost promulgated by competent state agencies; authorising use of state capital; allowing decisions on capital mobilization to expand service provision and on payroll and salary payment according to the state's salary scales and performance. Meanwhile, PSDUs providing normal services (especially PSDUs in the economic domain) are enabled to operate according to the entrepreneurial model and to equitize in due course.

The advent of these "socialization" policies leads to a radical change in the autonomy policies, evidenced by the issue of Government Decree 16 in 2015 regarding the autonomy mechanism of PSDUs. Decree 16 has some distinctions from preceding legal documents. First, the Decree sets the scope of PSDUs, covering services in education; vocational training; health care; culture, sports and tourism; information, communication and media; science and technology. Second, two types of public services are introduced: services whose costs are fully met by the state budget or not recovered fully in charges and fees with the balance covered by the state budget; and services which are likely to be highly "socialized" and thus are not subsidised by the state budget, but are charged for according to the market mechanism. Third, mechanisms to determine fees and charges of these two types of services are identified. For the first type of services, fees and charges are determined on the basis of economic - technical norms and cost norms issued by competent state agencies. A roadmap for a full count of costs is prescribed, whereby fees and charges will have included wage costs and direct costs by 2016; wage costs, direct costs and management costs by 2018 ; and wage costs, direct costs, management costs and depreciation by 2020 . For the second type, PSDUs can determine fees and charges according to the market 
mechanism, decide on units and levels of fees and charges to cover reasonable costs and accumulate savings pursuant to legal provisions pertinent to service areas. This entitlement is, however, not applicable to health care and education; instead, public health care facilities and educational institutions are to follow state regulations regarding fees and charges. Fourth, four levels of financial autonomy are specified, corresponding to the classification of PSDUs into four groups: PSDUs that self-finance capital and operating expenses; PSDUs that self-finance operating expenses; PSDUs that partially self-finance operating expenses; and fully-subsidized PSDUs. Fifth, the Decree specifies various forms of state funding to PSDUs: purchasing, contracting, task assignment and budget allocation on the basis of economic-technical norms or budget estimates in a three year period. Sixth, the Decree emphasizes the role of the state in the formulation of criteria and standards of public services and mechanisms of supervision, measurement, and accreditation of the performance of PSDUs.

All in all, the most notable change in this autonomy policy is the cost recovery prescription for different types of PSDUs. Accordingly, self-financing units are entitled to determine service fees and charges according to the market mechanism while units fully and partially subsidized by the state budget are allowed to progressively incorporate full costs in their service fees and charges along a detailed roadmap. The incentive for the increasing financial self-reliance is a higher degree of autonomy, mostly of financial operations, on the part of PSDUs. It is noteworthy that the spirit of this incentive was reflected in the preceding autonomy legal documents, but this time, it is reinforced by entitlement to a full recovery of costs followed by the greater discretion to use the revenue results.

This policy change signifies the shift in Vietnam's approach to the autonomy of PSDUs. If the party-state previously took a cautious approach to the transition from subsidy to cost recovery, by this time they have become more determined to take the path of switching costs to service users. Invariably, the party-state's resolution to renew PSDUs' operational mechanism is largely associated with this shift, leaving their autonomy almost intact in most of the managerial dimensions. Following is the summary of PSDUs' autonomy prescribed in Decree 16: 
Table 6-4: Government Decree 16/ND-CP 2015: PSDUs Autonomy and Constraints (The parts in italics indicate the constraints on autonomy)

\begin{tabular}{|c|}
\hline Task perfo \\
\hline $\begin{array}{l}\text { Regarding public services not funded by the state budget, PSDUs establish their own } \\
\text { plan and report to the overseeing agencies for monitoring, inspection, and } \\
\text { supervision; regarding public services funded by the state budget, PSDUs establish } \\
\text { their plan and submit it to the overseeing agencies for approval. }\end{array}$ \\
\hline $\begin{array}{l}\text { Decide on measures for performing duties according to the plan; participate in } \\
\text { bidding for the provision of public services; form joint ventures with organizations } \\
\text { or individuals in accordance with laws. }\end{array}$ \\
\hline Orga \\
\hline $\begin{array}{l}\text { PSDUs which self-finance capital and operating expenses and PSDUs which self- } \\
\text { finance operating expenses are entitled to decide on establishing, restructuring, and } \\
\text { dissolving affiliates which do not belong to units established under the decision of } \\
\text { competent state agencies, conforming to criteria, conditions, and standards } \\
\text { prescribed in laws; develop plans to restructure affiliates which belong to units } \\
\text { established under the decision of competent state agencies and submit it to } \\
\text { competent agencies for decision. } \\
\text { PSDUs which partially self-finance operating expenses and fully-subsidized PSDUs } \\
\text { are entitled to set up the organisational apparatus plan to submit to competent } \\
\text { agencies for decisions. }\end{array}$ \\
\hline Governing Council \\
\hline $\begin{array}{l}\text { PSDUs which self-finance operational and capital expenses establish the governing } \\
\text { council; when necessary, ministries, ministerial-level agencies, and governmental } \\
\text { agencies, the People's Committees of centrally-run cities or provinces stipulate the } \\
\text { establishment of the governing council for PSDUs that are not governed by the } \\
\text { above regulation. } \\
\text { The governing council comprises } 5 \text { to } 11 \text { members including representatives of the } \\
\text { line management agency; the Chair and members of the governing council are } \\
\text { appointed by competent state agencies granting the establishment decision. } \\
\text { Procedures for establishment, position, functions, duties, powers, organizational } \\
\text { structure and approval for the operational regulations of the governing council, the } \\
\text { relationship of the governing council and the head of PSDUs and the overseeing } \\
\text { agencies conforms to instructions of the Ministry of Home Affairs }\end{array}$ \\
\hline Pers \\
\hline $\begin{array}{l}\text { Formulate job positions and personnel structure by professional titles for submission } \\
\text { to competent state agencies for approval; recruit, use, appoint, discharge, reward, } \\
\text { discipline and manage public employees in accordance with regulations; entitled to } \\
\text { sign definite contracts with outside employees to perform tasks; }\end{array}$ \\
\hline
\end{tabular}


PSDUs which self-finance capital and operating expenses, and those which selffinance operating expenses decide on payroll; PSDUs which partially self-finance operating expenses put forward the payroll proposal to be submitted to competent state agencies for approval; fully-subsidized PSDUs submit the payroll proposal based on the average payroll quotas specified in the preceding 5 years and not exceeding the current payroll to competent state agencies for decisions.

PSDUs pay basic wages based on the salary scales and ranks and job positions and allowances in accordance with the governmental regulations

\section{Service fees and charges}

Regarding public services not financed by state budget, PSDUs are allowed to set service charges according to market mechanism, ensuring service charges adequate to recover reasonable expenses and to accumulate earnings in accordance with regulations applied to each sector; the charges of medical examination and treatment and education and training services are governed by the state regulations on prices.

The charges of public services financed by state budget are determined on the economic - technical basis and cost norms adopted by competent state agencies and the roadmap for calculating a full amount of expenses in which salary costs are calculated based on the basic salary level, salary coefficients, scales, ranks, and positions and payroll quotas assigned by ministries, central agencies and provincial People's Committees.

\section{Capital mobilization}

PSDUs are entitled to borrow from credit institutions, mobilize capital from their staff to invest for the expansion and improvement of services.

PSDUs that finance capital and operating expenses are allowed to borrow and mobilize capital to invest in facility improvement.

\section{Financial autonomy}

PSDUs that self-finance capital and operating expenses are entitled to establish investment projects, and submit them to competent state agencies for approval; decide which projects to finance and issues related to the construction extent, method, capital fund, capital source and execution stages in accordance with regulations on capital expenses;

PSDUs that self-finance operational and capital expenses and PSDUs that selffinance operating expenses decide on the operating expenses higher or lower than the expense limits promulgated by competent state agencies and these expenditure levels must be stipulated in the internal expenditure regulation; must comply with state regulations in terms of depreciation of fixed assets; 
PSDUs that partially self-finance operating expenses and fully-subsidized PSDUs decide on the level of operating expenses but these expenses must not exceed the expenditure limits stipulated by competent state agencies.

Non-operating expenses must conform to the law on the state budget and applicable laws on each type of budget; comply with the government's regulations on spending limits, criteria and norms on using cars, offices, home phones and mobile phones; regulations on overseas travels and foreign visitor reception and international conferences organized in Vietnam.

PSDUs are entitled to retain net revenues and must use net revenues in priority order as follows:

PSDUs that self-finance operational and capital expenses set aside 25 per cent for establishing the capital fund; decide on the staff additional income fund (the level not restricted); set aside the reward fund and the welfare fund of which the maximum level must not exceed the 3-month basic payroll of the unit; set aside other funds in accordance with regulations;

PSDUs that self-finance operating expenses set aside 25 per cent for establishing the capital fund; the staff additional income fund must not exceed three times the stateregulated basic payroll; set aside the reward fund and the welfare fund of which the maximum level must not exceed the 3-month basic payroll of the unit; set aside other funds in accordance with regulations;

PSDUs that partially self-finance operating expenses set aside at least 15 per cent for establishing the capital fund; set aside the staff additional income fund not exceeding twice the state-regulated basic payroll of the unit; set aside the reward fund and the welfare fund of which the maximum level must not exceed the 2-month basic payroll of the unit; set aside other funds in accordance with legal regulations;

Fully-subsidized PSDUs set aside at least 5 per cent for establishing the capital fund; set aside the staff additional income fund not exceeding the state-regulated basic payroll; set aside the reward fund and the welfare fund of which the maximum level must not exceed the one-month basic payroll of the unit; set aside other funds in accordance with legal regulations.

Summarised by the researcher based on Government of Vietnam (2015a)

The above summary shows that there have been radical changes in the autonomy policies. These changes are primarily related to the revenue-generating incentives such as setting up fees and charges, service provision, capital mobilization, operating expenses and net revenues distribution. Another notable change is that more of these entitlements and incentives have been conferred on PSDUs that self-finance capital and operating expenses and those that self-finance operating expenses. The indication is that more financially self-reliant PSDUs will be rewarded a higher degree of autonomy. Apart from these incentives, many important autonomy dimensions of both 
self-financing and state-financed PSDUs remain largely unchanged. Indeed, much of PSUDs' autonomy, as shown in the italic letters in the above table, is still bound by a system of rules and regulations, norms, quotas, criteria, and conditions prescribed by the state.

\subsubsection{Autonomy policies targeted at health care and higher education}

In health care, the issue of Government Decree 85 and Joint Circular 04 in 2012 reflects the health sector's effort in reinforcing the "socialization" of health services amidst the reduced state subsidies for the health sector. The Decree, which was later mirrored by Government Decree 16 governing the autonomy of PSDUs, stipulates in detail the operational and financial mechanism of state health facilities. A major shift of the policy is the removal of state subsidies to state health facilities by incorporating full costs of providing services into the service prices. The Decree specifically provides for an implementation of the roadmap towards appropriate and adequate calculation of user-fees by 2018. Accordingly, the health care service prices will include all costs of providing services including direct costs (drugs, consumables, wage, maintenance of fixed assets, depreciation) and indirect costs (overhead costs, training, and research) (Government of Vietnam, 2012a).

Legal documents guiding implementation of Decree 85 have been developed, including Joint Circular 04 of the Ministry of Health and Ministry of Finance (2012) on the adjusted price schedule for health services. In replacement of Decree 95/CP/1994 on partial user fees, the Joint Circular 04 sets the maximum prices in a schedule covering 447 examination and treatment services at state health facilities, based on the principle of partial cost recovery. Price levels are determined on the basis of some of the cost components of services (i.e. drugs and materials, utilities, maintenance and materials for equipment, salaries and supplements for overnight and weekend duty and for performing surgeries and procedures). This price adjustment has created a significant change in health financing reform in state health facilities by a calculation of full service cost. It lays out a roadmap starting in 2012 to adjust the medical service prices so that by 2018 the medical service prices will include all costs of providing health services including direct costs (drugs, consumables, salary, maintenance of fixed assets, depreciation) and indirect costs (such as overhead costs, training and research costs to apply new technologies).

In higher education, the enactment of the country's first Higher Education Law in 2013 and the issue of Government Resolution 77 in 2014 indicate a further attempt in 
reforming university governance, and at the same time in "socializing" higher education services. The Law, for the first time, specifies universities' autonomy in a number of dimensions. The Law allows universities to formulate tuition fees within the tuition fee ranges set by MOET; to open up new study programmes within their approved list of study programmes; to determine their enrolment quota; to manage their academic affairs within the curriculum frameworks set by MOET; to issue degrees to their graduates; to choose the education quality accreditation agency from a list of accreditation agencies approved by MOET; among others (National Assembly of Vietnam, 2012). The Law gives universities' principals the authority to develop strategic plans; set up, reorganize, integrate, separate, and dissolve their departments; appoint and dismiss staff, but the Law does not remove the line ministry mechanism which means MOET and other line ministries continue to appoint and promote universities' principals.

The above prescription of universities' autonomy again shows that the Higher Education Law, whilst extending autonomy to various aspects of management, displays a high level of ambiguity in that it affirms the state control in nearly all the autonomy it grants to universities. Such ambiguity reveals the great reluctance of the party-state to delegate substantive autonomy to universities in almost all managerial areas. Therefore, the Law, instead of creating a radical reform that can reform the higher education governance system, only brings in some incremental policy changes to the autonomisation of public universities.

As compared the Higher Education Law, Government Resolution 77 (2014) represents a clear approach to "socializing" higher education by relaxing the stringent stateregulated tuition fee caps for universities that self-finance capital and operating expenses. Accordingly, the tuition fees that this group of universities can charge are stipulated to be equivalent to the state-regulated tuition fee caps plus the state funding for operating expenses per student. Meanwhile, the Resolution, in line with the Law, continues to attach various conditions to the autonomy granted. Universities are allowed to open up new study programmes only when they satisfy criteria stipulated by law; to determine enrolment targets according to state regulations; to collaborate with domestic and foreign institutions in academic affairs but these joint-venture study programmes are not to exceed the total targets established by the universities themselves; to determine additional income for employees but the levels of this income source must accord with the internal expenditure regulation agreed on by the 
university's employees; to decide on the use of revenues but the net revenues must be allocated to the capital fund, the reward fund, the welfare fund, the reserve fund for income stabilization and the student assistance fund, in which at least 25 per cent is deducted for the capital fund and the deduction amount for others is determined by universities' rector in accordance with the internal expenditure regulation.

The issue of Government Decree 86 (2015b) stipulating the adjusted tuition fee schedules for public universities continues to reflect the increased "socialization" of higher education services. Accordingly, the tuition fees for public education at selffinanced universities are determined based on economic and technical standards and cost norms while the tuition fees for public education at partially state-financed universities are sourced from both government and students with the aim of reducing state subsidies for public universities.

In conclusion, Vietnam's autonomy policies have been through some crucial evolution to reach where they are now: autonomy is very limited in many aspects of management and largely shaped by the socialist-oriented market path dependence in which the triumph often belongs to the supposedly old thinking. Determined by the socialist elites whose preferences are bound by the desire to maintain absolute power, which is, however, tremendously threatened by the exhaustion of resources and legitimacy due to the regime's flawed economic structure and inherent problems of cronyism and corruption, the autonomy policies are utilized as a strategic instrument to mobilize resources indispensable for the socialist survival. Autonomy is thus featured by the inclination towards commercializing and privatising public services through entitling PSDUs to widening structures of incentives to revenue generation. In this connection, the autonomy policies do not necessarily reflect a retreat of the party-state, but instead a new form of interventionism that allows the party-state to harness resources and legitimacy to preserve the communist dictatorship. This means that the autonomy reforms serve only as a myth. On the surface, these autonomy reforms are adopted ceremonially by the communists because they are believed to improve the legitimacy of the socialist regime. In reality, these reforms are tailored to the communists' own preferences - preferences that are highly self-interested and anti-reformist. The next chapter will explore how the autonomy policies are perceived and practised on the ground. 



\section{CHAPTER 7}

\section{AN INSTITUTIONAL ANALYSIS OF THE AUTONOMY PRACTICES OF VIETNAM'S PUBLIC SERVICE DELIVERY UNITS}

This chapter presents a cross-case analysis of the empirical data in relation to the perceptions and practices of autonomy among hospitals and universities in Vietnam. The main purpose is to understand how autonomy is perceived and practised in three main aspects of management within hospitals and universities: finance, personnel, and organisation of service provision. These perceptions and practices are justified and analysed in the light of the institutional context against which autonomisation takes place. Accordingly, formal rules and informal norms and values that shape the perceptions and practices of autonomy will be carefully considered. The analysis of the empirical data helps the researcher form two primary research findings: the autonomy of PSDUs is bound by a system of formal and informal rules and norms and cultural values; and autonomisation induces rent-seeking and corrupt behaviour among PSDUs. These two research findings are elaborated in detail in the following:

Autonomy is bound by a system of formal and informal rules and norms and cultural values.

The previous chapter shows that varying degrees of autonomy have been formally assigned to PSDUs in financial management, payroll, organisational apparatus and task performance. The chapter also shows that the party-state, whilst delegating power and authorities to PSDUs, imposes many forms of regulatory control on PSDUs. This section examines the actual autonomy practices of public hospitals and public universities in these key areas. It finds that the actual autonomy that public hospitals and public universities experience is bound not only by the formal control through a set of rules, regulations, norms, and criteria but also by the informal control and command as well as informal norms and cultural values within which PSDUs operate. It also reveals challenges hospitals and universities have been encountering as well as strategies and tactics (both positive and negative) that hospitals and universities have been using to cope with their limited decision space.

\subsection{Financial management}

The financial autonomy (and control) of PSDUs is mainly associated with fees and charges, spending, and the use of net revenue. With respect to autonomy (and control) in these financial dimensions, considerable variances between fully and partly self- 
financing PSDUs have been observed. The following sections discuss these dimensions in detail.

\subsubsection{Fees and charges and state subsidy}

Fees and charges are the main non-budgetary source of revenue of PSDUs. All the six PSDUs in this study, whether fully self-financing or partly self-financing, are subject to the partial user-fee policies prescribed by the state even though at the time of interview the new user-fee schemes have been introduced to incorporate the various cost components. It is widely accepted among employees that the stringent caps on hospital charges and tuition fees are significantly restraining their financial capability, leading to the limitation in the reinvestment for the improvement of service quality. As interviewees put it:

"The revenues of our hospital are inadequate because it is subjected to the state-prescribed hospital fees and charges. Although the hospital is funded by the state budget, its financial demand is huge. The reinvestment of our hospital is limited as a consequence" (a deputy director of hospital B).

"Our university is keen to invest in high-tech and equipped laboratories for students, but we need to increase the tuition fees for the investment and maintenance. Some universities can invest in high-tech equipment but refrain from allowing students to practise on the equipment due to the fear of incurring costs for major repair. Meanwhile, a number of universities do not have enough money to invest in equipment and laboratories. The Vietnamese students are strong in theory, but poor in practice and technology as a matter of fact" (a deputy director of university F).

In particular, the state-prescribed user-fees are regarded irrational for fully selffinancing units such as hospital A and university D because the user-fees does not adequately consider the distinction between fully self-financing and partly selffinancing service delivery units. The partial user-fees place hospital A and university $\mathrm{D}$ at a disadvantage compared to partly self-financing PSDUs which are subsidised by the state for some of the uncovered parts of the operating costs including wages and depreciation.

The partial user-fees are also unfavourable to hospital $\mathrm{C}$ because the cost components included in its service charges are regarded lower for district-level units. As a consequence, the hospital's service charges are stipulated to be lower than those of the 
higher-level hospitals even though the costs of services, particularly the costs of drugs, electricity, and water are similar for both lower- and higher-level units (interview with a personnel manager).

The low and irrational caps on user-fees have sparked a lot of reactions and resulted in a variety of fraudulent practices among PSDUs. A deputy director of hospital C confirms the hospital's failure to meet the ratios of medical practitioners per bed within the revenue boundary:

"The hospital is assigned 235 beds by MOH. To satisfy the standard prescribed in Circular 08 regarding the minimum medical practitioners per bed, the hospital needs to have 255 employees but currently, it has only 217 employees on its payroll. If the hospital recruits more employees to correspond to the assigned beds, it cannot ensure the additional income or any other additional incomes for its employees other than the basic wage".

Equally, the caps on tuition fees, coupled with the control of student admission (number of students/a lecturer introduced by MOET Circular 32 in 2015) are believed to lead many universities to distort their number of lecturers on their payroll through signing fake contracts with outside lecturers in order to be able to admit more students to generate revenues (interview with a deputy director of university D).

It is fascinating to know that while the state applies partial user-fees to all types of PSDUs, it does not entirely guarantee that the state subsidy allocated to partly selffinancing units, which is based on a system of norms (định mức) (i.e. number of assigned beds and permanent employees for hospitals; student admission targets, number of permanent employees and campus sizes for universities) can supplement the uncovered part of the service costs. A deputy director of hospital $\mathrm{C}$ reveals that the state budget allocated to the hospital accounts for around 20 per cent of its operating expenses and the state budget only covers 20 per cent of its payroll. In this connection, a deputy director of university E refers to a dilemma: "the state assigns staff norms, but the state does not ensure sufficient funds for the pay".

The inefficient allocation of the state budget is attributed to not only the system of state-specified rigid norms but also a system of top-down distribution in which the distribution of funding and resources is heavily influenced by the "applications grants" mechanism, literally known as the "asking-giving" mechanism (cơ chế xin cho). The "applications - grants" mechanism is the Vietnamese popular public finance 
phenomenon reflecting the centrally-planned approach to budgeting. Accordingly, the state budget is distributed only when public units request (ask) and are subsequently approved (given) by higher-level authorities. This ad hoc approach to budget planning and distribution is believed by some respondents to distort the relationship between public units and their state management agencies and in some cases results in the abuse of power and bribery (interview with a deputy director of university E).

The pressure to generate sufficient revenues as a result of the partial user-fees and the inefficient state budget allocation is said to be huge among the six studied units. As some statements illustrate:

"The challenge is that the state leaves the hospital to live on its own financially. At present, we are under loans to build our facilities.... The competition among hospitals is huge which puts us under great pressure in the sense that we have to maintain sufficient patients to secure enough revenue" (a deputy director of hospital A).

"Autonomy brings more burden on managers, requiring their competence and leadership to improve. As with other services, health care needs to be more customer-oriented and autonomy is to be conducted towards this end. Otherwise, service users will opt for other health care facilities" (a personnel manager of hospital A).

In this connection, a deputy director of hospital $\mathrm{C}$ exclaims: "to be able to survive, we have to increase our working time". The overload situation is actually taking place within hospital C:

“The hospital's doctors have to work double and only take leave in exceptional circumstances. Many doctors cannot take compensatory holidays. Some service faculties have only two doctors, whilst there are days when there are up to 20 patients. If one takes compensatory holidays, the other cannot manage" (a personnel manager of hospital C).

In this respect, a personnel manager of university D makes an outspoken remark: "the current autonomy mechanism proves to be very difficult for PSDUs. This kind of autonomy is primarily meant to push PSDUs to be self-sufficient. It has no intrinsic values". 


\subsubsection{Spending}

The fully self-financing units such as hospital A and university D are granted autonomy in determining the operating expenses, be they higher or lower than those set by state competent agencies. According to a finance manager of university $\mathrm{D}$, this discretion enables the university to realize the strategy of maintaining a low number of permanent lecturers while being able to pull more prestigious and well-qualified lecturers from various disciplines. The university sees this an advantage, especially when considering that the state-specified payment levels for outside lecturers are low and fail to align with the market. Meanwhile, the partly self-financing units such as hospitals $\mathrm{B}$ and $\mathrm{C}$ and university $\mathrm{E}$ and $\mathrm{F}$ are not allowed to spend more than the statestipulated expense levels in this respect.

Like operating expenditure, capital expenditure represents a significant difference between these two types of PSDUs. While partly self-financing PSDUs have to submit plans or projects to the state management agencies to obtain their approval for the purchase of valuable equipment and for major repair and maintenance (interviews with finance managers of hospital B and university E), fully self-financing PSDUs can decide procurements based on their requirements, but they must consult the state management agencies regarding the procurement of fixed assets worth over one billion VND (interview with a finance manager of hospital A).

Nevertheless, both fully and partly self-financing units are subject to the government's provisions regarding the maximum spending level when it comes to the expenditure of some items concerning using cars (Decision 32/2015/QD-BTC), telephone equipment at home and mobile phones (Decision 78/2001/QD-BTC), the regime for traveling per diem and the organisation of conferences (Circular 97/2010/TT-BTC), the regime for overseas-travelling per diem (Circular 102/2012/TT-BTC), and the regime for receiving foreigners and for the organisation of international conferences (Circular 01/2010/TT-BTC). Most of these spending norms (định mức chi tiêu) are considered to be "irrationally low", illustrative of the legacy of the centralised planning model which is still ingrained in the governance system (interviews with a finance manager of hospital A, a deputy director of university D).

Respondents believe these spending norms are "unrealistic" because they are determined in line with the state-stipulated basic wage, which itself is regarded "low" and "not down to earth" (interviews with a deputy director of university D, a deputy director of university E). Indeed, the basic wage for state employees and civil servants 
has been adjusted over the past years to meet the rising living costs (the most recent is stipulated in the Government Decree 47/2016), but there are still substantial gaps between the wages of state employees and civil servants (equivalent to the basic wage multiplied by a coefficient corresponding to the employee's position and scale) and the living standards and expenditures (see Bruynooghe et al., 2008; Poon, Nguyen, \& Do, 2009).

Many respondents confirm that this system of norm-based spending control has induced negative tactics from PSDUs. For instance, the state provides a spending cap on receiving visitors, but this cap is low and insufficient. Consequently, universities must make up a virtual number of visitors higher than the actual number. Similarly, a low spending cap is placed on travels, and as such universities invent a fake number of travel days as opposed to the real one. "So this system is mock. MOET overlooks these frauds even when the ministry is aware of them", a deputy director of university D says bitterly, "this system is not operational in the sense that regulations are ostensibly respected but fraudulent acts are used to counteract unrealistic provisions". In addition to the sets of rules and norms based on which the party-state can directly control PSDUs, the state imposes some forms of informal control on all types of units, including fully self-financing units assigned autonomy in a number of spending items. The informal control is maintained through the existence of a Party Committee within each PSDUs, organised on the principle of democratic centralism which acknowledges the freedom of members of the political party to discuss and debate matters of policy and direction, but expects all members to uphold the final decision once it is made by majority vote. Under this principle, no party member can stray from or criticize the party line when a decision has been made. With this organisational principle in place, the party-state requires that all types of PSDUs establish their own internal expenditure regulation (quy chế chi tiêu nội bộ). This internal expenditure regulation is required to conform to the state-stipulated operational spending levels. The spending level of the items not regulated by the state is required to be jointly established and agreed on by all employees. According to a deputy director of hospital $\mathrm{C}$, this rule significantly weakens the decision-making power of the heads of PSDUs:

"There is no mechanism in place to entitle the heads of PSDUs to pay for its employees. The internal expenditure regulation is developed by all members of the units in compliance with the state regulation. The mechanism needs to be changed by giving the heads the right to pay employees". 
The party-state also maintains its control of PSDUs' spending by requiring them to deposit their budgetary and non-budgetary revenues at the State Treasury. Many respondents claim that this requirement originates from the fact that the state regards fees and charges as accruing to the state budget although PSDUs can retain this source of revenues. Accordingly, the expenditure of PSDUs, be they fully or partly selffinancing, is administered by the State Treasury. For PSDUs in this research, this form of control causes a delay in their spending:

"The hospitals' revenues, from any sources, have to be deposited at the Treasury and as such, they have to apply to the Treasury for any spending item. The Treasury monitors the spending of PSDUs through checking whether the spending is appropriate to the units' internal expenditure regulation. The settlement time by the Treasury is generally slow, taking up to one week as compared to only one day if that is settled by a bank" (a finance manager of hospital A).

That fees and charges are treated as state budget revenues has discouraged their efficient use by PSDUs. To some respondents, this demonstrates the lack of an appropriate legal framework for autonomy to be realized effectively:

"The use of state budget cannot be as efficient as that of universities themselves. At present, universities have to apply to the State Treasury for any of their spending items, and as a consequence, their responsibility for spending becomes weak. In general, the state gives us autonomy but the state has yet to create an effective legal framework for autonomy implementation. It is, therefore, necessary to have separate rules applied to fully and partly selffinancing units and these rules should enable units to manage their budget like the way businesses do" (a deputy director of university D).

\subsubsection{Use of net revenues}

PSDUs are entitled to retain their annual net revenues but under the autonomy mechanism, they must establish a capital fund, a reward fund, a welfare fund, a reserve fund for income stabilization and an additional income fund corresponding to the statespecified deduction percentage. A minimum deduction level from net revenue for the capital fund is stipulated for each type of PSDUs. A cap on the reward fund, welfare fund, and additional income fund is also specified for each type of PSDU. In this regard, there is a variation in the degree of autonomy between fully and partly self- 
financing PSDUs. Fully self-financing hospital A and university D are allowed to set up additional income funds at their discretion: "there is no restricting cap on the fund, the more revenues PSDUs generate, the more additional income their employees are paid" (a finance manager of hospital A). Subsequently, hospital A deducts a minimum of 45 per cent and a maximum of 60 per cent out of the net revenue for the additional income fund (interview with a finance manager). University D does not specify any restricting cap on the annual additional income of its employees (interview with a finance manager).

Unlike fully self-financing PSDUs, partly self-financing PSDUs are subject to the regulations relating to the maximum deduction for the additional income fund. Decree 16 stipulates that the additional income fund must not exceed twice the annual basic payroll. In accordance with the rule, university $\mathrm{E}$ and university F place a cap on their additional income fund, which is twice their basic payroll (interview with finance managers of university $\mathrm{E}$ and university F). As for hospital C, because its net revenue is limited, the monthly additional income payment for employees makes up roughly 40 per cent of their annual basic payroll (interview with a personnel manager).

Unlike the other PSDUs in this research, hospital B's actual practice does not conform to the rule regarding the payment of the additional income for its employees. According to a finance manager of hospital B, the payment of additional income is mostly based on its revenues and the hospital imposes no restricting cap on the additional income fund. When asked why there is such a divergence from the rule, the respondent simply answers that hospital B is the largest public health care facility in the province and so the provincial authority has relaxed much of its control over the hospital. The respondent implies that the province is seen as one of the health care sector's leading pioneers, which may have been an influential factor in central government.

In the broader Vietnamese government system, this explanation is understandable given the tendency of local government to not follow the central rule and guidance especially when it has more power thanks to increasing self-sufficiency and a larger contribution to the state budget (see Painter, 2005; Vu et al., 2014). Furthermore, the influential "village culture" (văn hóa làng xã) is likely to contribute to the predominance of local rules over central laws and regulations. In Vietnam, there is a well-known proverb "the king's laws stop at the village gate" (luật vua thua lệ làng) which literally means that the king's laws lose out to village customs. Local 
government grows out of this tradition of village self-governance even though villages have never been recognized as an administrative unit of the state apparatus. This "village culture" contributes to the notion that while power is centralized, local government still have some influence on central laws and regulations and enjoy a certain degree of actual autonomy.

\subsection{Personnel management}

PSDUs' personnel autonomy is primarily represented in recruitment, appointment, dismissal, appraisal, and payment. The units' decision on these matters is, however, not extended to the heads and deputy heads of the units, since they are regarded as civil servants under the Law on Cadres and Civil Servants. The status of the head and deputy heads is thus distinct from other state employees of PSDUs (see section 3.1.1, chapter 2). Civil servants are under the authority of the state management agency while the management of state employees is delegated to PSDUs themselves. These regulations are represented in the de facto autonomy (and control) of six PSDUs studied in this research. Specifically, all the six hospitals and universities confirm that the recruitment, appointment, increase of ranks and grades, secondment, dismissal, and performance appraisal of their head and deputy heads are controlled by the state management agency - MOH for (central) hospital A and MOET for university D, E, and $\mathrm{F}$ and the Provincial Health Bureau for (provincial) hospital B and (district) hospital C. Senior lecturers (i.e. associate professors and professors) are also regarded to have civil servant status because the power of decision on their employment is reserved to MOET rather than the universities.

\subsubsection{Recruitment, appointment and dismissal of state employees}

Government Decree 16/2015 stipulating the autonomy of PSDUs and Decree 41/2012 providing for the determination of job positions (vị trí việc làm) within PSDUs prescribe that both fully and partly self-financing PSDUs are entitled to determine their annual payroll based on the structure of state employees and job positions (cơ cấu viên chức và vị trí việc làm). While fully self-financing units only need to inform the state management agency of their payroll plans, partly self-financing units must submit their payroll plan to the state management agency to obtain its approval.

The actual practice of PSDUs shows some forms of deviation from this regulation, to which existing rules and norms, prescribed by either central or local government, are attributable. Hospital A, is legally entitled to determine its payroll, recruit staff and receive employees transferred from other hospitals or provinces, but is constrained 
from doing so because of the MOH's assignment of bed norms (định mức giường bệnh) and staff norms (định mức biên chế) prescribed in MOH's Circular 08/2007 requiring the minimum number of medical practitioners per number of assigned beds: "Annually, $\mathrm{MOH}$ assigns the number of beds to our hospital. To determine the employment positions of our hospital, we still have to rely on Circular 08 regarding staff norms, which stipulates that level-1 specialised hospitals like us must have 1.35-1.4 staff per bed. Circular 08 obviously contradicts Decree 41 " (a personnel manager of hospital A).

The past and current regulations pertinent to downsizing, especially the most recent Decree 108 in 2014, which states that PSDUs are allowed to recruit only 50 per cent of the total number of leaving staff, also limit PSDUs from determining their payroll. As a personnel manager of hospital A comments:

"Recruitment is at our discretion, but we still have to consult MOH. If the ministry does not agree, this right cannot be exercised. For example, in 2014, the hospital notified the ministry of its recruitment. By then, we had made the employment announcement as well as the distribution and collection of job applications. However, in the last minutes, the ministry sent us an official correspondence requesting the hospital to stop the recruitment, reasoning that this is in response to Decree 71 on downsizing and the hospital needs to finalise the construction of its facility before carrying on with the recruitment. Until now, the hospital has not carried out any new recruitment yet".

Like hospital A, university D, which was assigned 300 teaching and administrative employees in 2010, was requested to stabilize its payroll in 2013 by MOET (interview with a personnel manager of university D). In the respondent's opinion, this is a typical example of the lack of de facto autonomy when the university, which self-finances its operating and capital expenditure, is, in principle, granted autonomy in determining its payroll. Referring to such discrepancy between de-jure and de facto autonomy due to the informal intervention of MOET, the respondent exclaims: "this example indicates half-hearted, formalistic and fake autonomy; the actual autonomy is not so much different from the independence within an iron cage".

The restriction on the payroll adversely affects the university's student admission because the number of students the university can admit, under MOET's Circular 32 in 2015, is determined by the number of permanent teaching staff (different 
coefficients applied to different qualifications), alongside the campus size of the higher education institution. The most recent number of students admitted to university D was 2,300, exceeding the permitted maximum number of student per lecturer. The university deals with its shortage of permanent lecturers by pulling more lecturers from off campus. This strategy has its own limitation since the university is not allowed to include these lecturers as part of its payroll, except when the university signs a minimum 12-month contract with these lecturers. The attached condition is that these lecturers must not be on the payroll of any state agencies and are committed to work only for the university. Up to the time of interview, university D can include only some dozens of these lecturers in their payroll whilst the actual number can be much higher. As with payroll, recruitment is promulgated by law to be at the discretion of such units as university D. However, the university must follow many provisions specified in a number of legal documents including decrees, circulars, and instructions. These provisions provide the detailed procedures and processes to ensure a proper recruitment, but, from the viewpoint of the respondents, following them requires lots of hard work and is not worth the effort in cases when a qualified applicant does not wish to take the job because of the low state-regulated basic wage and the modest additional income that the university can offer.

Like hospital A and university $\mathrm{D}$, the actual autonomy in recruitment and appointment of hospital B, hospital C, university E, and university F is more constraining than their legal autonomy. This is due to the existence of centrally- and locally-stipulated rules, norms, and criteria to which PSDUs are subject. Hospital B, for example, finds the centrally- and locally-stipulated recruitment criteria rigid although it has had some relaxed control from the provincial authority in terms of payroll. These state-regulated recruitment criteria are said to greatly restrict the hospital's discretion from developing its own criteria that can meet its own needs:

"Many central and local policies are constraining. For example, Decree 29/2012, instead of specifying conditions for PSDUs to build their own criteria, requires units to obey detailed recruitment criteria. As for the recruitment of nurses, hospitals are required to recruit only those that have university degree although hospitals can accept nurses that have diplomas as long as they are skilful and experienced. Locally-specified criteria are also rigid such as the prohibition of recruiting staff outside of the province or the rule of only 
recruiting those who have been working for PSDUs under temporary contracts" (a personnel manager of hospital B).

Hospital C also finds the recruitment criteria and procedures specified in Decree 29 inflexible. Specifically, the hospital must take every step and follow every provision in terms of application files, modes of recruitment, establishment of a recruitment council and an organizing board, time of filing, period of notice, and priorities. In the viewpoint of a personnel manager of hospital $\mathrm{C}$, this recruitment process is "timeconsuming, costly and unfavourable" in comparison with the one involving basic steps such as interviews, checking references and probation that is being applied by the more autonomous units.

The procedure in relation to appointment is not more facilitating than recruitment. A personnel manager of university F claims that "the appointment process is too lengthy. Following the process requires lots of hard work. Since the process involves meticulous steps, it indispensably results in shortcuts". The respondent gives the following example as an illustration: an officer is required to have good health to be promoted. To have good health, that officer has to "buy health", which implies that the officer who does not wish to undergo health inspection can give an "envelope" to a health practitioner to obtain a certificate of good health.

While both the central and local rules have already undermined the flexibility of PSDUs, their conflict arguably compounds the difficulties faced by units' managers. The conflict, in most cases caused by localism (chủ nghĩa địa phương), which is likely to result from the unclear division of functions and responsibilities between central and local government, is demonstrated through the tendency of local government not to follow central guidance or to issue regulations contradictory to those of central government (Vasavakul, 2002, 2001). As a personnel manager of university F claims:

"The legal normative documents with respect to the management of employees have conflicting details. For example, the Party has a resolution on the personnel work; ministries have their own documents providing guidelines for their vertically managed sector, and provincial party committees also elaborate more details in their instruction guiding their supporting agencies. As a result, although these documents follow a directive from the higher authority, they may prescribe different approaches to doing one thing”. 
The conflict between central and local rules also might suggest that some local governments have more latitude than others in implementing central laws and regulations and in experimenting with local strategies (Litvack \& Rondinelli, 1999). Besides the increased power of local government and the "village culture" mentioned in the previous section, Vietnam's government organisational structure which is highly fragmented and characterised by the increasing level of fiscal and administrative decentralisation (Painter, 2005; Vu et al., 2014) can help explain the conflict. The fourtier government system from the central to three sub-national levels creates the possibility that the outcomes of central policies are subject to the local discretion. Localities tend to focus on developing their own policymaking power in the absence of incentives and mechanisms to cooperate for more effectual policies.

In this regard, the recruitment of temporary employees in hospital $\mathrm{C}$ is a case in point. Central rules (i.e. Decree 16/2015) stipulate that contracting employees on a temporary basis is at the discretion of PSDUs. This recruitment approach has been utilized by some PSDUs as the solution to the temporary manpower shortage. Nevertheless, PSDUs including hospital C subject to the Provincial People's Committee's Directive 30 , can do so only with the provincial authority's approval on the structure, number, positions, and titles of temporary recruits. The issue of the Directive is perceived to limit temporary recruitment among PSDUs in response to the alleged continuation of contracts even when there is no longer demand for such temporary employees. The effect of the Directive is to discourage the hospital from recruiting temporary employees other than permanent employees with whom it cannot terminate the contracts when their job positions are no longer needed and for whom it must ensure a lifetime career (interview with a deputy director of hospital C).

The recruitment, as well as the appointment and dismissal of state employees, are influenced and constrained not only by formal rules but also by informal factors, of which the most notable is nepotism and cronyism. Some respondents believe these forms of favouritism are the norms in Vietnam's public sector. The indication is that the practice of favouring members of the family, friends, and associates is deeply entrenched in the system to the extent that it has become normal behaviour. For example, in hospital B, nepotism and cronyism are persistent in the recruitment and appointment, meaning that positions have been granted to family members or friends because of connections rather than credentials or experience. These practices are 
perceived to be unfair since they give undue advantage to those who do not necessarily merit these treatments:

"Favouritism is rampant in health care service faculties. These faculties have to recruit the qualified doctors as well as the unqualified ones. The unqualified receive the same incomes and additional incomes as the qualified. In every health care service facility, there are always some jobs such as managing records that can be assigned to the unqualified doctors" (a doctor of hospital B).

It is worth highlighting that the recruitment and appointment of relatives and associates are sometimes imposed on the Personnel Department of hospital B by the hospital's rectors and the higher-level authority. The hospital's autonomy in merit-based recruitment and appointment is consequently greatly affected:

"It is sometimes difficult to avoid nepotism and cronyism in our recruitment and appointment decisions. Our hospital values meritocracy, but we still have to place unfit persons in some certain positions. In some cases, the Personnel Department has to follow the command of our director/deputy directors and/or the higher-level authority" (a personnel manager of hospital B).

A deputy director of university D shares this idea when saying that "nepotism and cronyism have become unwritten rules in the Vietnamese public sector. The rule of law principle is in many cases breached because people in power still grant positions in PSDUs to their children and networks". A personnel manager of university F regards nepotism and patronage as the most important informal criteria in recruitment and promotion, referring the problems to the Vietnamese popular saying "descendants come first, relationships second, money third, and knowledge fourth" (nhất hậu duệ, nhì quan hệ, ba tiền tệ, bốn trí tuệ).

The value of sentiments over reasons (trọng tình hơn lý) and the cultural belief that "a bad compromise is better than a good lawsuit" (dĩ hòa vi quý) are construed by some respondents as the major informal factors that affect PSDUs' decisions on personnel matters including dismissal. These cultural values reflect the oriental way of thinking which is itself underpinned by Confucianism and Buddhism. The core of these ethical, philosophical and religious systems is humanistic, which emphasises that legal rules are subordinate to moral and pragmatic expediency. A case in point is university $\mathrm{E}$ whereby the dismissal of lecturers in French and Russian language is a formidable task 
even though the teaching of these languages has become redundant in the current time. Decree 29/2012 specifies circumstances in which PSDUs can terminate an employment contract with state employees if they do not accomplish their tasks during two consecutive years or if their skills are no longer needed. This rule is, however, difficult to be enforced in practice because the spirit of the policy may not resonate with the cultural values of real life:

"When a lecturer has been recruited, he/she cannot be easily dismissed. For example, in response to the social needs at some certain points, the university recruited a few lecturers to teach Russian and French, but so far when the social demands have dropped, the university continues to employ them and transfer them to other faculties/departments of the university. The university does not fire them because of the long-time devotion they have made to it. The state's downsizing policy stipulates that lecturers achieve a foreign language standard to be able to take a test to become permanent employees. If they do not meet the standard, they still can work for the university under a temporary contract. Their benefits are the same. The only difference is that they are not promoted. In reality, many staff who are under temporary contract can work for the university for a long time" (a deputy director of university E).

\subsubsection{Performance appraisal, wages and additional income}

Alongside recruitment and appointment, performance appraisal of state employees is at the discretion of the heads of PSDUs. Interviewees discussed the emergence of performance-based appraisal and payment of additional income in PSDUs. For example, task achievement has been regarded as a criterion for the appraisal of employees at hospital A:

"On a monthly, quarterly and yearly basis, we carry out appraisals of our employees. Accordingly, deputy heads of the hospital appraise heads of departments, and heads of departments appraise their subordinates. The payment of additional incomes for employees is therefore based on not only their qualification and position but their task achievement as well" (a personnel manager of hospital A).

At university F, performance has been taken into account in the payment of additional income for employees. An interview with a personnel manager of university F shows that the evaluation of employees' performance is contingent mostly upon their job 
accomplishments and strict compliance with professional regulations and partly upon their active engagement in other activities of the university. In particular, the final evaluation outcomes are determined by employees' self-evaluation, the assessment of the employees' line manager and of the university's evaluation committee, and the students' course feedback.

Despite the emergence of performance-based pay, the practice is generally formalistic because the basic wage has already been prescribed by the state according to employees' positions or grades. This state-stipulated basic wage scheme emphasizes the equality of income at the expense of salary differentiation between grades. The differential between wages for lower- and higher-level positions is arguably too small to be a meaningful incentive (Bruynooghe et al., 2008; Poon et al., 2009). There may be an ideological component to this wage scheme: the socialist orientation that gives primacy to equality.

Performance-based pay also makes little difference to salary margins between employees of the interviewed PSDUs. Hospital C, for instance, pays its employees additional incomes relatively equally with a view to "encouraging every employee" (interview with a deputy director). For university D, employees' task achievements are supposed to be appraised at functional departments/teaching faculties every month and, in principle, the university pays more for those who have better performance, but this is not implemented consistently or frequently (interview with a personnel manager of university D). As for university E, it is difficult to realise performance-based pay in practice because the university applies a "soft" approach to appraising its employees given the "educational environment" (interview with a personnel manager of university E).

A few respondents contend that the basic wage and additional income payment mechanism trumps seniority, which rewards employees for their length of time serving the organization, and egalitarianism (chủ nghĩa bình quân), which aims to treat employees equally irrespective of the variances in performance. This approach to payment has been regarded as a disincentive to employees' productivity:

"Many of our employees think that however much or little they work, they still receive the same basic wage and a certain amount of additional income. There is no mechanism in place to pay basic wage to employees based on their productivity. Meanwhile, a number of employees still receive additional income (though the rates are a bit less) despite not satisfying their job 
requirements. Our hospital has therefore not been able to encourage the working spirit of its employees through its pay mechanism" (a doctor of hospital C).

The legacy of centralised planning and state subsidy (tập trung bao cấp), in which targets were set in details and expenditure subsidised fully by the state, is thought to be deeply ingrained in Vietnam's state agencies including PSDUs. Consequently, dependency and passiveness are found to be relatively common among employees of PSDUs. A deputy director of university D notes that "autonomy means creating a democratic working environment, but this is significantly constrained due to the employees' mindsets which are still shaped by the long-lived subsidy mechanism". A financial manager of university $\mathrm{F}$ refers to the line ministry mechanism as a typical legacy of the central planning model to which universities have been long exposed. The respondent emphasizes centralised planning as a cultural value entrenched in the mind and heart of state employees and strongly conditioning their behaviour. A doctor of hospital $\mathrm{C}$ points to the low productivity as a direct consequence of the culture of centralised planning, stressing that such counter-productive behaviour becomes notable especially when an effective pay mechanism is absent:

"The productivity of a faculty in our hospital is only 50 per cent because its employees do not want to treat certain patients. They occasionally refer patients to the higher-level hospitals with the pretext that those cases are beyond their capability" (a doctor of hospital C).

\section{Autonomisation induces rent-seeking and corrupt behaviour among public service delivery agencies}

The previous chapter demonstrates that the autonomisation of PSDUs is primarily associated with the process of switching costs from the state to service consumers. As such, the autonomy policies provide strong incentives for PSDUs to generate alternative non-budgetary revenues to substitute for the reduced state subsidy. The first section in this chapter further confirms that there is a considerable difference in the actual autonomy between fully self-financing and partly self-financing units with respect to such financial dimensions as capital mobilisation, spending and use of net revenues. This difference suggests that the party-state incentivized PSDUs that do not rely (or rely less) on the state budget by offering them the greater flexibility in generating and allocating revenues and the greater additional income for employees. The following section shows that this policy intention has greatly induced the rent- 
seeking and corrupt behaviour among PSDUs, thus resulting in a propensity for the rapid, aggressive and unregulated commercialisation of public services.

\subsection{Organisation of service provision}

When it comes to the organisation of service provision, there are significant divergences between health care and higher education. The propensity for the commercialisation of health care services because of the prevailing rent-seeking behaviour among hospitals emerges as the most serious issue whereas within the higher education service, the rent-seeking behaviour constitutes just one of the many governance issues the sector is facing. These divergences reflect the different nature of the two service sectors as well as the considerable differences in the party-state's treatment of the two services. While the organisation and provision of health care services seem to be largely delegated to hospitals, that of higher education is strongly controlled by the party-state. These two service domains will be discussed separately in the following.

\subsubsection{Health care}

\subsubsection{Two-tier clinical services and charges}

Decree 85 stipulates that both fully and partly self-financing PSDUs are allowed to elaborate working plans specifying targets and tasks of the assigned services and of the services designed by the units. While the state maintains some forms of control of the units' service activities (fully self-financing PSDUs report plans to the state management agency while partly self-financing PSDUs submit plans to the state management agencies for approval), this regulation has resulted in a great delegation of power to PSDUs on the ground. Thus, all three hospitals in this study are found to provide the "patient-requested" services (dịch vụ theo yêu cầu) alongside the normal services assigned to them by the state. While the state imposes stringent caps on normal services, no caps are applied to non-core services such as "patient-requested" services (interview with a deputy director general of $\mathrm{MOH}$ ).

Asked whether there is any fundamental difference in the quality of care, respondents answer that the difference between the two types of services is that the "patientrequested" services are topped up with better-equipped hospital accommodation (e.g. air conditioner, heater, television) and hygienic facilities, advanced medical equipment, greater choices of medical practitioners and surgery dates, less waiting time. The "patient-requested" services do not necessarily imply better-qualified medical practitioners because there is no big difference in the qualification of medical 
practitioners of the People's Medical Service Faculty (Khoa Khám Bệnh Nhân Dân) which provides normal services and the "Patient-requested" Medical Service Faculty (Khoa Khám Bệnh Yêu Cầu) which provides “patient-requested” services. Following are some typical illustrations of the two-tier clinical services and charges:

"There are two service delivery systems in a public hospital: normal services and "patient-requested" services. The wealthy people receive better care and treatment. This is obviously a discrimination, demonstrating the lack of humanity. "Patient-requested" services can offer air-conditioned rooms, private rooms, private toilets etc.... This puts a lot of pressure on the patients' family to provide a better care for them" (a personnel manager of hospital B). "Patient-requested" services are distorted in two respects: (i) there is no such demand for "patient-requested" services, but patients are forced into using those forms of services and (ii) there is no basis for the establishment of charges of "patient-requested" services. Individuals who force patients into using "patient-requested" services and who determine the charges of "patientrequested" services must know that their behaviour is distorted but they still do so collectively and so the responsibility is collective" (a deputy director general of $\mathrm{MOH})$.

As the "patient-requested" services provide top-ups, the main revenue source of this type of services is from the out-of-pocket expenses of patients - those are "anxious and impatient" and "want to go straight to the patient-requested services" (interview with a doctor of hospital B). Meanwhile, patients with state health insurance mostly choose to use normal services. There is no significant imbalance in the number of patients of the two types of services for lower-level hospitals, but this is not the case for the topspecialty central-level hospitals where "the "patient-requested" services are always in great demand from patients rushing from various provinces for better medical care" (interview with a doctor of hospital B).

Some respondents of the three hospitals contend that the development of two-tier services and charges is utilized as a mechanism for generating revenues by hospitals. Interestingly enough, respondents refer to the "patient-requested" services as the "advanced services" or "quality services" and the concentrated investment in these services can help the hospital generate revenues: 
"If hospitals provide many high-quality services, they will attract a lot of customers and raise more revenues as a result. Hence a number of hospitals utilize the "patient-requested" services by pulling most of their resources to invest in the highly-priced and high-tech "patient-requested" services to be able to generate revenues" (a personnel manager of hospital B).

Most important is that such development of two-tier services and charges is said to be popular with health care facilities. It is characterised as the health care sector's "systemic issue" which is "driven by money at the expense of humanity" (interview with a personnel manager of hospital B). It is construed as "the shortest way to undermine the public goods" (interview with a personnel manager of hospital B). The "patient-requested" services are likened to a distorted form of service provision and a deflection of the autonomy mechanism given that there is no sound foundation for the prices of such services and there is no request on the part of service users but forces to use such services on the part of service providers (a deputy director general of $\mathrm{MOH}$ ). The entitlement to provide the patient-requested services explains for itself the reason why a large majority of hospitals are "desperate for autonomy". Since the "patientrequested" services help generate an important source of revenues, hospitals tend to place greater weight on "patient-requested" services than on normal ones. A financial manager of hospital A especially connects financial gains to the increased investment in the "patient-requested" services in claiming that "because the current demands for the advanced services are huge, hospitals can become financially autonomous by focusing on this type of services". A deputy director of hospital B emphasizes the needs to improve the "patient-requested" services to respond to the increasing demands from the better-off customers:

"Patients who use state health insurance card can only access services of a limited quality level. Those who want higher quality services must use other packages, such as the ones offered from "patient-requested" services. It is common that affordable customers opt for better quality service packages while others use less advanced services. Equality is hard to achieve in any society. Our hospital must meet all patients' needs, especially the need to access quality services of the wealthy. Our hospital has established a marketing department to be able to frequently survey the patients' needs".

Driven by the strong desire to maximise revenues, hospitals are perceived to push their service users to use the patient-requested services. Hospitals do so through a range of 
tricks and tactics that they can make up in dealing with their service users. For example, doctors may manipulate patients through some of these statements or suggestions: "the state beds are already occupied, the "socialised" beds are the only option" or "no "patient-requested" operation, then no high-technique, advanced equipment or golden hands" or "if you want prompt services, you need to choose the "patient-requested" services" (interview with a personnel manager of hospital B). Even the most difficult district-level hospitals in deep and remote areas where a majority of residents are social welfare dependents manage to offer the "patientrequested" services. With the power of a provider in the service area of which users often have little understanding, hospitals can easily entice their patients to use the "patient-requested" services at their will. Furthermore, hospitals can leave their service users in the situation whereby the "patient-requested" services are the only option because the normal service system is often left in decay:

"When the doctor says that this case must use the "patient-requested" services, patients have no option but to follow his/her suggestion for the non-patientrequested services are featured by the dilapidated buildings, the peeling walls, the rickety beds with each bed shared by multiple patients while the "patientrequested" services can supply each patient a cosy bed, nice room and clean facility" (a personnel manager of hospital B).

As the rents from "patient-requested" services are believed to be a significant source of incomes of hospitals, all public hospitals are reported to engage in providing such form of services. According to a deputy director general of $\mathrm{MOH}$, the systematic involvement in the provision of "patient-requested" services indicates that "there are very important persons who agree to such provision" notwithstanding "a corrective correspondence in which $\mathrm{MOH}$ requests public hospitals reconsider the form of services". The respondent points to the collective responsibility as a shield from the risk of punishment that leads individuals to provide "patient-requested" services and forces households to use this form of services even though they may be aware that such service provision is a form of abuse and a distortion.

\subsubsection{A systemic distortion of medical services}

Decree 85 stipulates that health facilities are entitled to decide measures to implement their plans and $\mathrm{MOH}$ provides the professional guidelines and technical protocols and procedures. In practice, the three hospitals differ in terms of the choice of the technical protocols and procedures of medical examination and treatment. In (central) hospital 
A and (provincial) hospital B, service faculties can decide by themselves whether to develop their own technical procedures of medical examination and treatment and technical protocols for medical diagnosis and treatment or to apply the MOH's protocols and procedures (doctors of hospital A and hospital B). Meanwhile, (district) hospital $\mathrm{C}$ has more limited discretion in this respect. The hospital must follow a number of professional regulations and procedures such as consultancy procedures and emergency procedures provided by $\mathrm{MOH}$ and central-level hospitals. Lower-level hospitals, from the perspective of a doctor of hospital C, are not allowed to develop their own professional procedures but are able to bypass these procedures only in cases under their control. In the respondent's view, the strict compliance with professional procedures is essential to hospital $\mathrm{C}$, given the generally low qualification of its doctors and the inability of its senior doctors to take full control due to their high working pressure.

Despite the presence of the technical protocols and procedures, all the three hospitals in this research are found to distort their health care services to maximize revenues. The medical services are distorted primarily through such practices as the overprovision of therapies and tests, the overuse of high-tech equipment, the increase in the length of stay, and the overprescription of drugs. According to a doctor of hospital A, it has become a popular practice that doctors exaggerate patients' diseases to be able to provide more services. A doctor of hospital B demonstrates that doctors can determine the diagnosis and treatment protocols and as such doctors can suggest patients undergo numerous high-tech diagnostic tests and therapies, many of which might be not so relevant. Since much of hospitals' facilities including high-tech equipment is procured from investments by their employees and external partners on a profit-sharing basis, doctors often have the stimulus to prescribe the usage of these privately-owned facilities (interview with a personnel manager of hospital B).

A personnel manager of hospital B identifies the doctor-patient relationship with asymmetric information whereby the doctor has relevant information that the patient lacks and thus can manipulate the patient into obeying the doctor's diagnoses and prescriptions. As the following statement illustrates:

"For the purpose of generating revenues hospitals may breach a health care examination procedure through adding and missing some steps to increase revenues and reduce expenditure respectively. Take the appendicitis surgery as an example. The surgery regularly involves ultrasound, but because 
hospitals have installed a CT scanner so the surgery involves CT scan as well although it is not necessary; the technical procedure does not have this step. Patients do not know anything about the procedure but follow the treatment steps provided by doctors. Consequently, it is patients who suffer from not only financial loss but also health damage" (a deputy director general of $\mathrm{MOH}$ ).

A notable sharing of a doctor continues to reveal how doctors manipulate patients into taking numerous tests and therapies. The interesting thing is that the degree of service overprovision is based on patients' ability to afford the extra charges. As such, patients who appear able to afford more are more likely to be offered unnecessary tests and therapies:

"When examining patients, doctors may come up with several diagnoses and suggest associated tests that patients can choose to take. For example, if patients have chest pain, doctors may suggest some causes in their order of importance: the first is pneumonia, the second heart disease, and the third muscle pain. It is up to patients' affordability to take all of the related tests or alternative tests. To be straightforward, overprovision of services is certain. When carrying out an examination, it is necessary to identify several causes. But in case doctors already know for sure that pneumonia is the most probable cause, they still offer patients tests related to others. It is important for patients that pay fees by themselves to undergo every test to guarantee the absolute safety" (a doctor of hospital B).

Asked how doctors can judge the patients' affordability, the respondent answers that doctors often suggest patients taking some tests and therapies in their order of priority. The affordable patients can take all the suggestions whereas the less affordable can take suggestions step by step. The provision of medical services is even compared to the sale of Phở (noodle soup) in that customers cannot grab delicious Phở unless they can afford it. There are many cases in which doctors frankly ask about patients' affordability:

"Because it is all about out-of-pocket expenses, we need to be frank with our patients by asking them whether they can afford to pay for a test or therapy or how much money they have so that we could decide the service to be provided. Technically, we provide the services for which patients say they can manage to pay" (a doctor of hospital B). 
Besides the overprovision of tests and therapies and the overuse of high-tech equipment, the increase in patients' length of stay in hospitals is the other tactic hospitals often use to generate revenues. A personnel manager of hospital B gives an example: "patients can be discharged after 3-5 days, but they are often kept to stay in hospitals longer".

Overprescription (e.g. prescription of expensive imported drugs) also is the practice believed to be prominent among public hospitals especially the central-level ones, since "doctors can prescribe any drug they want to":

"Drugs made in Vietnam or India cannot be compared to those from France or Germany. For minor diseases, domestic drugs are regularly prescribed, but sometimes even when patients' diseases are not severe, doctors might prescribe more expensive, imported drugs" (a doctor of hospital B).

The factor leading doctors to overprescribe expensive imported drugs is claimed to be financial gain. Doctors, while prescribing medicine, may assume that patients would feel more secure purchasing drugs at the pharmacies owned by, and located at, the hospital even though the hospital's pharmacies are known to sell drugs at higher prices (interview with a personnel manager of hospital B). Doctors also might have some suggestions that patients purchase the prescribed drugs at specific pharmacies since doctors and such pharmaceutical companies often have some sorts of mutual agreements (interview with a doctor of hospital B). The trade of drugs is said to relate to not only patients and pharmacies but also "a group of agents" (nhóm trung gian), implying the prescribers - those who get very high commission (hoa hồng) from pharmaceutical companies (interview with a personnel manager of hospital B). It is the "commissions" or kickbacks (lại quả) from pharmaceutical companies to health practitioners for prescriptions that are blamed for the very high prices of medicines, especially in public hospitals (interview with a personnel manager of hospital B). This practice is "extensive" considering that even the health care facilities at the commune level engage in drug trade since this entails huge interests (interview with a personnel manager of hospital B).

The distorted medical practices are regarded as pervasive among public hospitals given that medical practitioners can "decide on the technical protocols for medical diagnosis and treatment based on their judgement" (a doctor of hospital B). In particular, the practices are mostly exclusive to the services paid by the out-of-pocket expenses as the medical practices under this scheme are not monitored by any agencies whereas 
the services covered by social health insurance are frequently inspected by the Vietnam Social Security. The practices are predominant among public hospitals since under the autonomy mechanism public hospitals are incentivized to maximize revenues to reinvest in facilities and supplement employees' incomes in the face of underfunding and the employees' low basic wage. These autonomy incentives are so strong that they are seen as the major factor inhibiting central-level hospitals from dealing with their persistent overcrowding problem by transferring advanced technology to satellite hospitals because the central-level hospitals themselves are strongly incentivized to attract as many patients as possible to safeguard their revenues (interview with a deputy director of hospital A).

The distorted provision of medical services is especially considered "systemic" in the sense that the practices are not spontaneous among the frontline medical practitioners, but organized activities because they are "incited" and "pressured" by hospitals" executives:

"The hospital gives rights to the service faculties, inducing them to take advantage of patients paying fees for services wherever possible in order to generate more revenues for the hospital. Service faculties have targets to complete. At present, pressure on revenue generation for service faculties is relatively significant" (a doctor of hospital B).

The practices are even rewarded when considering that the hospitals' appraisal of their employees' performance and the size of additional income employees are paid are closely connected with their faculties' success in attracting patients and generating revenues (interview with a deputy director of hospital C).

\subsubsection{The solicitation and receipt of "envelopes"}

The solicitation and receipt of "envelopes" or under-the-table payment (tiền phong bì) are viewed as persistent issues faced by public hospitals including the interviewed hospitals. This practice is said to be strengthened under the autonomy mechanism since public hospitals are pressured to generate revenues through the various ways including the solicitation of bribery. The indication is that the solicitation and receipt of "envelopes" are not individual, but collective, often faculty-level, actions in which the money is then shared by members of the faculty.

Interviews with three hospitals first give an impression that there is no clear distinction between gift-giving and bribery in the mindset of medical practitioners. This form of 
informal payment is overwhelmingly seen as a reflection of the Vietnamese gift-giving customs - a tradition that values interpersonal relationships and encourages the exchange of gifts on certain occasions to express respect, appreciation or gratitude. For instance,

"In most cases, patients give "envelopes" to doctors to express their thankfulness because they perceive that the medical care is the privilege they receive from their doctors" (a doctor from hospital A).

That said, respondents also admit that the gift-giving is not limited to expressing gratitude because there are numerous situations in which patients give "envelopes" to doctors to "speed up processes" (a deputy director of hospital A) or to "receive greater attention and care from doctors" (doctors from hospital A, B, and C). It is interesting to know that "doctors often do not want to receive "envelopes" from poor-looking people, but they are willing to do so if the "envelopes" are likely to come from a businessman" (a doctor from hospital A).

There is a shared agreement among respondents that the solicitation and receipt of "envelope" have become so rampant among public hospitals that the phenomenon is labelled a culture. The "envelope culture" is considered an "inevitable" issue due to the large population impact and the overcrowding problem that leads to situations in which patients have to give "envelopes" to medical practitioners to avoid the supposedly long waiting time (interview with a deputy director of hospital A). The issue is also caused by the superior attitude on the part of medical practitioners and the poor self-esteem on the part of service users (interview with a deputy director of hospital A). In this regard, the "envelope" payment is the product of the "asking giving" culture (văn hóa xin cho), meaning that service users have to "ask" and bribe so as to be "given" services (interview with a quality manager of hospital B). The "asking and giving" culture, in its turn, results from the legacy of central-planning and state subsidy which survived in the transition to market economy (interview with a deputy director of hospital A). This helps explain the prevalence of "envelope" payments in the North as compared the South where private clinics had long existed prior to Đổi Mới (interview with a deputy director of hospital A). 


\subsubsection{Higher education}

\subsubsection{Governing council}

The Higher Education Law and Decree 16/2015 stipulate that a governing council (hội đồng trường) is required to be established within a university to decide on long-term strategies and plans. The establishment of a governing council gives rise to a paradox in the sense that all public universities, like any other public entities in Vietnam, already have a Party Committee which includes the key personnel of the entity as members and has the responsibility to uphold the Party's guidelines and lead the overall operation of the entity. The establishment of the governing council is viewed as unnecessary by three studied universities because most members of the governing council are members of the Party Committee and most of its tasks are similar to the tasks of the Party Committee. In this connection, a personnel manager of university D insists that the role of the governing council is definitely inferior to that of the Party Committee since the Party Committee is viewed, under the Vietnamese political system, as the political nucleus, the centre of unity, the leader of all aspects of the university including personnel, organization, and finance:

"Our university has established its governing council, but its operation is limited. In fact, it has no effect at all. For private universities, a governing council is very important because it is the fund management agent. Meanwhile, the governing council of public universities does not have to manage the capital, but to give guidelines and development orientations. Nonetheless, these tasks overlap with 70 per cent - 80 per cent of the tasks of the Party Committee. Most members of the Party Committee are also members of the governing council. In particular, the current president of our governing council is the secretary of the Party Committee" (a personnel manager of university D).

The presence of a governing council in a university is also perceived to have little meaning when it comes to key personnel matters. In principle, the governing council should have the right to appoint the principal and deputy principal of the university, but in practice, the governing council's role is limited to proposing candidates for the positions, since the power to decide the members of the university's rectors is concentrated at the line ministry (bộ chủ quản) of the university (interview with a deputy director of university E). In this regard, a former senior manager of MOET mentions about the line ministry mechanism (cơ chế bộ chủ quản) that can overrule 
the university's governing council because the personnel department of the line ministry of a university is deeply involved in the appointment of the principal and deputy principal of the university. This line ministry mechanism is viewed contradictory to the purpose of establishing the governing council and greatly undermines the mandate of the governing council. The line ministry mechanism is also seen to inhibit the autonomy mechanism because the line ministry of a university controls the personnel and financial management of the university while its governing council should take control of these managerial areas. The co-existence of these conflicting mechanisms means that the governing council is dysfunctional. A governing council is still established within universities but is considered as a forced establishment.

An interviewee contended that the governing council is not authorized to appoint the principal and deputy principal of the university because MOET does not want to relinquish the substantial benefits from the power of appointment. This is where MOET is assumed to create the "applications-grants" mechanism:

"In Vietnam, laws are formulated by the executive agencies. The National Assembly only gives inputs to the proposed laws. The Higher Education Law is developed by MOET, who, like any executive agency, desires to do what is of its own interest. The interest groups of MOET desire to concentrate in themselves as much power as possible. Hence, the interest groups create various "applications-grants" mechanisms, such as the authority of the governing council to propose candidates for universities' principals and deputy principals, so that they can get private benefits at the expense of the public interests. If the governing council had the power to appoint these positions, the Personnel Department of MOET would lose that great power, which itself breeds many great benefits. The Department thus endeavoured to maintain that power to protect the accompanying benefits" (a former senior manager of MOET).

The traditionally powerful status of the director of the higher education institution also potentially limits the importance of the governing council. The status of the director of the university and of the president of the governing council is suggested to be likely to give rise to a clash in terms of power and authority between the two positions. This situation is regarded at high risk in university $\mathrm{E}$ because the president of its council is at lower executive rank than the director of the university. As a deputy director of 
university E shares "tensions are highly likely to arise given that the current president of our governing council is not the principal of the university, but the head of a department of our university”.

The limited representativeness of members outside of the university also potentially reduces the mandate of the governing council for a university. For example, in university D, most members of the governing council are the key personnel of the university, mostly representatives from the university's rectors, youth union and trade union. External representatives are in the minority and have little say in the governing council's decisions (interview with a personnel manager of university D).

In this respect, the presence of a representative from MOET in a governing council is believed to be of little value. A personnel manager of university $\mathrm{F}$, for instance, expresses his cynical view about the effectiveness of the inclusion of a senior representative from MOET in a governing council:

"Having the representative attend bi-annual meetings of governing council is difficult. It is likely that the representative will assign a junior expert of the ministry to attend on his/her behalf. There is a possible risk that the expert can offer misleading advice”.

Because of the complexity that the presence of a governing council might bring to the management of the university, up to the time of interview, university $F$ had yet to establish its governing council.

\subsubsection{Academic curriculum}

MOET issues regulations and guidelines covering almost every aspect of the provision of academic services. Some have rigid and detailed provisions that universities are required to comply with, while others provide flexibility for universities to decide by themselves (interview with an academic affairs manager of university D). For example, the universities have to follow the MOET's frameworks for academic curricula, but have some room within these frameworks to construct their own curricula. An academic affairs manager of university D attaches importance to such guidance from the ministry:

"The MOET's curriculum frameworks specify the minimum and maximum number of credits for each discipline and the minimum and maximum numbers of credits for students, ensuring adequate time for self-study, discipline knowledge, foundation knowledge, and thesis defence. In general, the MOET's 
curriculum frameworks are only the skeleton and universities have the discretion to apply "meat" to the skeleton. Without the guidance from the ministry, universities would have difficulty in constructing their own academic curricula".

An academic affairs manager of university E similarly claims that the MOET's curriculum frameworks have created lots of flexibility for the university to decide their own curriculum:

“The MOET's curriculum frameworks are not as rigid as before. Since the adoption of the credit-based system, the ministry's curriculum frameworks have become flexible, enabling universities to promote their strengths. The ministry's curriculum frameworks provide guidelines for each block of disciplines, leaving universities to decide which knowledge to deliver. For example, regarding social science, the ministry previously required universities to incorporate such courses as Vietnam's general literature, Vietnam's general history, the history of world civilization, and Vietnam Eastern thoughts into their curricula. Currently, these courses do not necessarily have to be stand-alone courses, but universities can integrate the content of these courses into others. The ministry's curriculum frameworks require a minimum of 120 credits for a discipline having a 4-year study period and 150 credits for a discipline having a 5-year study period. Based on these standards, the university can decide their own curricula".

With relative independence in the development of academic curricula, the three universities appear able to some extent to build on their strengths. For example, university $\mathrm{D}$ has been building their curricula according to three orientations: researchoriented curriculum, practice-oriented curriculum, and application-oriented curriculum. University E has been able to adjust its curricula every year, making them aligned with changes in Vietnam and the world at large. In its academic curriculum adjustment and development, the university has gradually increased the volume of practice and internship. University F has developed a Profession-Oriented Higher Education programme with output standards taking account of industries' requirements for specific disciplines.

While universities are mostly able to decide the knowledge content of disciplines they offer, they must include the MOET's prescribed common knowledge in every discipline. The common knowledge considered " $a$ must" includes Marxist-Leninist 
political sciences, scientific socialism, history of the Communist Party, Ho Chi Minh Thought, defence and security education, and physical education. MOET prescribes in detail the curriculum, materials, volume, time, examinations and assessment for these courses. The three universities studied in this research take compliance with these requirements for granted, citing the nature of the Vietnamese political system. An academic affairs manager of university $\mathrm{F}$ associates the study of these common courses with the understanding of the country's political contexts and the ability to think "philosophically" and "logically" while another academic affairs manager of university D considers the knowledge provided by these courses "essential" and even "foundational":

"Political subjects must be included considering the Vietnamese political context. Each university graduate will become an expert in the country's science and technology system and so they must understand its political system. Philosophical subjects create philosophical thinking and logical reasoning. Philosophy, as well as math, physics, and basic sciences should not be abandoned" (an academic affairs manager of university F).

"Common courses, such as political theory, scientific socialism, and philosophy provide the theoretical and political foundation for other courses. We have no objection to the courses. Rather, we take the provision of these courses for granted. In our world, there are many schools of thoughts that should be taught at universities. However, given Vietnam's historical context, at the present time, Ho Chi Minh's thoughts and Marxist-Leninist political sciences are relevant. Students can refer to other schools of thought but at the end of the day, they need to bear in mind that only Ho Chi Minh's thoughts and Marxist-Leninist political sciences are foundational. Students may not be interested in learning these courses but later they will understand the knowledge provided by these courses is essential. Students can relate to reality in doing these courses. They are given the right to give their thoughts, comment, and think broadly in answering questions such as "what do you think about Uncle Ho's thoughts". In some respects, these courses are appropriate and necessary. They are not obsolete; students may think they are but later they will find them necessary" (an academic affairs manager of university D). 


\subsubsection{Research}

Interviews with the three universities show that universities are entitled to decide research topics if they are funded by their own budget. Universities are confirmed to have less discretion to decide research topics if they are ministerial- and state-level research, meaning they are funded by MOET and some other ministries such as the Ministry of Science and Technology, the Ministry of Trade, the Ministry of National Resources and Environment. During 2012-2014, universities could bid for the ministerial-level and state-level research, most of which are proposed by universities themselves. From 2015 onwards (and also prior to the 2012-2014 period), instead of bidding, MOET decides on the funding of the research proposed by universities. The MOET's switch from the bidding for research to the allocation of research funds is said to be because many small universities could not compete with bigger universities for the ministerial-level research (interview with a research manager of university D). The switch is also seen "inevitable" because the ministry considers the accomplishment of the ministerial-level research as an important criterion for ministerial-level and state-level research grants (interview with a research manager of university D).

The ministry's allocation of research funds to universities is said to be based on criteria such as number of students, number of permanent lecturers including doctors, associate professors and professors, campus size, number of accomplished research projects, written textbooks, and national and international research papers of the universities. For university D, this funding approach is unfavourable because the university, in focusing on distance study, has limited on-campus size and tends to minimize permanent teaching staff. While the number of admitted students and academic capacity (measured through the percentage of graduates having jobs out of the total graduates) of university D are said to be comparable to many bigger universities, these criteria are not considered in the MOET's allocation of research funds. This approach to research funding also poses a similar disadvantage to university F. Even though the research capacity of the university is perceived to be comparable to that of bigger universities, this is just one of a number of criteria prescribed by MOET.

The MOET's allocation of research funds is believed to be determined not only by such formal criteria but also by informal factors. For example, university $\mathrm{F}$ gets funded for just a few research topics out of the many topics it submits annually to MOET. The 
underlying reason for this, in the view of a research manager of university $F$, is not about the universities' research capacity but other factors such as the "applicationsgrants" mechanism and the close connections between universities and MOET.

The application process for research funds is cumbersome and complex. The research capacity is in many cases secondary in the funding decision. The MOET-stipulated research funding criteria are unfavourable for small universities even though the research capacity of these universities is not inferior to that of bigger ones. The research funding decision is predominantly characterised by the "applications-grants" mechanism. Some universities must have good relationships with MOET to be allocated research funds. Such close connection should have brought huge benefits for MOET given that universities must "ask" to be "given" whilst they ought not to "ask" but still should be "given" owing to their research capacity" (the word in bold signifies the emphasis of the respondent, implying that the respondent implicitly refers “ask" to "bribe").

The difficulty in getting research funds from the ministry is confirmed as one of the main contributing factors that undermine the interest in doing research among a large number of lecturers. That is even though MOET sets the required time a lecturer needs to allocate for research. MOET 's Circular 47 stipulates that at least one-third of a lecturer's total working time of the year be reserved for research and the annual evaluation result of his/her performance be susceptible to the completeness of his/her research duty. The Circular also specifies that a lecturer's total working time of the year is 1,760 hours and the required standard time for teaching per year is 270 hours. A research manager of university $F$ confirms that, in practice, lecturers can change the compulsory working time for research into the standard time for teaching. For example, in university F, a lecturer's compulsory time for research in a year is equivalent to 150 standard hours of teaching in that year. This teaching time is under lecturers' control given that most lecturers have often exceeded the standard time of teaching. That is not to mention a great many lecturers have been lecturing at other universities outside of their working time at their own university. In the respondent's view, the switch from research to teaching is a common practice among a large number of lecturers because they are not keen on doing research, which is itself seen as a hard job while the income is unsatisfactory and the research environment is discouraging. 
Additionally, the restriction in choosing research topics is viewed as an important factor that discourages lecturers' motivation to do research. In this regard, a former senior manager of MOET refers to the revocation of the Master's degree of Do Thi Thoan ${ }^{5}$ as "a typical example about the brutal violation of academic freedom in Vietnam" and "a convincing proof that Vietnam cannot have academic freedom due to its political characteristics".

\subsubsection{Establishing high-quality classes and new study programmes}

Universities are entitled to provide high-quality classes as long as they satisfy the MOET-specified criteria in relation to the facility and equipment and the number of students per lecturer. Unlike tuition fees for mass study programme which are stateregulated, universities can set tuition fees for high-quality classes. According to a deputy director of university $\mathrm{F}$, universities that meet the MOET's criteria have provided a number of high-quality classes to generate more revenues. There would be little concern with respect to the establishment of high-quality classes unless the

5 In 2010, Do Thi Thoan (pen name as Nha Thuyen) was granted a Master's Degree in Language and Literature by Hanoi National University of Education after she had received very positive evaluation about her thesis by the examining committee. In 2014, another committee revoked her degree without an explanation to Ms. Thoan or her thesis supervisor. The decision was made in secret even though there was no evidence about the academic misconduct committed by the candidate. Ms. Thoan lost her job as a contracted lecturer at the university. Her supervisor, Associate Professor Nguyen Thi Binh, was forced to retire early. The revocation of Ms. Thoan's Master's Degree exhibits the lack of due process, which invariably implies that the university's decision was made because of political pressure, rather than based on academic credentials (Lebowitz, Plotz, \& Reich, 2014). Prior to the revocation, a campaign was initiated in the state-controlled media strongly criticising the lack of political correctness of Ms. Thoan's thesis. Later on, a leaked document from the Propaganda and Education Committee, a powerful organ of $\mathrm{CPV}$, showed that secret directives were issued to the media, commanding it not to report any adverse reaction to the affair (Tienve, 2014). Titled "The Marginalized's position: OpenMouth Group's poetic experiments from a cultural perspective”, Ms. Thoan's thesis investigates the work of Mở Miệng (Open Mouth), a group of Vietnamese writers who often express their strong critiques of contemporary Vietnamese society and whose poetic experimentation is regarded as dirty or rude by the Cultural Police, an influential organ of the Vietnamese Security Police (Ibid.). Considered taboo inside Vietnam, their work has thus been published overseas. The Mở Miệng writers themselves have been subject to frequent police harassment and intimidation. For this reason, researching their work and writing about it could have been viewed by the Party as an "act of defiance and of diffusing and lauding "dirty" thoughts" (Ibid.). 
quality of high-quality classes is no different from that of the normal ones. The interview with a deputy director of university F, however, shows that the high-quality classes and the normal ones are distinct not in the quality, but in that "with the former students are examined on what they are taught whilst students are not with the latter". Universities may use this deceptive practice to attract students into the so-called highquality classes with the aim of generating more out-of-pocket payments.

Similarly to the provision of high-quality classes, universities are entitled to open up new study programmes providing that they satisfy the MOET-stipulated criteria. One important criterion is the required quantity and quality of permanent teaching staff. In this regard, the requirements placed on non-public universities are more relaxed than on public universities. Since a non-public university can hire and include a retired professor as a permanent teaching staff whereas a public university is not allowed to do so (interview with an academic affairs manager of university F).

As with the provision of high-quality study classes, the opening-up of new study programmes may be driven by the desire to maximise revenues. In this respect, an academic affairs manager of university $\mathrm{F}$ states:

"A lot of universities are rent-seeking in providing mass study programmes and opening up new study programmes extensively. They especially have been rushing to open up the study programmes that promise to be profit-making whilst avoiding the basic science which requires huge investment but attracts only a few students".

\subsubsection{Student admission}

Previously, MOET assigned targets to universities regardless of whether these targets were lower than the universities requested. MOET has now permitted universities to identify their student admission targets according to their permanent staff numbers and facility conditions. A deputy director of university $\mathrm{E}$ does not see this permission an entitlement:

"Under the current rule, universities are granted autonomy in student admission targets, but they must base them on their number of lecturers and facilities. This mode of control is rash in terms of personnel management and productivity. One organization only needs a good governance system, then it can invite outside experts to deliver lectures. The problem just lies in which price can buy which quality. This control indicates the conflict between price 
and quality. MOET wishes to make sure the university's student admission targets are in line with its number of lecturers, which itself implies autonomy is not conferred on the university".

This control, though to some extent less restrictive than before, creates circumstances in which universities make up a virtual number of lecturers higher than the actual number to increase their student admission targets (interview with an academic affairs manager of university D). Similarly, some universities have been tempted to further invest in high-tech equipment and facilities to be able to admit more students and get more research funds, rather than to serve academic purposes (interview with a deputy director of university F). As an interview with a financial manager of university $F$ reveals:

"A large number of universities have used the state fund to purchase advanced equipment but ended up leaving it unused. Apart from the unwillingness to pay for the maintenance, this circumstance happens due to the universities' selfinterest to gain credits".

Universities are entitled to determine their annual student admission targets, but according to the current rule, universities are not allowed to exceed the targets once MOET has agreed upon them. From the perspective of an academic affairs manager of university D, this rule embodies risks. Every year universities determine their student admission targets based on the targets in the previous year. Because the targets of this year may differ from those of the previous year, universities are at risk of either exceeding or failing to meet their approved targets. If they exceed the targets, which happens when universities lower their admission thresholds (i.e. national exam mark levels), they may be subject to some forms of punishment. If targets are not met, universities may encounter a revenue shortfall as a consequence of not admitting enough students.

This regulation, from the viewpoint of an academic affairs manager of university E, places universities in a situation in which they are required to precisely anticipate the number of students that they are likely to admit. In this respect, university $\mathrm{F}$ was once punished when it admitted more students than projected. In the opinion of an academic affairs manager of university $\mathrm{F}$, this rule is an indication of the lack of autonomy in practice given the fact that universities should be able to determine their student targets as long as they bear full responsibility for the quality of their outputs. 


\subsubsection{The solicitation and receipt of "envelopes"}

As with the health care sector, the "envelope" or "under the table" payment from students in exchange for getting higher marks or passing courses is believed to be a prevalent issue in the higher education sector. In the opinion of a deputy director of university $\mathrm{F}$, this phenomenon illustrates that petty corruption is popular in the higher education sector. From the point of view of a financial manager of university D, it would be a "delusion" to believe that the "envelope" payment no longer exists.

Most academic affairs managers and quality assurance managers of the three interviewed universities, however, believe that the solicitation and payment of "envelopes" related to exams may have reduced because, with the separation of education activities from testing and marking, exams have been carried out in an independent and objective manner. Course lecturers do not know which exam questions to be used in a particular exam because they are taken from the university's exam question banks managed by the university's Testing and Quality Assurance Department. Course lectures also cannot know the identity of the owners of the exam papers they are marking because this detail has been encrypted by a separate team also from the Testing and Quality Assurance Department. In general, with the involvement of the Testing and Quality Assurance Department in the organization of exams, the solicitation of "envelope" payment in exchange for higher marks or exam passes seems to have considerably decreased.

Nevertheless, this is not the case in relation to the home-based assignments and theses. Some respondents refer to the rumours that theses at different levels of study (i.e. undergraduate and postgraduate) have different prices, implying the higher the degree, the more expensive the thesis. There is even a rumour that advice on the minimum amount of money to be put in an envelope for each examiner of a thesis defence is passed to the Masters students undertaking a study programme at a university.

The low state-regulated basic wage coupled with the limited additional income due to the stringent caps on tuition fees while the allocation of the state budget is inadequate, are perceived to lead lecturers to solicit "“envelope" payments from students in exchange for getting higher marks or passing. The following cites a statement from a deputy director of university F:

"The current pay for lecturers is generally inadequate. As a consequence, lecturers have been hustling to make a living. A large group of lecturers have 
been working both inside and outside of their university. Why is the salary regime in the education and health care sector so much different from that of other sectors such as banking or state enterprises? The consequence of such salary disparity is that a great many universities have been soliciting their students to give "envelopes" to pass their courses".

The solicitation and receipt of "envelopes" are also considered to result from the "asking - giving" culture. The influence of this culture may be reflected in the attitude of both supervisors and students: "Supervisors behave as if they are giving favours rather than delivering services while students act in the manner of asking for favours", an academic affairs manager of university E explains.

In summary, this chapter examines different dimensions of autonomy among public hospitals and public universities from an institutional perspective. A better understanding regarding the financial and personnel autonomy and the autonomy in organisation and provision of public services of the studied PSDUs helps paint a clearer picture of the actual autonomy perceived by PSUDs' managers and staff (see table 7-1). The evidence provided in the research shows that the autonomy of PSDUs is greatly constrained across a number of managerial dimensions. The constraints are caused by various formal and informal rules and norms and values. While public hospitals and public universities are subject to the same autonomy framework, the autonomy of public universities seems to be much more restricted which is probably due to the inherent nature of their services and the political and economic implications their services may have for the country. There is evidence that sometimes the formal and informal features of autonomy complement one another to reproduce dysfunctional behaviour. There is also evidence for a disconnect between the formal and the informal, such as detailed formal rules are not applied or conformed to. 
Table 7-1: Formal and Informal Features of Autonomy

\begin{tabular}{|c|c|c|c|}
\hline $\begin{array}{l}\text { Management } \\
\text { dimensions }\end{array}$ & Formal autonomy & Informal/actual autonomy & $\begin{array}{c}\text { Complement/ } \\
\text { Disconnect }\end{array}$ \\
\hline $\begin{array}{l}\text { Fees and } \\
\text { charges, } \\
\text { quality } \\
\text { management }\end{array}$ & $\begin{array}{l}\text { - Caps on fees and charges } \\
\text { - State-prescribed ratios of medical practitioners/bed } \\
\text { and numbers of students/lecturer }\end{array}$ & $\begin{array}{l}\text { Hospitals breach the ratios of medical } \\
\text { practitioners/bed; universities distort the numbers of } \\
\text { lecturers to admit more students }\end{array}$ & Disconnect \\
\hline \multirow[t]{2}{*}{ Spending } & $\begin{array}{l}\text { Norm-based spending in using cars, phones, travelling, } \\
\text { receiving visitors, and organisation of conferences }\end{array}$ & $\begin{array}{l}\text { PSDUs make up virtual numbers of visitors or fake } \\
\text { travel days }\end{array}$ & Disconnect \\
\hline & $\begin{array}{l}\text { - Norm-based operating expenditure; the requirement } \\
\text { of state approval for capital expenditure } \\
\text { - PSDUs are required to deposit their budgetary and } \\
\text { non-budgetary revenues at the state Treasury for the } \\
\text { administering purpose. }\end{array}$ & $\begin{array}{l}\text { The internal expenditure regulation established by } \\
\text { PSDUs according to the CPV's core principle of } \\
\text { democratic centralism undermines the power of the } \\
\text { head of PSDUs }\end{array}$ & Complement \\
\hline $\begin{array}{l}\text { Use of net } \\
\text { revenues }\end{array}$ & $\begin{array}{l}\text { The setting up of the additional income fund conforms } \\
\text { to the state-specified deduction percentage regarding } \\
\text { the use of net revenues; restricting caps are placed on } \\
\text { the additional income fund of partly self-financing } \\
\text { PSDUs. }\end{array}$ & $\begin{array}{l}\text { The actual practices deviate from the formal rule, } \\
\text { probably due to the influence of local government's } \\
\text { self-sufficiency and the "village culture" that make } \\
\text { local rules override central laws and regulations. }\end{array}$ & Disconnect \\
\hline $\begin{array}{l}\text { Personnel } \\
\text { management }\end{array}$ & $\begin{array}{l}\text { The recruitment, appointment, increase of ranks and } \\
\text { grades, secondment, dismissal, and performance } \\
\text { appraisal of PSDUs' head and deputy heads are } \\
\text { controlled by the state management agency under the } \\
\text { Law on Cadres and Civil Servants. }\end{array}$ & $\begin{array}{l}\text { The actual autonomy of universities is further } \\
\text { limited because the power on the employment of } \\
\text { senior lecturers (i.e. associate professors and } \\
\text { professors) is also reserved to MOET }\end{array}$ & Complement \\
\hline
\end{tabular}




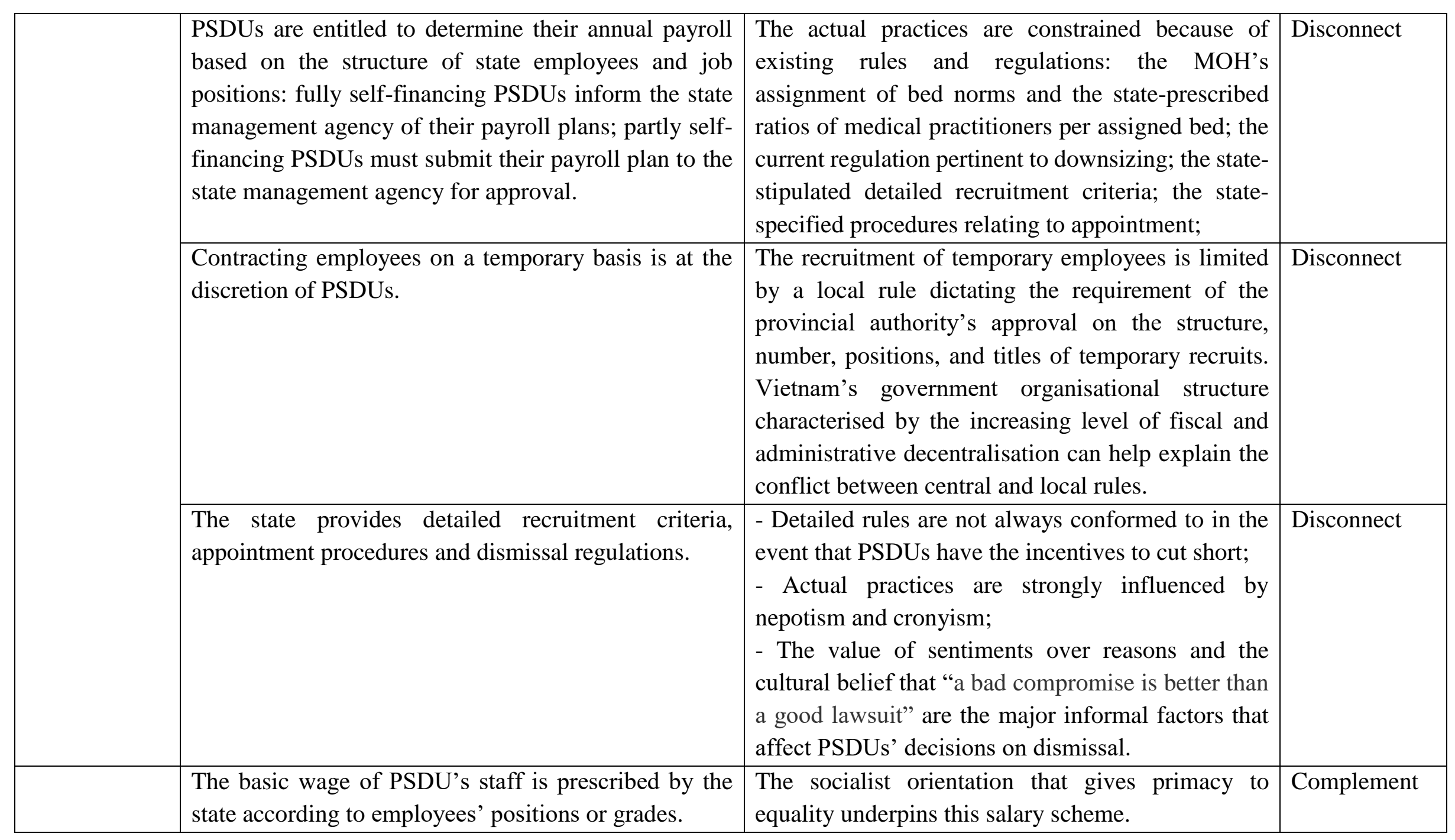




\begin{tabular}{|c|c|c|c|}
\hline & $\begin{array}{l}\text { Performance-based appraisal and pay of state } \\
\text { employees is at the discretion of the heads of PSDUs }\end{array}$ & $\begin{array}{l}\text { The traditional seniority convention and the } \\
\text { ideological egalitarian philosophy both contribute to } \\
\text { lessening PSDUs' actual autonomy in performance- } \\
\text { based pay }\end{array}$ & Disconnect \\
\hline \multirow[t]{2}{*}{$\begin{array}{l}\text { Organisation } \\
\text { of service } \\
\text { provision }\end{array}$} & $\begin{array}{l}\text { - PSDUs are allowed to elaborate working plans } \\
\text { specifying targets and tasks of the assigned services and } \\
\text { of the services designed by the units: fully self- } \\
\text { financing PSDUs report plans to the state management } \\
\text { agency; partly self-financing PSDUs submit plans to } \\
\text { the state management agencies for approval. } \\
\text { - Caps are placed on normal services; no caps are } \\
\text { applied to non-core services. } \\
\text { - SPSDUs are entitled to retain net revenues (after a } \\
\text { deduction is made to reserve for the capital fund) for } \\
\text { staff bonuses. }\end{array}$ & $\begin{array}{l}\text { - The rent-seeking behaviour drives hospitals to } \\
\text { provide the "patient-requested" services alongside } \\
\text { the normal services assigned to them by the state. } \\
\text { Hospitals use most of their resources to invest in } \\
\text { "patient-requested" services, leaving normal } \\
\text { services in decay. } \\
\text { - Universities are induced to provide high-quality } \\
\text { classes and open up profit-making study } \\
\text { programmes. }\end{array}$ & Complement \\
\hline & $\begin{array}{l}\text { - Health facilities are allowed to decide measure to } \\
\text { implement their service delivery plans; } \\
\text { - PSDUs are entitled to mobilize capital from their staff } \\
\text { to invest in services; establish joint-ventures or } \\
\text { cooperation with organizations and/or individuals to } \\
\text { provide services; } \\
\text { - PSDUs are entitled to retain net revenues (after a } \\
\text { deduction is made to reserve for the capital fund) for } \\
\text { staff bonuses. }\end{array}$ & $\begin{array}{l}\text { The rent-seeking behaviour drives hospitals to } \\
\text { overprovide therapies and tests, to overuse high-tech } \\
\text { equipment including the equipment procured from } \\
\text { investments by their employees and external } \\
\text { partners on a profit-sharing basis; to increase the } \\
\text { length of stay at hospitals, and to overprescribe. }\end{array}$ & Complement \\
\hline
\end{tabular}




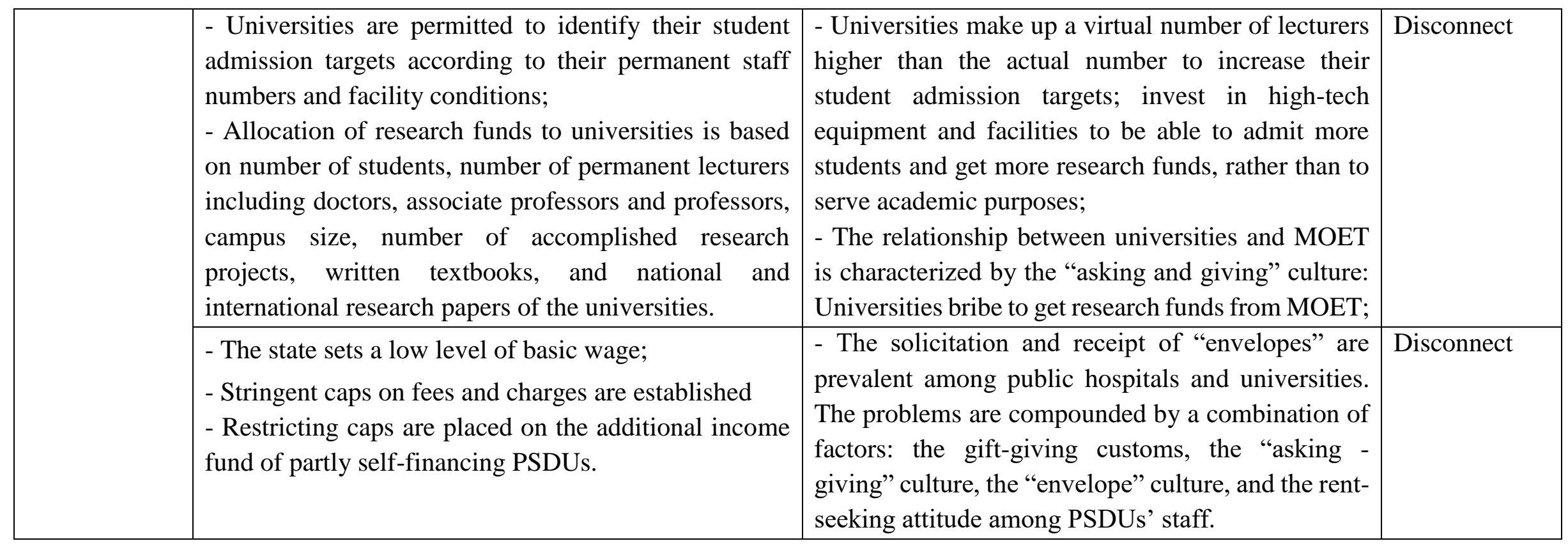




\section{CHAPTER 8}

\section{THE NATURE OF AUTONOMY OF PUBLIC SERVICE DELIVERY UNITS IN VIETNAM}

The previous two chapters provide analyses of the formal and the (perceived) actual autonomy of Vietnam's PSDUs in the light of the country's various formal and informal institutional factors that exert considerable influences on the autonomy policy formulation and implementation. This chapter will discuss the main findings of this research in relation to the autonomy theories and concepts that have been widely accepted in the public management field. In doing so, the chapter will offer an illuminating insight into the real meaning of autonomy and its implications on the behaviour of Vietnam's PSDUs with reference to service provision. Each of the insights into the nature of autonomy of Vietnam's PSDUs will then be related to the findings of prior research about the autonomy and the reform of public service delivery agencies in Vietnam and in countries that share similar backgrounds.

\subsection{Autonomy is the political rhetoric aimed at consolidating the VCP's legitimacy}

In the previous two chapters, the researcher argues that the autonomy reforms of PSDUs are the VCP's political rhetoric about its resolve to address weak state management resulting from the centrally-planned economy. This argument is made in considering that Vietnam's adoption of the autonomy reform is not simply aimed at enhancing the means-end efficiency informed by the rational explanation, but largely as a result of the coercive pressures from its powerful donors to carry out reforms in line with the neoliberal market policies favoured by Western countries. More importantly, the concern for social legitimacy and resources, which were exhausted due to the serious socio-economic crisis because of the failing adoption of the central planning model, instead of the efficiency consideration, explains the reason why the autonomy reforms were initiated as part of the broader economic reforms towards decentralization, liberalization, and marketization. The argument is also made acknowledging that the autonomy reforms were conducted in the context of an ongoing substantial divergence of opinions within VCP between the advancement of market institutions and the state's increased interference in the economy. In such policy deliberation, the greater intervention of the state is often given primacy, which invariably results from the socialist path that VCP pursues to consolidate the authoritarian regime. The following subsections justify the argument. 


\subsubsection{Autonomy is bound by a system of formal and informal rules and norms and cultural values}

The analysis of the autonomy regulatory framework shows that the formal autonomy assigned to PSDUs is limited and even non-existent in some dimensions given that it is conditioned by a set of state-specified rules, regulations, norms, criteria, standards, procedures, processes, and prescriptions. The analysis of the perception and actual practice of autonomy among hospitals and universities further demonstrates that the (perceived) actual autonomy is formalistic, non-intrinsic or even fake because it is restrained (in most cases) not only by formal rules, which extend to the formal political and governance structure but also by the informal control of the party-state and the various informal norms and cultural values. The implication of such findings is that the autonomy reforms may bring about some changes in PSDUs' formal rules and structures in response to the international and domestic institutional pressures, but these changes are superficial. Indeed, not only is this nature of autonomy determined by the policy choices driven by the socialist-cum-market path but more importantly, it is constructed by the governance system underpinned by authoritarian communism and the sets of norms and values imbued with central planning legacies that entirely contradict the neoliberal values underlying autonomy.

While recognising that autonomy is a relational term since it addresses the issue of how much discretion agencies have in making decisions and how much they are circumscribed by rules or norms (Pollitt et al., 2004), the research claims that the autonomy of Vietnam's PSDUs is mostly rhetorical since it is bound by a system of formal and informal rules, norms, and cultural values. Indeed, autonomy is real and intrinsic only when it creates a certain decision-making space within which agencies can, to varying extents, decide on the choice and use of resources (managerial autonomy) or on the policy matters including objectives, target groups, policy instruments, quality and quantity of outputs, processes, and procedures, and issuing of general regulations or decisions in individual cases (see Lægreid \& Verhoest, 2010). This means that the legal, normative, and cultural factors that are likely to impose some constraints on such autonomy are relaxed to some extents. However, that is not the case in Vietnam where autonomy is largely circumscribed by numerous rules, norms, and values, leaving agencies with very limited decision-making power. 


\subsubsection{Autonomy is accompanied by the control of inputs and processes}

Verhoest et al. (2004a) suggest that the assignment of autonomy to agencies is accompanied by a shift in the traditional ex ante (input) control towards a new form of control, which is more ex post and result-oriented. The ex post control mostly focuses on the achievement of the intended organizational goals through objective setting, monitoring, evaluation, audit, and sanctions. In Vietnam, however, party-state control mainly concentrates on the choice and use of resources in service provision. This traditional ex ante control emphasizes the 'before the act' formulation of detailed rules and regulations that give directions to PSDUs so that the desired objectives will be achieved. The major concern of this control approach is to secure PSDUs' strict adherence to the centrally imposed rules and regulations, rather than creative and efficient management towards targets. This mode of control further indicates that the actual autonomy conferred on PSDUs is in many aspects greatly restrained.

Pollitt et al. (2004, pp. 19-20) note that the purpose of giving agencies autonomy is to enhance flexibility through freedom from central civil service rules, which is assumed to lead to more exploration of cost-effective alternatives, a wider use of market-type instruments in the delivery of public services and greater competition in the public sector, resulting in higher quality services and efficiency. This objective, whilst being publicly stated in Vietnam's autonomy policies, is highly unlikely to be materialized in practice due to the party-state's formal and informal control over the choice and use of inputs. Consequently, state employees are generally limited to the role of administrators who are preoccupied with conforming, or pretending to conform, to regulations, procedures, and standards rather than managers who are more concerned about achieving targets and responding to clients. While the advantage of government regulations and guidelines is that employees can regard them as the "legal stick" to rely on, as a personnel manager of university D claims, the disadvantage is that they do not create a facilitating institutional environment in which employees can take initiatives and become entrepreneurial as the autonomy theories suggest.

The intrinsic value of ex ante control is to make sure rules, procedures, norms, and criteria are obeyed. Unfortunately, the autonomy practices of PSDUs shows that this mode of control has reverse effects in reality given the PSDUs' endemic violation of state-stipulated rules, procedures, norms, and standards. As interviews with universities and hospitals suggest, state regulations are systematically infringed primarily because they are conflicting, confusing, inconsistent, irrational and 
irrelevant. Although the party-state control appears to be comprehensive, which is at least demonstrated in the many detailed regulations, there are still loopholes in this control that PSDUs can exploit in pursuit of their private interests. Hence, the regulatory framework that the autonomy policies create results in situations in which PSDUs use various tactics and tricks to encounter state regulations. This, in some ways, implies that the autonomy that PSDUs actually have is greater than the formal autonomy they are entitled to.

The analysis of autonomy practices further shows that the ex ante control is not simply aimed at upholding the rule of law but more precisely is designed to reinforce central power and to ensure that its benefits are shared between the state management agencies and PSDUs. Ex ante control is thus clearly observable in the managerial areas that conceivably bring in great benefits for the controllers such as the allocation of budget and the management of key personnel. These areas are where the "applications-grants" mechanism flourishes, distorting the relationship between the state management agencies and PSDUs and leading to the solicitation of bribes and bribes in exchange for autonomy and entitlements.

\subsubsection{Autonomy is not associated with depoliticisation}

In most advanced countries, agencification and autonomisation often take place simultaneously. They involve creating or moving functions to public bodies that are subsidiary to or separate from a ministry and devolving some degrees of autonomy to these public bodies. The central aim is to lessen political interference to allow managers to manage, and thereby achieve higher efficiency and to allow regulatory or quasi-judicial decisions to be taken in an impartial way (Pollitt et al., 2004). Indeed, the depoliticisation of many government decisions has been on the reform agenda of many advanced countries, resulting in the process of agencification taking place in various functions including public services, regulation, adjudication, advice and policy development, and information and research (see Bouckaert \& Peters, 2004).

In Vietnam, depoliticisation is not the driver of autonomisation. This explains why autonomisation mostly takes place in public service delivery. Prior to autonomisation, PSDUs had already operated, though with little formal autonomy, as separate statutory entities under the centralized planning mechanism. There has been no such proliferation of agencies as in other countries since the other important state management functions such as regulation and adjudication which might require the most impartiality still rest with ministries (see also Vo \& Lofgren, 2016). The 
autonomy reforms are thus limited to autonomisation, conceivably aiming at separating public service delivery, and business administration, from state management functions (see also Vasavakul, 2002).

The analysis of the autonomy practices of PSDUs in chapter 7 strongly demonstrates that depoliticisation cannot be the driving factor behind the autonomy reforms because of the presence of the organisational network, together with the operational principles, of the party elites cutting across all managerial aspects of PSDUs. In personnel, the Party retains its political power through control of the appointment, dismissal and performance appraisal of PSDUs' heads and deputy heads (see section 7.2, chapter 7). In payroll, the Party maintains a national basic salary system to uphold its core egalitarian tenet even though that system fails to recognise performance (see section 7.2.2, chapter 7). The Party undermines the power of individuals through its fundamental principle of democratic centralism which vests supreme and unquestionable leadership in the Party (see section 7.1.2, chapter 7 for the compulsory establishment of the internal expenditure regulation within each PSDUs). The Party closely watches and monitors the academic curriculum and research of universities whereby academic freedom can affect the ideology and principles of socialism (see section 7.3.2, chapter 7). The Party deeply intervenes in the operation of PSDUs via the Party Committee comprising key personnel of PSDUs, which reports to the Party on PSDUs' key decisions and any matter the Party assumes likely to affect its power and legitimacy. In this regard, the presence of a governing council within PSDUs, supposed to increase autonomy and accountability, is no more than window dressing (see section 7.3.2, chapter 7). Overall, with such Party network's extensive and deep penetration in all PSDUs' operational areas, there is no likelihood that all the theoretical assumptions of autonomisation outlined above can be materialized in practice.

In most advanced countries which autonomise many of their state functions, the rule of law principle has been institutionalized. This means that the interference of the governing political parties in agencies' operations is often clearly specified in laws. In many cases, the intervention of the governing political parties in managerial matters of agencies is even forbidden (see section 2.2.1, chapter 2). The Vietnamese autonomisation, however, shows that it is the rule of the Party, not the rule of law, that governs the country's service delivery system. The Constitution claim that the Party "leads" and the state "manages" with an aim to distance the routines of administration 
from the politics of the Party's leadership. However, the analysis of the autonomy practices of PSDUs shows that the Party intervenes to varying degrees in the state's management process, violating the principle of "law-governed state" prescribed by the Constitution.

The Party's control indicates that it truly does not intend to delegate power to the state, and particularly to PSDUs. As previously discussed, its ultimate concern is about power and resource gain, not the actual autonomy that PSDUs should have to be productive and effective. As Abuza (2001, p. 22), an observer of Vietnam's politics, once put it:

"The Vietnamese political system, in sum, is primarily geared to the maintenance of the VCP's political monopoly. In terms of policymaking, it tends to be very reactive to problems. The system is geared towards maintaining the status quo, rather than leading the country forward".

Consequently, autonomisation is a process of "push and pull": push to gain resources by using some elements of market forces but pull to gain power and political monopoly. The autonomy reforms thus mainly have symbolic meaning, or more exactly the power delegation component (not the resource gain component) of the autonomy reforms is symbolic. The success of this symbolic meaning is that it serves to maintain the VCP's legitimacy, an attempt at survival or a need to maintain resources; that is despite the autonomy reforms are far from gaining the legitimacy among PSDUs. The resource gain component of the autonomy reforms will be discussed in section two of this chapter.

\subsubsection{Consideration of the research finding in relation to prior research}

The argument that PSDUs' autonomy is a political rhetoric is original. That the research can make such a claim is largely attributable to the research design. First, the research relates its main findings about the nature of PSDUs' autonomy to the widelyaccepted theories and concepts surrounding autonomy as well as the common practices with respect to autonomy and management of hospitals and universities of advanced countries. Second, the research takes a holistic approach by drawing on the analysis of the evolution and substance of the autonomy policies of PSDUs in general and of two essential sectors considered the most susceptible to autonomisation - health care and higher education. The research also bases its analysis on the in-depth interviews with hospitals and universities about their perceptions and practices of autonomy across 
varying dimensions of management - financial management, personnel, and organization of service provision. Third, the research situates the development and implementation of the autonomy policies within the broader institutional perspective and analyses how the policies and practices are constructed and reconstructed by the various formal and informal institutional factors. It is thanks to this analytical framework that the research could situate the autonomy reforms in the surrounding socio-economic conditions; relate the evolution and substance of the policies to the path dependence platform and the political economy landscape; and associate the autonomy practices with the nature of politics and governance and with the underlying cultural values and norms. Without the institutional reflection, it would be impossible for the research to discern, to the full, the typical features of PSDUs' autonomy, since autonomy, as well as any form of behaviour, is influenced and shaped by institutions. It is owing to such research design that helps offer an illuminating insight into this essential meaning of PSDUs in Vietnam - the meaning that has never been identified in prior research.

Having said that, the research supports and further expands some findings of a few existing studies about the autonomisation of PSDUs in specific areas, mainly health care and higher education. Specifically, the research matches with the study by Tran et al. (2015) which indicates that Vietnam's public hospitals have more independence in governing finances and expanding services, those that are associated with revenuegenerating practices to be discussed in section 2 of this chapter, but are still limited in their autonomy over personnel management. The research supports Hayden and Lam (2007) who claim that Vietnam's public universities do not have much institutional autonomy particularly in terms of determining curriculum frameworks and setting tuition fees. The research also shares their argument that there is limited political support for the autonomisation of universities due to the strong desire to retain control of the socialist orientation of universities and of the deployment of the higher education sector within the centralized national economic management framework. The research agrees with Dao's (2014) claim that autonomy granted from MOET is conditional and with Pham's (2012) argument that the higher education system is maintained by the central control characterised by the many detailed prescriptions and bureaucratic procedures. The research highlights the limited academic freedom, in line with George (2011, p. 227) who notes that in Vietnam "the requirement to study Marxism-Leninism and the state oversight of the curriculum remain non-negotiable". 
The research accords with the observation by London (2010, pp. 375-377) that in Vietnam "problems in higher education stem from the Ministry of Education and Training's outmoded, overcentralized, and conservative management approach" and "all providers of education - state or non-state and at all levels - remain thoroughly penetrated by Party organs".

The research is also consistent with prior research regarding the decentralization for public services from central to lower levels of government in Vietnam. For example, $\mathrm{Vu}$ (2016b) and Vasavakul (2006) both argue that decentralisation in Vietnam is fiscal and administrative only. $\mathrm{Vu}$ (2016b) especially argues that personnel decentralisation - a form of political decentralisation - is the most conservative dimension of decentralisation in Vietnam because of the CPV's immutable principle, that is the Party must retain absolute control and management of state personnel. This argument aligns itself with the research in that there is a lack of political commitment for successful decentralisation in Vietnam since CPV desires to preserve the centralised and unitary political structure. The research also resonates with Vu's (2016b) finding that local government's actual autonomy in the provision of public services is limited because it has to follow central guiding formulas in the form of quotas, standardization or cost norms applied to budget allocation. Equally, the research is consistent with Lieberman et al. (2005) in that the actual autonomy of lower levels of government in Vietnam is constrained by the system of norms that determine almost every kind of inputs.

The research also shares its findings with prior research on agencification in developing and transitional countries. In particular, tight central control of autonomous public organisations is identified as a common feature of agencification among some developing countries as China, Thailand and Tanzania (see Billinton \& Xin, 2000; Bowornwathana, 2004; Sulle, 2010). Vietnam's experiences are especially similar to those of China in that both countries are ruled by the communist party whose political influence remains powerful and substantial.

Overall, prior research has, by and large, discovered some of the features of autonomy of PSDUs and, more broadly, of local government in Vietnam. The research finding, whilst corresponding to prior research, has sharpened the previous findings and formed a new scholarship foundation by identifying the essence of the autonomy reforms, that is the political rhetoric designed by CPV to harness the legitimacy and resources necessary to maintain the authoritarian regime. As the political rhetoric, autonomy is 
limited by a set of formal and informal rules and norms; it is not accompanied by result-oriented control; and it is also not meant to render managerial decisions taken in an impartial way. Hence, autonomy in Vietnam is hardly about liberating PSDUs from unnecessary political and administrative constraints to be efficient and innovative although CPV has paid lip-service to the NPM models in its reform rationales. Autonomy, probably like other neoliberal-oriented policies that CPV has adopted since Đổi Mới, is a position taken by the Party in its dealings with the international community to secure its own objectives.

The research further enriches its main finding by exploring the interrelationship between formal and informal institutions in their impacts on the actual autonomy of PSDUs. The research particularly finds that the system of autonomy rules become more manipulated when they are supported by other elements such as norms and cultural beliefs. Across PSUDs' managerial aspects, it is easily observable that many of the informal institutional factors tend to complement the formal ones, thus contributing to further constraining PSDUs' actual autonomy. For example, both the formal norm-based system and the informal "applications-grants" modality combine to reduce the effectiveness of the state budget allocation and create opportunities for the solicitation of bribery and bribery. Also, the formal norm-based spending control and the informal control through the CPV's core tenet of democratic centralism constitute great inhibitors in PSDU's actual autonomy in expenses. Additionally, the formal rules and the informal favouritism norm undermine PSDUs' entitlement to merit-based recruitment and appointment.

The research, at the same time, finds that many other informal institutional factors tend to compete with the formal ones, providing PSDUs with decision space which is sometimes more and sometimes less than conferred by the formal rules. Concretely, the increasing financial self-sufficiency and the "village" culture create opportunities for PSUDs to depart from central rules in rewarding their employees. Conversely, the traditional seniority convention and the ideological egalitarian philosophy both contribute to lessening PSDUs' actual autonomy in performance-based pay. Similarly, the value of sentiments over reasons and the cultural belief about "a bad compromise is better than a good lawsuit" are seen to considerably restrain PSDUs' staff dismissal. Also, the legacy of centralised planning and state subsidy sustained through the transition to market economy is primarily ascribed to the common issue of dependency and passiveness among PSDUs, which is contradictory to the innovative and risk- 
taking values underscored by autonomy theories and concepts. Meanwhile, localism which results from the unclear division of functions and responsibilities between central and local government and from the fragmented and increasingly decentralized government organisational structure can sometimes give PSDUs more flexibility in aspects of personnel management.

The research also deepens its main finding by providing a detailed account of the challenges that formal and informal autonomy creates for PSDUs. Typical challenges include the revenue-generating pressure due to the irrationally low fees and charges schemes and the inadequate state budget allocation, the norm-based spending control, the rigid norms and criteria pertinent to recruitment and appointment, the statestipulated basic wage scheme that restricts performance-based pay and fails to reward performance. Apart from these challenges, universities, in particular, are confronted with many others such as the pressure to establish a governing council notwithstanding its symbolic meaning, the limitation in academic freedom, and the conditions imposed on admitting students and establishing new study programmes. Altogether, these vast challenges represent the wide range and great extent of the constraints faced by PSDUs across almost all key managerial aspects, thus contributing to shaping the very limited autonomy to which PSDUs are entitled.

\subsection{Autonomy is about generating alternative non-budgetary sources of revenue under the label of "socialisation"}

The analysis of the autonomy policies in chapter six demonstrates that the autonomy reforms are associated with "socialisation" which tacitly means the switch of cost from the state onto society. The autonomisation of PSDUs, which is instrumental in the implementation of the broader "socialization" of public services, is aimed at generating alternative non-budgetary sources of revenue to cut back on state expenditure on public services. Towards this end, the autonomy policies provide some incentives including management of service provision, the entitlement to set fees and charges for some services, capital mobilization, and distributing net revenues. These entitlements are greater for the more financially autonomous PSDUs. The analysis of the autonomy practices of hospitals and universities in chapter seven further shows that the autonomy policies have incentivized PSDUs to maximize revenues with a view to rewarding their employees with higher bonuses.

In most advanced countries, public services including health care and higher education, in principle, are publicly financed to varying degrees, since they are 
regarded at least in part as public or merit goods (Pollitt et al., 2001). The infusion of market forces, such as competition, freedom of choice, individual responsibilities and flexibility, into the publicly-financed systems of public services are aimed to increase efficiency and responsiveness. Although user charges have been introduced to many countries' public services in order for service users to share the costs, government regulation and financing still remain important mechanisms of coordination (Gabriele, 2006; Government of Vietnam \& World Bank, 2017; Teixeira \& Dill, 2011). The allocation of public resources is targeted at ensuring equity as well as efficiency in service provision.

Vietnam's autonomisation of PSDUs is distinct in that it is overwhelmingly about pushing PSDUs to generate alternative non-budgetary revenues. The process is part of the broader "socialization" strategy that the party-state maps out to reduce, and progressively to remove, the state subsidy through generating alternative nonbudgetary revenues. The implication of such strategy is the shift of the financial burden onto PSDUs and thence onto service users. In this connection, the Vietnamese autonomy can be labelled as "socialised" autonomy, denoting that autonomy aims to "socialise", which tacitly means to marketize and privatize public services. This nature of autonomy is typical of Vietnam; it is a home-grown product of a socialist nation intent on borrowing some capitalist policies in order to survive politically and financially.

Under the socialist political philosophy, the state has a central role in shaping the development of the nation. However, the "socialization", autonomisation, and privatization of public services represent a radical change in the state's role in Vietnam. The concept of "socialised" autonomy officially dictates the state's withdrawal of its commitment to the socialist principle which guarantees the citizenry's universal access to public services provided by socialist institutions. It signals a deeper engagement in the market economy in which public services are increasingly marketized and commercialised. It unravels the tendency of the state to significantly diminish its role in the assurance of the citizenry's equal access to public services. It can be said that nowhere is the unfettered neoliberal ideology more strongly represented than in this meaning of Vietnam's autonomy reforms.

Hitherto, this diminished role of the state in public services is seldom the result of the belief in the efficacy and efficiency of markets, in economic rationality and a move away from large and centralised government towards devolution and privatisation. 
Instead, it denotes the fact that public services in Vietnam are undervalued compared to other economic sectors, which in turn helps explain why "socialization" and autonomisation mainly take place within the public service domain. Public spending on such public services as health care and education remains at very low levels although incomes have grown significantly (see section 3.2, chapter 3). As further presented in chapter 6 , the "socialization" and autonomisation of public services are intensified in the context that the country's political economy generates constant fiscal deficits due to the big losses of a number of key state conglomerates, while the private sector is underdeveloped and faced with numerous unfavourable treatments from the state. Against this backdrop, scarce resources are prioritized for economic growth through investment in infrastructure at the expenses of public services. In a polity preoccupied with economic growth, public services are considered as social burdens and economic costs rather than a significant component of economic development.

As the autonomy policies primarily connect with the increasing shift of responsibility from the state to society, they are designed in ways that give more favour to more selfsufficient PSDUs. In other words, the stronger PSDUs perform financially, the more autonomy they get. In this sense, autonomy becomes the reward that PSDUs are given in exchange for their self-sufficiency. Conversely, self-sufficiency is the condition that PSDUs must satisfy to get autonomy.

Driven by the desire to make PSDUs self-sufficient, the autonomy policies are aligned with stimulating PSDUs to generate revenues through giving them wider autonomy in service provision, setting up fees and charges for some types of services, capital mobilization from private organizations and staff, and retaining and distributing net revenues. The most notable of the incentives is the entitlement to retain net revenues of which a large proportion can be distributed among staff as additional income. It is this entitlement per se that provokes the rent-seeking and corrupt behaviour among PSDUs. In the absence of an effective regulatory and accountability framework, this behaviour becomes endemic, resulting in the burgeoning, aggressive and unregulated commercialisation and marketization of public services. This will be discussed in section 8.3 of this chapter.

\subsubsection{Consideration of the research finding in relation to prior research}

The commercialisation and marketization of public services in Vietnam have been discussed in prior research, much more in connection with user-fees and much less with the "socialization" of public services (see, for example, Forsberg, 2011; London, 
2004; London, 2008). A few studies that examine autonomy explicitly mention the link of the autonomisation of PSDUs with the objective of making them more selfsufficient financially. Wagstaff and Bales (2012) indicate that the autonomy reforms force public hospitals to become less reliant on budget allocations and to generate nonbudgetary revenues by giving them broader autonomy in clinical decision-making, capital mobilization from private organisations and individuals, investments in equipment and infrastructure, the distribution of residual claims and the payment of additional income for employees. Pham (2012) states that the Vietnamese government, driven by financial pressures, grants universities more autonomy in operation to cut back on public funding. London (2008, p. 126) asserts that the thrust of autonomy policy is "unmistakable: to reduce the burden on the central budget and encourage units to develop new forms of income". Painter (2014, p. 209) contends that such policy measures are "motivated primarily by shifting the administrative and financial burden to the local unit and thence (via fees and charges) to the client and customer".

The research finding supports and further expands these research statements by associating autonomisation with the broader "socialization" of public services, identifying this dual process with the strategy of switching costs from the state onto society. The research makes a clearer connection between the autonomisation and "socialization" of public services with user fees, regarding the form of financing through user fees as the basis for the various revenue-generating activities of service providers. The research finding contributes to previous knowledge through explicitly attributing the autonomisation and "socialization" of public services to the socioeconomic conditions and the political economy in which limited public resources are prioritized for economic development at the expense of public services. The other contribution of the research to knowledge also lies in the thoroughness of its articulation of the perceptions and practices of autonomy among PSDUs, which helps underscore the connectedness between autonomy and the switch of cost burden from the state onto society. It follows that the research's distinct contribution is its revelation of the nature of a socialist state, that is an inept state in terms of its espoused noble goal of socialism to ensure the wellbeing of its citizenry, but also a self-serving state, in the sense that it utilizes autonomisation and "socialization" as a means of gathering social resources to shore up its overburdened and corrupt bureaucratic system, the ultimate aim of which is to form an unofficial patronage network in which CPV can exist and thrive. 
In uncovering this underlying intent of autonomy, the research simultaneously supports and validates the claim of Pollitt et al. (2004, p. 20) that a less noble objective of agencification and autonomisation is to create "islands of income generation" for various purposes. The research's result resonates with the findings that agencification in some countries in Central and Eastern Europe and in China are associated with transferring the responsibility for public services to agencies without providing corresponding financial support (see Beblavy, 2001; Moynihan, 2006; Painter, 2008, 2014) The research's finding accords with Painter (2014) who explores a similarity between China and Vietnam in the motives of autonomisation of public services, that is to generate resources to supplement official salaries and to recover service costs in the face of diminishing state subsidy.

The research's findings, at the same time, agrees with the argument that agencificiation is initiated in developing countries and transitional economies for the purpose of joining international institutions and receiving external aid (see Laking, 2005; Moynihan, 2006; Painter, 2012). The research particularly shares the point given by Moynihan (2006) who discovers that agencification in Slovakia is meant to assure the EU that it conforms to the set of administrative standards prescribed by the EU in reforming its public sector as part of the accession process.

\subsection{Autonomy, which is conducted against poor regulation and weak accountability, is aligned with rent-seeking and corrupt behaviour}

In advanced countries, the creation of agencies at arm's length has increasingly replaced traditional accountability emphasizing compliance with rules and procedures with a new accountability system more concerned with achieving targets and responding to clients (Hughes, 2003). This new accountability system emphasizes clear targets, performance measurement using performance indicators and standards, reporting on results and their full costs, and personal responsibilities of managers. Some other accountability mechanisms have also been given primacy such as the presence of users, interest groups and other stakeholders in boards, customer satisfaction surveys, public reporting, use of websites, freedom of information laws, externally oriented quality instruments like quality charters, certification, benchmarking, quality systems like ISO, and balanced scorecard (Verschuere et al., 2006). The means of accountability that have been well-established in the bureaucracy including official rules, codes of conducts, professional ethics, minister control, legislative committees, parliamentary questions, financial audits, judicial reviews, 
advisory committees, ombudsmen, anti-corruption agencies, public hearings, opinion polls, and media scrutiny, whilst still important, have been less prioritised (Haque, 2007).

Vietnam embarks on the autonomisation of public services in the context that a new control and accountability system associated with the result-oriented management and objectives that should accompany the increased autonomy is not yet present. Planning and reporting are perceived as the main tools the state management agencies currently use to hold PSDUs to account for their performance, but planning and reporting are conducted mostly against inputs and processes due to the state management agencies' input- and process-based control (see section 3.1.3, chapter 3 and section 8.1.2 of this chapter). In the absence of indicators to measure the achievement of the planned targets, PSDUs' accountability for outcomes is greatly restrained (see section 3.1.3, chapter 3). Although quality assurance systems have recently been arranged for both hospitals and universities to self-assess their performance, the effectiveness of these systems is contestable given that the accreditation agencies to evaluate the selfassessment results of hospitals and universities are not independent of $\mathrm{MOH}$ and MOET (see section 3.2, chapter 3).

Interviews with hospitals and universities reveal that the current approach to the supervision and inspection of PSDUs taken by the state management agencies (and state competent bodies such as the state Audit, the state Treasury, and Government Inspectorate) is primarily to ensure PSDUs' compliance with rules, regulations, procedures, processes, norms, criteria and standards irrespective of whether compliance is aimed at efficiency and effectiveness. This approach raises doubt about whether the state management agencies have enough workforce to frequently and effectively check PSDUs' compliance with the state rules: an academic affairs manager of university F wonders "how the Department of Tertiary Education which only has over twenty experts can administer the quality of services of more than two hundred and fifty universities nationwide”. It is thus understandable when the Executive Committee of CPV, in its Notification of the Politburo's Concluding Remark dated 26/05/2011 on the Ministry of Finance's Project "Reforming the operational mechanism of public service delivery units and intensifying the "socialization" of some particular public services", refers to the absent or untimely supervision and inspection of the state as the major shortcoming of the autonomy implementation. 
The Concluding Remark also points out another major shortcoming of state management: professional misconduct is not detected and prevented in a timely fashion and not punished in a strict manner. Analysis of empirical data in chapter 7, however, indicates that the late detection of misconduct and the lack of strict punishment reflect not only weak state management, but more importantly, the lack of political commitment on the part of state management agencies to curb the destructively rent-seeking and corrupt practices. This problem is more evident in health care, when $\mathrm{MOH}$ has done almost nothing to correct the abuse and distortion of service provision among hospitals apart from the request for "reconsidering" the provision of "patient-requested" services which proves to be ineffective in practice (see section 7.3.1, chapter 7).

The lack of political commitment to combat the problem of rent-seeking and corrupt behaviour among public service providers is manifest. The root of the problem lies in the incentive structures of the dual process of "socialization" and autonomisation of public services which the communist policy-makers designed to switch the cost burden from the state onto households. Such policy measures, in turn, derive from the flawed economic structure which gives primacy to SOEs at the expense of the immature private counterpart. The return to so much preferential treatment granted to the state economic sector is poor corporate governance, wastefulness, and corruption in a range of state conglomerates, resulting in huge public debts and a stagnant economy. In the face of extremely scarce resources primarily reserved for infrastructure and economic growth, public services, especially health care and education, are left with insufficient attention and poor investment from the state. Hence, the commercialisation and autonomisation of public services have constituted an essential part of the "socialization" myth, all aimed at reducing the state's role in maintaining its citizenry's wellbeing. The commercialisation of public services is rapid, aggressive and unregulated mainly due to the perverse incentive structures shaped by such political economy and policy approach. As the incentive structures are provider-induced, the fight against the rent-seeking and corrupt practices among public service providers, where applicable, is more apparent than real.

In short, Vietnam's autonomisation of PSDUs unfolds against poor regulatory and weak accountability arrangements in which planning and reporting, supervision, inspection, and punishment are not yet effective instruments for improving accountability. In this context, the political commitment to detect and tackle 
misconduct is lacking. This is illustrative of a dilemma because the underlying cause of the issue is the core intentions of the autonomy policies designed by the communist elites per se. Meanwhile, the accountability of CPV, as demonstrated in section 3.1.3, chapter 3 , is greatly limited in the context that the operation of civil society and the media is restrained because of their lack of independence from the party-state. Against this backdrop, the autonomy mechanism has shifted the incentives of PSDUs towards maximizing revenues at the expense of service quality and equitable access.

The systemic abuse and distortion of service provision to squeeze money from service users represent the rent-seeking and corrupt behaviour of PSDUs. This typical behaviour among PSDUs has its roots in the perverse incentives of the autonomy policies which invariably leads them to secure non-budgetary sources of funds through revenue-generating activities in the face of the government's scant fiscal support; but it is compounded by the lack of appropriate regulation and effective accountability which should be formed side by side the autonomy mechanism. The endemic rentseeking and corrupt behaviour of PSDUs amounts to a serious question about the whole notion of "public" service providers mandated in law to be non-profit when their rent-seeking behaviour is more like their private counterparts. Considering a state described itself as socialist, its legitimacy with respect to the provision of public services becomes greatly questionable.

\subsubsection{Consideration of the research finding in relation to prior research}

The rent-seeking and corrupt behaviour among PSDUs, particularly in the health care and higher education sectors has been identified as an unexpected result of the autonomy reforms in a few existing studies. In health care, London (2013) shows some indications of service abuse in finding the correlation of autonomisation with the rapid expansion of "patient-requested" services; the increased use of technologicallysophisticated diagnostic equipment; the increased mobilization of capital for new investments in infrastructure; the increase in the average length of stay; the significant increases in the price of services due to the introduction of "patient-requested" services across the full range of medical procedures in more autonomous hospitals; and the expansion of revenues generated from "patient-requested" services and use of privately-procured equipment and the significant increases in staff pay among higherautonomy hospitals. In this connection, Vian et al. (2012) show that over-treatment and informal payments are common forms of corruption in health care services. While over-treatment is believed to be driven by financial incentives, informal payments are 
presumed to relate to overcrowding and high demand, which create pressures for patients to bribe doctors to be seen sooner or assured of attention from providers, as much as cultural expectations and ideas of social reciprocity and prevailing attitudes towards corruption.

In higher education, Pham (2012) suggests that public universities, in the face of state underfunding, tend to increase revenues through expanding student enrolment in "informal" study programmes such as in-service and on-site programmes where the MOET's oversight is neglected or in the study programmes that have high market demand while investment in the academic capacity and facility in these study programmes is disproportionate to the expansion. Nguyen et al. (2016) discover that the deployment of the English as a medium of instruction programme of a Vietnamese public university is mainly a strategy to gain resources to navigate through the new autonomy regime, but unfortunately is not accompanied by the increase in educational quality. McCornac (2012, p. 269) further demonstrates the institutional corruption in higher education according to which "the practice of gift-giving has often been exploited to mask a corrupt practice in the disguise of a cultural expectation". On these accounts, London (2010, p. 376) points to "the further stratification of the education system" as the hazard of the decentralization of higher education which, according to him, brings the risk of commercializing higher education with little regard to quality improvements.

The research result supports and enriches all the findings of these studies in that it provides a more in-depth narrative of the various rent-seeking and corrupt practices including the abuse and distortion of services and the solicitation and receipt of envelope payments among public service providers. For health care, rent-seeking and corruption are represented in the inducement of users into "patient-requested" services, the focused investment in this type of services at the expense of normal services, the overprovision of therapies and tests, the overuse of privately-owned high-tech equipment, the increase in patients' length of stay in hospitals, the over-prescription of drugs, the higher-level hospitals' competition with, rather than complement to, lower-level counterparts in attracting patients, the breach of the state-prescribed ratios of medical practitioners per bed, and the solicitation and receipt of "envelopes" from patients. For higher education, rent-seeking and corruption are manifested through the inducement of students into high-quality classes, the extensive opening up of profitmaking study programmes, the breach of the state-prescribed ratios of students per 
lecturer, the engagement in bribes for research grants, and the solicitation and receipt of "envelopes" from students. Obviously, these findings offer a much broader and more detailed and comprehensive picture of the rapid, aggressive and unregulated commercialisation of public services and of the prevalent and rampant rent-seeking behaviour, service delivery abuses and corruption among public service providers.

The research also goes deeper than the current research in reflecting on the rentseeking and corrupt practices with reference to the wider institutional environment infused with a system of rules, norms and cultural values, in a bid to understand why those practices are so widespread and entrenched and why they have become a takenfor-granted routine, a popular mode of behaviour, a common way of interaction, a dominant norm, and above all, a culturally-rooted cognition among Vietnam's public service providers. The research especially finds that the rent-seeking and corrupt behaviour among PSDUs are already stimulated by the autonomy rules and incentives, but that they have become so deeply embedded in the system is largely because they are supported by a weak regulatory and accountability structure as well as by a web of norms and cultural beliefs that promote these unethical practices such as nepotism and cronyism, the "envelope" culture, the "asking-giving" culture, localism and the "village" culture. Clearly, a major finding of the research is that the rent-seeking and corrupt practices have been deeply institutionalized in Vietnam's politics and bureaucracy, which requires the need of a wholehearted effort of the entire system to transform, starting at least from the political commitment of the communist leaders.

Unfortunately, the fight against the rent-seeking and corrupt practices among public service providers, according to the research finding, is a conundrum in Vietnam's contemporary context. The research points out the incentive structures of the autonomy reforms as the root of the problem, which is in line with Painter's $(2014$, p. 215) observation that "a by-product of these reforms has been to encourage service delivery abuses, including widespread corruption, and highly unequal access due both to affordability issues and also to the commercially-driven incentives driving investment in and location of facilities".

The research highlights the hazards of the placement of profits and private benefits before public interests due to inadequate regulation and immature accountability. In this respect, the research supports Laking's (2005) suggestion that in transitional and developing countries, agencies are often created in circumstances when the right institutions supporting agencification have not been established. This is clearly evident 
in a number of countries like China, Slovakia, Latvia, and Tanzania (see Moynihan, 2006; Pollitt, 2004; Sulle, 2010; Tam, 2010). In particular, the research's findings are in common with Tam's (2010) study which attributes China's declining health service quality to the dramatic cutbacks in public health financing and the lack of strong and effective regulatory institutions. The research especially shares the study's claim that in China the revenue-generation imperative is so strong that it can override any effort to establish effective regulatory framework. The research also finds a similar feature characterising Vietnam's and Thailand's public sector, that is the prevalence of nepotism and patronage in the process through which autonomous public organisations are created, run and managed.

By emphasizing this feature of Vietnam's autonomisation, the research is in agreement with some observers who emphasize Vietnam's lack of proper regulation and appropriate accountability mechanisms in the transition towards autonomisation. Specifically, the research concurs with Painter (2014, p. 209) in that "many education and health services in... Vietnam are now managed and provided by lightly regulated "para-state" entities with limited budget subsidy". The research agrees with Fritzen (2007, p. 81) when the author notes that "[c]entral authorities have not yet proven adept in harnessing autonomy by adjusting regulatory and enforcement efforts to prevent price gouging... Their lack of disaggregated information system on local performance coupled with a blunt approach to performance monitoring leaves them essentially "flying blind" when transferring managerial autonomy to hospitals and clinics." The research accords with the argument of Vallely and Wilkinson (2008) that the current higher education governance system does not ensure universities are accountable to outside stakeholders, nor does it ensure universities are accountable within the hierarchy considering that the current norm-based funding is not tied to performance and research funding is awarded uncompetitively and primarily a form of salary supplementation.

The research, however, goes further in claiming the lack of political commitment to improve the current regulatory and accountability arrangements due to the state's ultimate desire to relieve its budget burden and to transfer such financial burden onto its citizenry by offering PSDUs extensive opportunities to pursue their material selfinterests, to the detriment of the larger public goods. The research emphasizes that the current autonomy policies operate mainly on the supply side and the demand side does not weigh heavily in the policy development. The research's implication is that the 
regulatory and accountability mechanisms, if improved, will still have little effect on the current endemic problem of rent-seeking and corruption unless there is a radical institutional change in the political economy, economic incentives, and the role of the state in public service delivery. 



\section{CHAPTER 9}

\section{CONCLUSION}

\subsection{Summaries of research findings}

This research sought to explain the association between autonomy and the increasing commercialisation of public services and the mounting cost burden experienced by millions of Vietnamese service users. The research's aim was to provide a greater understanding of the nature of autonomy in public service delivery in contemporary Vietnam. The research's question is therefore:

\section{What is the meaning of the autonomy of PSDUs in Vietnam?}

To answer the research question, the research was guided by the three research subquestions:

1. What is the substance of the autonomy policies of PSDUs in Vietnam?

2. How is autonomy practised in finance, personnel, and organization of service provision among public hospitals and public universities in Vietnam?

3. What are the specific institutional factors that affect the autonomy of public hospitals and public universities in Vietnam and how do they affect it?

In response to the research question and sub-questions, the research addressed two main aspects of Vietnam's autonomy reforms: the substance of the autonomy policies and the implementation of autonomy across different dimensions of financial and personnel management and organisation and provision of public services. The research analysed these two aspects of the autonomy reforms in the light of the country's historical and sociological institutional factors. In doing so, the research described and analysed Vietnam's socialist-cum-market development path, policy-making characteristics, and political economy and discerned their implications for the autonomy policies. The research identified specific formal rules (legislation, regulation, organisational structure of Vietnam's political and administrative system) and informal rules, norms, and values embedded in this dual government system and explored how these formal and informal rules, norms, and values influence the implementation of autonomy in practice. The data sources for the analysis were Vietnam's autonomy legal framework, government's reports, and empirical data gained from in-depth interviews with participants who have practical experience with autonomy. The research, therefore, illuminates a holistic and rich picture of the nature of autonomy in Vietnam and its implications for public services. Given all that has 
been scrutinised in this research, it would be worth highlighting the meaning of autonomy of PSDUs in Vietnam:

First, Vietnam's autonomy reforms are the political rhetoric that VCP initiated primarily to strengthen effective government management as a pillar of its legitimacy, at risk due to the serious socio-economic crisis, and its need to be seen to be replacing the failing centrally-planned system. As a rhetoric, autonomy is bound by a system of formal and informal rules and norms and cultural values. It is specifically constrained by the party-state's formal and informal control over inputs and processes aimed at protecting the ultimate authority of CPV in a decentralised management system and to ensure that the benefits flowing to PSDUs from autonomisation are shared with central government.

Second, autonomy of management of public services is not linked to the depoliticisation necessary for management decisions to be taken in the interests of organisational efficiency and effectiveness. The insulation of administration from politics is not on the agenda of Vietnam's autonomy reforms.

With the presence of the organisational network and the operational principles of the party elites cutting across all managerial aspects of Vietnam's PSDUs, there is no significant aspect of management that can be depoliticised. As discovered in this research, political intervention in administration is pervasive. It is present in personnel (political control of the appointment, dismissal and performance appraisal of PSDUs' heads and deputy heads), in payroll (a national basic salary system to uphold the socialist core egalitarian tenet), in internal spending (diminishing the power of PSDUs' heads through the fundamental socialist principle of democratic centralism), in organisational strategies and directions (through the presence of the Party Committee within each PSDU to impose control on matters likely to affect the CPV's power and legitimacy), in academic curricula (compulsory courses on ideology and political thought), and in research (control of research topics to limit challenges to political authority). Political intervention in administration is both formal, through official powers of regulation, and informal, through direct intervention, not specifically authorised by state law, by central Ministry and party officials.

Third, the research explores the interrelationship between formal and informal institutions in their impacts on the actual autonomy of PSDUs. The research finds that many of the informal institutional factors (i.e. the CPV's core tenet of democratic centralism, the informal norm of favouritism) tend to complement the formal ones in 
restraining PSDUs' actual autonomy. Additionally, the research explores that many informal institutional factors (i.e. the financial self-sufficiency tradition, the "village" culture, the traditional seniority convention, the ideological egalitarian philosophy, the value of sentiments over reasons, the cultural belief about " $\mathrm{a}$ bad compromise is better than a good lawsuit", the legacy of centralised planning and state subsidy, and localism) tend to compete with the formal ones, providing PSDUs with more or less decision space than they are conferred by the formal ones.

Fourth, the maintenance of input- and process-based control greatly reduces the flexibility and innovation of state employees, who are generally cast in the role of administrators preoccupied with conforming, or pretending to conform, to regulations, procedures, and standards rather than managers, who are more concerned about achieving targets and responding to clients. On the other hand, regulatory control is less than fully effective in practice because officials in PSDUs frequently violate state regulations when they see them as constraining, conflicting, confusing, ineffective, inconsistent, irrational or irrelevant, and when they have personal or organisational incentives to act outside the rules.

Fifth, a principal consequence of the dual process of autonomisation and "socialisation" in the PSDUs under study was a significant shift of the costs of service provision from the state to service providers and thence onto service users to make room for increasing public expenditure on other priorities. This shift through increased user charges was a matter of deliberate policy. The autonomy policies have created incentives to induce PSDUs to generate revenues in the face of a diminishing subsidy from the state. The autonomy policies are thus designed in ways that confer greater incentives and entitlements on financially self-sufficient PSDUs.

Sixth, autonomy is associated with the various forms of abuse and distortion of services. These rent-seeking and corrupt practices unfold in the provision of "patientrequested" services, the overprovision of therapies and tests, the increase of the length of stay at hospitals, the overuse of high-tech equipment, the overprescription of drugs, the establishment of high-quality study programmes and new study programmes, and the solicitation and receipt of "envelopes". These practices are widespread, organised, and systemic among PSDUs. The root cause is the design of autonomy policy that presents PSDUs with both the opportunity and the incentive to maximize revenues to enrich their staff and patrons. 
Seventh, the problems of rent-seeking and corruption become seriously compounded by the lack of an effective regulatory and accountability system. In particular, the absence of regulation and accountability lies in not only the absent or untimely supervision and inspection of the state or the weak quality assurance systems, but more importantly the lack of political commitment of state management agencies, especially of the top elites, to fight against corruption. As a consequence, the problems of rentseeking and corruption are unresolved, resulting in the unregulated, rapid, and aggressive commercialisation of public services.

Eighth, corruption in Vietnam is highly political, but it is the country's historical and cultural institutional factors that render corruption endemic and systemic. The research discovers the presence of such institutional factors as the "applications-grants" modality, the line ministry mechanism, the "envelope" culture, and the "askinggiving" culture in many aspects of management and service provision of PSDUs. Deeply embedded in the public sector, these institutional factors breed and facilitate rent-seeking and corrupt behaviour among state employees. While resulting from the legacy of central-planning and state subsidy, they are further abused by state employees in their pursuit of personal interests.

\subsection{Research contributions}

\subsubsection{Theoretical contributions}

The previous literature shows that agencification in developing countries and transitional economies is "poorly defined territory" (OECD, 2002). The research's results provide empirical evidence to contribute to improving the map by providing a better understanding of the autonomy reforms of a developing country which is transitioning from a centrally-planned economy to a market-based economy. A significant contribution of the research to the academic literature lies in its rich narrative of the perceptions and practices of autonomy among public organisations. The research gives a clear explanation of the nature of autonomy of Vietnam's public service providers through situating the autonomy reforms in the context of historical and sociological institutions. The research underlines the primary intent of the autonomy policies and its implications for public organisations' performance.

The research offers an illuminating insight into the burgeoning commercialisation of public services that exerts substantial financial pressure on their Vietnamese clients. The research argues that the commercialisation of public services in Vietnam is aggressive because it is driven by the rent-seeking and corrupt behaviour among public 
service providers. The problem of rent-seeking and corruption, in its turn, is caused by the incentive structures provided by the autonomy policies which are designed primarily to shift the cost burden from the state onto service users. In the absence of effective regulation and accountability and political commitment, rent-seeking and corruption among public organisations become persistent and unresolved.

In addition to narrowing the gap in the academic literature, the research makes a significant theoretical contribution by integrating the theoretical insights from historical institutionalism and sociological institutionalism to study the autonomy policies and their implementation in practice. This theoretical framework argues for the need to consider both historical institutions and sociological institutions, each of which offers a distinctive and meaningful insight that contributes to drawing a holistic picture of autonomy and its implications for public organisations' performance. The simultaneous use of the two institutional approaches helps identify the different institutional factors that shape the evolution and substance of the autonomy policies and the implementation of these policies on the ground.

\subsubsection{Research implications for policy-making}

The nature of autonomy of Vietnam's public service providers highlights the need for a radical institutional change in the political economy, economic incentives, and the role of the state in public services. The economic structure needs to be transformed in ways that create a level playing field for effective competition between the state economic sector and its private counterpart. Simultaneously, the restructuring of SOEs needs to be effective to separate between the functions of the state as the owner of SOEs and as a regulator for the whole economy. An improvement in the internal governance mechanism of SOEs is also required to make SOEs more transparent and accountable. These are important measures to enhance SOEs' efficiency and to address the corruption problem which is rampant among SOEs.

The adverse impacts of autonomy policy illustrate the necessity to alter the economic incentives primarily designed to induce public organisations to generate revenues. This indicates the importance of increased state financing for public services. High priority needs to be given to public services (especially health care) instead of leaving public financing in services to commercialisation and out-of-pocket payment to cover service costs. These structural changes require a profound transformation in the thinking of the state towards the role of public services in economic growth, in which public 
services such as health care and higher education should be regarded as an investment in development, rather than an economic burden.

Economic growth, while significant, does not necessary mean that poverty can be addressed. A welfare state maintaining state investment in public services is vitally important, since poor outcomes of public services, particularly of health care services, can result in people becoming poor and poverty continuing to exist. As Sidney Hillman famously quipped: "Politics is the science of who gets what, when, and why". Rapid commercialisation of public services cannot replace the role of the state in financing for public services and in improving service outcomes. Here political choice matters concerning the decision on how much of national income to devote to redistribution and spending on public goods.

In this connection, a well-designed institutional framework needs to be put in place to fit in well with the reform ideas, especially when considering that these reforms ideas are borrowed and transferred from advanced countries. The institutional framework needs to include state financing design to make public services affordable and accessible. Furthermore, as the research demonstrates, a more effective regulatory and accountability system is needed to counterbalance the greater flexibility to which public organisations are entitled. That system requires not only an improvement in regulatory quality, performance management and quality assurance but more importantly it demands the political accountability from the top leaders of CPV.

\subsection{Limitations and future research}

Considering that public organisations in Vietnam are traditionally close and nontransparent, approaching these organisations for information about their perceptions and practices is a formidable task. This explains the limited information available to the public so far regarding the performance and service outcomes of public organisations. Although this research drew on a considerable amount of data from interviews and government reports, the research's results could have been more substantial with more sources of evidence. The notable limitation of the research is that it could not make use of the strength of case-study research by combining different research methods to collect data for triangulation. When approaching cases, the researcher tried to gain access to documents generated by PSDUs but the amount of documentation collected was trivial and could not constitute a robust and reliable source of evidence for study. Also, the researcher was unable to use the observation 
method to capture the actual implementation of autonomy among PSDUs, especially at their front line where services are provided.

Further, this research takes a cross-sectoral approach, but its study was limited to the analysis of autonomisation in two sectors. While the research's generalisability is extensive because of its analysis of the autonomy policies applicable to all public service sectors and its multiple-case approach, the research's focus on health care and higher education means that the implementation of autonomy among other service sectors remains open to question.

In addition, that this research primarily aimed to provide empirical account of autonomy practices among service providers pre-empted it from exploring the perspectives of policy-makers who might have designed autonomy reforms under various international and local pressures. As such, the actual source or origin of the ideas and models that lay behind Vietnam's autonomy reforms has not been properly researched.

Lastly, the research analyses the implications of autonomy from service providers' perspectives. While the research was informed by prior literature regarding the autonomy impacts on public services, the research's reliance on the perceptions and experiences of service providers precluded the research from taking any further study of the experiences of service users when accessing public services.

The research's limitations create opportunities for future research. These include an exploration of autonomisation across service sectors using multiple sources of evidence to garner a deeper and more comprehensive picture of the autonomy reforms, especially the implementation of Government Decree 16, which strongly promotes the acceleration of the "socialisation' of public services. The perspectives of policymakers also worth discerning, especially in relation to the ideas and models behind the design of autonomy policies. The perception and experiences of service users also should be further investigated so that a complete understanding of the impacts that the autonomy reforms have so far made on public services could be achieved. 



\section{APPENDICES}

\section{APPENDIX A: PROPOSAL FOR RESEARCH PARTICIPATION}

I am a doctoral student in Public Policy at Victoria University of Wellington. In fulfilment of this Degree, I am undertaking a research to explore how autonomy is exercised in practice in specific functions of task performance, organisational apparatus, personnel and finance within public universities and public hospitals in Vietnam. It is expected that the results of the research will inform future design of autonomy policy in Vietnam and elsewhere. Ethics approval for this research has been granted by the Victoria University Human Ethics Committee.

I would like to invite you to participate in my research. The research will primarily involve interviews of directors, managers and staff of public hospitals and public universities. The potential interviewees from each agency are the director and/or deputy directors, managers and staff in charge of organisational apparatus, personnel and finance as well as professional staff. The research will also extend to interviewing key personnel from the Ministry of Health and the Ministry of Education and Training, and experts in the public sector reform.

Questionnaires will be sent to the interviewees prior to the interview. It is envisaged that the interview will take from one to two hours. Participation in the research is voluntary and each participant may ask to withdraw from the research within two days after the interview.

Responses will form the basis of the findings of my research and will be presented using pseudonyms. It is not possible for interviewees and their agency/ministry's department to be identified. All data collected will be kept confidential and exclusive to me and my supervisor, Associate Professor Karl Löfgren. Data will be destroyed 5 years after the end of the research.

The thesis will be deposited in the library of Victoria University of Wellington. It is intended that data and results from the interviews also will be used for publications in academics or professional journals, presentations at academic or professional conferences, and policy reports and discussion papers to inform relevant policy decisions. Participants will be given the opportunity to request a summary of the research findings. It is hoped that the results of this research will be of value to you.

If you would like to receive further information about the research or have any questions, please contact me by email Minh.Vo@vuw.ac.nz and phone 6444639499 
or my supervisor, Associate Professor Karl Löfgren by email

Karl.Lofgren@vuw.ac.nz and phone 6444636349.

Thank you

Minh Vo 


\section{APPENDIX B: INTERVIEW GUIDE FOR DIRECTOR, DEPUTY DIRECTORS, MANAGERS AND STAFF OF PUBLIC SERVICE DELIVERY UNITS}

\section{Interview guide}

This research examines the autonomy practice of public service delivery agencies in terms of task performance, organisational apparatus, personnel and finance. Practice in this research is defined as a set of actions that displays a pattern that can remain relatively stable across time. Practices consist of what a group of people do and the unintended consequences of those actions.

The autonomy practices of agencies is analysed through the institutional lenses, which define institutions as formal rules and informal norms and values that shape individual and organisational actions. Formal institutions are rules and regulations that are formally codified in written documents; they are enforced by the state with sanctioning activities for failure to obey. Informal institutions are norms, conventions, customs, traditions, cognitive scripts, moral templates, models, symbols and values. They are often self-asserting and self-enforcing when they are rooted in the beliefs and/or attitudes of individuals.

\section{Questions}

1. What autonomy in terms of task performance, organisational apparatus, personnel and finance does your unit have in practice? Are there any differences between formal autonomy set out in formal rules and actual autonomy of your unit? Does the autonomy in one dimension or more than one dimensions correspond with the autonomy in the other dimensions?

2. What are your unit's autonomy practices in terms of task performance, organisational apparatus, personnel and finance?

3. What are your opinions about the autonomy practices of your unit in terms of task performance, organizational apparatus, personnel and finance?

4. How do formal rules pertaining to autonomy enhance/restrict the autonomy practices of your unit?

5. How is your unit controlled and held accountable for its performance? What is the effect of these accountability mechanisms on the autonomy practices of your unit?

6. Are there any other formal rules that affect the autonomy practices of your unit and how do they affect? 
7. How do informal norms such as informal standard operating procedures, professional ethics, and codes of conduct affect the autonomy practices of your unit?

8. How does the culture of centralized-planning and bureaucratic decisionmaking affect the autonomy practices of your unit?

9. How do cultural values such as the hierarchical relationships, traditional moral principles that value virtue and sentiment over rules and reasons, "village" culture that prioritizes organizational rules and habits over national rules, and "asking and giving" culture affect the autonomy practices of your unit?

10. There have been several reported cases of nepotism, clientelism, rent-seeking and corrupt practices within public service delivery units? How could these problems happen and how do they relate to the autonomy practices? How would you deal with these problems if they arise within your unit?

11. Are there any other informal norms and values that affect the autonomy practices of your unit and how do they affect?

12. The Government's autonomy policy is to bring into full play agencies' own capabilities in order to provide high-quality services for service users and at the same time to increase revenues to step by step ensure their staff's incomes. How does this affect the autonomy practices of your unit? 


\section{APPENDIX C: INTERVIEW GUIDE FOR SENIOR MANAGERS FROM MOH/MOET/ OTHER STAKEHOLDERS}

\section{Interview guide}

This research examines the autonomy practice of public service delivery units in terms of task performance, organisational apparatus, personnel and finance. Practice in this research is defined as a set of actions that displays a pattern that can remain relatively stable across time. Practices consist of what a group of people do and the unintended consequences of those actions.

The autonomy practices of public service delivery units is analysed through the institutional lenses, which define institutions as formal rules and informal norms and values that shape individual and organisational actions. Formal institutions are rules and regulations that are formally codified in written documents; they are enforced by the state with sanctioning activities for failure to obey. Informal institutions are norms, conventions, customs, traditions, cognitive scripts, moral templates, models, symbols and values. They are often self-asserting and self-enforcing when they are rooted in the beliefs and/or attitudes of individuals.

\section{Questions}

1. What autonomy in terms of task performance, organisational apparatus, personnel and finance do public service delivery units under the control of your ministry have in practice? Are there any differences between formal autonomy set out in formal rules and actual autonomy of units? Does the autonomy in one dimension or more than one dimensions correspond with the autonomy in the other dimensions?

2. What are the autonomy practices of units under the control of your ministry in terms of task performance, organisational apparatus, personnel and finance?

3. What are your opinions about the autonomy practices of units under the control of your ministry in terms of task performance, organizational apparatus, personnel and finance?

4. How do formal rules pertaining to autonomy enhance/restrict the autonomy practices of units under the control of your ministry?

5. What types of control do your ministry have over public service delivery units? How does your ministry hold units accountable for their performance? How do 
these control and accountability mechanisms affect the autonomy practices of units?

6. Are there any other formal rules that affect the autonomy practices of units under the control of your ministry and how do they affect?

7. How do informal norms such as informal standard operating procedures, professional ethics, and codes of conduct affect the autonomy practices of units under the control of your ministry?

8. How does the culture of centralized-planning and bureaucratic decisionmaking affect the autonomy practices of units under the control of your ministry?

9. How do cultural values such as the hierarchical relationships, traditional moral principles that value virtue and sentiment over rules and reasons, "village" culture that prioritizes organizational rules and habits over national rules, and "asking and giving" culture affect the autonomy practices of units under the control of your ministry?

10. There have been several reported cases of nepotism, clientelism, rent-seeking and corrupt practices within units? How could these problems happen and how do they relate to the autonomy practices of units? How would you deal with these problems if they arise within units under the control of your ministry?

11. Are there any other informal norms and values that affect the autonomy practices of units under the control of your ministry and how do they affect?

12. The Government's autonomy policy is to bring into full play units' own capabilities in order to provide high-quality services for service users and at the same time to increase revenues to step by step ensure their staff's incomes. How does this affect the autonomy practices of units under the control of your ministry? 


\section{REFERENCE}

Abonyi, G. (2005). Policy reform in Viet Nam and the Asian Development Bank's state-owned enterprise reform and corporate governance program loan: Asian Development Bank.

Abuza, Z. (2001). Renovating politics in contemporary Vietnam: Lynne Rienner Publishers.

Acuna-Alfaro, J. (2009). Media's coverage on corruption in the health sector in Vietnam: the tip of the iceberg? Paper presented at the Anti-Corruption Dialogue meetings, Hanoi. Vietnam.

Adam, F. (2003). Decentralisation in Vietnam-Working effectively at provincial and local government level - a compative analysis of Long An and Quang Ngai provinces. Hanoi: Australian Agency of International Development.

Akram-Lodhi, H., Chernomas, R., \& Sepehri, A. (2005). Penalizing patients and rewarding providers: user charges and health care utilization in Vietnam. Health Policy and Planning, 20(2), 90-99.

Allen, P., Cao, Q., \& Wang, H. (2014). Public hospital autonomy in China in an international context. International Journal of Health Planning and Management, 29(2), 141-159. doi:10.1002/hpm.2200

Amenta, E., \& Ramsey, K. M. (2010). Institutional Theory. In K. T. Leicht \& J. C. Jenkins (Eds.), Handbook of Politics: State and Society in Global Perspective. LLC: Springer Science.

Anderson, R., \& Klaassen, H. (2012). The fallacy of the context. International Journal of Productivity and Performance Management, 61(5), 483-501. doi:http://dx.doi.org/10.1108/17410401211232939

Baldwin, R., \& Cave, M. (1999). Understanding Regulation, Theory, Strategy, and Practice. Oxford: Oxford University Press.

Barbour, R. S. (2008). Introducing qualitative research: a student guide to the craft of doing qualitative research. Los Angeles: London.

Beblavy, M. (2001). Understanding the waves of agencification and the governance problems they have raised in Central and Eastern European Countries. OECD Journal on Budgeting, 2(1), 121-139.

Beeson, M., \& Pham, H. H. (2012). Developmentalism with Vietnamese characteristics: the persistence of state-led development in East Asia. Journal of Contemporary Asia, 42(4), 539-559.

Behn, R. D. (2002). Rethinking Democratic Accountability. Washington, UNITED STATES: Brookings Institution Press.

Béland, D. (2009). Ideas, institutions, and policy change. Journal of European Public Policy, 16(5), 701-718.

Bell, S. (2002). The Limits of Rational Choice: New Institutionalism in the Test Bed of Central Banking Politics in Australia. Political studies, 50(3), 477-496. doi:10.1111/14679248.00380

Berdahl, R. (1990). Academic freedom, autonomy and accountability in British universities. Studies in Higher Education, 15(2), 169-180. doi:10.1080/03075079012331377491

Billinton, J., \& Xin, L. (2000). An analysis of university autonomy and governance in three universities: Canada, Britain, and China. International Education, 30(1), 50-73.

Bouckaert, G., Peters, B. G., \& Verhoest, K. (2010). The Coordination of Public Sector Organisations: Shifting Patterns of Public Management: Palgrave Macmillan.

Bouckaert, G., \& Peters, G. B. (2004). What is available and what is missing in the study of quangos. In C. Pollit \& C. Talbot (Eds.), Unbundle Government: A critical analysis of the global trend to agencies, quangos and contractualisation London and New York: Routledge. 
Bowornwathana, B. (2006). Autonomisation of the Thai state: some observations. Public Administration and Development, 26(1), 27-34. doi:10.1002/pad.368

Bowornwathana, B. (2012). Thailand. In K. Verhoest, S. Van Thiel, G. Bouckaert, \& P. Laegreid (Eds.), Government Agencies: Practices and Lessons from 30 countries: Palgrave macmilan.

Bowornwathana, B. (Ed.) (2004). Putting new public management to good use: Autonomous public organisations in Thailand. London and New York: Routledge.

Brinkerhoff, D. W. (2004). Accountablility and Health Systems: Toward Conceptual Clarity and Policy Relevance. Health Policy and Planning, 19(6), 371 - 379.

Bruynooghe, S., Faingold, I., Firmalo, T., Futrell, A., Kent, J., \& Mukherjee, R. (2008). Implementation of Civil Service Legislation in Vietnam: Strengthening Elements of a Position-Based System Service. Paper presented at the Princeton University: Graduate Policy Workshop Final Reports.

Bryman, A. (2008). Social research methods. Oxford; New York: Oxford University Press.

BTI. (2012). Vietnam Country Report. Retrieved from https://www.btiproject.org/fileadmin/files/BTI/Downloads/Reports/2012/pdf/BTI 2012 Vietnam.p df:

Bui, T. H. (2013). The development of civil society and dynamics of governance in Vietnam's one party rule. Global Change, Peace \& Security, 25(1), 77.

Bui, T. Q. (2011). School Dropout Trends in Vietnam from 1998 to 2006. In J. London (Ed.), Education in Vietnam. Singapore: Institute of Southeast Asian Studies.

Busuioc, M., Curtin, D., \& Groenleer, M. (2011). Agency growth between autonomy and accountability: the European Police Office as a 'living institution'. Journal of European Public Policy, 18(6), 848-867. doi:10.1080/13501763.2011.593313

Campbell, J. L. (1998). Institutional analysis and the role of ideas in political economy. Theory and Society, 27(3), 377-409. doi:10.1023/a:1006871114987

Campbell, J. L., \& Pedersen, O. K. (2001). The rise of neoliberalism and institutional analysis: Princeton University Press.

Caulfield, J. (2004). Creating executive agencies in Tanzania. In C. Pollitt \& C. Talbot (Eds.), Unbundled Government: A critical analysis of the global trend to agencies, quangos, and contractualisation: Routledge.

Chen, L. C., \& Hiebert, L. G. (1994). From socialism to private markets: Vietnam's health in rapid transition: Harvard Center for Population and Development Studies, Harvard School of Public Health.

Christensen, J. G. (2001). Bureacratic autonomy as a political asset In B. G. Peters \& J. Pierre (Eds.), Politicians, Bureaucrats and Administrative Reform: Routledge.

Christensen, T., Danielsen, O. A., Laegreid, P., \& Rykkja, L. H. (2016). COMPARING COORDINATION STRUCTURES FOR CRISIS MANAGEMENT IN SIX COUNTRIES. Public Administration, 94(2), 316-332. doi:10.1111/padm.12186

Christensen, T., \& Lægreid, P. (2004). Governmental autonomisation and control: the Norwegian way. Public Administration and Development, 24(2), 129-135. doi:10.1002/pad.318

Christensen, T., \& Lægreid, P. (2006). Autonomy and regulation: coping with agencies in the modern state. Northampton, MA; Cheltenham, UK: Edward Elgar.

Christensen, T., Lægreid, P., Roness, P. G., \& Røvik, K. A. (2007). Organization theory and the public sector: Instrument, culture and myth: Routledge.

Clemens, E. S., \& Cook, J. M. (1999). Politics and institutionalism: Explaining durability and change. Annual Review of Sociology, 25, 441-466. 
Cobbe, J. (2011). Education, education financing, and the economy. In J. London (Ed.), Education in Vietnam. Singapore: Institute of South East Asian Studies.

Communist Party of Vietnam's Executive Committee. (2011). Thông báo Kết luận của Bộ Chính trị về Đề án" Đổi mới cơ chế hoạt động của các đơn vị sự nghiệp công lập, đầy mạnh xã hội hóa một số loại hình dịch vụ sự nghiệp" (Notification of the Politburo's Concluding Remark on Project "Renovating the operational mechanism of public service delivery units, intensifying the "socialization" of some particular public services"). Hanoi.

Communist Party of Vietnam. (2016). Điều lệ Đảng Cộng Sản Việt Nam (Charter of the Communist Party of Vietnam). Hanoi.

Crispin, S. W. (2012). Vietnam's press freedom shrinks despite open economy.

Dan, S. (2014). The effects of agency reform in Europe: A review of the evidence. Public Policy and Administration.

Dang, D. D. (2017). Một số vấn đề về đổi mới quản lý dịch vụ công ở Việt Nam (Some issues on the renovation of public services management in Vietnam): danangtimes.

Dao, M. C. (1997). Administrative reform in Vietnam: need and strategy. Asian Journal of Public Administration, 19(2), 303-320.

Dao, V. K. (2014). Key challenges in the reform of governance, quality assurance, and finance in Vietnamese higher education - a case study. Studies in Higher Education, 1-16. doi:10.1080/03075079.2013.842223

DiMaggio, P. J., \& Powell, W. W. (1983). The Iron Cage Revisited: Institutional Isomorphism and Collective Rationality in Organizational Fields. American Sociological Review, 48(1), 147.

Dollar, D., \& Ljunggren, B. (1995). Macroeconomic adjustment and structural reform in an open transition economy: the case of Vietnam. Prepared for a Confrence on Participation of Reforming Economies in the Global Trading and Financial System, UNU/WIDER, Helsinki, Finland.

Drewry, G., Greve, C., \& Tanquerel, T. (Eds.). (2005). Contracts, performance measurements, and accountability in the public sector (Vol. 25). Amsterdam; Washington, DC: IOS Press.

Duric, I. (2011). The new institutionalism(s): a framework for the study of public policy in post-conflict and post-communist countries. Politicka misao, 48(5), 85-105.

Emmerson, G., \& Goodrick, D. (2013). Mixed Methods in Social Research. Program Course Notes.

Fahey, S. (1997). VIETNAM AND THE 'THIRD WAY': THE NATURE OF SOCIO-ECONOMIC TRANSITION. Tijdschrift voor economische en sociale geografie, 88(5), 469-480. doi:10.1111/j.1467-9663.1997.tb01640.x

FForde, A. (2004). Vietnam: What Needs to be Done? The Asia-Pacific: A region in transition, 285-299.

Fforde, A., \& De Vylder, S. (1996). From plan to market: the economic transition in Vietnam. Boulder, Colo: Westview Press.

Fjeldstad, O.-H. (2002). Fighting fiscal corruption: The case of the Tanzania Revenue Authority. Retrieved from https://econpapers.repec.org/paper/chmwpaper/wp2002-3.htm website:

Fligstein, N., \& Freeland, R. (1995). Theoretical and comparative perspectives on corporate organization. Annual Review of Sociology, 21(1), 21-43.

Flinders, M., \& Buller, J. (2006). Depoliticization, Democracy and Arena Shifting. In T. Christensen \& P. Laegreid (Eds.), Autonomy and Regulation: Coping with Agencies in the Modern State (Vol. ). UK: Edward Elgar Publishing Limited. 
Forsberg, L. T. (2011). The Political Economy of Health Care Reform in Vietnam. Paper presented at the Oxford Symposium on Urbanization, Health and Human Security: Challenges for Emerging Markets, Green Templeton College, Oxford.

Forsberg, L. T. (2013). The Political Economy of Healthcare: Commercialisation in Vietnam: The Global Economic Governance Program: University of Oxford.

Foucault, M. (2008). The birth of biopolitics. New York: Palgrave Macmillan.

Freedomhouse. (2016). Vietnam: Freedom of the Press 2016.

Fritzen, S. (2002). The 'foundation of public administration'? Decentralization and its discontents in transitional Vietnam. Paper presented at the Governance in Asia: Culture, Ethics, Institutional Reform and Policy Change, Hong Kong.

Fritzen, S. (2005a). Beyond "Political Will": How Institutional Context Shapes the Implementation of Anti-Corruption Policies. Policy and Society, 24(3), 79-96. doi:10.1016/S1449-4035(05)70061-8

Fritzen, S. (2005b). The 'misery'of implementation: Governance, institutions and anticorruption in Vietnam. Corruption and good governance in Asia, 98-120.

Fritzen, S. (2007). Reorienting Health Ministry Roles in Transition Settings: Capacity and Strategy Gaps. Health Policy, 83(1), 73 - 83.

Fritzen, S. A. (2006). Probing system limits: Decentralisation and local political accountability in Vietnam. Asia-Pacific Journal of Public Administration, 28(1), 1-24.

Fukuyama, F. (2006). Do defective institutions explain the gap between the United States and Latin America? The American Interest, 2(2), 1-39.

Gabriele, A. (2006). Social services policies in a developing market economy oriented towards socialism: The case of health system reforms in Vietnam. Review of International Political Economy, 13(2), 258-289. doi:10.1080/09692290600625504

Gainsborough, M. (2002). Beneath the veneer of reform: the politics of economic liberalisation in Vietnam. Communist and Post-Communist Studies, 35(3), 353-368. doi:http://dx.doi.org/10.1016/S0967-067X(02)00015-6

Gainsborough, M. (2003). Changing Political Economy of Vietnam : The Case of Ho Chi Minh City. Abingdon, Oxon, UNITED STATES: Taylor and Francis.

Gainsborough, M. (2010). Present but not powerful: Neoliberalism, the State, and development in Vietnam. Globalizations, 7(4), 475-488.

General Statistics Office of Vietnam. (2002). Main results of establishment census of Vietnam 2002. https://www.gso.gov.vn/default en.aspx?tabid=481\&idmid=4\&ItemID=8385: GSO.

George, E. S. (2011). Higher education reform in Vietnam: Boundaries of autonomy. In J. London (Ed.), Education in Vietnam. Singapore: Institute of Southeast Asian Studies.

Gill, D. (2002). Signposting the zoo. OECD Journal on Budgeting, 2(1), 27-79.

Gillen, J. (2011). A battle worth winning: The service of culture to the Communist Party of Vietnam in the contemporary era. Political Geography, 30(5), 272-281. doi:http://dx.doi.org/10.1016/j.polgeo.2011.05.001

Gillespie, J. (2006). Transplaning Commercial Law Reform: Developing a "Rule of Law" in Vietnam. Burlington (USA): Ashgate.

Goldmann, K. (2005). Appropriateness and consequences: The logic of neo-institutionalism. Governance, 18(1), 35-52.

Government of Vietnam. (1997). Nghị quyết và chủ trương xã hội hoá các hoạt động giáo dục, y tế, văn hoá (Resolution on socialisation of educational, health care, and cultural activities). Hanoi.

Government of Vietnam. (1999). Nghị định của Chính phủ về chính sách khuyến khích xã hội hoá đối với các hoạt động trong lĩnh vực giáodục, y tế, văn hóa, thể thao (Government 
Decree on encouraging socialisation of educational, health care, cultural, and sports activities). Hanoi.

Government of Vietnam. (2002). Nghị định của Chính phủ số 10/2002/ND-CP ngày 16 tháng 01 năm 2002 về chế độ tài chính áp dụng cho đơn vị sự nghiệp có thu (Government Decree 10/2002/ND-CP dated 16/10/2002 on financial mechanism appliced to revenue-generating units). Hanoi.

Government of Vietnam. (2005). Nghị quyết của Chính phủ về đẩy mạnh xã hội hoá các hoạt động giáo dục, y tế, văn hoá và thể dục thể thao (Government Resolution on acceleration of socialisation of educational, health care, cultural, and sports activities). Hanoi.

Government of Vietnam. (2006). Nghị định quy định quyền tự chủ, tự chịu trách nhiệm về thực hiện nhiệm vụ, tổ chức bộ máy, biên chế và tài chính đối với đơn vị sự nghiệp công lập (Government Decree 43/ND-CP on the right to autonomy and selfresponsibility for task performance, organizational apparatus, payroll and finance of public service delivery units). Hanoi.

Government of Vietnam. (2008). Nghị định về chính sách khuyến khích xã hội hóa đối với các hoạt động trong lĩnh vực giáo dục, dạy nghề, y tế, văn hóa, thể thao, môi trường (Government Decree on encouraging socialisation of education, vocation training, health care, culture, sports, and environment). Hanoi.

Government of Vietnam. (2012a). Nghị định số của Chính phủ Về cơ chế hoạt động, cơ chế tài chính đối với các đơn vị sự nghiệp y tế công lập và giá dịch vụ khám bệnh, chữa bệnh của các cơ sở khám bệnh, chữa bệnh công lập (Government Decree on task performance and finance of public health care facilities and fees and charges of public health care services). Hanoi.

Government of Vietnam. (2012b). Nghị quyết Ban hành Chương trình hành động của Chính phủ thực hiện Thông báo kết luận của Bộ Chính trị về Đề án "Đổi mới cơ chế hoạt động của các đơn vị sự nghiệp công lập, đẩy mạnh xã hội hóa một số loại hình dịch vụ sự nghiệp công"(Resolution providing the Government's Action Plan on the implementation of Politbureau's Conclusion regarding Project "Reforming the operational mechanism of public service dilivery units and fostering socialisation of several types of public services" ). Hanoi.

Government of Vietnam. (2014). Nghị Quyết về thí điểm đổi mới cơ chế hoạt động đối với các cơ sở giáo dục đại học công lập giai đoạn 2014 - 2017 (Resolution on Piloting the renewed operational mechanism of public higher education institutions from 20142017). Hanoi.

Government of Vietnam. (2015a). Nghị định 16/ND-CP quy định cơ chế tự chủ của đơn vị sự nghiệp công lập (Decree 16/ND-CP on the autonomy mechanism of public service delivery units). Hanoi.

Government of Vietnam. (2015b). Nghị định số 86/2015/ND-CP của Chính phủ : Quy định về cơ chế thu, quản lý học phí đối với cơ sở giáo dục thuộc hệ thống giáo dục quốc dân và chính sách miễn, giảm học phí, hỗ trợ chi phí học tộp từ năm học 2015 - 2016 đến năm học 2020 - 2021 (Government Decree providing fees and charges of public education services and fee exemptions for the school year 2015-2016 to the school year 2020-2021). Hanoi.

Government of Vietnam, \& World Bank. (2017) Vietnam Public Expenditure Review: Fiscal Policies towards Sustainability, Efficiency, and Equity.

Greenwood, R., \& Hinings, C. R. (1996). Understanding radical organizational change: Bringing together the old and the new institutionalism. Academy of Management Review, 21(4), 1022-1054. 
Greve, C., Flinders, M., \& Van Thiel, S. (1999). Quangos-What's in a Name? Defining Quangos from a Comparative Perspective. Governance, 12(2), 129-146. doi:10.1111/0952-1895.951999095

Grinter, L. E. (2006). Vietnam's Thrust into Globalization: Doi Moi's Long Road. Asian Affairs, an American Review, 33(3), 151-165.

Hall, P. A., \& Taylor, R. C. (1996). Political science and the three new institutionalisms*. Political studies, 44(5), 936-957.

Halligan, J. (2006). The Reassertion of the Centre in a First Generation NPM System. In T. Christensen \& P. Laegreid (Eds.), Autonomy and Regulation: Coping with Agencies in the Modern State. Cheltenha: Edward Elgar.

Hansen, H. F., \& Pedersen, L. H. (2006). The Dynamics of Regulatory Reform. In T. Christensen \& P. Laegreid (Eds.), Autonomy and Regulation: Coping with Agencies in the Modern State. Cheltenham: Edward Elgar.

Haque, M. S. (2007). Limits of public accountability under the reinvented state in developing nations. Public Administration Quarterly, 31(3/4), 429-452.

Harden, I., \& Marquand, D. (1997). How to Make Quangos Democratic. In M. V. Flinders, I. Harden, \& D. Marquand (Eds.), How to Make Quangos Democratic. London: Charter 88.

Harvey, D. (2007). A Brief History of Neoliberalism. Oxford, UNITED KINGDOM: OUP Oxford.

Hay, C., \& Wincott, D. (1998). Structure, agency and historical institutionalism. Political studies, 46(5), 951.

Hayden, M., \& Lam, Q. T. (2007). Institutional autonomy for higher education in Vietnam. Higher Education Research \& Development, 26(1), 73-85.

Hayden, M., \& Lam, Q. T. (2010). Vietnam's Higher Education System. In G. Harman, M. Hayden, \& T. Nghi Pham (Eds.), Reforming Higher Education in Vietnam (Vol. 29, pp. 14-29): Springer Netherlands.

Henin, B. H. (1999). Transformation of Vietnam's upland farming societies under market reform. (NQ40455 Ph.D.), University of Victoria (Canada), Ann Arbor. ABI/INFORM Global; ProQuest Dissertations \& Theses Global: Social Sciences database.

Hoang, L. (2017) Accountability in Vietnam's Education: Toward effective mechanism in the decentralization context. Accountability in education: Meeting our commitments: UNESCO.

Hoang, T. M. H. (2002). Media and civil society in support of good governance and democracy in Vietnam. Media Asia, 29(1), 24.

Hoang, V. M., Nguyen, T. K. P., Saksena, P., James, C. D., \& Xu, K. (2013). Financial burden of household out-of pocket health expenditure in Viet Nam: Findings from the National Living Standard Survey 2002-2010. Social Science \& Medicine, 96(0), 258-263. doi:http://dx.doi.org/10.1016/i.socscimed.2012.11.028

Holmes, O. (2016). Vietnam's Communist party meets to elect new leaders - Q\&A. Retrieved from https://www.theguardian.com/world/2016/jan/27/vietnam-communistparty-elects-new-leaders-q-and-a website:

Hood, C. (1991). A PUBLIC MANAGEMENT FOR ALL SEASONS? Public Administration, 69(1), 3-19.

Hood, C. (2010). The Blame Game : Spin, Bureaucracy, and Self-Preservation in Government. Princeton, UNITED STATES: Princeton University Press.

Hood, C., Rothstein, H., \& Baldwin, R. (2001). The government of risks: Understanding risk regulation regimes. Oxford: Oxford University Press.

Howlett, M., \& Tosun, J. (2017). Preliminary Thoughts on Policy Styles: A New Approach Based on Regime Characteristics 
Hughes, O. E. (2003). Public Management \& Administration: An Introduction. New York: Palgrave Macmillan.

Huynh, T. D., \& Pham, D. N. (2015). Building a coalition for reform in Vietnam. Retrieved from Fulbright Economics Teaching Program:

Immergut, E. M. (1998). The Theoretical Core of the New Institutionalism. Politics \& Society, 26(1), 5-34. doi:10.1177/0032329298026001002

Jandl, T. (2014). State versus State Politics in Contemporary Vietnam (pp. 20). Basingstoke: Palgrave Macmillan.

John, P. (2013). Analyzing public policy: Routledge.

Katznelson, I. (1998). The doleful dance of politics and policy: can historical institutionalism make a difference? : JSTOR.

Keating, M. (2001). Public management reform and economic and social development. OECD Journal on Budgeting, 1(2), 141-212.

Kingdon, J. W. (2003). Agendas, alternatives, and public policies: Longman Pub Group.

Kirk, J., \& Miller, M. (1986). Reliability and Validity in Qualitative Research: Sage.

Klingler-Vidra, R. (2014). Building a venture capital market in Vietnam: diffusion of a neoliberal market strategy to a socialist state. Asian Studies Review, 38(4), 582-600.

Ladinsky, J. L., \& Levine, R. E. (1985). The Organization of Health Services in Vietnam. Journal of Public Health Policy, 6(2), 255-268. doi:10.2307/3342317

Lægreid, P., Opedal, S., \& Stigen, I. M. (2005). The Norwegian hospital reform: balancing political control and enterprise autonomy. Journal of Health Politics, Policy \& Law, 30(6), 1027-1064.

Lægreid, P., \& Verhoest, K. (2010). Governance of public sector organizations: proliferation, autonomy, and performance. Houndmills, Basingstoke, Hampshire, UK; New York, NY: Palgrave Macmillan.

Laking, R. (2005). Agencies: their benefits and risks. OECD Journal on Budgeting, 4(4), 7-25.

Lane, J.-E. (2000). The public sector: concepts, models and approaches: Sage.

Le, H. H. (2012). Performance-based Legitimacy: The Case of the Communist Party of Vietnam and Doi Moi. Contemporary Southeast Asia, 34(2), 145-172.

Le, H. H. (2013). Navigating the Crisis: The VCP's Efforts to Restructure the Economy and Fight Corruption. Southeast Asian Affairs, 348-365.

Lebowitz, J. L., Plotz, P. H., \& Reich, W. (2014). [Revocation of Degree Four Years Later Leads to Protest by Vietnamese Academics].

Lieberman, S., Capuno, J. J., \& Hoang, M. V. (2005). Decentralizing Health: Lessons from Indonesia, the Philippines and Vietnam. In World Bank (Ed.), East Asian Decentralizes: Making Local Government Work (pp. 155 - 178). Washington DC: World Bank.

Lieberman, S. S., \& Wagstaff, A. (2009). Health financing and delivery in Vietnam: looking forward: World Bank Publications.

Litvack, J. I., \& Rondinelli, D. A. (1999). Market reform in Vietnam : building institutions for development. Westport, Conn.: Quorum.

London, J. (2004). Social Provision and the Transformation of a Socialist State: Mass Education and Health Provision in Viet Nam, 1975-2000. Unpublished doctoral dissertation). Department of Sociology, University of Wisconsin-Madison London, J., van Ulford, PQ,(2008) Food prices, vulnerability and food security in Viet Nam-A UN perspective,, October, 30, 313-333.

London, J. (2009). Viet Nam and the making of market-Leninism. The Pacific Review, 22(3), 375-399. 
London, J. (2014). Politics in Contemporary Vietnam: Party, State, and Authority Relations: Palgrave Macmillan.

London, J. D. (2003). Vietnam's mass education and health systems: A regimes perspective. American Asian Review, 21(2), 125.

London, J. D. (2006). Vietnam: The Political Economy of Education in a "Socialist" Periphery. Asia Pacific Journal of Education, 26(1), 1-20.

London, J. D. (2008). Reasserting the state in Vietnam: Health Care and the logics of marketLeninism. Policy and Society, 27, 115 - 128.

London, J. D. (2010). Globalization and the governance of education in Viet Nam. Asia Pacific Journal of Education, 30(4), 361-379.

London, J. D. (2013). The promises and perils of hospital autonomy: Reform by decree in Viet Nam. Social Science \& Medicine, 96(0), 232-240.

Maggetti, M. (2007). De facto independence after delegation: A fuzzy-set analysis. Regulation \& Governance, 1(4), 271-294. doi:10.1111/j.1748-5991.2007.00023.x

Maggetti, M., \& Verhoest, K. (2014). Unexplored aspects of bureaucratic autonomy: a state of the field and ways forward. International Review of Administrative Sciences, 80(2), 239-256. doi:10.1177/0020852314524680

Malesky, E. (2004). LEVELED MOUNTAINS AND BROKEN FENCES: MEASURING AND ANALYSING DE FACTO DECENTRALISATION IN VIETNAM. European Journal of East Asian Studies, 3(2), 307-336.

Malesky, E., Schuler, P., \& Tran, A. (2011). VIETNAM: Familiar Patterns and New Developments Ahead of the 11th Party Congress. Southeast Asian Affairs, 339-363.

March, J. G., \& Olsen, J. P. (1984). The New Institutionalism: Organizational Factors in Political Life. The American Political Science Review, 78(3), 734-749.

March, J. G., \& Olsen, J. P. (1989). Rediscovering Institutions: The Organizational Basis of Politics: New York: Free Press.

March, J. G., \& Olsen, J. P. (1996). Institutional perspectives on political institutions. Governance, 9(3), 247-264.

March, J. G., \& Olsen, J. P. (1998). The institutional dynamics of international political orders. International organization, 52(04), 943-969.

Marsh, D., \& Stoker, G. (2010). Theory and methods in political science: Palgrave Macmillan.

Martin, N. V. V. M. (Ed.) (2013). Governance Reform in Higher Education: A Study of institutional autonomy in Asian countries. Paris: International Institute for Educational Planning.

McCargo, D. (Ed.) (2004). Rethinking Vietnam: RoutledgeCurzon.

McCornac, D. C. (2012). The challenge of corruption in higher education: the case of Vietnam. Asian Education and Development Studies, 1(3), 262-275. doi:http://dx.doi.org/10.1108/20463161211270482

McCourt, W. (2008). Public Management in Developing Countries. Public Management Review, 10(4), 467-479. doi:10.1080/14719030802263897

McGuire, L. (2004). Contractualism and performance measurement in Australia. In C. Pollitt \& C. Talbot (Eds.), Unbundled Government: A critical analysis of the global trend to agencies, quangos and contractualization Routledge.

McKinley, C. (2008). Can a State-Owned Media Effectively Monitor Corruption? A Study of Vietnam's Printed Press. Asian Journal of Public Affairs, 2(1), 12-38.

Meyer, J. W., \& Rowan, B. (1977). Institutionalized Organizations: Formal Structure as Myth and Ceremony. American Journal of Sociology, 83(2), 340-363. 
Miles, M. B., \& Huberman, A. M. (1994). Qualitative Data Analysis: An Expanded Sourcebook. Thousand Oaks, Calif: Sage.

Ministry of Finance, \& Ministry of Home Affairs. (2012). Tổng kết tình hình thực hiện Nghị định số 43/2006/ND-CP ngày 25/4/2006 của Chính phủ quy định quyền tự chủ, tự chịu trách nhiệm về thực hiện nhiệm vụ, tổ chức bộ máy, biên chế và tài chính đối với đơn vị sự nghiệp công lập (Report on the implementation of Government Decree 43/2006/ND-CP dated 25/4/2006 on autonomy and self-responsibility regarding task performance, organisational apparatus, personnel, and finance of public service delivery units). Hanoi.

Ministry of Health, \& Health Partnership Group. (2008) Health Financing in Vietnam. Joint Annual Health Review 2008. Hanoi, VN.

Ministry of Health, \& Health Partnership Group. (2011) Strengthenning management capacity and reforming health financing to implement the five-year health sector plan 2011-2015. Joint Annual Health Review 2011. Hanoi.

Ministry of Health, \& Health Partnership Group. (2014) Strengthening prevention and control of communicable disease. Joint Annual Health Review 2014. Hanoi.

Ministry of Health, \& Health Partnership Group. (2015) Strengthening primary health care at the grassroots towards universal health coverage. In M. P. House (Series Ed.). Joint Annual Health Review 2015. Hanoi.

Ministry of Health, \& Ministry of Finance. (2012). Thông tư liên tịch Ban hành mức tối đa khung giá một số dịch vụ khám bệnh, chữa bệnh trong các cơ sở khám bệnh, chữa bệnh của Nhà nước (Joint-Circular providing the maximum prices of health care services of public health facilities). Hanoi.

Ministry of Health \& Health Partnership Groups. (2012) Improving quality of medical services. Joint Annual Health Review. Hanoi, .

Ministry of Planning and Investment. (2006). Strengthening the Coordination between the State Management Agencies Responsible for the Service Sector. Hanoi.

Moynihan, D. P. (2006). Ambiguity in policy lessons: The agencification experience. Public Administration, 84(4), 1029-1050.

Mulgan, R. (2003). Holding power to account: Accountability in modern democracies. Basingstoke: Palgrave Macmillan.

Murray, B. (2017). Mother Mushroom: how Vietnam locked up its most famous blogger. Retrieved from https://www.theguardian.com/globaldevelopment/2017/jul/09/mother-mushroom-how-vietnam-locked-up-its-mostfamous-blogger website:

National Assembly of Vietnam. (1995). Luật Doanh nghiệp Nhà nước số 39-L/CTN (Law on State-Owned Enterprises No 39-L/CTN). Hanoi.

National Assembly of Vietnam. (2005). Luật Giáo dục (Law on Education). Hanoi.

National Assembly of Vietnam. (2010). Luật Viên Chức (Law on State Employees). Hanoi.

National Assembly of Vietnam. (2012). Luật Giáo dục đại học (Law on Higher Education). Hanoi.

National Assembly of Vietnam. (2013a). Hiến pháp nước cộng hòa xã hội chủ nghĩa Việt Nam (Constitution of the Socialist Republic of Vietnam).

National Assembly of Vietnam. (2013b). Luật báo chí (Media Law). Hanoi.

Ngo, D. D. (2006). Vietnam. In UNESCO (Ed.), Higher Education in South-East Asia. Thailand: UNESCO.

Ngu, V. Q. (2003). Total factor productivity growth of industrial state-owned enterprises in Vietnam, 1976-98. ASEAN Economic Bulletin, 20(2), 158-173. 
Nguyen, D. C., Pham, A. T., Bui, V., \& Dapice, D. (2004). History and Policy: Why Don't Northen Provinces Grow Faster: CIEM-UNDP.

Nguyen, H. T., Hamid, M. O., \& Moni, K. (2016). English-medium instruction and selfgovernance in higher education: the journey of a Vietnamese university through the institutional autonomy regime. Higher Education, 72(5), 669-683. doi:10.1007/s10734-015-9970-y

Nguyen, T., Teicher, J., \& Smith, R. (2010). Challenges for Public Governance in Vietnam. Paper presented at the Conference of the International Research Society for Public Management (IRSPM), Berne, Switzerland.

Nguyen, T. H., \& Fraser, S. (2007). The Impact of globalisation on Higher Education in China and Vietnam: Policies and practices. Retrieved from http://www.ece.salford.ac.uk/proceedings/papers/07 07.pdf website:

Nguyen, T. V. (2005). Vietnam's state-owned enterprise leadership culture: An exploratory case study. (3194295 D.M.), University of Phoenix, Ann Arbor. ProQuest Central; ProQuest Dissertations \& Theses Global database.

Nichols, P. M. (1998). Forgotten linkages - historical institutionalism and sociological institutionalism and analysis of the World Trade Organization. Journal of international economic law, 19(2), 461-511.

Nørlund, I., \& Nam, U. V. (2007). Filling the Gap: The Emerging Civil Society in Viet Nam: Viet Nam Union of Science and Technology Associations.

North, D. C. (1990). Institutions, institutional change and economic performance: Cambridge university press.

OECD. (1998). Public Management Reform and Economic and Social Development. Paris: OECD.

OECD. (2002). Distributed Public Governance: OECD Publishing.

OECD. (2012). Managing Aid for Trade and Development Results: Vietnam Case Study.

Ohno, K. (2009). Avoiding the middle income trap: Renovating industrial policy formulation in Vietnam. ASEAN Economic Bulletin, 26(1), 25-43.

Olsen, J. P. (2007). Understanding institutions and logics of appropriateness: Introductory essay.

Olsen, J. P. (2009). Democratic Government, Institutional Autonomy and the Dynamics of Change. West European Politics, 32(3), 439-465.

Olsen, J. P., \& March, J. G. (2004). The logic of appropriateness: ARENA.

Osborne, D., \& Gaebler, T. (1992). Reinventing government: How the entrepreneurial spirit is transforming the public sector (Vol. null).

Ostrom, E. (1990). Governing the commons: The evolution of institutions for collective action: Cambridge University Press Cambridge:

Overman, S. (2016). Great Expectations of Public Service Delegation: A systematic review. Public Management Review, 18(8), 1238-1262.

Painter, M. (2003). Public administration reform in Vietnam: problems and prospects. Public Administration and Development, 23(3), 259-271. doi:10.1002/pad.249

Painter, M. (2005). The Politics of State Sector Reforms in Vietnam: Contested Agendas and Uncertain Trajectories. The Journal of Development Studies, 41(2), 261-283.

Painter, M. (2008). From command economy to hollow state? Decentralisation in Vietnam and China. Australian Journal of Public Administration, 67(1), 79-88.

Painter, M. (2012). Comparing agencification in Eastern and African countries. In S. V. T. Koen Verhoest, Geert Bouckaert and Per Laegreid (Ed.), Government Agencies: Practice and Lessons from 30 countries. Great Britain: PALGRAVE MACMILLAN. 
Painter, M. (2014). Governance Reforms in China and Vietnam: Marketisation, Leapfrogging and Retro-Fitting. Journal of Contemporary Asia, 44(2), 204-220.

Party Central Committee. (1985). Nghị quyết Hội nghị lần thứ 8 Ban Chấp hành Trung ương Đảng (khóa V) (Resolution of the Eighth Plenum of the Vietnam Communist Party's Central Committee (tenure V)). Hanoi.

Party Central Committee. (2006). Báo cáo Chính trị Ban Chấp hành Trung ương Đảng khóa IX (Political Report of the 9th Central Committee) Hanoi.

Party Central Committee. (2011). Báo cáo Chính trị Ban Chấp hành Trung Ương Đảng khóa X (Political Report of the 10th Central Committee). Hanoi.

Patton, M. Q. (2002). Qualitative Research and Evaluation Methods. Thousand Oaks: CA: Sage.

Peters, B. G. (1996). Political institutions, old and new. A new handbook of political science, 205-220.

Peters, B. G. (1999). Institutional theory in political science: the new institutionalism: Pinter.

Peters, B. G. (2016). Institutionalism and Public Policy. In B. G. Peters \& P. Zittoun (Eds.), Contemporary Approaches to Public Policy: Theories, Controversies and Perspectives (pp. 57-72). London: Palgrave Macmillan UK.

Peters, B. G., \& Pierre, J. (2001). Politicians, bureaucrats and administrative reform. New York: Routledge.

Pham, D. N. (2015). Trách nhiệm giải trình: Vươn tới những chuẩn mực của một nền hành chính phục vụ phát triển (Accountability: Moving Toward Standards for Administration Serving Development). Retrieved from http://www.fetp.edu.vn/attachment.aspx?Language=\&ID=40747 website:

Pham, L. (2014). Trách nhiệm giải trình của trường đại học và cơ cấu thẩm quyền của trường ngoài công lập.

Pham, T. L. P. (2012). The Renovation of Higher Education Governance in Vietnam and its Impact on the Teaching Quality at Universities. Tertiary Education and Management, 18(4), 289-308. doi:10.1080/13583883.2012.675350

Phillips, N., \& Malhotra, N. (2008). Taking social construction seriously: Extending the discursive approach in institutional theory. Los Angeles: Sage.

Pierre, J. (2004). Central agencies in Sweden: A report from Utopia. In C. Pollit \& C. Talbot (Eds.), Unbundled Government: A critical analysis of the global trend to agencies, quangos and contractualisation Rouledge.

Pierson, P. (1996). The new politics of the welfare state. World Politics, 48(2), 143-179.

Pierson, P. (2000). Increasing Returns, Path Dependence, and the Study of Politics. The American Political Science Review, 94(2), 251-267.

Pincus, J., Vu, T. T. A., Pham, D. N., Wilkinson, B., \& Nguyen, X. T. (2012). Structural reform for growth equity and national sovereignty. Policy discussion paper prepared for the Vietnam Executive Leadership Program. Retrieved from Harvard Kennedy School (Asia Programs):

Pollitt, C. (1993). Managerialism and the public services: The Anglo-American experience (Vol. null).

Pollitt, C. (2004). Castles built on sand? Agencies in Latvia. In C. Pollit \& C. Talbot (Eds.), Unbundled Government: A critical analysis of the global trend to agencies, quangos and contractulisation London and New York: Routledge.

Pollitt, C., Bathgate, K., Caulfield, J., Smullen, A., \& Talbot, C. (2001). Agency fever? Analysis of an international policy fashion. Journal of Comparative Policy Analysis: Research and Practice, 3(3), 271-290. 
Pollitt, C., \& Talbot, C. (2004). Unbundled government: a critical analysis of the global trend to agencies quangos and contractualisation. New York: Routledge.

Pollitt, C., Talbot, C., Caulfield, J., \& Smullen, A. (2004). Agencies: How governments do things through semi-autonomous organizations: Palgrave Macmillan.

Poon, Y., Nguyen, K. H., \& Do, X. T. (2009) The Reform of the Civil Service System as Vietnam moves into the Middle-income Country Category. Hanoi: UNDP.

Powell, W. W., \& DiMaggio, P. J. (2012). The new institutionalism in organizational analysis: University of Chicago Press.

Rakner, L. (1996). Rational Choice and the Problem of Institutions. A Discussion of Rational Choice Institutionalism and its Application by Robert Bates.

Ramesh, M. (2013). Health Care Reform in Vietnam: Chasing Shadows. Journal of Contemporary Asia, 43(3), 399-412.

Randma-Liiv, T., Nakrosi, V., \& Hajnal, G. (2012). Comapring Agencies in Central and Eastern Europe. In K. Verhoest, S. Van Thiel, G. Bouckaert, \& P. Laegreid (Eds.), Government Agencies: Practices and Lessons from 30 countries: Palgrave macmilan.

Richardson, L. (Ed.) (2000). Writing: A method of inquiry. Thousand Oaks, CA: Sage.

Riedel, J., \& Turley, W. S. (1999). The Politics and Economics of Transition to an Open Market Economy in Viet Nam (Vol. 152): OECD.

Romzek, B. S. (1998). Where the buck stops: Accountability in reformed public organizations. Transforming government: Lessons from the reinvention laboratories, 193-219.

Roness, P. G., Verhoest, K., Rubecksen, K., \& MacCarthaigh, M. (2008). Autonomy and Regulation of State Agencies: Reinforcement, Indifference or Compensation? Public Organization Review, 8(2), 155-174. doi:10.1007/s11115-008-0057-4

Schick, A. (2002). Agencies in search of principles. OECD Journal on Budgeting, 2(1), 7-26.

Scott, W. R. (2013). Institutions and organizations: Ideas, interests, and identities: Sage Publications.

Seawright, J., \& Gerring, J. (2008). Case Selection Techniques in Case Study Research: A Menu of Qualitative and Quantitative Options. Political Research Quarterly, 61(2), 294-308. doi:10.1177/1065912907313077

Shanks, E., Luttrell, C., Conway, T., Vu, M. L., \& Landinsky, J. (2004). Understanding pro-poor political change: the policy process. Vietnam',(London: Overseas Development Institute).

Shaw, R., \& Eichbaum, C. (2008). Public policy in New Zealand: Institutions, processes and outcomes: Pearson Education New Zealand.

Silverman, D. (2006). Interpreting Qualitative Data: Methods for Analyzing Talk, Text, and Interaction: SAGE Publications.

Stake, R. E. (2006). Multiple case study analysis. New York: The Guilford Press.

Stigler, G. J. (1975). The citizen and the State: essays on regulation. Chicago: University of Chicago Press.

Stigler, G. J. (2001). An Agenda for Development for the Twenty-First Century. In G. Anthony (Ed.), The Global Third Way Debate. Cambridge: Polity Press.

Suchman, M. C., \& Edelman, L. B. (1996). Legal rational myths: The new institutionalism and the law and society tradition. Law \& Social Inquiry, 21(4), 903-941.

Sulle, A. (2010). The application of new public management doctrines in the developing world: An exploratory study of the autonomy and control of executive agencies in Tanzania. Public Administration and Development, 30(5), 345-354. doi:10.1002/pad.580 
Sundström, G. (2006). Management by Results: Its Origin and Development in the Case of the Swedish State. International Public Management Journal, 9(4), 399-427. doi:10.1080/10967490601077178

Talbot, C. (2004). Executive Agencies: Have They Improved Management in Government? Public Money \& Management, 24(2), 104-112.

Tam, W. (2010). Privatising Health Care in China: Problems and Reforms. Journal of Contemporary Asia, 40(1), 63-81. doi:10.1080/00472330903270700

Teixeira, P. N., \& Dill, D. D. (Eds.). (2011). Public vices, Private Virtures: Assessing the Effects of Marketization in Higher Education. The Netherlands: Sense Publishers.

Tenev, S., Carlier, A., Chaudry, O., \& Nguyen, Q. T. (2003). Informality and the Playing Field in Vietnam's Business Sector. Washington, D.C.: IFC, World Bank and MPDF.

Thayer, C. A. (2001). VIETNAM IN 2000 Toward the Ninth Party Congress. Asian Survey, 41(1), 181-188.

Thayer, C. A. (2009). Vietnam and the Challenge of Political Civil Society. Contemporary Southeast Asia, 31(1), 1-27.

Thayumanavan. (2001). Vietnam: One Step Forward, Two Steps Back? Economic and Political Weekly, 36(37), 3518-3524.

Thelen, K. (1999). Historical institutionalism in comparative politics. Annual review of political science, 2(1), 369-404.

Thelen, K. n. (2004). How institutions evolve: The political economy of skills in Germany, Britain, the United States, and Japan (Vol. null).

Thomas, G. (2010). How to do your case study: a guide for students. London: Sage Publications Ltd.

Thomas, P. G. (2003). Accountability. In B. G. Peters \& J. Pierre (Eds.), Handbook of Public Adminnistration. London: Sage.

Tienve. (2014). Academics call on the Vietnamese Government to respect Academic Freedom [đối thoại].

Tight, M. (1992). Institutional autonomy. In B. L. Clark \& G. Neave (Eds.), The Encyclopaedia of higher education. Oxford: Pergamon.

Tran, T. M. O., Khuong, A. T., Hoang, P., Nguyen, K. P., Ong, T. D., \& Hort, K. (Eds.). (2015). Public hospital governance in Vietnam (Vol. 1). World Health Organisation: World Health Organisation.

Tran, T. T. T. (2004). Vietnam's rural transformation: information, knowledge an diversification. In M. Duncan (Ed.), Rethinking Vietnam. RoutledgeCurzon.

Tran, V. T. (2013). Vietnamese Economy at the Crossroads: New Doi Moi for Sustained Growth. Asian Economic Policy Review, 8(1), 122-143.

Transparency International, Towards Transparency, UKaid, British Embassy, \& UNDP. (2011). The media's coverage of corruption in Vietnam 2006-2011.

Tuoitrenews. (2013). Ex-leaders of Vinalines get death in $\$ 19 \mathrm{mln}$ corruption case.

Un, K. (2018). Vietnam at the Crossroads: the Modern Political Economy.

UNDP. (2003). Education Medium Term Expenditure Framework Preliminary Report. Retrieved from http://www.undp.org.vn/projects/vie96028/PrelimrepE.doc:

Vallely, T. J., \& Wilkinson, B. (2008). Vietnamese higher education: Crisis and response. Memorandum: Higher Education Task Force, Harvard Kennedy School.

van Doorslaer, E., O'Donnell, O., Rannan-Eliya, R. P., Somanathan, A., Adhikari, S. R., Garg, C. C., . . . Zhao, Y. (2007). Catastrophic payments for health care in Asia. Health Economics, 16(11), 1159-1184. doi:10.1002/hec.1209 
van Thiel, S. (2000). Quangocratization: Trends, causes and consequences. Radboud University Nijmegen.

van Thiel, S. (2004). Trends in the Public Sector: Why Politicians Prefer Quasi-Autonomous Organizations. Journal of Theoretical Politics, 16(2), 175-201. doi:10.1177/0951629804041120

van Thiel, S. (2014). Research Methods in Public Administration and Public Management: An Introduction. Florence, US: Routledge.

Vasavakul, T. (2002). Rebuilding authority relations: public administration reform in the era of Doi Moi. Hanoi: Asian Development Bank.

Vasavakul, T. (2006). Co-Governance an Human Security: Decentralization, Grassroots Democracy and Poverty Alleviation in Vietnam. Paper presented at the Democracy and Human Security in Southeast Asia, Bankok, Thailand.

Vasavakul, T. (2014). Authoritarianism Reconfigured Politics in Contemporary Vietnam (pp. 22). Basingstoke: Palgrave Macmillan.

Vasavakul, T. (Ed.) (2001). Vietnam: Doi Moi Difficulties. Singapore: Institute of Southeast Asian Studies.

Verhoest, K. (2005). The Impact of Contractualisation on Control and Accountability in Government-Agency Relations: the case of Flanders (Belgium). In G. Drewry, C. Greve, \& T. Tanquerel (Eds.), Contracts, Performance Measurement and Accountability in the Public Sector. The Netherlands: IOS Press \& IIAS.

Verhoest, K. (2010). Autonomy and control of state agencies: comparing states and agencies: Palgrave Macmillan.

Verhoest, K., Peters, B. G., Bouckaert, G., \& Verschuere, B. (2004a). Controlling Autonomous Public Agencies as an Indicator of New Public Management. Management International, 9(1), 25-35.

Verhoest, K., Peters, B. G., Bouckaert, G., \& Verschuere, B. (2004b). The study of organisational autonomy: a conceptual review. Public Administration and Development, 24(2), 101-118.

Verhoest, K., Van Thiel, S., Bouckaert, G., \& Laegreid, P. (2012). Government agencies: practices and lessons from 30 countries. New York: Palgrave Macmillan.

Verhoest, K., Verschuere, B., \& Bouckaert, G. (2007). Pressure, Legitimacy, and Innovative Behavior by Public Organizations. Governance, 20(3), 469-497. doi:10.1111/j.14680491.2007.00367.x

Verschuere, B., Verhoest, K., Meyers, F., \& Peters, B. G. (2006). Accountability and Accountability Arrangements in Public Agencies. In T. Christensen \& P. Laegreid (Eds.), Autonomy and Regulation: Coping with Agencies in the Modern State: Edward Elgar Publishing Limited

Vian, T., Brinkerhoff, D. W., Feeley, F. G., Salomon, M., \& Vien, N. T. K. (2012). Confronting corruption in the health sector in vietnam: Patterns and prospects. Public Administration and Development, 32(1), 49-63.

Vietnamnet. (2017). PetroVietnam-invested projects incurred huge losses under Dinh La Thang.

Vo, D. H. (2009). Fiscal decentralisation in Vietnam: lessons from selected Asian nations. Journal of the Asia Pacific Economy, 14(4), 399-419. doi:10.1080/13547860903169373

Vo, T. H. M., \& Lofgren, K. (2016). Autonomy of Public Service Delivery Agencies in Vietnam and OECD: A Comparative Institutional Perspective. Asian Journal of Public Affairs, 9(1), 21-42. 
Vu, T. T., Zouikri, M., \& Deffains, B. (2014). The Interrelationship between Formal and Informal Decentralization and Its Impact on Subcentral Governance Performance: the Case of Vietnam. CESifo Economic Studies, 60(3), 613-652. doi:10.1093/cesifo/ifu003

Vu, T. T. A. (2016a). Does WTO Accession Help Domestic Reform? The Political Economy of SOE Reform Backsliding in Vietnam. World Trade Review, 16(1), 85-109.

$\mathrm{Vu}, \mathrm{T}$. T. A. (2016b). Vietnam: decentralization amidst fragmentation. Journal of Southeast Asian Economies, 33, 188+.

Vu, T. T. A., Chirot, L., Dapice, D., Huynh, T. D., Pham, D. N., Perkins, D., \& Nguyen, X. T. (2015). Institutional Reform: From Vision to Reality. Harvard Kennedy School: Harvard Kennedy School, United Nations Development Program, Government of Vietnam.

Vu, T. T. A., Le, V. T., \& Vo, T. T. (2007). Provincial Extralegal Investment Incentives in the Context of Decentralisation in Vietnam: Mutual Beneficial or a Race to the Bottom? Hanoi: UNDP.

Vuong, Q. H. (2014). Vietnam's Political Economy: A Discussion on the 1986-2016 Period. CEB-ULB WP(14/010).

Wagstaff, A., \& Bales, S. (2012) The Impacts of Public Hospital Autonomization: Evidence from a Quasi-Natural Experiment. Impact Evaluation Series No 61: World Bank.

Walter, M. (2010). Social research methods. South Melbourne, Vic: Oxford University Press.

Wescott, C. G. (2003). Hierarchies, Networks, and Local Government in Vietnam. International Public Management Review, 4(2), 20 - 40.

Westerheijden, F. D., Cremonini, L., \& Empel, v. R. (2010). Accreditation in Vietnam's higher education system. In G. Harman, M. Hayden, \& T. N. Pham (Eds.), Reforming Higher Education in Vietnam: Springer.

Wettenhall, R. (2005). Agencies and non-departmental public bodies: The hard and soft lenses of agencification theory. Public Management Review, 7(4), 615-635.

Wilkinson, J. (2005). The Growth of Performance Measurement: Help or Hindrance? In G. Drewry, C. Greve, \& T. Tanquerel (Eds.), Contracts, Performance Measurement and Accountability in the Public Sector. The Netherlands: IOS Press.

World Bank. (2008). Vietnam: Higher Education and Skills for Growth. Washington, DC: World Bank.

World Bank. (2009). 'Vietnam Development Report 2010: Modern Institutions'. Hanoi: World Bank.

World Bank. (2011). Vietnam Development Report 2012: Market Economy for a Middleincome Vietnam. Hanoi: World Bank.

World Bank. (2014). Moving towards Universal Coverage of Social Health Insurance in Vietnam. Washington, D.C.: World Bank.

World Bank, \& Ministry of Health. (2011). Lessons for Hospital Autonomy Implementation in Vietnam from International Experience. Washington, DC: World Bank.

World Health Organisation. (2011). A Health Financing Review of Vietnam: with a focus of social health insurance. Hanoi: WHO.

Wu, Y.-S., \& Sun, T.-W. (1998). Four faces of Vietnamese communism: small countries' institutional choice under hegemony. Communist and Post-Communist Studies, 31(4), 381-399. doi:http://dx.doi.org/10.1016/S0967-067X(98)00018-X

Xu, K., Evans, D. B., Kawabata, K., Zeramdini, R., Klavus, J., \& Murray, C. J. L. (2003). Household catastrophic health expenditure: a multicountry analysis. The Lancet, 362(9378), 111-117. doi:https://doi.org/10.1016/S0140-6736(03)13861-5 
Yang, R., Vidovich, L., \& Currie, J. (2007). "Dancing in a Cage": Changing Autonomy in Chinese Higher Education. Higher Education, 54(4), 575-592. doi:10.1007/s10734-006-90095

Yesilkagit, K. (2004). The design of public agencies: overcoming agency costs and commitment problems. Public Administration and Development, 24(2), 119-127. doi:10.1002/pad.317

Yin, R. K. (2014). Case study research: design and methods. Los Angeles: SAGE.

Zafirovski, M. (2004). Paradigms for analysis of social institutions: A case for sociological institutionalism. International Review of Sociology, 14(3), 363-397. doi:10.1080/0390670042000318250 